\title{
Technical change, competitiveness and poverty reduction : a study of the Ghanaian apparel industry
}

Citation for published version (APA):

Ayitey, D. K. (2010). Technical change, competitiveness and poverty reduction : a study of the Ghanaian apparel industry. [Doctoral Thesis, Maastricht University]. Datawyse / Universitaire Pers Maastricht. https://doi.org/10.26481/dis.20100922da

Document status and date:

Published: 01/01/2010

DOI:

10.26481/dis.20100922da

Document Version:

Publisher's PDF, also known as Version of record

\section{Please check the document version of this publication:}

- A submitted manuscript is the version of the article upon submission and before peer-review. There can be important differences between the submitted version and the official published version of record.

People interested in the research are advised to contact the author for the final version of the publication, or visit the DOI to the publisher's website.

- The final author version and the galley proof are versions of the publication after peer review.

- The final published version features the final layout of the paper including the volume, issue and page numbers.

Link to publication

\footnotetext{
General rights rights.

- You may freely distribute the URL identifying the publication in the public portal. please follow below link for the End User Agreement:

www.umlib.nl/taverne-license

Take down policy

If you believe that this document breaches copyright please contact us at:

repository@maastrichtuniversity.nl

providing details and we will investigate your claim.
}

Copyright and moral rights for the publications made accessible in the public portal are retained by the authors and/or other copyright owners and it is a condition of accessing publications that users recognise and abide by the legal requirements associated with these

- Users may download and print one copy of any publication from the public portal for the purpose of private study or research.

- You may not further distribute the material or use it for any profit-making activity or commercial gain

If the publication is distributed under the terms of Article $25 \mathrm{fa}$ of the Dutch Copyright Act, indicated by the "Taverne" license above, 


\section{TECHNICAL CHANGE, COMPETITIVENESS AND}

POVERTY REDUCTION:

A STUDY OF THE GHANAIAN APPAREL INDUSTRY 
2010 D. K. Ayitey

All rights reserved.

Cover page designed by D.K. Ayitey and Datawyse

Published by Universitaire Pers Maastricht ISBN 9789052789781

Printed in the Netherlands by Datawyse Maastricht. 


\section{TECHNICAL CHANGE, COMPETITIVENESS AND POVERTY REDUCTION:}

\section{A STUDY OF THE GHANAIAN APPAREL INDUSTRY}

\section{PROEFSCHRIFT}

ter verkrijging van de graad van doctor aan de Universiteit Maastricht,

op gezag van de Rector Magnificus, Prof. Mr. G.P.M.F. Mols, volgens het besluit van het College van Decanen

in het openbaar te verdedigen op woensdag 22 september 2010 om 16.00 uur

door

Donatus Kosi Ayitey

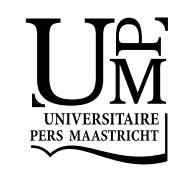




\section{Promotor:}

Prof. dr. Pierre Mohnen

\section{Co-promoter:}

Prof. Kaushalesh Lal, CESR, Delhi, India

\section{Beoordelingscommissie:}

Prof. dr. Théophile Azomahou, voorzitter

Prof. dr. Valentina Mazzucato

Prof. Sergio Perelman, HEC, Université de Liège

The following institutions supported this Ph.D. Research:

United Nations University, Institute for New Technologies (UNU-INTECH), Maastricht, The Netherlands (Presently Known as Maastricht Economic and Social Research and Training Centre on Innovation and Technology, UNUMERIT).

Netherlands Foundation for the Advancement of Tropical Research (WOTRO), NWO, The Netherlands.

African Economic Research Consortium (AERC), Nairobi Kenya. 


\section{Acknowledgement}

My sincerest inexpressible thanks to my promoter and supervisor Professor Dr. Pierre Mohnen for his role in my writing of this thesis. Prof. Mohnen, I am so grateful to you for all your support. To my supervisor Dr. Kaushalesh Lal, I extent my measureless thanks for accepting to co-supervise this work. You were so instrumental in getting Chapters 3 and 8 of this thesis published and for that I say thank you. I leant so much from my supervisors and hope to extend the nice gesture to others as well. I acknowledge Prof. Dr. Théophile Azomahou for agreeing to chair the reading committee and also thank Prof. Dr. Valentina Mazzucato and Prof. Sergio Perelman for their comments to help improve the thesis.

I also wish to thank the Ph.D. committee including the Dean of the Ph.D. programme Professor Dr. Robin Cowan and Professor Geert Duysters among others for yearly assessments of the progress reports that contribute to the timely completion of the course. To Dr. Ionara Costa, I extend my thanks for the pieces of advice and support through out this course and my appreciation goes to the Secretary of the Ph.D. training programmes Ms. Eveline in de Braek who helped not only in making sure that all the requirements and niceties for the course are satisfied but also that students fill at home to do the course. The encouragement from Professor Banji Oyelaran-Oyeyinka and Prof Dr. Luc Soete at the early stages of the coursework was crucial at the formative stages of this thesis and I am so appreciative of that. I learnt a lot from Dr. Padmashree Gehl Sampath and I thank her for that.

The writing of this thesis would not have been possible without the financial support of UNU-MERIT and African Economic Research Consortium (AERC). I am particularly grateful to Mr. Marc Vleugels who helped me in organizing my trip for the fieldwork and to Ms. Emma Rono of AERC for ensuring that my fieldwork went according to plan. I am grateful to my colleagues at the Ghana Statistical Service for their time and effort during the fieldwork. To Ms. Wilma Coenegrachts and Ms. Monique Raedts, I say thank you for all the support. My thanks will not be complete without acknowledging the services

of the information specialist Mr. Ad Notten, system administrator Mr. Mourik Jan Heupink, webmaster Herman Pijpers and general clerk Mr. Eric Engelen. 
I wish to acknowledge Dr. Albert Schram for his support and my office and class mates Radhika Perrot, Tina Saebi, Asel Doranova, Sergey Filippov, Zakaria Babutsidze, Evans Mupela, Lina Sonne, Ezequiel Tacsir, Alexis Habiyaremye and Jan Philipp Schmidt. For productive conversations with other colleagues Nora Engel, Jun Hou, Than Le Phuoc, Bilal Mirza, Marion Motari, Flavia Pereira de Carvalho, Iman Rajabzadeh, Shuan SadreGhazi, Fernando Santiago-Rodriguez, Francisco Toro ,Branka Urem, Bertha Vallejo , Daniel Vertesy, Kirsten Wiebe, Ying Zhang, Abraham Garcia, Daniel Dalohoun, Geoffrey Gachino, Semih Akçomak, Victoria Kravtsova, Saurabh Arora and Yoseph Yilma Getachew, I say thank you all. My thanks to my colleagues from Oxford Oemetse Mogapi, Gurjinder Singh Mohan, Carolyne Ndila and Qian $\mathrm{Wu}$ for their pieces of advice.

I will like to dedicate this thesis to my family and love ones. My mother Aurelia Ayitey, my father Peter Ayitey, my brother Sylvester Ayitey, my nephew Wisdom Ayitey, my wife and daughter Patricia Ayitey and Fredricka Ayitey, my half sisters Theodora Ayitey and Helen Ayitey and my friend Sant Rajinder Singh. 
To my family 


\section{Table of Contents}

Table of Contents.....................................................i

List of Tables..................................................vii

List of Figures.....................................................ix

List of Abbreviations................................................xi

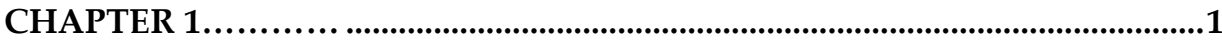

Introduction ...........................................................................................................................

1.1 Background: Technical Change and Millennium Development Goals... 1

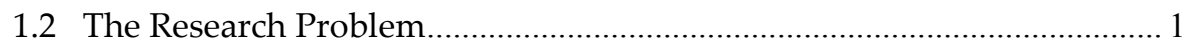

1.3 The choice of the Apparel Sector .............................................................. 4

1.4 Firm Competitiveness Building as a more Sustainable Survival Approach and Effective Poverty Reduction Strategy ..................................... 5

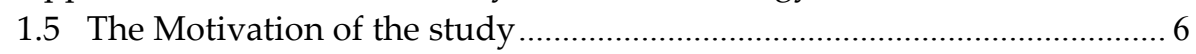

1.6 The Study Objectives and Research Questions......................................... 9

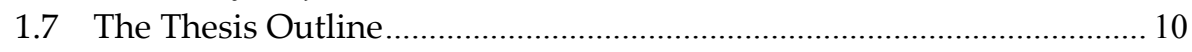

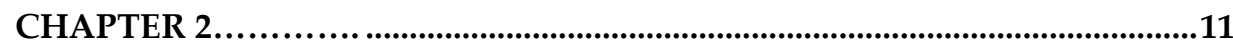

Technical Change, Competitiveness and Poverty: Theoretical and Empirical

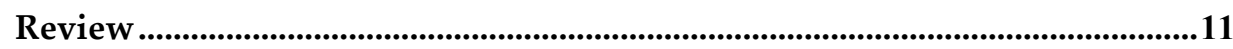

2.1 Theoretical Foundations of Measures and Definitions........................... 11

2.1.1 Economic, Technical and Allocation Efficiencies................................ 14

2.2 Embodied and Disembodied Technical Change ……............................. 16

2.3 Induced and Autonomous Theories of Technical Change...................... 18

2.4 Endogenous versus Exogenous Theoretical underpinnings of Technical

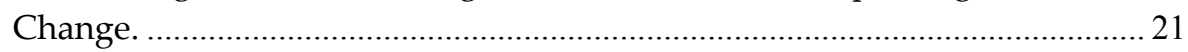

2.5 Capacity Utilization and Technical Change............................................. 21

2.6 Firm Competitiveness and Productivity Growth................................... 23

2.7 New Technologies and firm Competitiveness...................................... 24

2.7.1 Channels of Technology Transfer: the Process of building Firm

Competitiveness ..................................................................................... 28

2.8 Productivity Growth and Poverty Reduction........................................ 28

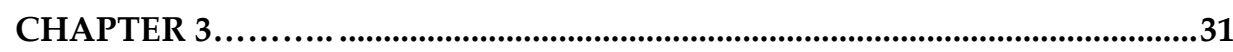




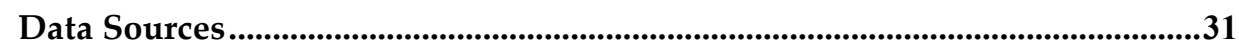

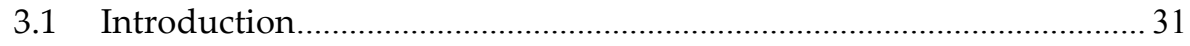

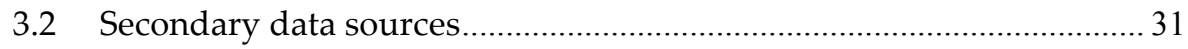

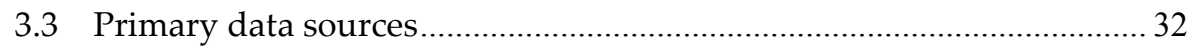

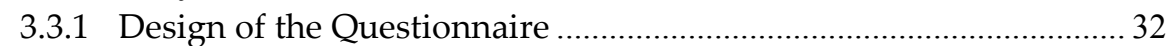

3.3.2 Sampling Technique and Firm Survey ……….................................. 33

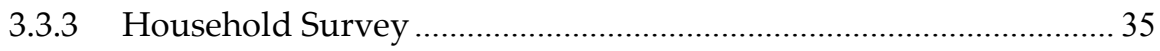

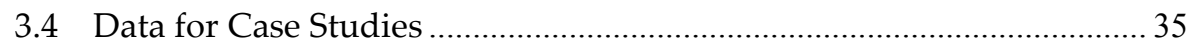

Appendix 3 .....................................................................................................................37

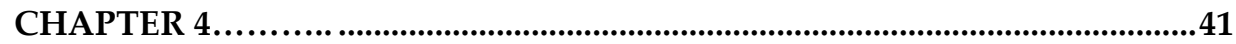

Technological Capacity Building Initiatives in Ghanaian Apparel Industry 41

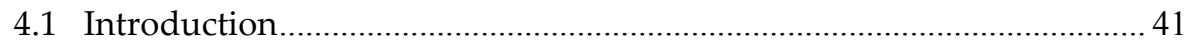

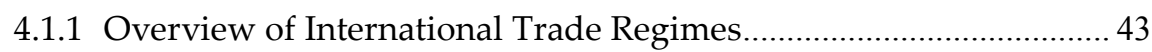

4.2 Textile and Apparel Industry in Ghana..................................................... 45

4.3 Developments in Pre-Trade Liberalization Era: Prior to 1984 .................. 46

4.3.1. Historical Context of the Textile and Apparel Industry..................... 46

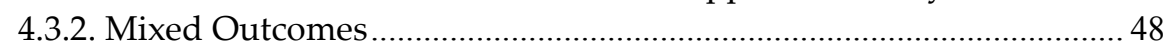

4.3.3. Trade Policy Impact on Employment in Textile and Apparel ........ 50

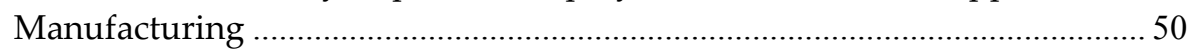

4.3.4. Trade Policy and Value Added in Textile and Clothing

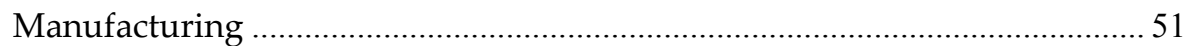

4.3.5. Technology Adoption and Policy Initiatives ........................................ 52

4.3.6. Technology Transfer Institutions for Innovative Textile and Apparel

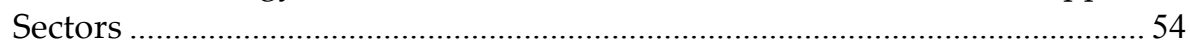

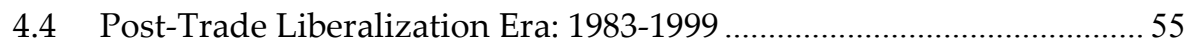

4.4.1. Tariffs and Trade in Textiles and Apparel ..........................................5 57

4.5 'The Golden Age of Business' and Ghana Export Promotion Action

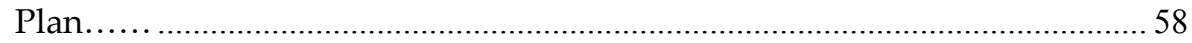

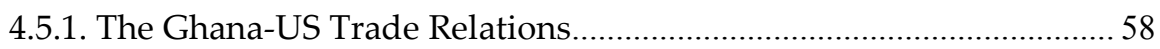

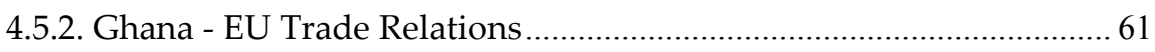

4.5.3. Presidential Special Initiative on textile and Garments (PSI, 2001- ) 62

4.6 Technological Capacity Building and Performance................................... 64

4.6.1. Technology Content of Textile and Apparel Exports from Ghana ... 64

4.6.2. Worsening Textile and Apparel Trade Conditions in the World

Market 65

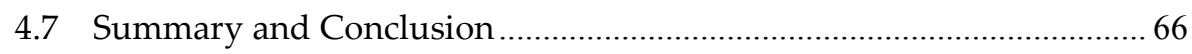


CHAPTER 5

Accounting for Standards in Productivity and Competitiveness Assessment67

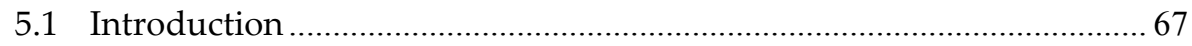

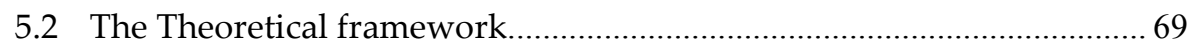

5.2.1 The Standard-corrected Production Possibility Approach ............... 71

5.3 The Methodology............................................................................. 72

5.3.1 Accounting for Standards in Productivity Measurement................. 72

5.3.1 Non-separability of a product from its standards............................... 73

5.3.2 Measuring Standards Intensities of the Product (SIP) ....................... 74

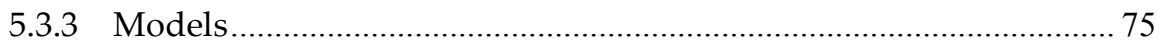

5.3.4 The Non-parametric Method based on Malmquist Index ............... 76

5.3.6 Summary of Expected Results .............................................................. 78

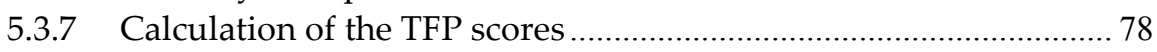

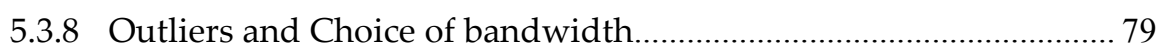

4.3.10 Data and Description of Variables ................................................. 80

5.4 The Presentation and Analysis of Results ............................................... 81

5.4.1 Incidence of Productivity Growth among small apparel businesses

5.4 Research Hypothesis: Firms are losing competitiveness due to slow

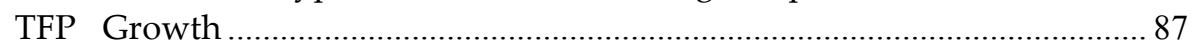

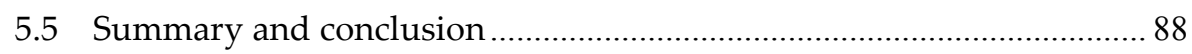

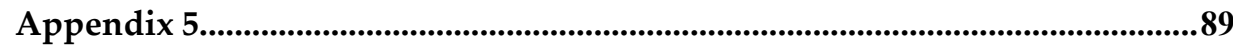

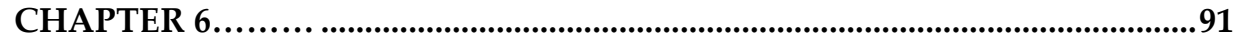

Appraisal of sources of Productivity Growth in the Apparel Sector................91

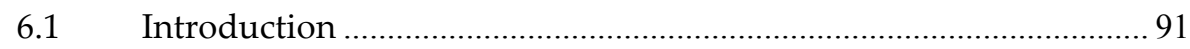

6.2 Technical change as a source of TFP growth: Some theoretical

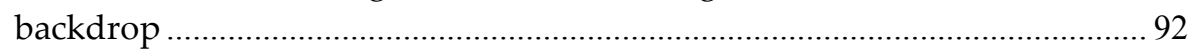

6.2.1 Some empirical insights on productivity growth ............................. 95

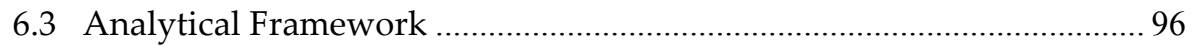

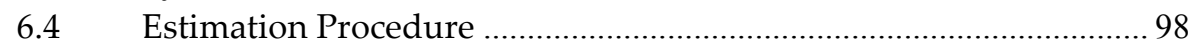

6.4.1 Test for statistical significance: Bootstrapping procedure .............. 101

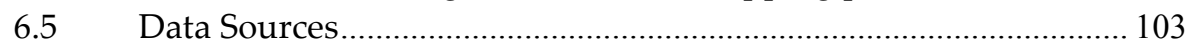

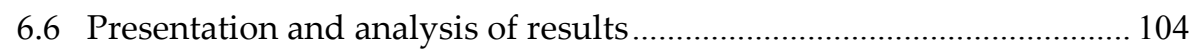

6.6.1 Sources of Productivity Growth..................................................... 104

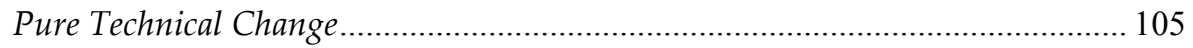

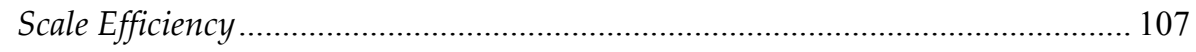




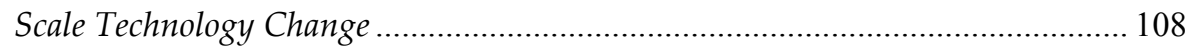

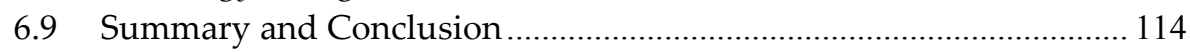

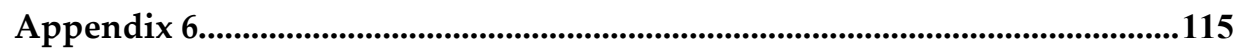

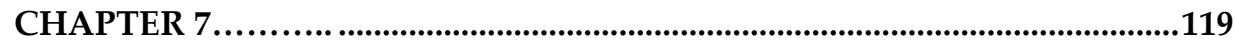

Poverty Measures and Analysis in the Apparel Sector using Fuzzy Sets and

Techniques ....................................................................................................119

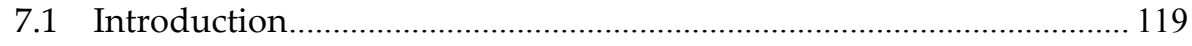

7.2 Conceptualization of Poverty and Well-being ………….................... 119

7.3 Theoretical Framework and Multidimensional Measure of Poverty 121

7.3.1 Classical versus Fuzzy Sets ............................................................... 122

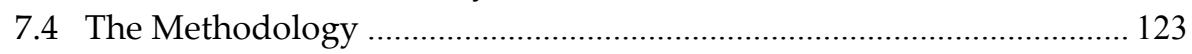

7.5 The Choice of Membership Functions …………................................... 127

7.5.1 Capturing Poverty/Deprivation Changes Overtime:......................... 129

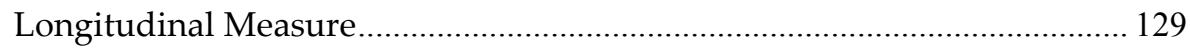

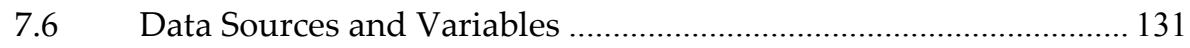

7.6.1 Aggregation of attributes and their dimensions ............................... 133

7.7 Presentation and analysis of results: Static measures ..................... 133

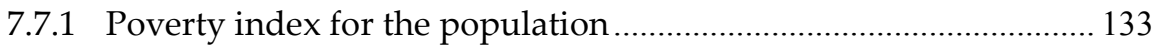

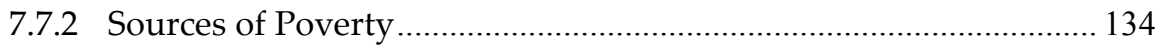

7.7.3 Dynamic Assessment of Poverty................................................... 138

6.8 Summary and Conclusion ................................................................ 140

Appendix 7 ......................................................................................................................142

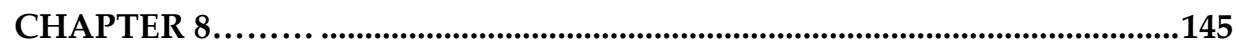

Linking Firm Competitiveness/Productivity Growth to Poverty in the

Apparel Sector....................................................................................................145

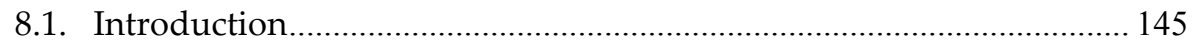

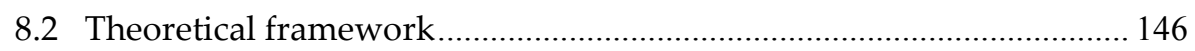

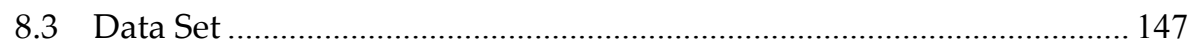

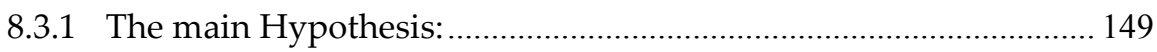

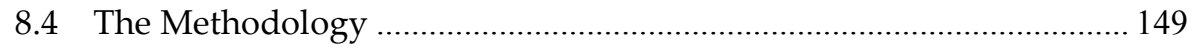

8.4.1 The Beta Regression Approach and Parameter Estimation............. 149

8.5 Presentation and analysis of results............................................. 151

8.6 Summary and Conclusion................................................................ 156 


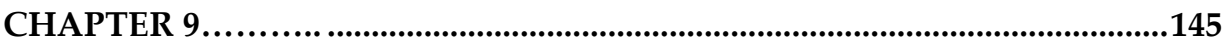

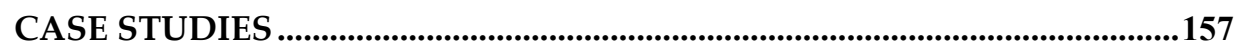

(Textile-Apparel industry in Ghana) .............................................................157

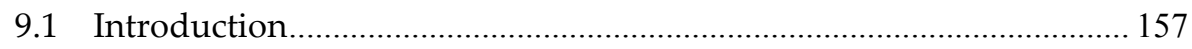

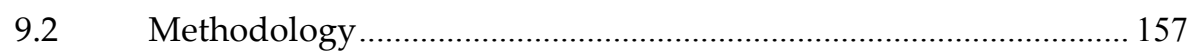

9.3 Profile of Sampled Companies .......................................................... 158

9.3.1. Printex Limited Company (formerly Millet Textiles Corporation) 158

9.3.2 Akosombo Textile Limited.......................................................... 159

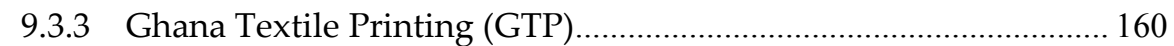

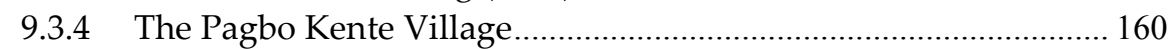

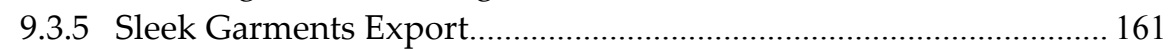

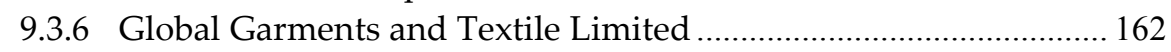

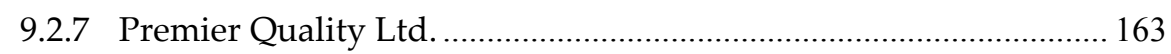

9.4 Assessment of Sampled top Textile and Apparel Companies ............... 164

9.4.1 Technology Transfer and Skills Acquisition ....................................... 164

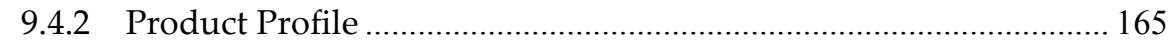

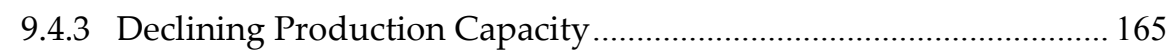

9.4.4 Price Competitiveness in the Domestic Market................................. 166

9.4.5 Increasing delays in delivery times................................................ 168

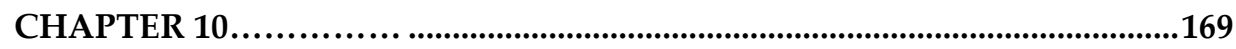

Discussion and Conclusions ...........................................................................169

10.2 Some other contribution of the study ……....................................... 175

10.3 Limitations of the Study and prospects for further research............. 177

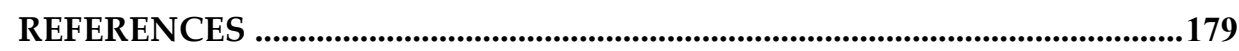

\section{Summary}

Samenvatting

About the Author 


\section{List of Tables}

\section{Chapter 1}

Table 1:

\section{Chapter 3}

Table 3.1:

Table 3.2:

\section{Chapter 4}

Table 4.1:

Table 4.2:

Table 4.3:

Table 4.4:

Table 4.5:

Table 4.6:

Table 4.7:

Table 4.8:

Table 4.9:

Table 4.10:

\section{Chapter 5}

Table 5.1:

Table 5.3.1:

Estimation Procedure .78

Incidence of Positive TFP Growth among Apparel

Manufacturing Firms. .82

Table 5.3.2: $\quad$ Incidence of Growth (\% change between 2002 and 2007)...85

Headcount Poverty Trends in some 14 countries in the early 1990s and 2000s.... .8

Firms distribution by size and Location.....................33

Profile of some textile manufacturing companies in

Ghana .36

Share of textiles and apparel employment in Manufacturing. .51

the $\mathrm{T} \& \mathrm{C}$ industry for Taxes on imports of some selected textile and apparel products................................................... 58

Value of US T\&C imports from Ghana in ‘000 of US dollars

T\&C trade relationships between Ghana and United States under AGOA in '000 of US Dollars.........................61 Exports performance of Ghana to the European Union and vice versa...............................................62 PSI on textile and garments...............................64 technology content $\mathrm{T} \& \mathrm{C}$ products exports from Ghana's trade performance in textile with the world in US million dollars at current prices.............................65 Ghana's trade performance in clothing with the world in US million dollars at current prices.............................66 


\section{Chapter 6}

Table 6.1: $\quad$ Pure Technical Inefficiencies: performance by Region and

Firm Size Between 2002 and 2007........................106

Table 6.2: $\quad$ Pure Technical Change: Performance across Region and Firm

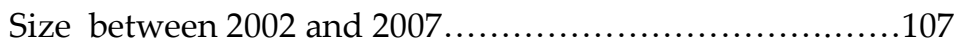

Table 6.3: Scale efficiency: Performance across Region and Firm Size between 2002 and 2007....................................109

Table 6.4: Scale Technology: Performance across Region and Firm Size

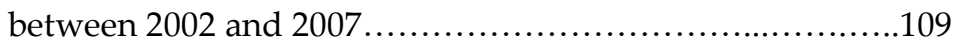

\section{Chapter 7}

Table 7.1: $\quad$ Examples of Membership Functions.........................127

Table 7.2: $\quad$ Examples of Multidimensional Measure of Poverty at a Point

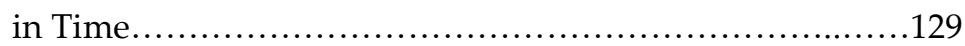

Table 7.3: $\quad$ Variable Combinations......................................132

Table 6.4: $\quad$ Poverty index for the $\mathrm{j}$-th attribute and population...............134

\section{Chapter 8}

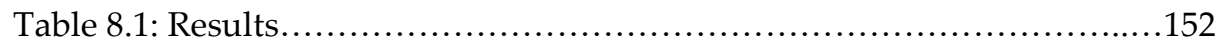

Table 8.2: Modeling the Effects of TFP Growth on Poverty.....................155

\section{Chapter 9}

Table 9.1: $\quad$ Change in production capacity of four major textile firms (in million yards)............................................166

Table 9. 2: $\quad$ Changes in Delivery Times of Exports to Unite States......168

viii 


\section{List of Figures}

\section{Chapter 2}

Figure 2.1: $\quad$ Farrell's Technical and Allocation Efficiencies..................16

Figure 2.2: $\quad$ Kennedy and Ahmed models...............................20

Figure 2.3: Chamberlain's Theoretical Approach..........................23

\section{Chapter 3}

Figure 3.1: $\quad$ Categories of our data sources.................................

Figure 3.2: $\quad$ Map of Ghana....................................................34

\section{Chapter 4}

Figure 4.1: International trade rule and innovation within the T\&C

Industry................................................ 45

Figure 4.2: $\quad$ Structure of Ghana's Textile and Garment Industry (1997).

Figure 4.3: $\quad$ Textiles and clothing value added in manufacturing in Percentage...

Figure 4.4: $\quad$ Value of $T \& C$ composition in gross manufacturing output in Percentage ................................................49

Figure 4.5: $\quad$ T\&C Growth in gross manufacturing output in percentage.

Figure 4.6: Growth of textile and clothing manufacturing value added.52

Figure 4.7: $\quad$ T\&C manufacturing production growth rates $(1977=100) \ldots .56$

\section{Chapter 5}

Figure 5.1:

Shift of Production Possibility Frontier . .72

Figure 5.2: $\quad$ Growth Distribution by Region, Firms Size and Entire Sample for Models 1 \& 2b............................................ 86

Figure 5.3: $\quad$ TFP Growth by Firm Size and Region.........................87

\section{Chapter 6}

Figure 6.1: The Producer's Decision.................................97

Figure 6.4a: Mean Pure Technical Efficiency Change and respective 95\%

confidence bounds ( Non standards \& Standards Corrected)...110 
Figure 6.4b: Mean Pure Technical Change and respective 95\% confidence bounds ( Non standards \& Standards Corrected)................111

Figure 6.4c: Mean Scale Efficiencies and respective 95\% confidence bounds( Non standards $\mathcal{E}$ Standards Corrected).................112

Figure 6.4d: Mean Scale Technology change and Respective 95\% confidence bounds (Non standards \& Standards Corrected)....113

\section{Chapter 7}

Figure 7.1: $\quad$ Attributes and their Contribution to Deprivation in 2002

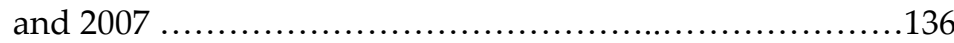

Figure 7.2: $\quad$ Poverty Dynamics Across Firms and Regions (2002 and 2007).

\section{Chapter 8}

Figure 8.1:

Simplifying Framework and Units of Analysis......

Figure 8.2:

Distribution of our dependent variable(poverty) and independent variables.

Figure 8.3 Figure 8.3: Effects of output growth on poverty reduction by location, gender and firm size.

\section{Chapter 9}

Figure 9.1: $\quad$ Price differences of textile print in percentage with respect to China............................................................167 


\begin{tabular}{|ll|}
\hline & \multicolumn{1}{c|}{ List of Abbreviations } \\
AFD : & Agence française de développement \\
AGOA: & African Growth and Opportunities Act \\
APC: & Africa, Caribbean and Pacific \\
ATL: & Akosombo Textile Limited \\
BMZ: & Bundesministerium für wirtschaftliche Zusammenarbeit und \\
& Entwicklung \\
CCR : & Charnes, Cooper and Rhodes' \\
CEPS: & Ghana Customs, Excise and Preventive Service \\
CSIR : & Council for Scientific and Industrial Research \\
CTTC: & Clothing Technology Training Center \\
ECOWAS: & Economic Community of West African States \\
EDIF : & Export Development and Investment Fund \\
EPA : & Economic Partnership Agreement \\
EU: & European Union \\
FDI: & Foreign Direct Investment \\
FEAR : & Frontier Efficiency Analysis in R \\
GATT: & General Agreement on Tariff and Trade \\
GIPC: & Ghana Investment Promotion Centre \\
GSP: & The Generalized System of Preferences \\
GTP: & Ghana textile Printing \\
GTZ: & Deutsche Gesellschaft für Technische Zusammenarbeit \\
IPC: & Innovation Possibility Curve \\
IPRs: & Intellectual Property Rights \\
KfW: & Kreditanstalt für Wiederaufbau \\
LTA: & Long-term Arrangement on international trade in Textiles \\
MFA: & Multi-fiber Agreement \\
MPDI : & Management Development and Productivity Institute \\
NHIL: & National Health Insurance Levy \\
NICs: & Newly Industrialized Countries \\
NRC: & National Research Council \\
OPPG: & Operationalizing Pro-Poor Growth \\
PSI: & Presidential Special Initiative \\
R\&D: & Research and Development \\
SAP: & Structural Adjustment Programme \\
SMEs: & Small and Medium Sized Firms \\
\hline
\end{tabular}




\begin{tabular}{ll}
\hline STA: & Short-term Arrangement to govern international trade in \\
& Cotton and Textiles \\
T\&C: & Textile and Clothing \\
TFP: & Total Factor Productivity \\
TTC: & Technology Transfer Center \\
UN HDR: & United Nations Human Development Report \\
UNCTAD: & United Nations Conference on Trade and Development \\
USTR: & United States Trade Representative announcement . \\
AGI: & Association of Ghana Industries \\
WDI: & World Development Indicators \\
WTO: & World Trade Organisation
\end{tabular}




\section{Chapter 1}

\section{Introduction}

\subsection{Background: Technical Change and Millennium Development Goals}

This study sets out to contribute to the understanding of 'how' the first Millennium Development Goal (reduce by one-half those faced with extreme poverty by 2015) in Ghana can be achieved. Thus, it seeks to explore the role of new technologies in firm performance and the subsequent impact on the poor through productivity growth. The impact of new technologies on almost all spheres of human endeavour has been phenomenal especially within the last three decades of the $20^{\text {th }}$ century. The first goal of this study therefore, is to establish the rate of technical change, efficiency improvement and productivity growth in general among small and medium scale apparel manufacturers in Ghana. This has been inspired in part by the advent and increasing adoption of new technologies in manufacturing production across the world so as to boost output quantities and standards levels at relatively lower cost.

Traditional production theories by their nature have focused more on firms' success in obtaining optimum output from a given sets of inputs and less on incorporating the standards at which the goods or services have been produced. But building competitiveness so crucial to the survival of firms from especially developing countries in an era of increasing globalization should never lose sight of how to account for product/service standards, be they safety, quality, interoperability among others and this study proposes an approach to account for standards. The second goal thus, is to investigate the extent to which the livelihoods of these apparel manufacturers are connected to and explained by the performance of their businesses.

\subsection{The Research Problem}

Of grave concern since the beginning of the new millennium is how to find a lasting solution to extreme poverty and hunger facing a significant proportion of the world's population? Over 1 billion people in the world live 
on less than US \$1 a day two-third of whom are from Sub-Saharan Africa (UN HDR, 2003). Among measures agreed upon to deal with poverty at the 2005 G8 Summit in Gleneagles, Scotland, were to cancel the debts of the world's poorest nations, increase development aid to the poorest countries and the opening up of the developed nations' markets through the removal of agricultural subsidies and export tariffs. By and large, questions over where to start and how to reduce the level and rate of poverty and deprivation among people in a more sustainable way still remain basically unanswered. Perhaps, a more inviting approach to achieve the first Millennium Development Goal is the suggestion by Lall (2001) that developing nations should build competitiveness in their manufacturing industries. This study builds on Lall's idea by hypothesizing that 'start competitiveness building with pro-poor manufacturing industries' in order to impact on the poor directly and to realize this objective faster.

Building international competitiveness involves the ability of home firms to produce and sell in rivalry with those abroad. It is also possible for a firm to transcend a few national borders to become competitive at the global level by capturing and protecting some market share. To do this, a firm must use technologies, skills and organizational forms that will minimize inefficiencies and match international level of quality, cost, flexibility and delivery. One significant development in this era is how ever changing the production processes and products and even consumers taste have become because of the technological advances. Today, not a single firm regardless of where it is located on the globe and of its size, age and nature is immune to the effects of the new technologies. The rapid nature of technical change has made some writers to believe in the advent of a new technological paradigm (Freeman and Perez, 1990). The competitiveness of firms in this age depends decisively on the technological innovation (Dosi et al., 1998). With new technologies come new markets and new opportunities for firms in both developed and developing nations. Technical change in the form of changes in physical, organizational or design technologies has therefore become of crucial importance not only for competitiveness building of small and medium sized firms (SMEs) in developing countries but for those in developed nations as well. Technical progress increases welfare by relaxing the production constraint on the economy (Dawson et al., 2005) 
The vital role played by SMEs in developing economies has been increasingly realized over the past years. However, SMEs in Sub-Saharan Africa are being confronted with many challenges in the wake of economic liberalization and globalization. Few of them are able to cope with increasing pressure from the persistent effects that economic liberalization, deregulation and globalization simultaneously, are having on their local economies particularly through international trade and foreign direct investment (Mani and Romijn, 2004). In both industrialized and developing countries there is increasing awareness that technical change which comprises the use of new and better methods and technologies in production can help SMEs boost their competitiveness both domestically and internationally. Despite that, much attention has not been given to the role that these new technologies and methods of production through technical change are playing or can play in building competitiveness of these firms.

This study raised a number of issues namely: which sector(s) can help Ghanaians make the greatest dent on poverty? What is (are) the state of those sector(s) currently in terms of performance and competitiveness both locally and internationally? How has technological advances impacted on these sectors? To what extent are the livelihood of those involved in these businesses linked to their performances and what is the way forward? To find answers to these questions, this work focuses on how Ghana can achieve their targets by specifically building competitiveness in the apparel industry which is associated directly and indirectly with over one million people ${ }^{1}$ most of whom are men and women in poverty endemic areas. The study lays emphasis on the productivity of SMEs because over ninety percent of firms in the apparel industry in Ghana are small and medium sized and their competitiveness has significant income redistribution and poverty reduction implications. This research therefore, seeks to investigate how technical change (Lall, 2000) in particular and productivity growth in general can play a significant role in the struggle to grow pro-poor businesses and achieve international competitiveness so as to reduce poverty.

${ }^{1}$ Ghana Investment Promotion Centre (GIPC) 


\subsection{The choice of the Apparel Sector}

The criteria that guided the selection of the sector was informed by the study objectives and goals which can succinctly be expressed as focusing on the development of a sector which can largely lead to the realization of the first millennium development goal through the acceleration of the pace of poverty reduction in the country. The choice of the apparel sector was therefore based on its actual and potential contribution to the promotion and improvement of exports earnings, employment, women development, propoor businesses, rural development, pro-poor incomes and income redistribution among others. The apparel sub-sector actually is part of cotton textile and apparel value chain. The sector is unique in the sense that there is a gradual shift from more capital intensive upstream processes, such as cotton production, yarn preparation, spinning and weaving in textile manufacturing to downstream apparel making operations such as designing, cutting and sewing. The processes becomes less capital-intensive and less knowledge-intensive and more labor-intensive at the downstream part, while the scale of operations tends to decline significantly due to the tailor-made and user driven nature of the sector. Moreover, the number of firms increases as one moves downstream, with many of their firms in apparel manufacturing being SMEs. Employment and value- added therefore, tends to be usually higher in the apparel sector than in the cotton and textile sectors.

Cotton has been important to the livelihood of people and development of many economies in Africa. West and Central Africa taken together are the world's second largest exporters of cotton after the United States and out of 1-2 million households that are into cotton production in West Africa, about 100,000 of them are from the three northern regions of Ghana with the cotton companies employing about 35 per cent of the working population of the area $^{2}$.

The textile industry a lone in Ghana comprise of over 50 formerly registered small, medium and large scale enterprises. This is besides numerous

\footnotetext{
2 'Protect Industries and Farmers' written by Integrated Social Development Center (ISODEC), Ghana
} 
informal textile firms located in various parts of the country. Out of 80,267 people employed in the manufacturing sector in 1980, 19,637 were from textile, wearing apparel and leather goods sub sector accounting for 24.9 per cent of the share of manufacturing employment (Asante, 2002). That share of employment according to Asante, dropped to 23.4 per cent in 1981 and then still further to 16.5 per cent in 1987 and by 1994, it has fallen to 13.5 per percent. This decline has been partly attributed to trade liberalization. The national estimates indicate that the apparel industry alone employs between $600,000-1,000,000$ people, including the members and employees of the Ghana National Tailors and Dressmakers Association and the Ghana Association of Fashion Designers, as well as the many independent tailors and seamstresses operating throughout the country.

According to Steel (1972), the composition of gross manufacturing output for textiles experienced a steady rise from 0.8 per cent in 1958 to 21.5 per cent in 1968. The good performance of the textile industry continued into early 1970s and peaked in mid 1970s. The apparel industry offers some special prospects not only in satisfying the basic needs of millions of people who can afford low cost products locally but also in export of much improved products which look attractive in global markets because of their uniqueness, quality and Afro-centric origin. Apparel made of traditional 'Kente' cloth is a typical example of the products that have gained international recognition and acceptance and can form a chunk of Ghanaian exports. Besides tapping the readily available skills and labour of tailors and dressmakers, opportunities will be created for four out of every five females who opts for dressmaking and tailoring. It is not surprising therefore that the sector received a boost from African Growth and Opportunities Act (AGOA) and is now part of the Presidential Special Initiative (PSI).

\subsection{Firm Competitiveness Building as a more Sustainable Survival Approach and Effective Poverty Reduction Strategy}

Firm-level competitiveness and pro-poor firms in particular appear rather inviting not only to researchers concerned with poverty reduction but to policy makers and development partners as well because of its direct link with people's livelihood. Even though, competitiveness building can be at the regional, national or sectoral levels, that performance depends largely on 
how competitiveness is built at the level of the firm. The ability of firms from developing countries to use the means at their disposal to produce goods and services that match international standards is crucial for their survival. This perspective of competitiveness is less strict compared to the standard textbook definition of firm competitiveness which refers to producing goods and services that are superior to those of other firms in price, quality and appearance among others. From developing economies perspective, catching-up and keeping-up but not necessarily getting ahead are necessary and sufficient for firms' survival. The issue here is therefore not competitive advantage with superiority over other competing firms but "competitiveness matching" which proposes that a firm should strive to catch-up and at least keep-up with other competing firms. This study therefore, focuses on technical change and efficiency improvement as major means to product and service upgrading and quantity expansion whilst accounting for standards.

\subsection{The Motivation of the study}

Contrary to many views, new technologies have continued to make their mark in so-called 'low-tech' traditional sectors such as cotton-textile-apparel industry in both developed and developing nations. Precision farming technologies for cotton production are being adopted by farmers to monitor and manage crops better on smaller scale. Yield monitoring through remote sensing, yield mapping software, global positioning systems, and geographic information systems technologies have enabled low yielding areas and soil conditions of pieces of land under cultivation to be established. There are integrated pest management systems including boll weevil eradication by the use of BT cotton, biological controls using trap crops and resistant varieties. New techniques to produce high yielding cotton seeds among others are now in vogue. All these technical changes have helped increased cotton yield and quality several folds.

Technological advances within the five main stages of textile-apparel production chain namely: (1) spinning; (2), weaving or knitting and nonwoven; (3), dying, printing and finishing; (4) Designing and cutting; and (5) sewing are remarkable. Many types of spinning technologies starting 
from the very simple hand spindles through more complex mechanical ones to modern electric wheels are outstanding. The speed of fabric production, weaving efficiency and fabric quality among others are the main drivers of technical change in the weaving industry. Fastest Air Jet machines with the weaving ability of 2,000 meters per minute, fastest Projectile, Rapier and Multiphase weaving technologies are among the latest to appear in the weaving industry. Dying techniques have developed from slow and microscale manual dying processes to small, medium and large-scale cost effective dying ones such as Super Jet Dyeing Machines, Atmospheric Soft Flow Dyeing Machines and Multi Nozzle Soft Flow Dyeing Machines. Printing techniques have evolved from hand block-printing considered to be the earliest, simplest and slowest to modern digital printing technologies. Fabric cutting has also evolved from simple pair of scissors to laser cutting techniques in automotive and technologically advanced industrial textiles production. Computer-aided designing, computer-aided manufacturing and automated multi-dimensional sewing technologies are some of the latest in the apparel industry, an industry considered by many to be for the low skilled workers and the poor.

Country studies carried out by operationalizing pro-poor ${ }^{3}$ growth (OPPG,2003) came to a common conclusion that, there is a general link between the speed of poverty reduction and economic growth (See table 1.3). Pro-poor growth has proven to be a necessary means of tackling poverty because of its direct impact on the poor. Normally, general per capita income or GDP growth does not reveal the hard facts of a particular poverty situation because it is based on aggregate values. Out of the 14 case studies (Table 1), Vietnam has been the most successful in tackling poverty due to high growth figure of 5.7 percent achieved over the period. Ghana managed to reduce poverty by 3.8 percent from 51.7 in early 1990s to 39.5 percent in early 2000s. Romania's poverty situation has worsened over the period by 6.1 percent in line with the low growth rates.

\footnotetext{
${ }^{3}$ Pro-poor growth refers to measures that have greatest positive impact on the poor people.
} 
Table 1 : Headcount Poverty Trends in Some 14 countries in the early 1990s and 2000s

\begin{tabular}{|c|c|c|c|c|c|c|c|c|}
\hline Country & $\begin{array}{l}\text { GDP per } \\
\text { capita(\% } \\
\text { annual) } \\
\text { Early } 1990 \text { s }\end{array}$ & $\begin{array}{l}\text { GDP per } \\
\text { capita(\% } \\
\text { annual) } \\
\text { Early } \\
2000 \text { s }\end{array}$ & $\begin{array}{l}\text { GDP } \\
\text { per } \\
\text { capital } \\
\text { annual } \\
\% \\
\text { change } \\
\end{array}$ & $\begin{array}{l}\text { Poverty } \\
\text { Headcount } \\
\text { Early } \\
1990 \mathrm{~s} \\
\end{array}$ & $\begin{array}{l}\text { Poverty } \\
\text { Headcount } \\
\text { Early } \\
2000 \mathrm{~s} \\
\end{array}$ & $\begin{array}{l}\text { Poverty } \\
\text { Headcount } \\
\text { annual } \\
\% \text { change }\end{array}$ & $\begin{array}{l}\text { Pop. } \\
\text { Growth } \\
1990 \\
\text { in ‘000s }\end{array}$ & $\begin{array}{l}\text { Pop. } \\
\text { Growth } \\
2000 \\
\text { in '000s }\end{array}$ \\
\hline Vietnam & 247.2 & 412.8 & 5.7 & 58.1 & 28.9 & -7.8 & 66,200 & 78,523 \\
\hline El Salvador & $1,400.10$ & $1,759.70$ & 2.5 & 64.4 & 39.6 & -5.4 & 5,110 & 6,209 \\
\hline Uganda & 260.3 & 363.5 & 3.3 & 55.7 & 37.7 & -3.9 & 17,359 & 23,250 \\
\hline Ghana & 356.6 & 399.5 & 1.6 & 51.7 & 39.5 & -3.8 & 15,277 & 19,593 \\
\hline India & 360.3 & 463 & 4.2 & 36 & 28.6 & -3.8 & 849,520 & $1,015,900$ \\
\hline Tunisia & $1,823.20$ & $2,469.50$ & 3 & 6.7 & 4.6 & -3.8 & 8,154 & 9,564 \\
\hline Bangladesh & 291.5 & 373.2 & 3.1 & 46.7 & 39.8 & -2.8 & 110,030 & 131,050 \\
\hline Senegal & 526.9 & 626.3 & 2.5 & 67.8 & 57.1 & -2.5 & 7,327 & 9,530 \\
\hline Brazil & $4,116.00$ & $4,628.90$ & 1.5 & 61.6 & 51.4 & -2.3 & 147,960 & 170,100 \\
\hline Burkina & & & & & & & 8,880 & 11,274 \\
\hline Faso & 241.4 & 295.5 & 2.2 & 55.5 & 47.2 & -1.8 & & \\
\hline Bolivia & $1,113.20$ & 951.6 & 1.2 & 76.9 & 67.2 & -1 & 6,669 & 8,317 \\
\hline Indonesia & 817.4 & $1,060.20$ & -0.8 & 15.4 & 16 & 0.7 & 178,230 & 206,260 \\
\hline Zambia & 465.5 & 397.4 & -2.3 & 68.9 & 75.4 & 1.3 & 7,784 & 9,886 \\
\hline Romania & $1,632.10$ & $1,652.20$ & 0.2 & 20.1 & 28.9 & 6.1 & 23,207 & 22,443 \\
\hline
\end{tabular}

Country Case Studies by OPPG

Given that the answer to significant poverty reduction depends largely on competitiveness of pro-poor manufacturing industries and that new technologies have provided some opportunity for industrial upgrading, the relationships between the speed of operation, efficiency and quality of products which have been among the core drivers of technological choice and adoption by producers in cotton-textile-apparel industry needs to be assessed and ascertained. This study which therefore seeks to offer evidence of efficiency-improvement should first provide useful knowledge of whether these firms are catching-up with the leaders within their own locality and consequently with those on the international stage. Secondly and more importantly, evidence of technical progress in the apparel industry will be particularly welcoming as that should indicate the extent to which the firms are upgrading with the help of new technologies in this industry in Ghana. The nature and depth of poverty/deprivation among the apparel manufacturers and the link to firm performance should also guide future technology, industrial and poverty reduction policy planning and formulation. 


\subsection{The Study Objectives and Research Questions}

The overriding aim of the government of Ghana's economic development programme is the reduction of poverty and the general improvement on the welfare of Ghanaians. The strategy for poverty reduction lays emphasis on economic growth in general and productivity growth in particular. Part of the motivation of this study has been the realization that the cotton-textileapparel industry can offer a unique opportunity for increased employment, poverty reduction, rural development and the capacity to generate increased incomes. In an effort to contribute to the understanding of poverty and business activities within the apparel industry in Ghana, this study proposes to address the following questions:

(1) Have SMEs within the apparel industry in Ghana built Competitiveness overtime through the economies of:

- Technical Change,

- Technical Efficiency,

- Scale Efficiency,

- TFP Growth in general and output growth in particular?

(2) What is the nature and depth of poverty/deprivation among the apparel manufacturers in Ghana?

(3) To what extent is this poverty/deprivation connected with and is explained by the performance/competitiveness of their businesses?

(4) How can the businesses of apparel manufacturers in particular be improved upon? (Policy) 


\subsection{The Thesis Outline}

This study has been organized into ten chapters which are broadly classified into three parts. PART ONE is made of three chapters namely Chapter 1 which sets the stage for the analysis of the issues addressed in this thesis by first providing the background information which comprise of the research problem explaining the need to look into the options that new technologies can offer in building competitiveness of pro-poor businesses. Chapter 1 is particularly clear about why the choice of the apparel sector and the focus on SMEs in Ghana can help realize the first millennium development goal. The motivation of the study and some stack revelations about the trends of poverty in some countries presented in Chapter 1 throws more light on the dire nature of the problem.

The study objectives and research questions were also presented in Chapter 1. In addition to that, the methodology to be employed and how the questions are to be approached have been given a cursory account. Chapter 2 presents the theories on technical change, firm competitiveness, productivity and poverty. The sources of data used in the study are presented in Chapter 3. Data types and data collection techniques are also presented in Chapter 3. Chapter 4 established the context of the study by touching on the technological capacity building initiatives in Ghanaian apparel industry.

PART TWO of the study focuses on four main chapters with Chapter 5 on accounting for standards in productivity and competitiveness assessment. Chapter 6 touches on sources of TFP growth in the apparel sector. Chapter 7 presents poverty measures and analysis in the apparel sector using fuzzy sets and techniques whilst Chapter 8 centers on linking firm competitiveness/productivity growth to poverty in the apparel sector.

PART THREE presents two chapters namely Chapter 9 which establishes the state of textile and apparel industry relying on case studies of some large textile and apparel manufacturing companies in Ghana. The case studies were carried out over a four month period in early 2008. Finally, Chapter 10 presents discussion, conclusions, limitations of the study and how the study can be improved. 


\section{Chapter 2}

\section{Technical Change, Competitiveness and Poverty: Theoretical and Empirical Review}

\subsection{Theoretical Foundations of Measures and Definitions}

The theoretical contributions to the measures, estimations and interpretations of effects of technical change on economic and productivity growth have been facilitated over the years by the works of Cobb and Douglas (1928) who attempted to find answers to the questions of how changes in the amounts of labour and capital used in the production process accounted for changes in the volumes of output. They also attempted to determine in a separate question the relationships that exist between three factors of labor, capital and product. Establishing the rate of growth of factors of production from year to year can lead to clues as to whether any increase in production has been unexpected, caused by changes in techniques or changes in production inputs. Cobb and Douglas captured the isolated effects of these variables within the limits of their own theoretical production function. In their writings:

"As the proportions of labor to capital changed from year to year, may it be possible to deduce the relative amount added to the total physical product by each unit of labour and capital and what is more important still by final units of labor and capital in these respective years?" (Cobb and Douglas 1928, p. 139)

Perhaps worth mentioning are so many restrictions defining Cobb-Douglas production function ${ }^{4}$ in which output, labour and capital are so related that, any multiplication of these inputs by any factor leads to the output to

${ }^{4}$ Mathematically expressed as $P=b L^{k} C^{1-k}$ where $\mathrm{P}$ is output, capital $\mathrm{C}$ and labour L. In their empirical estimation of this model, Cobb and Douglas arrived at the marginal productivity of: (1) labour is $3 / 4 \mathrm{P} / \mathrm{L}$ (2) capital is $1 / 4 \mathrm{P} / \mathrm{L}$ (3) total labour is $3 / 4 \mathrm{Q}$ and (4) total capital is $1 / 4 \mathrm{P}$. The elasticity of output with small changes in labour is $1 / 4$. The elasticity of output with small changes in capital is $1 / 4$. Small changes in labour therefore has three times the effect on output compared to capital. 
increase by that same factor making the production function to be homogeneous of degree one. Some of the conclusions to their seminal work include their advice to relax the assumption of total constant relative contributions of each factor to total product so as to allow for variations from year to year and the extension of the model to include the third factor of natural resources.

Durand (1937) expressed some thoughts on marginal productivity theory and threw more light on how restricted Cobb-Douglas production function was because of the assumption of constant returns to scale where the exponents of capital 1-k and that of labour $\mathrm{k}$ add up to 1 and more so capital was dependent on labour indicating the existence of an economic law which in actual fact will have to be tested and not to be predetermined by the production function. Durand (1937) thought that allowing the exponent of capital not to be dependent on that of labour, would make it possible for any verification as to whether there is an increasing, constant or decreasing returns to scale. This was later accepted by Douglas (1948). Duran again stated that homogeneous linear functions ${ }^{5}$, constant returns to scale and unchanging techniques of production assumptions were unrealistic.

Although, the theoretical works of productivity analysis were taken a step further by the studies of Tinbergen (1942), it was not until 1956 that Abramowitz attempted to use US data to answer some questions specifically trying to find out the size of the net aggregate per capita output in the US economy, the extent to which it has been explained by productivity growth, the rate of growth of net aggregate output per capita and whether apart from some short time fluctuations, there have been any major swings in output per capita since 1870 and if so, to what extent have they occurred?(Abramowitz 1956). Going a step further, Solow (1956) also modeled long- run growth where he allowed for neutral technological change.

\footnotetext{
${ }^{5}$ A function such that a given percentage increase of all productive factors will result in the same percentage increase in the product--- see Euler's Theorem (Durand, 1937, p.742)
} 
However, the path breaking theories and measurements of contributions and effects of technical change on output through the use of aggregate production function appeared in the writings of Solow (1957, 1958 and 1959). In an attempt to separate changes in output per head due to technical change and that due to changes in capital per head, Solow based his theory on the assumptions that the factors are paid their marginal products and that the aggregate production function is homogeneous of degree one to facilitate the expression of the variables in their intensive form ${ }^{6}$.

The difference between this model and that of Cobb and Douglas was the introduction of another variable $t$ for time. The $t$ allowed for the technical change to be explicitly expressed and estimated. Technical change was used to mean any kind of shift in the production function capturing economic slowdowns, speed-ups and improvement in education among others. Starting with the Hicks' neutral technical change where marginal rates of substitution of one factor for another are left unchanged with an increase or a decrease in output, Solow made a case for the production function to be mathematically stated as $Q=A(t) f(K, L){ }^{7}$ with $\mathrm{A}(\mathrm{t})$ as the measure of the cumulative effects of shifts overtime. Knowing the annual changes (time series) in output $(\dot{Q} / Q)$, capital $(\dot{K} / K)$ and labour $(\dot{L} / L)$ and capital $\left(w_{K}\right)$ and labour $\left(w_{L}\right)$ shares, it was possible to estimate annual change in technical progress $(\dot{A} / A)$ and then effects of shifts overtime [A(t)]. His idea of technical change was fundamentally what was left unexplained by the

${ }^{6}$ Solow's model was stated as $Q=F(K, L ; t)$ Where Q represents output and $\mathrm{K}$ and $\mathrm{L}$ capital and labour respectively expressed in physical units.

${ }^{7}$ The total differentiation of this function and division by $Q$ gives $\frac{\dot{Q}}{Q}=\frac{\dot{A}}{A}+A \frac{\partial f}{\partial K} \frac{\dot{K}}{Q}+A \frac{\partial f}{\partial L} \frac{\dot{L}}{Q}$ with dots as time derivatives. Defining $w_{K}=\frac{\partial Q}{\partial K} \frac{K}{Q}$ and $w_{L}=\frac{\partial Q}{\partial L} \frac{K}{Q}$ the relative share of capital and labour. Also, there is $\frac{\dot{Q}}{Q}=\frac{\dot{A}}{A}+w_{K} \frac{\dot{K}}{K}+w_{L} \frac{\dot{L}}{L}$ with $\frac{\partial Q}{\partial K}=A \frac{\partial f}{\partial K}$. By assuming that capital and labour and the production function to be homogeneous of degree zero we have the final equation as $\frac{\dot{q}}{q}=\frac{\dot{A}}{A}+w_{K} \frac{\dot{k}}{k}$. In this case $\mathrm{q}=\mathrm{Q} / \mathrm{L}=$ output per head, $\mathrm{k}=\mathrm{K} / \mathrm{L}$ = capital per head (Solow 1957, p. 313). 
model and so often referred to as Solow residual or the measure of our ignorance.

Some criticisms have been made against Solow including those of Hogan (1958). One of them is that the shift parameter, identified with technical change is exogenously expressed and appears like 'manna from heaven' in addition to lumping together all the shifts in the production function, including many which may not be related to technical change. Another criticism has to deal with the meaning and definition of technical change in the model. Whilst it may be true that the value of physical capital stock can decline, it may not necessarily be the case that there is a fall in an economy's stock of knowledge. Solow (1958) acknowledged that any type of negative shifts need not be interpreted as lost of technical knowledge because knowledge once acquired, continuous application results in its growth overtime.

\subsubsection{Economic, Technical and Allocation Efficiencies}

Working contemporaneously with Solow, Farrell (1957) raised a theoretical argument on the measurements of productive efficiency. The theory was further developed and applied in subsequent works of Farrell and Fieldhouse (1962) where it was used to estimate efficient production function with increasing returns to scale. Farrell's theory pointed out the importance of an increase in output by simply increasing efficiency and holding the production inputs constant. Prior to this conception, it was adequate to refer to labour efficiency using a measure of average productivity of labour which according to him neglects the theoretical side of the problem. His simple theoretical case was based on a perfectly efficient firm defined as the ability to produce the largest possible amounts of output from a given sets of inputs. In the case of a firm employing only two factors of production ( $x$ and $y$ ) to produce a single product under the conditions of constant returns to scale where an efficient production function ${ }^{8}$ is known, an illustration with isoquants is illuminating (see Figure 2.1A). P shows the inputs of two factors per unit of output that a firm is observed to use. The

\footnotetext{
${ }^{8}$ The output that a perfectly efficient firm produce from a given combination of inputs (Farrell, 1957 p. 254)
} 
various combinations of inputs used to produce a unit of output is shown by the isoquant $\mathrm{SS}^{\prime}$.

If the inputs combinations are represented by the points $\mathrm{J}, \mathrm{K}$ and $\mathrm{P}$ and the point $\mathrm{K}$ represents an efficient firm using inputs in the same ratio as $\mathrm{P}$, the same output is produced only with input ratio OK/OP and this is a measure of technical efficiency of the firm P. MM' is an isocost curve representing the ratio of cost of inputs and $\mathrm{OJ} / \mathrm{OK}$ ratio is a measure of allocation efficiency. $\mathrm{K}^{\prime}$ and not $\mathrm{K}$ is the optimal method of production because the cost of producing at $\mathrm{K}^{\prime}$ is only a fraction of that at $\mathrm{K}$. this is what Farrell referred to as price efficiency. Given that technical efficiency is held constant, an observed firm can have its cost reduced by a factor OJ/OK just by changing the proportion of its inputs from $\mathrm{K}$ to $\mathrm{K}^{\prime}$. This means that if a firm is both technically and allocationally (with respect to prices) efficient, its costs will be only a fraction OJ/OP. The overall efficiency is the product ${ }^{9}$ of technical $^{-}$ and price efficiencies.

Of considerable importance in Farrell's method is the theoretical foundation to the measurement and conceptualization of allocation efficiency (in his own words price efficiency) and technical efficiency. The distinction is that allocation efficiency measures a firm's success in choosing optimal sets of inputs and technical efficiency measures a firm's success in producing maximum outputs from a given set of inputs. Now Figure 2.1B represents production possibilities frontiers define as the maximum productivity of output possible at a given time with specific sets of inputs mix and production technology. Not attaining the maximum output possible implies an inefficient outcome (see point A). Point B is an efficient outcome because it is on a production frontier and point $C$ looks rather unattainable.

${ }^{9} \frac{O J}{O P}=\frac{O K}{O P} \times \frac{O J}{O K}$ Where the left hand side is the total or economic efficiency and the right hand side is the technical and allocation efficiencies respectively. 
Figure 2.1: Farrell's Technical and Allocation Efficiencies

A. Farrell's Technical, Allocation and

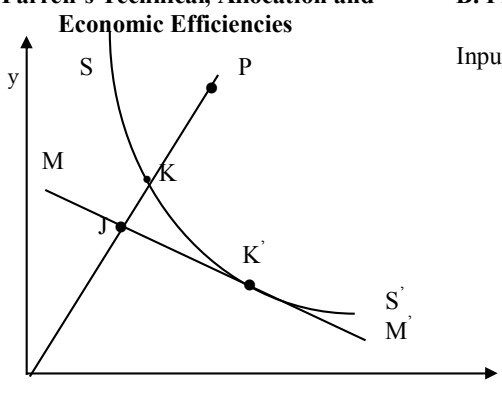

B. Production Possibilities

Frontiers

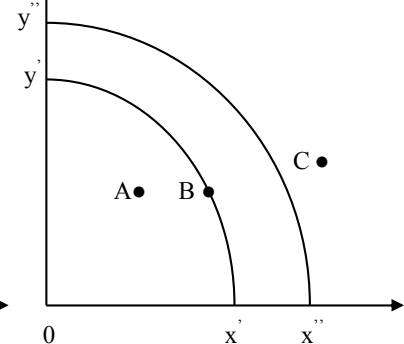

$\mathrm{x}$

Production Technology

A different set of input combination and a better technology, would cause an outward movement of the production possibility frontier from $y^{\prime} x^{\prime}$ to $y^{\prime \prime} x^{\prime \prime}$. Outward shifts of the production possibility curve are as a result of technical change. In Figure 2.1B, it is assumed that quantities of inputs increased in the same proportion with the change in technology with even greater production. Now focusing on a set of inputs $y^{\prime}$ in Figure 2.1B, there may be the case that with a better technology, a reduction in inputs used is possible. In the case of two inputs, capital and labour, technical change is Hicks neutral if the proportion of inputs used (Capital labour ratio) remains unchanged, Solow neutral if it is capital augmenting(Labour-output ratio remains unchanged) and Harrod neutral if it is labour augmenting (Capital output ratio remains unchanged).

\subsection{Embodied and Disembodied Technical Change}

Technical change involves all changes in production techniques and technologies leading to the improvements in inputs and/or product qualities and quantities or both. The term technical change has two forms: embodied and disembodied technical change. Embodiment of technical change was used in the studies of Nelson (1964). He wrote on the capital and labour qualities and the embodiment effects in an attempt to deepen the 
understanding of total factor productivity (TFP) ${ }^{10}$ growth as the previous models by Cobb and Douglas (1928) and Solow (1957 and1958) did not take into account the embodiment properties of factor inputs. Domar (1963) had pointed out the importance of recognizing the effects of improvement in the quality of capital on productivity. Johansen (1959), Jorgenson (1966) and Hulten (1992) among others have raised the issue of embodiment technical change referring to improvement in the efficiency of inputs used as a result of switching from the use of an old technology to a new and better one.

Nelson (1964) noted that, two models, one of which focuses on the quality of capital and the other of which focuses on the improvements in the quality of labour can help understand total factor productivity better. He specified models ${ }^{11}$ of embodied technical change growth which were much related to that of Cobb-Douglas' model ${ }^{12}$. In the footnotes 10 and 11, the terms $(1-b) \lambda_{k}$ and $b \lambda_{L}$ are those parts that need to be embodied in new capital and labour respectively. $\Delta A^{*} / A^{*}$ is that part that does not need to be embodied and is the relative rate of growth of total factor productivity. $\Delta A^{*} / A^{*}+(1-b) \lambda_{k}$ is the rate of growth of total factor productivity similar to that of original Cobb-Douglas model and $\Delta \bar{a}$ reflects changes in the difference between the average technology in use and the best technology available.

Jorgenson (1966) explained that there are two different approaches to analyze total factor productivity (TFP). The first approach is the one in

\footnotetext{
${ }^{10}$ Output measure of an industry, or an economy in relation to the amount of total primary factor inputs used in the production process, sometimes referred to as Solow residual.$$
\Delta O / O=\Delta A / A+b \Delta L / L+(1-b) \Delta K / K
$$$$
{ }^{11} \Delta O / O=\left[\Delta A^{*} / A^{*}+b \lambda_{L}+(1-b) \lambda_{k}-(1-b) \lambda_{k} \Delta \bar{a}\right]+b \Delta L / L+(1-b) \Delta K / K
$$$$
\Delta O / O=\left[A^{*} / A^{*}+b \lambda_{L}+(1-b) \lambda_{k} \bar{a}_{t-1} \delta\right]+b \Delta L / L+(1-b)\left(1+\lambda_{k} \bar{a}_{t-1}\right) \Delta K / K
$$$$
\Delta O / O=\left[\Delta A^{*} / A^{*}+(1-b) \lambda_{k}-(1-b) \lambda_{k} \Delta \bar{a}\right]+b \Delta L / L+(1-b) \Delta K / K
$$$$
\text { where } \Delta O / O, \Delta A / A \text { are ralative rates of growth of output and total }
$$$$
\text { factor productivi ty respective ly, } \Delta K / K \text { and } \Delta L / L \text { are the relative }
$$$$
\text { rates of growth of capital and labour inputs, advances in techno log } y
$$$$
\text { allows the quality of new machines to improve at } \lambda_{k} \text { per year, } \Delta \bar{a} \text { is the }
$$$$
\text { change in average age of capital. }
$$ 
which TFP is treated as index number measuring the ratio of total output to total inputs and because the growth rates of inputs change overtime, TFP is bound to change to. The second approach is a situation where TFP may be treated as a function and in the case of an exponential function of time, the parameters may be treated as unknowns and can be estimated from the inputs output data. In both approaches, he indicated, TFP is interpreted as shifts in aggregate production function or as disembodied technical change. He also pointed out that Solow (1960) has interpreted these changes in index of productivity as 'technical change embodied in new goods' with the assumption that this embodied technical change takes place at a constant exponential rate. Denison (1964) has written that the whole issue of embodiment may not be that relevant to US policy even though it may be that the issues of embodied and disembodied technical change have some implications which could be of some significance to economic policy.

An earlier attempt by Griliches (1961) to analyze total factor productivity is perhaps very informing. Griliches theoretical approach to the perception of total factor productivity starts from the assumptions that changes in output are attributed to changes in the quantities and qualities of inputs and to economics of scale instead of to technical change. He referred to the residual identified as technical change as resulting from errors in measurements and cited how variables can be misspecified, mismeasured and wrong weights used in the estimation process. He claimed that his approach does not remove technical change from the explanation of growth but rather changes what he called 'catch all residual variable' into identifiable changes associated with the qualities of productive inputs.

\subsection{Induced and Autonomous Theories of Technical Change}

The induced theory of technical change is built on the notion that both the rate and direction of technical change depend on some market demand factors (e.g. relative prices of factors of production) and supply factors (e.g. the degree of factor endowments, investment). Two theoretical models namely: the economic growth and microeconomic versions have been used to explain induced technical change (Rutttan, 2001). Hicks (1932) argued that technical change would attempt to replace the more expensive factor 
(Acemoglu, 2001 p. 1). Hicks' explanation was later criticized that it is the reduction of the total cost that matters whether this is achieved by using less of more expensive factor or not is actually not an issue. After all, cost reduction can be the direct result of factors of production becoming more efficient.

The term autonomous technical change as appeared in the works of Nadiri (1970) and Grubb and Koehler (2000) among others depends mostly on autonomously supplied inventions, autonomous trends and government R\&D and it is not driven by market forces or economic motivations. In fact, most studies including Solow (1957, 1958 and 1959), Griliches (1961) and Denison (1964) just attempted to isolate the effects on output growth resulting from any change in physical technology, organizational technology and design technology based simply on the idea that producers find these new techniques commercially useful. How fast and to what extent new techniques are replaced by old ones hinges crucially on what future prospects are likely to be.

The microeconomic theory of induced technical change has been popularized by the works of Salter (1960), Fellner (1961), Kennedy (1964), Samuelson (1965), Ahmad (1966), Kamien and Schwartz (1968), Atkinson and Stiglitz (1969), Lucas R. (1967), Binswanger (1974), Dosi (1988), Ruttan (2001) and Antonelli (2003). This approach is grounded on Schumpeterian tradition and it seeks to explain that, at any given point in time, there exists a set of production process, determined by the basic state of knowledge available to be developed. For the purpose of this study, theoretical insights from Kennedy (1964) and Ahmad (1966) will be worth elaborating upon.

Kennedy's model is based on what he called Innovation Possibility Curve (IPC) labeled nn in Figure 2.2C and it shows the available sets of techniques at a particular point in time. The vertical $\left(\delta_{L}\right)$ and horizontal $\left(\delta_{K}\right)$ axes respectively represent the rate of reduction in Labour (L) and capital (K) requirements associated with the adoption of a new technology. With the technological transformation function nn showing the trade-off between the factor reductions requirements rates, he demonstrated that technical change is induced by the relative factor shares. It will therefore be prudent for a firm to decrease the use of inputs with greater relative share of total cost. The 
equilibrium point e shows where the IPC is tangent to the line $\mathrm{h}_{2} \mathrm{~h}_{2}$ representing where the slope of IPC is same as that of the ratio of the factor shares (slope of $\mathrm{h}_{2} \mathrm{~h}_{2}$ ). Given the choice between equally costly capital and labour reduction techniques, if the ratio of capital share to labour share is the same, producers will be indifferent between the two techniques but if capital share is larger, producers will prefer the labour using or capital saving techniques. If labour share is larger, producers will naturally go for capital using or labour saving techniques.

Figure 2.2: Kennedy and Ahmed models

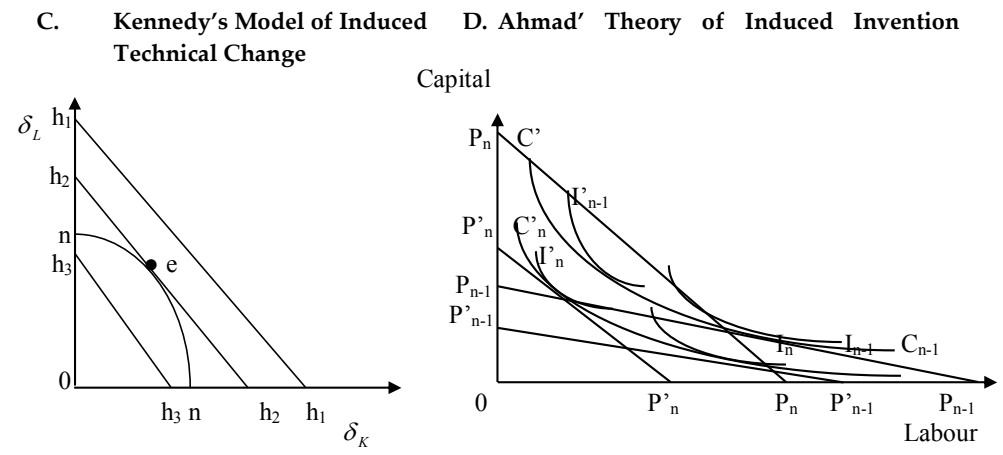

Ahmed's microeconomic model of induced innovation is based on factor prices instead of factor shares. He illustrated that a rise in the price of say labour will lead to an innovation which is labour saving. He started with what he called a neutral historical IPC. In Figure 2.2D, capital and labour are plotted on vertical and horizontal axes in that order. There are two periods, previous and present with symbols n-1 and n correspondingly. The Cs, the Is and the Ps represent IPCs, isoquants and price of factors respectively. He made the assumptions that the isoquant ( represents a particular invention) chosen is one which minimizes the cost of production with a given relative price of factors and that it takes longer to invent than to change the factor combination. A choice of isoquants (techniques) nearer to the vertical axis is labour saving and that nearer to the horizontal axis is capital saving. 


\subsection{Endogenous versus Exogenous Theoretical underpinnings of Technical Change}

Endogenous theory of technical change viewed knowledge as a factor of production which is determined by the previous levels of investment. Arrow (1962) realizing the importance of experience in productivity growth hypothesized that technical change can be attributed to experience. Lucas (1988) in his model made labour augmenting technical change endogenous by linking it to human capital accumulation decisions. He emphasized the growth process that relies on investing first and getting a return later. In Lucas' model, growth rate depends positively on productivity of the learning process, negatively on discount rate, positively on intertemporal elasticity of substitution, and knowledge spillovers. Romer (1986), contribution to the endogenous theory of technical change did not supplant the neoclassical model but fills an important gap with a rigorous description of the source of technological progress. He pointed out that if innovation in his model was to stop, then his model would collapse to the neoclassical model.

Theories of exogenous technical change assume that technical knowledge is based on factors other than the economic system itself. The new knowledge only emerges in response to factors such as the curiosity of the inventors to pursue knowledge for knowledge sake. From the point of view of a firm or a nation, the models of exogenous technical change expressed it like 'manna from heaven'. Many theoretical models including Solow (1957), Griliches (1961) and Denison (1964) have all treated technical change as an exogenous process carried out by universities and research centers which can be tapped into when the need arises. The distinction between the terms exogenous and endogenous technical change on one hand and embodied and disembodied technical change on the other is that, whilst the former refer to the source of technical change the latter refer to the forms of that change.

\subsection{Capacity Utilization and Technical Change}

Theoretical considerations of capacity at the level of the firm, an industry or a nation has appeared in many studies including Smithies (1957), Klein 
(1960), Klein(1973), Edmondson(1973), Perry (1973), Prochaska (1978), Berndt and Morrison (1981), Fare and Grosskopf (1992), Nelson (1989), Fare, Grosskopf and Kokkelenberg (1989), Fixler and Zieschang (1992) and Borger and Kerstens (2000) among others but known to have started in the 1940's with the works of Chamberlain (1947). Capacity utilization generally refers to the ratio of actual output to some measure of potential output. Capacity utilisation is theoretically and technically expressed as the output corresponding to (i) the minimum point on the short-run average total cost curve and (ii) the point of tangency between long-run total cost curves and short run average total cost curves (Nelson 1989, p. 273).

Smithies used the word full-capacity output to mean "the output that the existing stock of equipment is intended to produce under normal working conditions with respect to hours of work, number of shifts, and so forth" (Smithies, 1957, p. 8). This approach thus gives the opportunity to compare actual output to full-capacity output at any point in time. He theorized that actual output can exceed or fall short of full capacity output. In a situation where full capacity output exceeds actual output, it means that, reserve capacity is being used, there is intensive use of capacity through additional shifts or working overtime. When actual output falls short of full capacity out put, there is excess capacity. This excess capacity can be removed by increasing output through more employment of production inputs, working overtime or in shifts. Technical change can therefore, be captured as part of the difference between last and this year's full-capacity output.

Klein (1960) noted that Smithies conceptualized of the capacity concept is not enough to allow for practical application. He indicated that Chamberlain's theory which is based on cost functions and implies that imperfect competition in an economic system can cause inefficiencies and give rise to excess capacity is also inflexible because of the need to estimate those cost functions. According to Chamberlain (1947), full capacity is that output level achieved with full competitive equilibrium. In Figure 2.3E, full capacity is at the minimum of average cost curve represented by the equilibrium output $\mathrm{OC}$ and marginal cost curve (MC) equates average cost curve $(\mathrm{AC})$, price $(\mathrm{P})$ and marginal Revenue $(\mathrm{MR})$. In Figure 2.3F, imperfect competition ensures that there is excess capacity (PC) because equilibrium occurs at output level OP instead of OC. 
As Prochaska (1973) implied, the general definition of economic capacity as the output level at the minimum short run average total cost curve is only a value concept which is not the same as optimum physical capacity which arises when there is diminishing returns. In the long run, he wrote, optimum economic capacity refers to the scale of plant at which long run average cost curve is minimum. Capacity

Figure 2.3: Chamberlain's Theoretical Approach
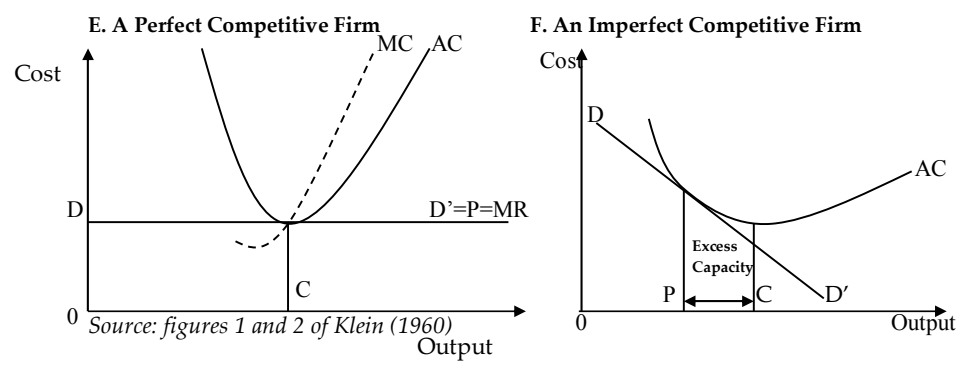

output and capacity utilsation are usually short run ideas based on the productive inputs of a firm, an industry or a nation. Sub-optimal outcomes can be improved by organizational technological changes and better inputs mix strategy.

\subsection{Firm Competitiveness and Productivity Growth}

In industrial organization literature, Porter (1983) writing on how a firm trying to compete set a number of economic and non-economic goals. He cited Learned et al (1965) as capturing some of those goals as well as operating policies along product development lines, manufacturing and marketing, among others. Strategically, a firm aims at business practices well suited to its external environment and tries to build its competencies in order to rise up to the challenge of others. As some studies have dwell on single aspects of industry structure (e.g. relative cost position of the industry, number and size distribution of firms, product differentiation or overall elasticity of demand) in an effort to explain the competitiveness of a firm, the comprehensive competitiveness position of such firms remain 
largely unknown, Porter noted. Explaining further, he identified how industry structure is a crucial determinant of collective performance of firms. Such performance which determines their competitive positions covers aspects of allocative efficiency or profitability, technical efficiency or cost minimization and innovativeness among others. It is these indicators that rightly capture the rate and level of firms' performance which however differ from industry to industry.

Whilst large firms competitiveness building have received a lot of attention and treatment in business and economics literature, small firms which for so many decades were regarded as those in transition and therefore largely ignored are beginning to take center stage both in business and economic development literature and even international trade debate with the growing realization that some if not most of small firms never get to the stage of large firms. The question is: can small firms be competitive in an era of increasing globalization? Olaf et al. (2006) responded positively by explaining that small firms can become competitive by improving their level of efficiency, improving quality and taking advantage of product differentiation, and by taking advantage of increase and changes in demand. Even as what the term 'competitiveness' really is has itself become a matter of public discussion, due to the fact that analogies are being drawn between corporate or firm competitiveness and country competitiveness. Krugman (1994) who considers a firm to be very different from a country was quick to write that failure of firms to be competitive can result in their demise and disappearance but nations on the other hand do not exit from the globe. $\mathrm{He}$ identified competitiveness with productivity growth which is much in line with the argument in this study that hinges on the link between this productivity growth and the pace of poverty reduction among owners of small and medium scale apparel producers in Ghana.

\subsection{New Technologies and firm Competitiveness}

Wangwe (1995) identified changes in technology hardware and software especially in the last two decades of the $20^{\text {th }}$ century as one of the major challenges in the world economy. These historic technological advances have become a blessing not only for so-called high-tech industries but even for low-tech ones as well. What is particularly interesting though is the 
transition from mass production in the 1950s and '60s to tailor-made production techniques and products. This is what many writers including Lall (2000) believe should drive competitiveness of SMEs. Large firms would even have to think of ways to produce tailor-made products that meet the varying needs and users as SMEs by their nature tend to cater for specific needs of their customers. Madu (1992) wrote that productivity, quality and competitiveness of a firm are all related to technology but warned that simply adopting new technologies may not produce the competitiveness aimed at as one would have to effectively manage these technologies in order to exploit their full potential. Citing Japanese managers as the success case in utilizing their skills to manage such technologies effectively, Madu(1992) referred to managers in US as re-evaluating their management practices in order to meet such challenges. What is obvious however is that new technologies are as good as the managers can successfully deal with them.

Technological reasons have been assigned to the increasing desire of firms to become competitive internationally (UNCTAD, 2003). The rising trend of innovation and its impact on productivity growth have left firms, no matter their place of location and stage of development without any choice but to improve. New technologies have full proof position of being beneficial to all firms and that they impact positively on both traded and non-traded products and services thereby serving as a vital determinant of peoples' welfare. What is more, new communication and transportation technologies have reduced the entire world into a 'global village'13 thus providing ample evidence that no single firm regardless of size and location is insulated from the global market. The cotton-textile-apparel industry in question is one widely considered as traditional and highly competitive especially with the phasing out of Multi-fiber Agreement (MFA) ${ }^{14}$ in January, 2005. These led many writers to predict that developing countries especially those in SubSaharan Africa are likely to lose their relatively small market share to countries like China and India.

${ }^{13}$ Used in the sense of Marshall McLuhan (1962) indicating referring to how geographical distance is being overcome by some new technologies.

${ }^{14} \mathrm{MFA}$ is a multilateral agreement signed in 1974 by Europe and US limiting general importation of fiber from some countries and instead had different bi-lateral arrangements with different countries. 
Teal (1999) emphasize two of the views which this study seeks to investigate. They are: 1) that Africa's problems lie in lack of technological development Lall et al (1994) and 2) technical inefficiencies charactering Africa's manufacturing sector. Efficiency is considered key to the manufacturing firms especially success in exporting. This is a view widely held by the New Trade Theory advanced by Krugman (1984, and 1997) and Grossman and Helpman (1991). Increasing productivity through investment in technology and policy reforms constitute one solution to boosting industrial production (Evenson and Westphal, 1994). Some studies have promoted that somehow, efforts should therefore, be directed at achieving adequate levels of technological development as inattention implies unimportance. Also, as investment, productivity, exporting and competitiveness are commonly regarded as integral part of growth and development, privately owned firms effort at promoting technical change needs public sector support because public private partnership is seen as a better approach that gets all hands on deck in the development process. Furthermore, some studies have identified that favorable macro economic environment, economic liberalization and strong but workable intellectual property rights (IPRs) policy can help build technological capacity in developing countries. Openness in particular is a channel for technology transfer.

Can SMEs play any significant role in technological development especially in developing countries? Levy (1990) noted in his study on transaction cost and size of the firm, among others in Taiwan and Korean footwear manufacturing sectors that the choice of product mix did not depend on the size of the firm per se and that differences in product mix could be explained by the underlying institutional comparative advantage making the Taiwanese firms to be more small-scale and market intensive in nature whilst those of Korea are more large-scale oriented. Therefore, the notion that technological advantages are enjoyed exclusively by large firms can be rejected on the basis that, it depends on the nature of operations and market environment. SMEs have been instrumental in technological development of Taiwan and Korea. In developing countries where SMEs dominate manufacturing production, it is needless to assume that technological progress should be the sole responsibility of large firms. 
Some studies including Kim (1997), and Kim and Nelson (2000) tried to answer the question about how South Korea and other newly industrialized countries (NICs) made it from relatively poor levels of industrial development to the current high economic success. At the heart of these successes is the technology development. Korea for example relied on imported technology and went through the process of reverse engineering in mid 1960s and 1970s. Imitation is quite possible with less complex products whilst formal R\&D may be necessary in the production of new and relatively complex goods. However, even imitation requires good sense of market needs, current and future demands as its competitive advantage are shortlived and sometimes based only costs that otherwise could have gone into $R \& D$. Like other NICs, reverse engineering which if legal is only good for the initial stages of technological development process ${ }^{15}$. As rightly acknowledged by some writers, micro-level technological capability building can form the basis for the development of national technological capabilities.

Kumar and Chadee (2002) writing on the international competitiveness of Asian firms realized that given the high export performance of these firms, one expects large volume of literature in this area but unfortunately, this was not the case presumably due to difficulty in obtaining firm level data that would allow cross-country comparisons to be carried out. Additionally, international competitiveness requires cross-functional expertise that has made it to remain outside the domain of any academic discipline and these have hindered the development of theories on firm competitiveness thus making their understanding very shallow. Employing theoretically valid approach to investigate issues of not only economic significance but also of social and political relevance is very crucial (Kumbhakar et al, 2007).

\footnotetext{
15 It should however be borne in mind that, developing countries need not go through linearly the technological stages that both developed and NICs went through as it become possible at some stage of the development process to leapfrog some stages by learning from and taking advantage of existing knowledge.
} 


\subsubsection{Channels of Technology Transfer: the Process of building Firm Competitiveness}

Even though, foreign direct investment (FDI) is widely regarded as important means of technology transfer upon which technological capability is realized, nations like South Korea instead of promoting FDI developed their technologies through the importation of capital goods. This expedited learning and assimilation of the technological knowledge by domestic firms laying a solid foundation for rapid industrial take-off. FDI provides probably the most important and cheapest channel of direct technology transfer as well as indirect, intra-industry knowledge spillovers to developing countries (Blomström and Kokko 1997). AT least four ways have been identified as means through which technology might be diffused from foreign investment enterprise to other firms in the economy: (1) demonstration - imitation effect. Here, local firms imitate foreign ones (2) competition effect- competitive faced by local firms induces them to introduce new products to defend their market share and adopt new management methods to increase productivity (3) foreign linkage effectforeign affiliates and upstream suppliers and downstream customers increases knowledge spillovers (vertical spillovers) and (4) training effect. He further acknowledged that not all spillovers are positive as FDI can generate negative externalities when foreign firms with superior technology force domestic firms to exit. These negative externalities are variously referred to as competition effect, crowding-out effect or business-stealing effect.

\subsection{Productivity Growth and Poverty Reduction}

Guibaud (2003) tried to identify the relationship between productivity growth and poverty reduction in some developing countries stated clearly how productivity which defines inputs-outputs relationship with some partial indicators as output labour ratio, output capital ratio and output raw material ratio among others is key to reducing by one half those confronted with extreme poverty by 2015. Whilst the literature on the relationship between economic growth and poverty reduction establishes unequivocally the poverty reducing effect of growth that has not been the case between productivity growth and poverty given the limited nature of the literature 
on the subject. The literature on the relationship between productivity and poverty especially in developing countries is limited even at the macro level and virtually non available at micro level focusing on SMEs. Hayes et al. (1994) established a two-way relationship between poverty and productivity using output per unit of labour as a proxy. Other studies by Datt and Ravallion (1998) and Fluet and Lefebvre (1997) have attested to the positive impact that productivity gains can have on poverty both directly and indirectly. Productivity gains resulting either from using less physical inputs to produce more physical outputs or in value terms such as higher value for the same output produced should negatively impact on privation.

Theoretically, this study proceeds as follows: Chapters 5 and 6 are based on Malmquist (1953) productivity index supported by the theoretical foundation to the measurement and conceptualization of technical efficiency and technical change (Farrell 1957, see sections 2.1.1 and 5.3.3). Farrell (1957) model was developed contemporaneously with Solow (1957) neoclassical growth model which assumes exogenous technological change. Same set of input combination and a better technology would cause an outward movement of the production possibility frontier. Malmquist (1953) productivity index is a non-parametric technique (does not make any prior assumption about the distribution from which the data is drawn) allows us to: 1) estimate TFP growth and 2) decompose TFP growth into technical change and technical efficiency change.

Chapter 7 is not built on classical set theory and logic which deals with precise measures and poverty lines, of say, one either belongs to a set of poor people or rich people but built on Fuzzy set theory and logic (Zadeh, 1965) based on admitting membership values in their imprecise form. For example, with respect to poverty/deprivation, the multidimensional measurements accommodate the degree of deprivation from completely deprived through partially deprived to completely non-deprived. There are no categorical arguments of say haves and have-nots. Chapter 8 brings together the findings of Chapters 5, 6 and 7 in line with Pineau (2004) and Guibaud (2003) proposition that gains in output and productivity should lead to reduction in poverty. 


\section{Chapter 3}

\section{Data Sources}

\subsection{Introduction}

This chapter focuses on sources of data and the respective collection techniques. It also provides insights into the types of data employed in the subsequent chapters. Our data were classified into three main categories and collected from secondary sources made up of a number of existing databases and primary sources obtained from face-to-face interviews. In Figure 3.1, the three broadly observed categories of our data sources are presented.

\subsection{Secondary data sources}

Our secondary data sources include the World Bank Group's World Development Indicators (WDI) of various years, Ghana's Export Bulletin (1997), Steel (1972) data, Lall and Pietrobelli (2002) and Quartey P. (2006) data, Ghana Customs, Excise and Preventive Service (CEPS, April 2008), US Census Bureau Foreign Trade Statistics, US Department of Commerce database, European Commission external trade statistics, Ghana's Ministry for Private Sector Development and PSI (2005) data, Ghana Statistical Service and the World Trade Organisation (WTO) trade statistics.

Figure 3.1: Categories of our data sources

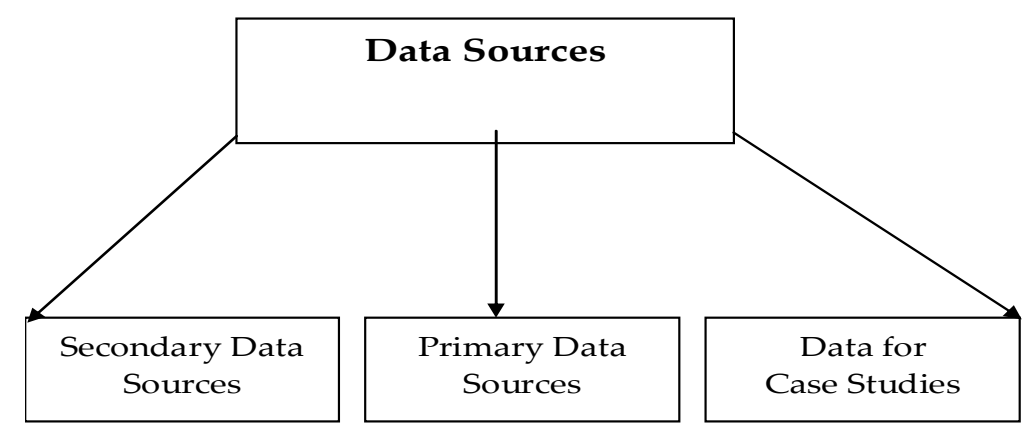




\subsection{Primary data sources}

Part of the empirical part of the study relied on a survey of SMEs within the apparel industry in Ghana. The other part was based on a survey of the apparel relate households obtaining data on the livelihoods of those in apparel manufacturing jobs.

\subsubsection{Design of the Questionnaire}

Semi-structured questionnaire was administered in multiple visits (see Appendix 3). The questionnaire was divided into two parts. The first part combined multiple choice and numeric open-end questions which include gender and age of owner, line of business operation, year established, number of employees and whether a respondent was a member of any associations. Other questions included types of machines being used, size of business fixed and total assets, amount in value of apparel produced, size and cost of labour, quantity of fabric input per year, share of output sold locally and exported in percentages, relative price of locally sold products compared to those exported and the perceived level of capacity utilization. Whilst the first part of questions focused on 2007, the second part repeated the same questions for 2002 which is five years back considered in this study as a period long enough to establish the rate of technical change in apparel industry(appendix 3).

The second part of the questionnaire focused on the households of apparel manufacturers. Thus, interviews centered on the name of the enterprise the individual household head is working for, gender of the person, size of the households, line of business within which they are working and year of starting or joining the business. The respondents who were randomly selected were required to have been in the business for at least five years. Questions on household attributes were raised and the respondents asked to compare their situation in 2007 to 2002. The first dimension referred to as D1 captures attributes on shelter ranging from the nature of the flooring materials, roofing, wall, number of rooms to its ownership. The second dimension (D2) detailed the source of water supply to the household. Whilst dimension three (D3) subdivided into three categories namely durable 
assets, food, and other assets are listed, dimensions four (D4) and five (D5) provided daily expenditure on food and monthly expenditure on clothing respectively Dimension six (D6) dwelled on sanitation. Other dimensions such as dimension seven (D7) addresses multiple choice questions on sources of household energy supply classified into lighting and cooking, dimension eight (D8) on health categorized into orthodox medication and self medication, D9 on capabilities grouped into education at home, school and at workplace, D10 touches on security and safety of location partitioned into financial/social attributes, violence and cost of living. The final dimension, D11 posted issues on category of income that best describes the respondent's situation.

\subsubsection{Sampling Technique and Firm Survey}

The sampling technique was based on a frame of various apparel producing firms in the country. In line with that developed for the Ghanaian Manufacturing Enterprise Survey in 2000 (Rankin, Soderbom and Teal, 2002), a stratified sample survey was carried out as firms within strata are relatively homogeneous but there is a great deal of heterogeneity between strata. In Ghana, these differences among firms have been identified and associated with location and size. Up to 200 formerly registered apparel manufacturing firms and many informally registered ones were contacted but the number of valid questionnaire after accounting for inaccuracies and other errors was 140 (Table 3.1).

Table 3.1: Firms distribution by size and Location

\begin{tabular}{llll}
\hline Location & $\begin{array}{l}\text { Micro-sized } \\
\text { firms }\end{array}$ & $\begin{array}{l}\text { Small\& medium } \\
\text { sized firms }\end{array}$ & Total \\
$\begin{array}{l}\text { Greater Accra } \\
\text { Region }\end{array}$ & 37 & 21 & $\mathbf{5 8}$ \\
Eastern Region & 20 & 17 & 37 \\
Volta Region & 29 & 16 & $\mathbf{4 5}$ \\
Total & $\mathbf{8 6}$ & $\mathbf{5 4}$ & $\mathbf{1 4 0}$ \\
\hline
\end{tabular}


The main survey was preceded by pre-testing of the questionnaire. Two persons, one a graduate and a research assistant and the other a member of apparel manufacturing association were trained and recruited to conduct the pre-testing of the questionnaire. Ten firms were sampled for pre-testing. Initially only single on-site visits were intended but as it tended out, multiple visits to some firms became necessary as respondents promised to cross-check some information correctness. Face-to face interviews led to 80

Figure 3.2: Map of Ghana

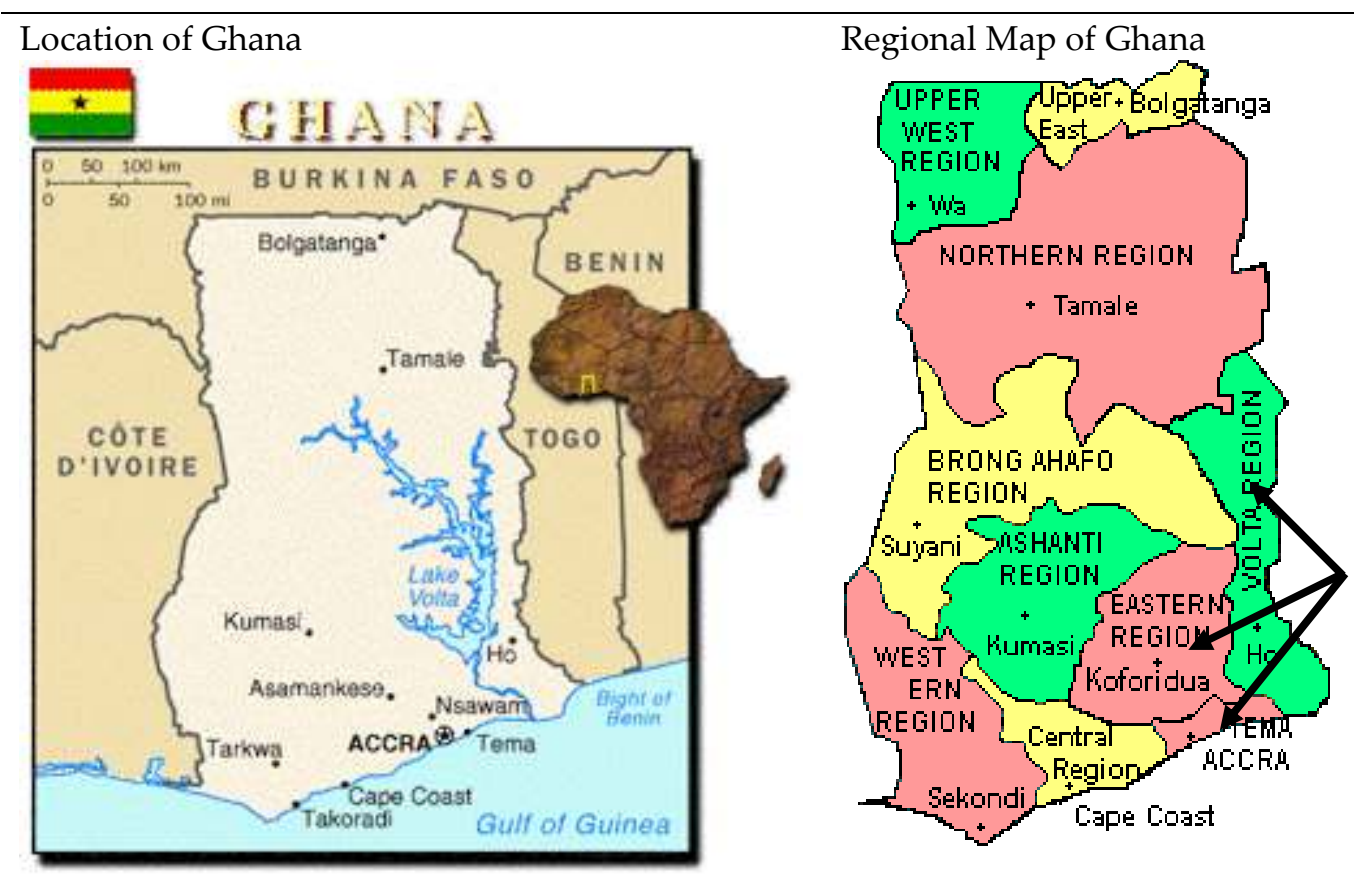

Sources: http://www.ghanaweb.com/GhanaHomePage/geography/maps.php

Greater Accra, Eastern and Volta Regions indicated by the arrows

percent response rate and a few invalid or wrongly answered questionnaires. It became clear during pre-testing that the sequence of some questions had to be adjusted which we did before the actual survey. 
In the actual survey, simple random sampling within each stratum allowed comparison to be made between strata. This means that at the firm level, micro, small and medium sized firms within each of the three carefully selected regions (see Figure 3.2) captured the information peculiar to the population of apparel manufacturing firms.

\subsubsection{Household Survey}

In the households' survey, the interviews yielded 140 valid questionnaires. Household heads selected randomly from the sample of 200 apparel firms were interviewed. This enabled household heads, most of whom are the owners of these micro, small and medium sized apparel businesses were interviewed and information on household attributes was obtained for 2002 and 2007. It is made sure that the interviewee was in business for at least five years and was requested to compare some selected household indicators in 2007 to 2002.

\subsection{Data for Case Studies}

Interviews were conducted in some selected major textile and apparel manufacturing companies in Ghana. The intention is to assess the performance of the top textile companies and top apparel manufacturing companies in the country. The profile of some of the selected textile and apparel companies are presented in Table 3.2. The companies as listed in the Table 3.2 include Printex Limited Company formerly known as the Millet Textile Corporation, Akosombo Textile Limited (ATL), Ghana Textile Printing (GTP) and a Pagbo Kente Weaving Village to represent indigenous Kente weavers producing for domestic and foreign markets. The apparel companies comprised of the Global Garments and Textile Limited, Sleek Garments Exports, Premier Quality Limited and Ghana textile Printing (GTP) among others. 
Table 3.2: Profile of some textile manufacturing companies in Ghana

\begin{tabular}{|c|c|c|c|c|}
\hline Company & Year Established & Types of products & o. of Machines & nployees \\
\hline $\begin{array}{l}\text { Pagbo Kente } \\
\text { Village }\end{array}$ & 1995 & $\begin{array}{l}\text { Quality Kente made } \\
\text { from woven yarns }\end{array}$ & $\begin{array}{l}13 \text { international } \\
\text { looms }\end{array}$ & 13 \\
\hline $\begin{array}{l}\text { Printex } \\
\text { Limited }\end{array}$ & late 1950 & $\begin{array}{l}\text { furnishing materials } \\
\text { suiting, shirting, } \\
\text { School uniforms, } \\
\text { Traditional dress, } \\
\text { Factory work clothing }\end{array}$ & na & 400 \\
\hline $\begin{array}{l}\text { Akosombo } \\
\text { Textile } \\
\text { Limited }\end{array}$ & 1967 & $\begin{array}{l}\text { Yarn, Grey Cloth } \\
\text { Dye/Print Fabric }\end{array}$ & $\begin{array}{l}\text { 1,144 weaving } \\
\text { looms, } \\
\text { 30,240 Spindles }\end{array}$ & 1400 \\
\hline $\begin{array}{l}\text { Sleek } \\
\text { Garments }\end{array}$ & 2002 & $\begin{array}{l}\text { Men \& women slacks \& } \\
\text { casual, shirts, } \\
\text { school uniforms, Medical, } \\
\text { Scrubs and lab coats }\end{array}$ & $\begin{array}{l}8 \text { production lines } \\
\text { of } 40 \text { machines each }\end{array}$ & 470 \\
\hline $\begin{array}{l}\text { Global } \\
\text { Garments }\end{array}$ & 2004 & $\begin{array}{l}\text { Casual Wear- } \\
\text { shirts, trousers, } \\
\text { Skirts; police \& military } \\
\text { Uniforms, hospital \& home } \\
\text { Fabrics }\end{array}$ & $\begin{array}{l}1,115 \text { and } \\
19 \text { head } \\
\text { embroidery } \\
\text { machines }\end{array}$ & 570 \\
\hline $\begin{array}{l}\text { Premier } \\
\text { Quality }\end{array}$ & 2003 & $\begin{array}{l}\text { Woven \& knit garments } \\
\text { men \& women slacks, } \\
\text { Fleece jackets, polo shirts, } \\
\text { Bib overalls, workers } \\
\text { Uniforms }\end{array}$ & 210 machines & 360 \\
\hline $\begin{array}{l}\text { Ghana Textile } \\
\text { Printing (GTP) }\end{array}$ & 1966 & Real Wax & na & 500 \\
\hline $\begin{array}{l}\text { TV Kente } \\
\text { Weaving } \\
\text { Enterprise }\end{array}$ & 1992 & $\begin{array}{l}\text { Quality Kente } \\
\text { Products }\end{array}$ & $\begin{array}{l}24 \text { international } \\
\text { looms }\end{array}$ & 24 \\
\hline
\end{tabular}




\section{Appendix 3}

APPENDIX

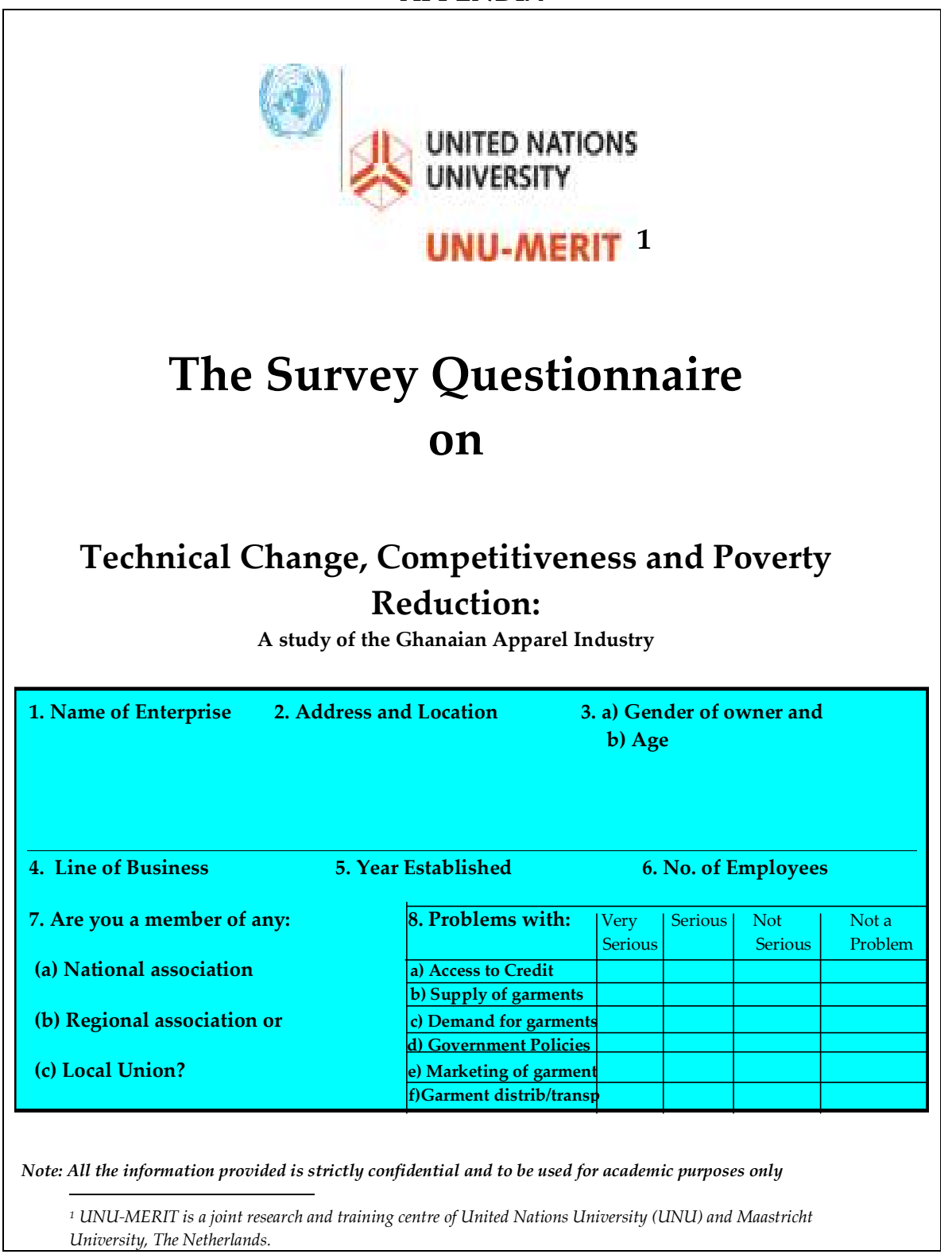




\begin{tabular}{|c|c|c|}
\hline \multicolumn{3}{|c|}{ Productivity and Firm Performance data } \\
\hline 9. Which: & 2007 & 2002 \\
\hline $\begin{array}{l}\text { a) Designer machines used } \\
\text { and year (s) installed? }\end{array}$ & & \\
\hline $\begin{array}{l}\text { b) Marker makers used } \\
\text { and year(s) installed? }\end{array}$ & & \\
\hline $\begin{array}{l}\text { c) Cutting machines used } \\
\text { and year(s) installed? }\end{array}$ & & \\
\hline $\begin{array}{l}\text { d) Sewing machines used } \\
\text { and year(s) installed? }\end{array}$ & & \\
\hline & 2007 & 2002 \\
\hline $\begin{array}{l}\text { 10. What was the estimate in GH } \mathrm{c} \\
\text { of your business: }\end{array}$ & & \\
\hline (a) Fixed assets? & & \\
\hline b) Variable assets? & & \\
\hline $\begin{array}{l}11 \text { What was the value at factory gate } \\
\text { prices in GH c of: }\end{array}$ & & \\
\hline $\begin{array}{l}\text { (a) i. Total garments produced: } \\
\text { ii. Success in adding to standards \%) }\end{array}$ & & \\
\hline $\begin{array}{l}\text { (b) i. men's wear produced: } \\
\text { ii. Success in adding to standards (\%) }\end{array}$ & & \\
\hline $\begin{array}{l}\text { (c) i. women's wear produced: } \\
\text { ii. Success in adding to standards (\%) }\end{array}$ & & \\
\hline $\begin{array}{l}\text { (d) i. children's wear produced: } \\
\text { ii. Success in adding to standards (\%) }\end{array}$ & & \\
\hline & 2007 & 2002 \\
\hline $\begin{array}{l}\text { 12a. How many people on the } \\
\text { average: } \\
\text { (a) Did you work with a day? } \\
\text { (b). No. of labor hours/person/day? }\end{array}$ & & \\
\hline $\begin{array}{l}\text { 13. What was your cost in } \mathrm{GH} \text { \& of: } \\
\text { (a) Labor per day? } \\
\text { (b). Average wage per person per day? }\end{array}$ & & \\
\hline $\begin{array}{l}\text { 14. What was the value in GH \& of: } \\
\text { (a) Fabric used a year? } \\
\text { (b) Other inputs used a year? }\end{array}$ & & \\
\hline $\begin{array}{l}\text { 15. What (\%) of your products sold: } \\
\text { (a) Locally? } \\
\text { (b) Exported? }\end{array}$ & & \\
\hline \begin{tabular}{|l|} 
16. What was in GH \& of: \\
(a) Local price per garment? \\
(b) Foreign price per garment?
\end{tabular} & & \\
\hline $\begin{array}{l}\text { 17. What was your perceived level of } \\
\text { capacity utilization rate (\%)? }\end{array}$ & & \\
\hline
\end{tabular}




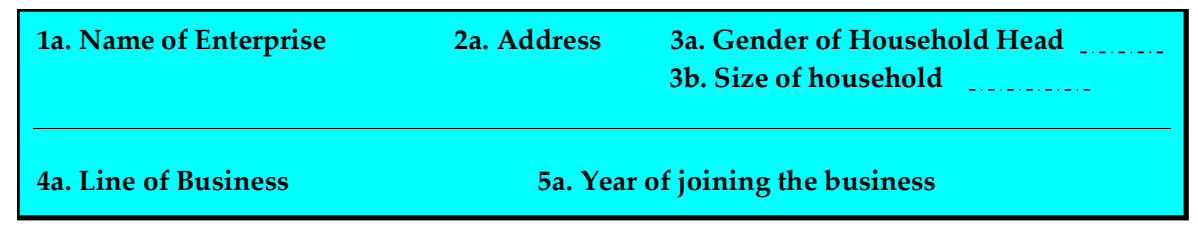

Welfare data: With reference to these attributes, compare your situation in 2007 to 2002

\begin{tabular}{|c|c|c|c|c|c|}
\hline D1. Shelter, D1A Floor & 2007 & 2002 & D1B Roof & 2007 & 2002 \\
\hline \multicolumn{2}{|c|}{ d1 Concrete/cement/Stones } & & d1.6 Metal roofing-zinc, copper, lead, & & \\
\hline d1.1 Wood Floors & & & d1.7 Concrete/ cement/slate/stone roofing & & \\
\hline d1.2 Carpeting & & & d1.8 Built-up roof /fiber glass/Tiles & & \\
\hline d1.3 Tile Flooring & & & d1.9 Wood/timber & & \\
\hline d1.4 Mud flooring & & & d1.10 Thatched/grass/leaves roofing & & \\
\hline d1.5 Other & & & d1.11 Other & & \\
\hline D1C Wall & 2007 & 2002 & D1D Number of rooms & 2007 & 2002 \\
\hline d1.12 Concrete/cement & & & d1.18 $\geq 5$ bedroom self-contained & & \\
\hline d1.13 Cement blocks & & & d1.19 3-4 bedroom self-contained & & \\
\hline d1.14 Brick \& Stone & & & d1.20 2 bedroom self-contained & & \\
\hline d1.15 Wood & & & d1.21 Chamber and Hall & & \\
\hline d1.16 Mud & & & d1.22 Single rooms & & \\
\hline d1.17 Other & & & d1.23 Other & & \\
\hline D1 E Ownership & 2007 & 2002 & D2 Water & 2007 & 2002 \\
\hline d1.24 Self-owned & & & Indoor water taps & & \\
\hline d1.25 Rented & & & d2.1 Own water tanks/Tapes & & \\
\hline d1.26 Family house & & & d2.2 Public taps/pipes/boreholes/Wells & & \\
\hline d1.27 Public apartment & & & d2.3 Rain/river/lake & & \\
\hline d1.28 Other & & & d2.4 Other & & \\
\hline
\end{tabular}

\begin{tabular}{|l|l|l|l|l|l}
\hline D3 Household Assets & & & & \\
\hline D3A Durable assets & $\mathbf{2 0 0 7}$ & $\mathbf{2 0 0 2}$ & D3 B Food & $\mathbf{2 0 0 7}$ & $\mathbf{2 0 0 2}$ \\
\hline d3 Telephone/Mobile phone & & & d3.11 Have breakfast everyday & & \\
\hline d3.1 Refrigerator & & d3.12 Have lunch everyday & & \\
\hline d3.2 Air conditioner & & d3.13 Have dinner everyday & & \\
\hline d3.3 Computer & & d3.14 Other & & \\
\hline d3.4 Electrical iron/other iron & & & & $\mathbf{2 0 0 7}$ & $\mathbf{2 0 0 2}$ \\
\hline d3.5 Water boiler & & & D3C Other assets & \\
\hline d3.6 Bed & & & d3.15 Commercial land & \\
\hline d3.7 Video recorder/TV & & & d3.16 Agricultural & \\
\hline d3.8 Car & & & d3.17 Other & \\
\hline d3.9 Wrist watch/clock & & & D6 Sanitation & $\mathbf{2 0 0 7}$ & $\mathbf{2 0 0 2}$ \\
\hline D3.10 Other & & D6A Toilet facilities & & \\
\hline & $\mathbf{2 0 0 7}$ & $\mathbf{2 0 0 2}$ & d6 Private flush toilets/water closet & & \\
\hline D4 Food/Nutrition & & d6.1 Private squat toilets & & \\
\hline d4expenditure on food /nutrit'(\$)/day & & d6.2 Public toilets & & \\
\hline
\end{tabular}




\begin{tabular}{|c|c|c|c|c|c|}
\hline Bathing facilities & \multicolumn{2}{|c|}{2007} & 2002 D6.C Other waste disposal facilities & 2007 & 2002 \\
\hline d6.6 Indoor bathtubs & & & d6.11 Private waste disposal options & & \\
\hline d6.7 Indoor showers & & & d6.12 Public waste disposal options & & \\
\hline d6.9 Totally/semi detached 'room & & & d6.13 Informal disposal systems & & \\
\hline d6.10 No bathrooms and others & & & d6.14 None/other & & \\
\hline Energy & 2007 & 2002 & & 2007 & 2002 \\
\hline D7A Lighting & & & D7B $\quad$ Heating/cooking & & \\
\hline d7 $\quad$ Solar power/electricity & & & d7.6 Electricity-powered cookstoves & & \\
\hline d7.1 Power generator & & & d7.7 Gas-powered cookstove & & \\
\hline d7.2 Hydro electricity & & & d7.8 Kerosene/fuel oil powered cookstove & & \\
\hline $\begin{array}{l}\text { d7.3 Kerosene lamps/wick-type } \\
\text { lanterns }\end{array}$ & & & d7.9 Charcoal/wood- powered cook stove & & \\
\hline d7.4 Candles lighting options & & & d7.10 Other & & \\
\hline \multicolumn{6}{|l|}{$\mathrm{d} 7.5$ Other } \\
\hline \multicolumn{6}{|l|}{ D8 Health } \\
\hline D8A Orthodox- medication & 2007 & 2002 & Self-medication & 2007 & 2002 \\
\hline d8.1 Access to private doctor & & & d8.6 Access to common drugs- paraceta' et & & \\
\hline d8.2 Hospital & & & d8.7 Herbalist & & \\
\hline d8.3 Pharmacist & & & d8.9 Priest or religious head & & \\
\hline d8.4 Nurse & & & d8.10 Unsupervised drug peddlers/drugg't & & \\
\hline d8.5 Other & & & $\mathrm{d} 8.11$ Other & & \\
\hline D9 $\quad$ Capabilities & 2007 & 2002 & D9B $\quad$ Education at school & 2007 & 2002 \\
\hline D9A Education at home & & & $\begin{array}{ll}\text { d9.6 } & \text { Tertiary } \\
\end{array}$ & & \\
\hline d9.4 Parental care & & & d9.7 Secondary & & \\
\hline d9.3 Brotherly/sisterly care etc. & & & d9.8 Primary & & \\
\hline d9.2 Extended family care & & & d9.9 Basic/adult & & \\
\hline d9.3 Neighbors help & & & d9.10 None & & \\
\hline d9.4 None & & & d9.11 Other & & \\
\hline d9.5 Other & & & & & \\
\hline & & & Security/safety of location & 2007 & 2002 \\
\hline D9C Education at Workplace & 2007 & 2002 & D10A $\quad$ Financial/Social & & \\
\hline d9.12 Over 6 years experience & & & D10 Own source of remuneration/salary & & \\
\hline d9.13 Between 3 and 6 experience & & & d10.1 Government/Public support & & \\
\hline d9.14greater than 1 but less than 3 & & & d10.2 Family support & & \\
\hline d9.15 Less than 1 year experience & & & d10.3 Friends support & & \\
\hline D9.16 None & & & d10.4 Other & & \\
\hline D10B Violence/Theft/Rob'ery etc & 2007 & 2002 & D10C Cost of living & 2007 & 2002 \\
\hline d10.4 Low on the average & & & d10.8 Low on the average & & \\
\hline d10.5 Relatively high & & & d10.9 Relatively high & & \\
\hline d10.6 Very high & & & d10.10 Very high & & \\
\hline d10.7 Other & & & d10.11 Other & & \\
\hline D11Income/ month in GH cedi & 2007 & 2002 & Income/ month & 2007 & 2002 \\
\hline d11 $\quad 0-50$ & & & d11.3 $500-1000$ & & \\
\hline $\begin{array}{ll}\mathrm{d} 11.1 & 50-100 \\
\end{array}$ & & & Greater than 1000 & & \\
\hline d11.2 $100-500$ & & & D11.5 & & \\
\hline
\end{tabular}




\section{Chapter $4^{16}$}

\section{Technological Capacity Building Initiatives in Ghanaian Apparel Industry}

\subsection{Introduction}

The textile and apparel industries in Ghana have been key to the development of the country's economy given the fact that not only do they play a very important role in meeting the basic needs of the people but have served as job openings for them as well. Skills in local textile production have been passed on from one generation to another and despite the advent of modern more efficient and effective technologies, archaic local technologies for spinning and weaving are still extant. Whilst cotton production is confined to the northern Ghana, textile and apparel production is common in Ashanti, Greater Accra and Volta regions in southern Ghana. Production of textile comprises mainly of some few large companies and many small and medium scale enterprises. The apparel industry is mainly made up of small and medium scale enterprises located in different parts of the country.

Currently, the textile industry alone comprise of about 50 formerly registered small, medium and large scale enterprises ${ }^{17}$. This is besides numerous informal textile firms located in various parts of the country. Out of 80,267 people employed in the manufacturing sector in 1980, 19,637 were from textile, wearing apparel and leather goods sub sector accounting for 24.9 per cent of the share of manufacturing employment. That share of employment dropped to 23.4 per cent in 1981 and then still further to 16.5 per cent in 1987 and by 1994, it has fallen to 13.5 per cent. This decline has been partly attributed to the over liberalization of the economy and cheap

\footnotetext{
${ }^{16}$ The chapter is published in a book entitled 'Innovation Policies and International Trade Rules-The Textiles and Clothing Industry in Developing Countries' Edited by Kaushalesh Lal and Pierre A Mohnen. Palgrave Macmillan, 2009

${ }^{17}$ Association of Ghana Industries (AGI)
} 
imported products especially from Asia ${ }^{18}$. These employment figures only refer to the formal sector. The size of Ghana's informal sector is placed at 80 per cent of the total labour force (Hormeku, 1998). The national estimates confirm that the apparel industry alone employs between 600 thousand and 1 million people, including the members and employees of the Ghana National Tailors and Dressmakers Association and the Ghana Association of Fashion Designers, as well as the many independent tailors and seamstresses operating throughout the country (AGI, 2003) ${ }^{19}$.

The international trade rule affecting Ghana's textile and apparel industry has mainly been defined by Ghana's relations with international partners. Over the years Ghana's main trade partners can be classified as European Union (EU), the US, the Economic Community of West African States (ECOWAS) and the rest of the world. Putting it tersely, the international trade in textile and apparel for the past five decades has been governed by various multilateral and bilateral agreements among and between nations. Many of these agreements on textile and apparel exports and imports have been such that producers and government must come out with innovation policies that promote and make the industry competitive in the international market in order to survive.

The purpose of this Chapter is to establish how 'international trade rules' on textile and apparel have shaped the performance of the industry in Ghana. There has not been any comprehensive innovation policy in Ghana over the years except in 1983 when Structural Adjustment Programme (SAP) was lunched which was more focused on macro changes rather than more sector specific policies. Since whatever happens at the macro level has some influence on the micro sectors, there is no doubt the textile clothing sectors might have been shaped by those policies. The first section of this Chapter starts with overview of international trade regimes and developments in the pre-trade liberalization period (1957-1983) analyzing the textile and apparel industries in relation to the international trade rules governing their performance and then moves on to discuss the performance within the trade

\footnotetext{
18 Yaw Asante (2002)

${ }^{19}$ Ghana Investment Promotion Centre (GIPC)
} 
liberalization era (1984 -1995). It finally touches on the era dubbed 'Golden Age of Business' in Ghana (2001- date).

The remainder of the chapter is organized as follows. Overview of the international trade regimes is presented in Section 4.1.1 while Section 4.3 presents the trajectory of development of T\&C sectors in Ghana. Section 4.4 presents the capacity building initiatives and the performance of $\mathrm{T} \& \mathrm{C}$ industry.

\subsubsection{Overview of International Trade Regimes}

A look at the external trade regimes over the pre-reform period and their implications on the textile-clothing production in Ghana indicated that the pre-reforms period coincided with the second phase of General Agreement on Tariff and Trade (GATT) which span from1959 to 1979. Its first phase began in 1947 and ended in 1959. With the good intention to take advantage of the eighteenth century economists Smith and Ricardo's proposed benefits form Free Trade through the elimination of restrictions and promotion of International Trade, GATT was seen as a better option when measured against full protection. The Generalized System of Preferences (GSP) which was formed in 1968 under the auspices of UNCTAD sought to extend preferences that developed countries offer to developing countries with respect to tariffs imposed on imports. Whilst agreement on textile and clothing was left out of GATT in 1947 due to its sensitive nature, it was not until 1974 that Multi Fibre Arrangement (MFA) which was basically an agreement governing developing countries textile and apparel exports to developed countries with quota arrangement was signed. Prior to that, France and her colonies have had Yaounde Convention signed in 1963 and renewed in 1969 which actually began and renewed in 1969 up to 1973 to actually begin a formal trade relations between EU and ACP countries.

At the same time the US had developed a Short-term Arrangement to govern international trade in Cotton and Textiles (STA) beginning in October 1961 and lasted up to September 1962 which involves nineteen countries. The STA sought to eliminate disruptions in textile trade by allowing non restricting countries to impose restrictions on textile 
importation to prevent their markets being flooded by products from other countries to their disadvantage but it thus went contrary to the principle of GATT which is based on the sprit of free trade. The goal to restrain other countries textile export was further supported by Long-term Arrangement on international trade in Textiles (LTA) which was signed in October 1962 upon the expiration of STA. The LTA could also employ bilateral approach in protecting their textile markets and could even result to unilateral measures such as quotas when deemed necessary. The MFA agreements between the EU and other developing countries and tended to discriminate more in favour of the African countries than countries from Asia. Most African countries were allowed to export with less restriction or no restrictions at all, while quotas were imposed on their Asian counterparts so as to give opportunity for other developing countries to compete effectively without necessarily stifling out big exporters such as China, India, Pakistan and Indonesia. Although MFA provided opportunity for bilateral deals, the US employed to her advantage by protecting the domestic market from been inundated with products from developing countries. The MFA was more welcome by the developing countries in particular compared with the LTA but even then trade was still restricted.

The first Lome Convention which came into effect in 1975 was a direct deal between EU on one hand and Africa, Caribbean and Pacific (APC) countries numbering 71 in total on the other. Textile and clothing sector in Ghana could not operate in isolation of other sectors as a good performance in other industries could have had some spillover effects albeit indirectly through increase in demand resulting from rising wages and employment in those sectors. Pomeranz (2001) noted that some of the reasons why exports from most African countries were so skewed to EU market emanated from the more favorable conditions of the Lome Convention compared to the more restrictive GSP adopted by the US. With regards to textile and clothing products, the market in US exceeded that of the EU mainly due to the presence of nearly 40 million African-American population. Their demand for products from Africa by far topped that of niches of markets in EU. Ghana could not be counted to have taken full advantage of Lome Convention as only Mauritius had been known to have benefited from the concessions on textile and clothing. This may be due to the fact that Mauritius is a larger exporter compared to Ghana. 
Figure 4.1 depicts the performance of the textile and clothing industries for the past four decades using growth rates of the value addition to the industry. In a nutshell, various international trade agreements are also captured and none of them appears to have correlated with any visible change in the sector.

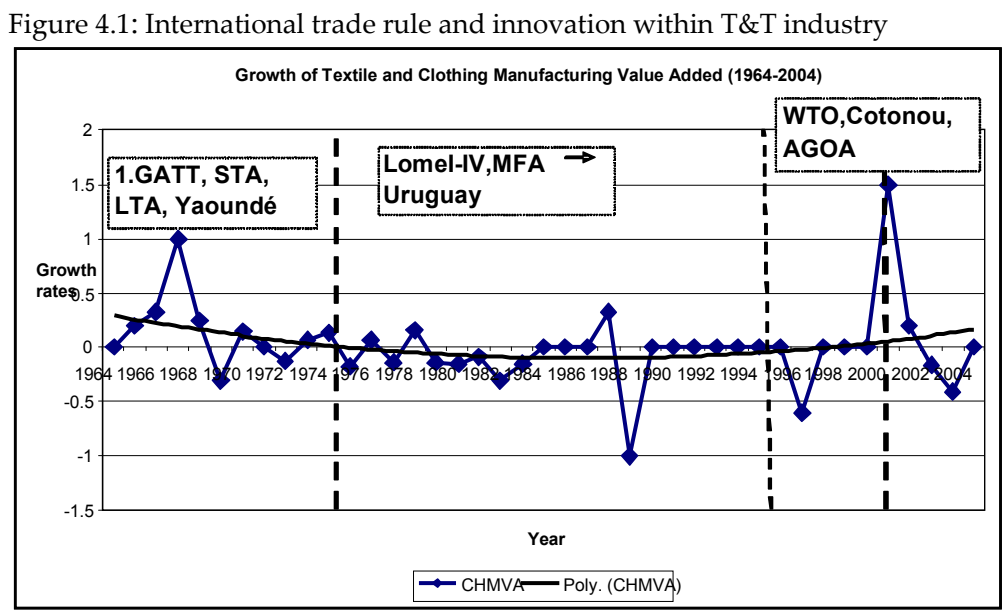

\subsection{Textile and Apparel Industry in Ghana}

The structure of the textile industry in Ghana comprise of spinning, weaving and finishing companies producing yarn, grey cloth, dye/fabric, wax prints and quality 'kente' 20 made from woven yarn by the traditional weavers among others. The major textile companies in Ghana have been established since the 1950s, 1960s and 1970s. Such companies have gone through periods of ups and downs but as the general trend explained in the first section reflected what is happening at the individual company level. Even if there might have been some isolated success cases, the broader picture is not good. As at 1997, the cotton producers were made up of two large plantation farms and several small sized farmers based in the Northern Region of Ghana (Figure 4.2).

\footnotetext{
${ }^{20}$ Kente is traditional textile produce in Ghana
} 
Figure 4.2: Structure of Ghana's Textile and Garment Industry (1997)

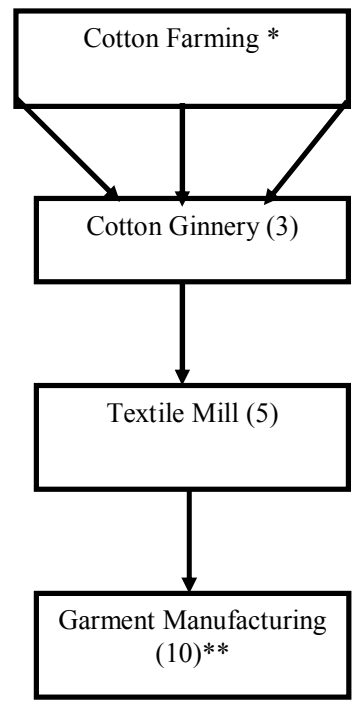

* Two large cotton plantations and many small-scale producers

** Garment Manufacturers excluding 179 small-scale exporters

NB: Number of textile mills and garment manufactures based on export promotion

Source: Ghana Export Bulletin (1997) and cited in Hoefter (2001)

\subsection{Developments in Pre-Trade Liberalization Era: Prior to 1984}

\subsubsection{Historical Context of the Textile and Apparel Industry}

After independence in 1957, the policy focus was on how to build the industrial base of the country. Import Substitution Policy (ISP) which was completely new to Ghanaians at the time was introduced. The policy led to the establishment of Ghana Business Bureau, a branch of the Management Development and Productivity Institute (MPDI) built in 1964 and entrusted with the task to oversee the promotion of high level management in industry and service sectors so as to promote productivity growth in those areas. It was not surprising therefore that between the period 1957 up until 1967, textile and clothing manufacturing value added more than doubled (see Figure 4.3). With the aim to reduce imports and promote exports of manufacturing products in order to be more independent economically, the 
early 1960s saw the proliferation of State own industries- a more socially oriented development agenda that worked up to a point and began to fizzle out in the late 1960s.

Figure 4.3: Textiles and clothing value added in manufacturing in percentage

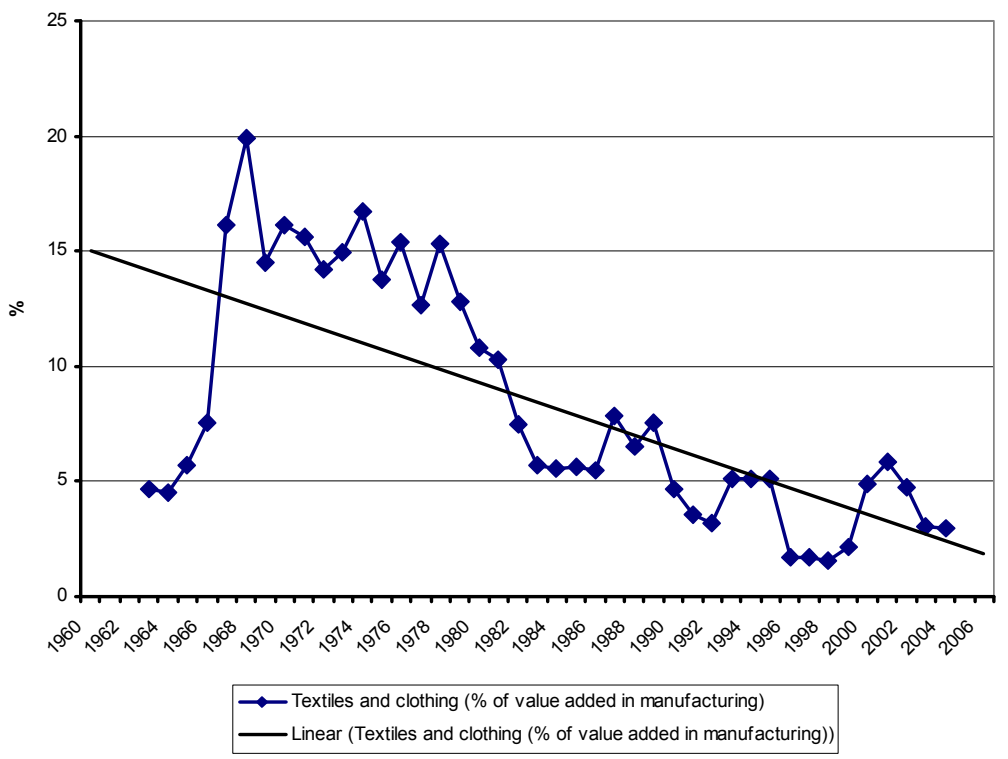

However, despite the effort to satisfy local demand for manufacturing products with domestically made goods, raw material and other manufacturing equipments would have to be imported which made local prices changes subject to other exogenous factors such as exchange rate and foreign prices among others. Coupled with a regime of price controls in the period, the initiative made a mockery of the entire exercise desired to spur the nation's industrial growth. More attention was focused on traditional sectors such as cocoa cultivation and exports to the extent that non traditional sector such as textile and clothing was not given due consideration. Producing goods such as textile and clothing domestically would not only had ease dependence on foreign-made but might had impacted positively on foreign exchange stance of the country. It was no surprise that, it became a secondary focus of import substitution strategy in 1963. Understandably though and as later acknowledgment by the policy makers in particular, textile and clothing industry did receive a boost 
between 1958 and 1968. Over this ten-year period, the value in gross manufacturing output appeared to have increased more than 26 folds (Figure 4.4), an indication of serious efforts not only on the part of the manufacturers uniting to invest resources into productive activities but as a nationalistic holistic spirit demonstrated by the policy makers as a whole. This period of mammoth performance of the textile and clothing sub-sector coincided with the period that Nkrumah's Seven Year Plan for National Reconstruction and Development (1962-1969) was in place. The Plan which was found on the slogan 'Work and Happiness' actually galvanized the populace behind their newly found idol, Nkrumah, the chief strategist supported by the then renowned scholars namely Arthur Lewis, Nicholas Kaldor and Albert Hirchman among others.

\subsubsection{Mixed Outcomes}

A closer look at the textile and clothing sub-sector revealed another scenario. Whereas there was a clear upward trend with respect to contribution to manufacturing GDP (Figure 4.4), the evidence was mix with respect to its growth over the period and as the trend in Figure 4.5 accurately captured, the downward turn of events might have sent some signals that the situation could after all not be perfect. Compared to 1958, Figure 4.5 depicted over 262 per cent improvement in growth contribution to manufacturing GDP, four years later in 1962 that dropped to a little over 124 per cent in the next two years and further to about 25 per cent in the subsequently two years in 1966. However, the situation reversed within the following two years and by 1968 improved to about 117.2 per cent. As Inikori (1989) pointed out that the import substitution strategy applied by Chenery (1960) and Hirchman two years earlier was meant to establish lead sectors that could be made to grow and contribute significantly to the economic development process of a nation than other sectors. In Ghana, the growth of the textile and clothing sector remained positive throughout the 1960s and its contribution to industrial output over the period really showed that there was the potential for further growth and development. 
Figure 4.4: Value of T\&C composition in gross manufacturing output in percentage

Value of Textile \& Clothing Composition in Gross Manufacturing Output(in \% 1958-1968)

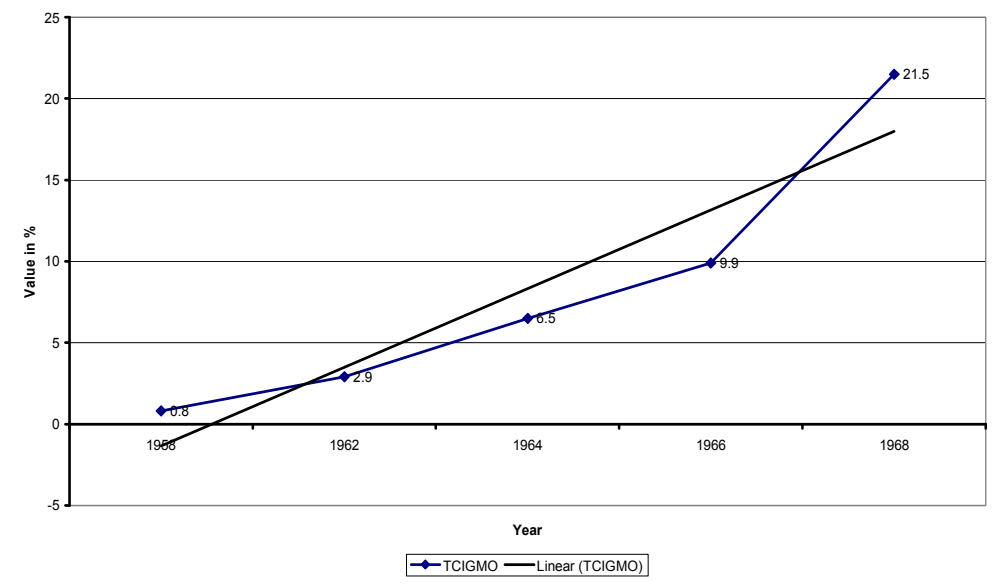

Source: Constructed from Steel (1972) data

Figure 4.5: T\&C Growth in gross manufacturing output in percentage

Textile and Clothing Growth in Gross Manufacturing Output in Ghana (Value in \%, 1962-1968)

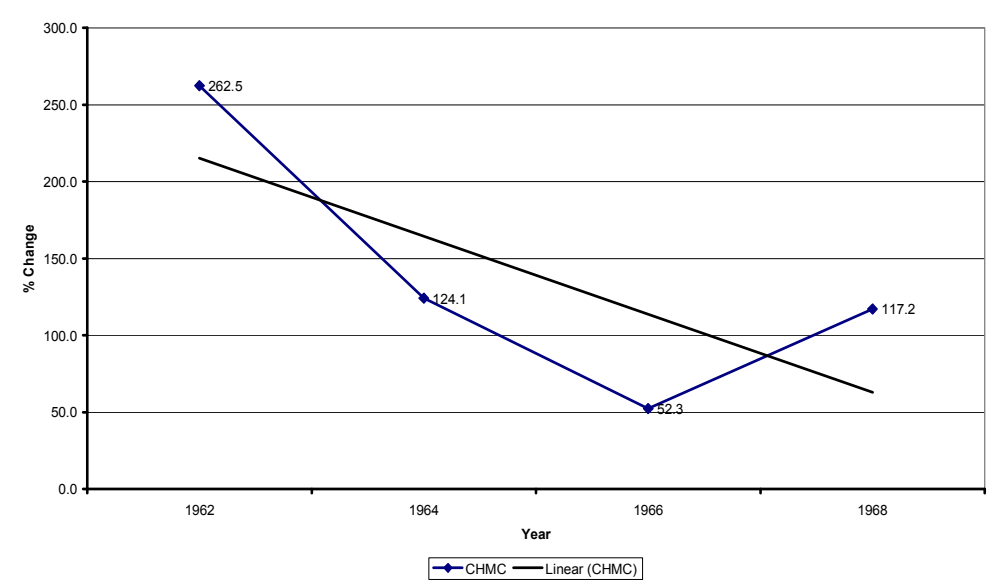

Source: Constructed from Steel (1972) data

Unlike other sectors, textile and clothing manufacturing activities are respectively capital and labour intensive and whilst textile production fit into the development agenda at the time, clothing manufacturing did not fit properly within the policy push for capital intensive industrialization process pursued immediately after independence. The cut in government 
spending in early 1960s partly as a result of a fall in cocoa prices which of course formed the major source of foreign exchange earning, even could not prevent the country from being plunged into budget deficit. Investment in clothing sub-sector which more labour using may perhaps have eased reliance on unbridled importation of capital inputs whilst promoting more labor demanding activities such as clothing production. For example ${ }^{21}$, gross national expenditure in constant local currency was in excess of 4 billion cedis in 1960 compared with a lower gross national income of about 4 billion-about 280 million cedis being the difference measured in constant local currency. It must be said that since 1960, budget surplus had been a rare occurrence in the country's balance sheet.

\subsubsection{Trade Policy Impact on Employment in Textile and Apparel Manufacturing}

Studying small scale employment with focus on firms with at least 10 people ${ }^{22}$ and sometimes 30 employees representing large scaled firms, Steel (1981) referred to the textile and apparel industry in the 1960s and 1970s in Ghana as high growth modern industry. This sought to confirm the state of the industrial process and policy pursued at the time. Table 4.1 seeks to support the common knowledge that whilst apparel industry is female dominant, the textile sub-sector is male centered. Between 1960 and 1970, the share of female employment in apparel sector varied from about 61 per cent to 64 per cent with the share of male employment in the textile sector dropping from about 89 per cent to 85 per cent. Women again tended to increase their share from 10.4 per cent to 14.6 per cent over the period. Small scaled firms however played a major role in both industries with their share of industry employment in the apparel sector between 1962 and 1970

\footnotetext{
2121 The figures quoted here are derived form World development Indicators reported by the World Bank.

${ }^{22}$ Information on firms with at least ten people was cited to have come from Labour Statistics in Ghana and those with at least 30 employees came from Industrial Statistics, see Steel 1981 page 154.
} 
approaching 99.2 and 96.3 per cent respectively and that of the textile sector not far of at 99 and 58 per cent over the 1962 and 1970 time stretch.

Table 4.1: Share of textiles and apparel employment in manufacturing

\begin{tabular}{|l|l|l|l|l|l|l|}
\hline \multirow{3}{*}{ Industry } & \multicolumn{3}{|c|}{ Male } & \multicolumn{2}{c|}{ Female } & \multicolumn{2}{c|}{$\begin{array}{c}\text { Increase (1960-70) } \\
\text { No. of }\end{array}$} \\
\cline { 2 - 8 } & 1960 & 1970 & 1960 & 1970 & Male & Female \\
\hline Apparel & 38.3 & 35.5 & 61.7 & 64.5 & N/A & 13,715 \\
\hline Textiles & 89.6 & 85.4 & 10.4 & 14.6 & N/A & 2,519 \\
\hline
\end{tabular}

Source: derived from Steel, W. 1981, Table 6.5

\subsubsection{Trade Policy and Value Added in Textile and Clothing Manufacturing}

The impact of trade policy on textile and apparel firms has not been given much attention but to identify the exact effects of trade policy among other factors on firm performance in Ghana, Pearson, Nelson and Stryker (1976) conducted a study on a sample of seven firms in Ghana, which included two textile manufacturing firms. They established that, incentives in form of tax concessions, credit subsidies and trade protection in general actually impacted positively on their profits and that the situation could had been much different without the policy. As to which of the factors played the greatest role in facilitating the competitiveness of the firm remain rather unclear because of the difficult nature in isolating the effects of each factor. Their study was limited by the sheer number of firms numbering only seven and only two from textile sub sector without any from the apparel production. In a related study by Pearson and Ingram (1980), the country trade policy, in particular the high incidence of protection was revealed when Ghana was compared to Ivory Coast with respect to seven industries including textile manufacturing. The c.i.f. import price per square yard of textile in 1972 was 0.48 cedis which was the same for Ivory Coast. However the domestic price for the same square yard of textile in the same year was 0.78 cedis with a difference of about 0.30 representing a huge deviation of about 63 per cent. At a relatively acceptable level, the social cost per square yard of textile could have been much lower and not exceeding 0.68 cedis $^{23}$.

${ }^{23}$ Refer to table 1 of Pearson S. R.; William D. Ingram (1980) for detail analysis. 
Tight policy control and inward looking trade strategy, together with government incentives for industrial promotion even thought done in good faith yielded mix outcomes that might be more favorable with the process of economic integration as suggested in extant literature.

In Figure 4.6, textile and clothing manufacturing value added assumed an upward trend between 1964 and 1968 but then experienced a free fall and hit rock bottom in 1969 which was the worse performance throughout the course of the pre-reformed period. The recovery process was a slow one though as periods of continuous upwards and downwards turns characterized the manufacturing value added till the early 1980s. Even though the value of textile and apparel production went up as illustrated in Figure 4.4, growth in value added rather revealed a bad performance.

Figure 4.6: Growth of textile and clothing manufacturing value added

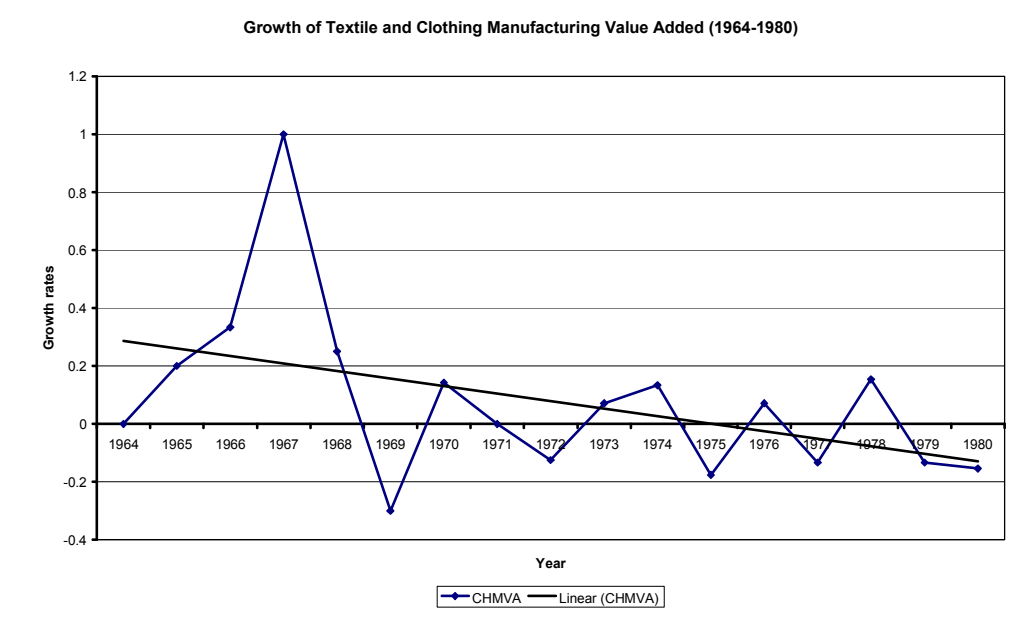

Source: Constructed from World Development Indicators, 2006

\subsubsection{Technology Adoption and Policy Initiatives}

Since the pre-trade liberalization era in Ghana span a little over two decades, as at early (1957-1983), it was natural that the policy measures designed to facilitate innovation at the level of the industry could had ample time to have materialized. Thus, assessing the performance of firms in relation to their choice of techniques and production technology became a task for 
some scholars including Ahiakpor (1989) who investigated the level of choice of appropriate technology in a number of industries including that of textile comprising of 57 firms employing at least 30 persons in 1970. Ahiakpor's measure of the choice of appropriate technology was based on some characteristics such as capital intensity of production technique, degree of skill mix in the production process and share imported inputs in total inputs employed in production process. The measures were design to reflect the economy's uniqueness such that a developing country like Ghana which should ensure that its industrial performance meets its national agenda in the form of promotion of employment, boosting exports and be competitive not only at the local level but at the international front as well. The appropriate technology and techniques of production in such circumstances should therefore be more labor using and capital saving, be more local skill using than foreign ones and be more dependent on homegrown raw materials.

Whilst it can be argued that the policy measures at the time in seeking to foster the national agenda of industrial growth among others sought to undermine in some aspects their own progress, it did not come as a surprise that Ahiakpor's investigation into the technological choice stance could not produce any definite answers based on the measured employed. Even though his study sought to establish no significant differences across industries, the main sector of relevance in this study which is textile did not yield any differences in capital intensity measured simply as the value of fixed assets per production worker in thousands of cedis ${ }^{24}$ across firms within the 57 firms sampled. A measure of skill mix compiled as the ratio of professional worker wages to the total wage bill was also found not to be statistically significant across firms in the industry. Along with the variable on the share of imported inputs in total raw material used which did not also prove significantly different across firms and all the three measure of the choice of appropriate technology together could neither be confirmed nor disconfirmed. One thing was clear for sure, which is that state owned firms in 1970 were more capital intensive than a mix of private and publicly owned ones.

${ }^{24}$ At the time of Ahiakpor's study using the data in the 1970, 1 cedi equivalent to the US dollar was 0.98 . 


\subsubsection{Technology Transfer Institutions for Innovative Textile and Apparel Sectors}

Numerous R\&D institutions were established long before the liberalization period to help shape not only the textile and apparel manufacturing but other industrial production too. Science and technology research has often been considered the foundation block for any meaningful industrial process. There was therefore the formation of National Research Council (NRC) in Ghana in 1959. To promote science and technology transfer and development also lead to the establishment of the Council for Scientific and Industrial Research (CSIR) in 1968 with the vision to develop and apply innovative technologies for industrial and other uses. However, it was not until 1981 that the Technology Transfer Center (TTC) was established under the direct control of CSIR but with the support of UNDP. TTC is to oversee the transferred of appropriate technology to Ghana by performing two things. The first is to oversee the building of local capacity for the adoption of these technologies by providing the necessary information to the local people. The second is to help in the process of identification of these foreign technologies, arrangement to acquire and delivery of these technologies to their respective users.

This way the government managed to help in acquiring various technologies such as the production of natural dyes ${ }^{25}$ for use in the textile industry. Ghana Standards Board, created in 1967, was responsible to oversee issues on meteorology, standards, testing, quality management, and conformity assessment. These institutions have been constraints by many factors such as reliance on funding from the government to carry out their mandate and as often with more than half of the country's budget coming from unreliable foreign sources, their capacity to perform has been greatly compromised. Under funded and under staffed, implies mediocre performance in the delivery of their duties that affects both producers and consumers alike.

\footnotetext{
${ }^{25}$ Natural dyes are basically made from natural sources such as roots,
} flowers, rinds, lichen and wood among others 


\subsection{Post-Trade Liberalization Era: 1983-1999}

Trade liberation has generally being considered to be inimical to the growth of the textile and apparel industry in Ghana for a number of reasons. The industry hitherto not used to intense competition both internal and external all of a sudden has to gird against external rivals especially the extremely competitive Asian products flooding into the local market. The protection offered them before the liberalization did little if not nothing at all to help them grow. Analysis of the performance of the sector with respect to manufacturing production however indicated that the 'must survive behavior and managerial measures' taken at the early phase of the liberalization period saw the manufacturing production of the two industries going up. Plant capacity utilization also increased correspondingly and reflected the underlying growth rates.

Presented in Table 4.2, capacity utilisation rates computed for only medium and large scaled firms rose steadily in both the textile and garments industry with only 17.3 per cent in 1984 for textile to 41.3 per cent in 1993 which was still over 50 per cent below the full capacity rate of utilization. However, by 2005 the rate of capacity utilization in the textile industry appeared to have recovered and risen to 49.4 per cent but still way below the 60 per cent mark attained by the industry in 1977 . The situation in the garment industry even though similar rose from 20.2 per cent in 1984 to more than 50 per cent reaching 53.3 by 1993 . Excess capacity for the entire manufacturing production was 82.0 per cent in 1984 lower than in the garment industry but higher than in the textile firms. The situation was same in 1993. It is obvious that problem of capacity under utilisation applied to the entire manufacturing production with grave economic consequences in term of the rate of employment in a country where unemployment and under employment are prevalent. Though sometimes good for a firm to carry excess capacity for economic and non-economic reasons, it is quite unaccepted for firms to operate less than a quarter of its capacity as appeared to be the case for textile and garment sectors at the early stages of liberalization. 
Table 4.2: Rate of capacity utilization in the T\&C industry for medium and large scaled firms in percentages

\begin{tabular}{|l|c|c|c|c|c|c|c|}
\hline \multicolumn{1}{|c}{ Year $\rightarrow$} & 1977 & 1984 & 1987 & 1989 & 1991 & 1993 & 2005 \\
\hline Textile & 60 & 17.3 & 24.0 & 45.0 & 45.0 & 41.3 & 49.4 \\
\hline Garments & n.a. & 20.2 & 25.0 & 22.0 & 30.0 & 53.0 & n.a \\
\hline All Manufacturing & n.a. & 18.0 & 35.0 & 40.6 & 40.5 & 45.7 & n.a \\
\hline
\end{tabular}

Source: Lall and Pietrobelli (2002) and Quartey P. (2006)

In line with the recovery in capacity utilisation, the growth in textile and garment manufacturing production showed an improvement as depicted in Figure 4.7. From 22.9 percentage growth rates in 1986, about two years after liberalization, there was a marked improvement to 28.7 per cent in1988, dropped a little in the following year to 24 per cent and increased again to 39.1 per cent in 1991. The subsequent years displayed no consistent pattern of growth even the rates were very unpredictable hitting 60.2 per cent in 1993, the highest registered over the 13 year period.

Figure 4.7: T\&C manufacturing production growth rates $(1977=100)$

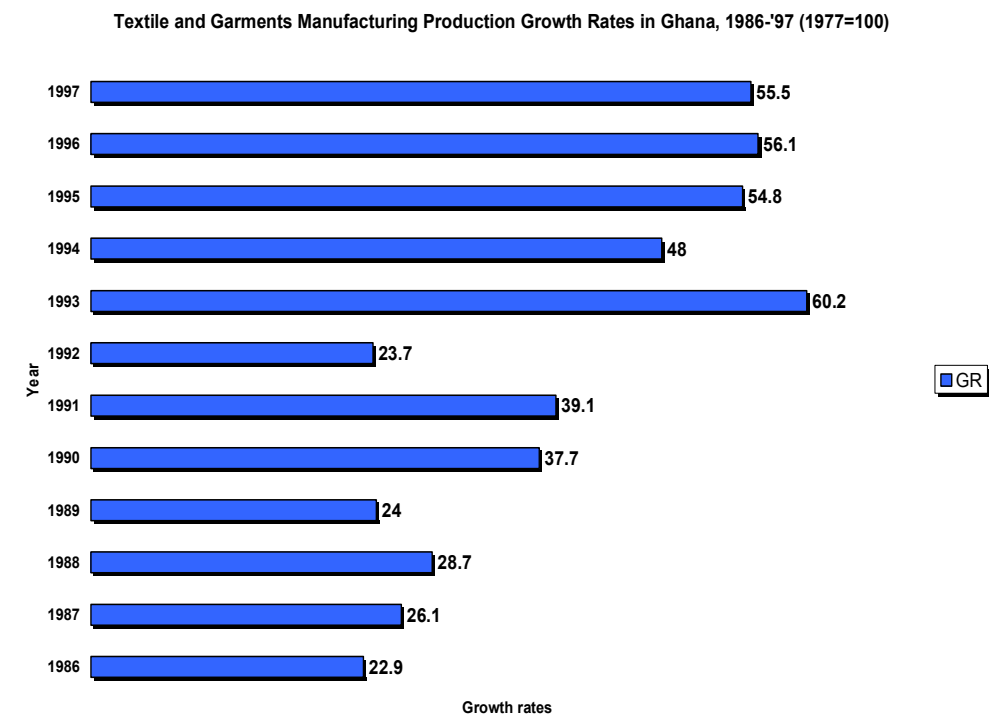

Several factors have been identified as posing problems to the textile and garments industry by primary surveys including Hoefter (2001). Among them is lack of access to adequate raw materials within the domestic market prompting these inputs to be imported. Those available are priced higher 
than they would normally sell at the international market. The situation results in large share of raw material cost in total cost of production thereby making it to an average of 70 per cent. Small scaled cotton producers are not able to satisfy local demand and sometimes their products are not of high quality. Lack of access to credit by both cotton growers and textile and apparel manufacturers as a result of high bank lending rates reaching 47 per cent the end of 2000 also compounded the situation. Even though that appeared to be improving as the lending rates have dropped considerably to around 24 per cent by 2007, lack of collateral security is often cited as a problem. Also apart from some large textile and apparel manufacturing companies that are using latest technologies and equipments in order to survive, over the years, the use of obsolete technologies and equipments has actually impacted negatively on the production performance. Influx of foreign products has also caused all sorts of problems to even companies employing latest technologies.

\subsubsection{Tariffs and Trade in Textiles and Apparel}

The tariff structure in Ghana consist of 0 per cent for basic and social goods, 5 per cent for raw materials, 10 per cent for intermediate goods and 20 per cent for finished products. Textile and apparel imports are either in the raw material inputs or finished products and so they are affected mainly by the three upper bands ( 5 per cent upwards). The lowest import duty rate as appeared in Table 4.3 is 10 per cent. VAT is 12.5 per cent, 2.5 per cent for National Health Insurance Levy (NHIL) on imports , Economic Community of West African States (ECOWAS) Levy of 0.5 per cent and Export Development and Investment Fund (EDIF) levy of 0.5 per cent. The NHIL was only added in 2004 by an act of parliament (Act 650, 2003) thus contributed to the already high rates on imported textile and apparel products. Ironically the high rates have not helped in curbing these imports (see Tables 4.9 and 4.10). 
Table 4.3: Taxes on imports of some selected textile and apparel products

\begin{tabular}{|c|c|c|c|c|c|c|c|c|c|}
\hline \multirow[b]{2}{*}{ Hs Heads Desc DES } & \multicolumn{5}{|c|}{ 2004-2008 } & \multicolumn{4}{|c|}{ 2001-2003 } \\
\hline & $\begin{array}{l}\text { Import } \\
\text { Duty }\end{array}$ & $\begin{array}{l}\text { Import } \\
\text { V.A.T. }\end{array}$ & $\begin{array}{l}\text { Import } \\
\text { Nhil }\end{array}$ & $\begin{array}{l}\text { Ecowas } \\
\text { Levy }\end{array}$ & $\begin{array}{l}\text { EDIF } \\
\text { Levy }\end{array}$ & $\begin{array}{l}\text { Import } \\
\text { Duty }\end{array}$ & $\begin{array}{l}\text { Import } \\
\text { V.A.T. }\end{array}$ & $\begin{array}{l}\text { Ecowas } \\
\text { Levy }\end{array}$ & $\begin{array}{l}{ }^{* *} \text { Edif } \\
\text { Levy }\end{array}$ \\
\hline $\begin{array}{l}\text { 1. Silk-worm } \\
\text { cocoons suitable for } \\
\text { reeling }\end{array}$ & $10 \%$ & $12.50 \%$ & $2.50 \%$ & $0.50 \%$ & $0.50 \%$ & $10 \%$ & $12.50 \%$ & $0.50 \%$ & $0.50 \%$ \\
\hline $\begin{array}{l}\text { 2. Greasy shorn } \\
\text { wool, not carded or } \\
\text { combed }\end{array}$ & $10 \%$ & $12.50 \%$ & $2.50 \%$ & $0.50 \%$ & $0.50 \%$ & $25 \%$ & $12.50 \%$ & $0.50 \%$ & $0.50 \%$ \\
\hline $\begin{array}{l}\text { 3. Cotton, not } \\
\text { carded or combed: } \\
\text { not ginned }\end{array}$ & $10 \%$ & $12.50 \%$ & $2.50 \%$ & $0.50 \%$ & $0.50 \%$ & $10 \%$ & $12.50 \%$ & $0.50 \%$ & $0.50 \%$ \\
\hline $\begin{array}{l}\text { 4. Flax, raw or } \\
\text { retted }\end{array}$ & $10 \%$ & $12.50 \%$ & $2.50 \%$ & $0.50 \%$ & $0.50 \%$ & $10 \%$ & $12.50 \%$ & $0.50 \%$ & $0.50 \%$ \\
\hline $\begin{array}{l}\text { 5. Sewing thread of } \\
\text { synthetic filament }\end{array}$ & $10 \%$ & $12.50 \%$ & $2.50 \%$ & $0.50 \%$ & $0.50 \%$ & $10 \%$ & $12.50 \%$ & $0.50 \%$ & $0.50 \%$ \\
\hline $\begin{array}{l}\text { 6. Synthetic filament } \\
\text { tow of nylon or other } \\
\text { polyamides }\end{array}$ & $10 \%$ & $12.50 \%$ & $2.50 \%$ & $0.50 \%$ & $0.50 \%$ & $10 \%$ & $12.50 \%$ & $0.50 \%$ & $0.50 \%$ \\
\hline $\begin{array}{l}\text { 7. Sanitary towels } \\
\text { and tampons, } \\
\text { napkins, etc, }\end{array}$ & $20 \%$ & $12.50 \%$ & $2.50 \%$ & $0.50 \%$ & $0.50 \%$ & $25 \%$ & $12.50 \%$ & $0.50 \%$ & $0.50 \%$ \\
\hline $\begin{array}{l}\text { 8. Carpets and other } \\
\text { textile floor } \\
\text { coverings, etc }\end{array}$ & $20 \%$ & $12.50 \%$ & $2.50 \%$ & $0.50 \%$ & $0.50 \%$ & $25 \%$ & $12.50 \%$ & $0.50 \%$ & $0.50 \%$ \\
\hline $\begin{array}{l}\text { 9. Woven pile fabrics } \\
\text { and chenille fabrics } \\
\text { of wool etc }\end{array}$ & $20 \%$ & $12.50 \%$ & $2.50 \%$ & $0.50 \%$ & $0.50 \%$ & $25 \%$ & $12.50 \%$ & $0.50 \%$ & $0.50 \%$ \\
\hline $\begin{array}{l}10 \text { Textile fabrics } \\
\text { coated with gum }\end{array}$ & $20 \%$ & $12.50 \%$ & $2.50 \%$ & $0.50 \%$ & $0.50 \%$ & $25 \%$ & $12.50 \%$ & $0.50 \%$ & $0.50 \%$ \\
\hline $\begin{array}{l}11 \text { Long pile fabrics, } \\
\text { knitted/crocheted } \\
12 \text { Men's or boys }\end{array}$ & $20 \%$ & $12.50 \%$ & $2.50 \%$ & $0.50 \%$ & $0.50 \%$ & $25 \%$ & $12.50 \%$ & $0.50 \%$ & $0.50 \%$ \\
\hline $\begin{array}{l}\text { coats, of wool knitted } \\
\text { /crocheted }\end{array}$ & $20 \%$ & $12.50 \%$ & $2.50 \%$ & $0.50 \%$ & $0.50 \%$ & $25 \%$ & $12.50 \%$ & $0.50 \%$ & $0.50 \%$ \\
\hline $\begin{array}{l}13 \text { Men's or boys } \\
\text { overcoats, etc, of } \\
\text { wool or fine animal } \\
\text { hair }\end{array}$ & $20 \%$ & $12.50 \%$ & $2.50 \%$ & $0.50 \%$ & $0.50 \%$ & $25 \%$ & $12.50 \%$ & $0.50 \%$ & $0.50 \%$ \\
\hline 14 Electric blankets & $20 \%$ & $12.50 \%$ & $2.50 \%$ & $0.50 \%$ & $0.50 \%$ & $25 \%$ & $12.50 \%$ & $0.50 \%$ & $0.50 \%$ \\
\hline
\end{tabular}

\section{5 'The Golden Age of Business' and Ghana Export Promotion Action Plan}

\subsubsection{The Ghana-US Trade Relations}

African Growth and Opportunity Act which was signed into law in 2000 has presented a market opening to Ghanaian exporters as well as many other countries in sub-Saharan Africa to do business with US in some selected products including textile and apparel products. Ghana become eligible for the textile and apparel shipment to the US market in March 2002 after it was passed by the United States Trade Representative announcement (USTR). Thus Ghana became the sixteenth out of thirty-six eligible sub-Saharan African Country who can access the facility. This is because the USTR has the duty to pass any country eligible for the facility as and when it is believed that all the conditions and rules to be fulfilled by the country are in 
place. Prevention of transhipment of textile and apparel products to US is central to the qualification process which recognizes the adoption of the US visa system and abiding by the rules.

The other status that Ghana also achieved in 2002 under AGOA was the Lesser-Developed-Country standing where a member state under AGOA can export textile and apparel products duty-free to the US utilizing fabric from any part of the world to manufacture products in Ghana. This is to circumvent the so-called the originality convention rule where inputs might have to come from US or from Ghana. One thing is clear though that AGOA is mutually beneficial to both the US and sub-Saharan African countries and cannot be seen only as an opportunity provided for African exporters. One thing is certain that the US market is a very competitive one where products are marketed based on quality, price and capacity to deliver on time. This tends to challenge Ghanaian exporters to look out for those factors that would not only improve the quality and price competitiveness but delivery time as well.

With duty free and quota free access for garments and textile products and Ghana's geographically relatively positioned to access US market quicker and easier compared to other countries in the sub-region with sailing time of 21 to 25 days and relatively competitive labour cost, positive outcomes from AGOA were not in doubt. The Ashanti and Ewe people have cultivated the reputation of producing uniquely woven, traditional cotton fabrics to take advantage of niche markets with less competition from other products in the international market. Textile and garments products of Afro-centric origin were destined to be patronized by large African-Americans on the US market thus presenting a rare opportunity for the Ghanaian exporters to break through.

Table 4.4 shows that composition of products Ghana exports to US. Over the 2002 and 2006 period, the bulk of the products have been in the form of household and apparel goods made of cotton. 


\begin{tabular}{|c|c|c|c|c|c|}
\hline & 2002 & 2003 & 2004 & 2005 & 2006 \\
\hline \multicolumn{6}{|l|}{ Cotton, Wool \& } \\
\hline Other Natural Fiber & 30 & 17 & 6 & 14 & 5 \\
\hline \multicolumn{6}{|l|}{ Cotton Cloth, Fiber } \\
\hline Thread and Cordage & 14 & 32 & 14 & 34 & 20 \\
\hline $\begin{array}{l}\text { Wool, Silk, Veg. Cloth } \\
\text { \& Fabric, Thread }\end{array}$ & 5 & 0 & 0 & 0 & 2 \\
\hline \multicolumn{6}{|c|}{ Synthetic cloth \& Fabric, } \\
\hline Thread \& cordage & 0 & 0 & 1 & 4 & 2 \\
\hline \multicolumn{6}{|l|}{ Finished textile } \\
\hline Industrial suppliers & 11 & 7 & 14 & 2 & 1 \\
\hline \multicolumn{6}{|l|}{ Apparel \& household } \\
\hline Goods-cotton & 407 & 4,395 & 6,846 & 4,707 & 4,929 \\
\hline \multicolumn{6}{|l|}{ Apparel \& household } \\
\hline Goods-wool & 0 & 0 & 0 & 0 & 1 \\
\hline \multicolumn{6}{|l|}{ Apparel \& household } \\
\hline Goods-other textile & 55 & 47 & 547 & 439 & 4,606 \\
\hline \multicolumn{6}{|l|}{ Natural Apparel \& } \\
\hline Household goods & 6 & 23 & 8 & 11 & 32 \\
\hline Total & 528 & 4,521 & 7,436 & 5,211 & 9,598 \\
\hline
\end{tabular}

Source: Computed from US Census Bureau Foreign Trade Statistics

The market value for these products appears to be falling as in 20046.8 million dollar value being the highest within these five years dropped to 4.9 million dollars. Apparel and textile goods made of other textile material have been the next biggest composition of the exports followed by cotton cloth, fibre thread and cordage. The less significant components include finished textile, synthetic cloth and fabric, wool, silk and other natural apparel. Overall, over 9.6 million dollar worth of exports in 2007 shows an encouraging sign with a huge jump from the 2002 low figure of 528 thousand dollars.

A look at the trade performance between the US and Ghana in textile and apparel establish some mixed performance (Table 4.5). Whereas the net exports by Ghana was negative, an indication of imports in excess of exports up to the tune of 4 million dollars in 2004, there was some marginal reduction by 2005 down to 3.9 million. The 2006 and 2007 show some 
improving trend but in actual fact, if AGOA is to benefit Ghana, foreign exchange from textile and apparel exports should not only be able to meet textile and apparel imports from the same country but should meet other demands beyond the textile and apparel; sectors.

\begin{tabular}{|c|c|c|c|c|}
\hline & 2004 & 2005 & 2006 & 2007 \\
\hline Ghana's Exports to US & 7,432 & 5,208 & 9,568 & $5,393^{*}$ \\
\hline Ghana's Imports from US & 11,467 & 9,110 & 7,123 & $3,532^{*}$ \\
\hline Exports-Imports (in ‘000 US \$) & $-4,035$ & $-3,902$ & 2,445 & 1,861 \\
\hline
\end{tabular}

\subsubsection{Ghana - EU Trade Relations}

The European market has been one of the main destinations for textile and apparel products from Ghana as one of the ACP countries since post independence in 1957. The textile and apparel industry in Ghana for over two and half decades (1975-2000) has been influenced by the multilateral agreement between the EU and ACP countries. The first Lome Convention which came into effect in 1975 was basically an EU initiative based on unilateral free access designed to open the market of the EU for commodities from ACP countries to easily get to Europe. It was a one-sided agreement which permitted tariffs on European imports whilst at the same time giving free passage of ACP products unto their market. The rule seems on the surface to favour ACP but with deteriorating commodity terms of trade and fluctuation in prices for products with basically little or no value added paints a different picture. More so, the textile and apparel industry in Ghana was not particularly favoured as the ACP agreement was skewed towards exports of primary products and did little to promote the manufacturing exports. Manufacturing products were imported from EU and other developed countries. It is worthy of note that the Multi-Fibre Arrangement (MFA) which was established in 1974 did not directly apply to Ghana because as part of the ACP countries, the country was exempted (McDonald and Dearden, 1992). This was supposed to put the country's textile and apparel exports in a better position to promote growth and development. 
Focusing on the current trade relations measured in terms tons of textile and apparel products imports and exports by Ghana, it is obvious in Table 4.6 that over the 2004 to 2005 period, the country actually imported more of the textile and clothing products from EU than it actually exported. Ghana is a net importer just like the situation with the US. The Ghana textile and clothing export to EU in 2004 was 2,979 tons compared to 43,269 imports from EU a difference 40,290 tons rising to 46,279 tons in 2005.

\begin{tabular}{|c|c|c|c|c|c|c|}
\hline \multirow[t]{2}{*}{ Sector } & \multirow{2}{*}{\multicolumn{2}{|c|}{$\begin{array}{l}\text { Ghana's exports to } \\
\text { EU }\end{array}$}} & \multirow{2}{*}{\multicolumn{2}{|c|}{$\begin{array}{l}\text { Ghana's imports from } \\
\text { EU }\end{array}$}} & \multicolumn{2}{|c|}{ Balance(in tons) } \\
\hline & & & & & $\begin{array}{l}\text { A-C } \\
2004\end{array}$ & $\begin{array}{l}\text { B-D } \\
2005\end{array}$ \\
\hline Textile (tons) & 2,966 & 1,746 & 1,324 & 1,719 & 1,642 & 27 \\
\hline Clothing (tons) & 13 & 33 & 41,945 & 46,339 & $-41,932$ & $-46,306$ \\
\hline Total & 2,979 & 1,779 & 43,269 & 48,057 & $-40,290$ & $-46,279$ \\
\hline
\end{tabular}

Source: European Commission, external trade statistics

Ghana as a member of ECOWAS continue to push for new trade agreement with the EU known as the Economic Partnership Agreement (EPA) which officially started in 2003 to be followed by several negotiations before it finally comes into effect in 2008. This is besides the Cotonou Agreement negotiated between the EU and ACP countries in 2000.

\subsubsection{Presidential Special Initiative on textile and Garments (PSI, 2001- )}

In 2001, the government of Ghana lunched an initiative known as the 'Presidential Special Initiative (PSI)' design to revamp and promote some selected sectors including textile and garments within the export-led mass production industrialization for growth and development policy framework. The idea basically is to help grow and transform the Ghanaian economy in general and industrial sector in particular with private sector as the engine of growth. And to attract foreign direct investment in the form of large textile and garment manufacturing firms to take advantage of the opportunities provided by the Export Processing Zone (EPZ) by relocating, producing and exporting from Ghana. It is expected that an accelerated export development strategy through export action programme for textile and garments involving the mass mobilization of rural labour and vulnerable groups could help curb poverty. 
However, the success of PSI on textile and garments depends on the pool of relevant skills available in the country. To this end, training and developing of skills necessary in the application of state of the art industrial sewing machines has been facilitated over the years by the Clothing Technology Training Center (CTTC) in Accra which since its inception in 2003 has had the capacity to train an average of 400 industrial sewing machine operators each month. It also undertakes R\&D on how to enhance the existing techniques and make them work at various stages of the production process. Other CTTCs have been designated for Kumasi and Takoradi in an effort to develop the critical mass of human resource to feed over one hundred medium sized textile and garment enterprises located within the Export Processing Zone and industrial hub of Ghana and beyond. The CTTCs are equipped with cutting edge technologies including computer aided design technology an example of a broader information and communication technology (ICT) for accelerated development policy introduced in 2004.

Even though the attention is to encourage exports and value addition to exports, the core process is to develop the capacity for increasing application of new technologies such as modern textile and garment manufacturing technologies including ICT.

The government together with the support from some financial institutions such as the National Investment Bank, United Bank of Africa and Eco-Bank via the Export Development and Investment Fund (EDIF) has invested about 15 million US dollars as at 2007 to acquire new technologies in the form of new textile and apparel manufacturing machines and to provide working capital for the initiative. EDIF was established in 2000 (Act 582) with the primary aim facilitating exports of primary, manufacturing and service sector products. However, despite this laudable scheme of PSI, numerous challenges such as serious price competition from smuggled and pirated textile and garments that find their way unto the local market, frequent power outages and lack of access to adequate and cheaper source of finance among others are threatening to undo the effort of the scheme. The PSI must first work in order to be able to realize its fundamental objectives of not only being totally export oriented but seeks to have the local market focused as well. Inability to compete at home might even have more serious consequences on the foreign market as the firms would be crowded out before they have the opportunity to grow and sustain themselves. 
Employment generation especially for the middle-level skill workers is considered an integral part of PSI and in that respect, since the beginning of the scheme, the evidence is there as presented in the Table 4.7. The table shows a list of companies that have responded to the PSI on textile and garments and indeed at 2005, many companies including the ones in the table have generated thousands of jobs.

Table 4.7: PSI on textile and garments

\begin{tabular}{|l|l|l|}
\hline Company & Location & $\begin{array}{l}\text { Size of Workforce } \\
\text { as at 2005 }\end{array}$ \\
\hline Global Garments Ltd & Accra & 300 \\
\hline Gold Coast Collection Ltd & Accra & 200 \\
\hline Belin Textiles Ltd & Accra & 200 \\
\hline 1647 Ltd & Accra & 100 \\
\hline Textile Pro & Tema & 500 \\
\hline California Link EPZ & Tema & 400 \\
\hline Network Knitwear fabrics Ltd & Tema & 1000 \\
\hline Oak Brook Ltd & Tema & 100 \\
\hline Premier Quality Ltd & Tema & 200 \\
\hline Total & & 3000 \\
\hline
\end{tabular}

Source: Ministry for Private Sector Development and PSI, 2005

\subsection{Technological Capacity Building and Performance}

\subsubsection{Technology Content of Textile and Apparel Exports from Ghana}

Lall (2000) attempted to classify manufacturing exports according to their technology content and established that the technology content of exports has effects on growth and development of a nation. The low technology content exports have the slowest influence compared to medium technology content and high technology content exports. According to Lall's classification, it is obvious that the bulk of Ghana's textile and apparel exports fall into low technology content category but the country also exports medium technology textile and apparel products. Synthetic filaments fall into medium tech category. As it is shown in Table 4.8, it is only in 2006 that the value of export performance reached 144,268 US dollars. The implication is that the country does not have any competitive edge in the manufacturing and export of these products. 
Table 4.8: Medium technology content T\&C products exports from Ghana

\begin{tabular}{|c|c|c|c|c|}
\hline \multicolumn{2}{|r|}{ Year $\rightarrow$} & 2004 & 2005 & 2006 \\
\hline HS CODES & $\backslash$ Indicators & $\begin{array}{c}\text { CUSTOM } \\
\text { VALUE(cedis) }\end{array}$ & $\begin{array}{c}\text { CUSTOM } \\
\text { VALUE(cedis) }\end{array}$ & $\begin{array}{c}\text { CUSTOM } \\
\text { VALUE(cedis) }\end{array}$ \\
\hline 5401100000: & Sewing thread of synthetic filaments & 182,151 & 0 & $194,553,791$ \\
\hline 5401200000: & Sewing thread of artificial filaments & 0 & 273,374 & $432,971,692$ \\
\hline 5404900000: & Strip and the like of synthetic textile materials & 0 & $160,642,503$ & 937,028 \\
\hline 5406100000: & Synthetic filament yarn (excl. sewing thread), & 0 & 0 & $186,255,200$ \\
\hline 5407300000: & Fabrics of synthetic filament yarn & 0 & 0 & $166,194,000$ \\
\hline 5407690000: & Other & $2,233,488$ & 0 & $52,984,845$ \\
\hline 5407740000: & Printed woven fabrics, $>=85 \%$ synthetic filaments & 0 & 911,345 & 0 \\
\hline 5408100000: & Woven fabrics of high tenacity synthetic filament yarn & 0 & $1,822,690$ & 0 \\
\hline 5408330000: & Coloured woven fabrics of artificial filament yarn & 0 & 0 & 924,318 \\
\hline 5501900000: & Synthetic filament tow, & 0 & 0 & $223,604,510$ \\
\hline 5503900000: & Synthetic staple fibres & 0 & 0 & $235,038,506$ \\
\hline Total & & $2,415,639$ & 163649912 & $1,493,463,890$ \\
\hline
\end{tabular}

Source: Ghana Statistical Service

\subsubsection{Worsening Textile and Apparel Trade Conditions in the World Market}

In both the textile and clothing trade with the world, there are some disturbing trends that even the current PSI on textile and garments has failed to address. The nation is a net importer of the textile and clothing (Tables 4.9 and 4.10 ) products that comparative advantage should make the nation export more than it actually imports.

Table 3.9: Ghana's trade performance in textile with the world in US million dollars at current prices

\begin{tabular}{ccllcc}
\hline Year & Textile Exports $(X)$ & Textile Imports $(\operatorname{Im})$ & \multicolumn{2}{l}{ X-Im\% change in X } & \% change in Im \\
\hline 1992 & 0.538 & 33.6 & -33.0 & - & - \\
1998 & 2.0 & 32.2 & -30.2 & 271.7 & -4.1 \\
1999 & 5.1 & 51.2 & -46.1 & 156.2 & 59.1 \\
2000 & 14.2 & 65.3 & -51.0 & 177.8 & 27.4 \\
2001 & 8.5 & 75.4 & -66.9 & -40.4 & 15.5 \\
2002 & 8.8 & 61.1 & -52.4 & 3.2 & -18.9 \\
2003 & 9.0 & 56.8 & -47.8 & 3.2 & -7.1 \\
2004 & 3.7 & 76.5 & -72.8 & -59.1 & 34.7 \\
2005 & 2.7 & 111.9 & -109.3 & -27.0 & 46.4 \\
2006 & 2.3 & 103.1 & -100.8 & -14.6 & -7.9 \\
\hline
\end{tabular}

Source: Computed from the WTO trade statistics 
Over the 1998 to 2006 period, not a single year in both textile and clothing trade with the world did the nation export more than its imports as the difference for textile rose from 33 million dollars in 1992 to over 100 million in 2006. The same applied to the performance in clothing as well rising from 10.9 million to 25 million dollars.

\begin{tabular}{|c|c|c|c|c|c|}
\hline Year & Clothing Exports $(X)$ & Clothing Imports (Im) & X-Im & $\%$ change in $X$ & $\%$ change in Im \\
\hline 1992 & 0.05 & 10.9 & -10.9 & - & - \\
\hline 1998 & 2.0 & 10.7 & -8.7 & 3673.6 & -1.6 \\
\hline 1999 & 3.0 & 12.5 & -9.4 & 52.2 & 16.0 \\
\hline 2000 & 0.7 & 11.4 & -10.7 & -75.4 & -8.2 \\
\hline 2001 & 0.6 & 9.7 & -9.1 & -18.3 & -14.9 \\
\hline 2002 & 1.2 & 12.4 & -11.2 & 97.9 & 27.7 \\
\hline 2003 & 2.4 & 24.2 & -21.8 & 97.9 & 94.5 \\
\hline 2004 & 1.4 & 21.3 & -19.9 & -43.5 & -11.7 \\
\hline 2005 & 1.1 & 24.2 & -23.1 & -21.3 & 13.2 \\
\hline 2006 & 4.7 & 30.6 & -25.9 & 344.1 & 26.7 \\
\hline
\end{tabular}

Source: Computed from the WTO trade statistics

\subsection{Summary and Conclusion}

In this Chapters, the textile and apparel industry were analyzed with respect to three time periods namely the pre-liberalization (1957-1983), the liberalization period (1984-2000) and the period dubbed the 'Golden Age of Business' (2001-date). The general conclusion was that the sector has been going through many challenges. The sector-wide performance with respect to growth in manufacturing value added was identified as good in the preliberalization period and bad in the post liberation. The textile and clothing value added in manufacturing continued to fall. Employment continued to go down. Continual application of old technologies over the period has not helped in turning around the fortunes of the sector and technology transfer centers will have to do more in this respect. The technology transfer centers also appear to be facing their own difficulties such as inadequate funds. Tariffs on imported textile and apparel products have understandably not being effective in rectifying the problems. 


\section{Chapter 5}

\section{Accounting for Standards in Productivity and Competitiveness Assessment}

\subsection{Introduction}

In this Chapter, we seek to ascertain the state of competitiveness of small businesses in the apparel industry by gauging their performance in productivity growth. It also attempts to isolate product standards improvement from quantity expansion. This is to have an idea of the state of growth due simply to producing more apparel at given standards or growth due to improvement of standards. It is likely that some firms can experience growth on two fronts, expanding quantity and raising product standards whereas some of them can experience a decline in both or in one aspect. All these are done using non-parametric techniques and estimating two models viz. standard-constant model where productivity growth is computed based only on input-output quantities and the second model which is standardcorrected where observed product standards are accounted for by a measurable indicator. Thus, issues such as, the degree to which small businesses are getting optimum output from a given set of inputs and the extent to which they are meeting both local and international standards so as to remain competitive are addressed.

Specifically, this paper tackled the following questions:

1. Are SMES in the apparel industry building competitiveness through total factor productivity (TFP) growth?

2. What changes when we account for product standards in TFP growth?

3. Based on the answers of 1 and 2, has the apparel sub-sector built or lost competitiveness between 2002 and 2007 since over 90 per cent of firms in the sub-sector are small businesses?

Correspondingly, the research hypotheses are: 
1. SMES in the apparel sector are losing competitiveness due to low total factor productivity (TFP) growth, not significant to keep them in operation.

2. Accounting for product standards (quality and non-quality) may not provide any improvement in TFP growth of SMEs

3. The apparel sub-sector as a whole is losing its competitive edge in both domestic and international markets resulting from low growth and low product standards which are not significant enough to keep them in operation.

Why accounting for standards important?

Competitiveness of firms in the apparel market in the era of globalization has become much more exacting than it was in the era of protected markets. Competitiveness which can be examined in the context of increasing productivity growth does not only comprise of output quantity expansion but must be associated with efforts in meeting standards which are usually technical specifications that must be met for products to be acceptable. For small and medium sized firms which want to be competitive internationally and continue to export their products, meeting the standards of international markets is just as important as expanding product quantity. There is also a negative side to standards as they have become indirect instruments for regulating markets, as tariffs are rather unpopular alternatives. These put extra burden on the producers of apparel products to meet these requirements.

To get the essence of how not meeting the standards can make a producer less competitive, lessons can be drawn from African Growth and Opportunity Act (AGOA) a trade agreement signed into law in 2000 which has presented a market opening to Ghanaian exporters as well as many other countries in subSaharan Africa to do business with US in some selected items including apparel products. However, to export to the US market, certain conditions such as tight stitching and carefully finished products including proper labeling and pre-packaging of individual items so that they can readily be put on the shelves must be met (Salinger and Greenwood, 2001). Products would not even be allowed onto the markets if these basic standards are not met. This means that in the competitiveness assessment, these product characteristics 
can no longer be overlooked. The issue of standards became prominent during our interviews with apparel producers in Ghana as some have complained that these technical requirements are actually making it more difficult to export not only to the US market but to other markets as well.

A typical success case is one Mr. Gbortsyo located in Ho, a town in Ghana who produces beautiful Kete products for niches of domestic and international markets. So far the demand for his products has far exceeded his capacity of production and currently meeting only 30 percent of the domestic market whilst demand from USA and Europe are still not being met. One thing that set Gbortsyo apart is zero tolerance for shoddy Kente products. Whilst his Kente products, are made of 79 warps per strip, the shoddy one has only 50 warps, thus not up to the exact technical specifications to last for a certain period of time and be competitive in the market because of lower standards. In addition to that, various niches of markets both home and abroad require their own specifications including honoring of contracts and meeting of delivery times and taste of the clients among others. To capture the real competitive situation of the two products implies that products standards be accounted for. Using the market value of the product may not present a very accurate picture as transportation cost and other taxes could inflate the real value of the product. It is therefore important that in our measurements and assessment of performance especially at the firm level, these characteristics known as standards or specifications need to be incorporated. That is why this study attempts to measure standards and apply them in the assessment of the productivity and competitiveness performance of some small and medium sized businesses in apparel manufacturing firms in Ghana.

\subsection{The Theoretical framework}

Generally, the conditions under which firms from developed countries build competitiveness are different from those of the developing countries, and more so small business. The targets of firms from developed countries appear also to be different from those of the firms from developing economies. It is evident that most models of technical change emphasized the conditions and the targets of firms from developed countries. Demand and supply forces driving technical change in developed countries include mainly relative prices 
of the factors of production and the level of factor endowments. Thus, the aim of firms from developed countries is to build competitiveness based on some factors including cost advantages. The reality is that if it costs US \$100 per unit of labour to produce one unit of output in developing countries and it costs US $\$ 2000$ per unit to produce the same unit of output in developed countries, there are serious cost disadvantages producing that product in developed countries. The rate and direction of technical change should be towards employing technologies which reduce greater reliance on relatively expensive factor. The cost cuts are important for firms in developing countries but priorities will have to be established in order to properly address the firms especially small businesses within the developing countries. To this, I would like to refer to Kennedy and Thirlwall (1972):

'Technical progress in all its aspects is impossible to measure precisely but its essential quantitative characteristic is to shift the production function (embodying all the previous known techniques) enabling greater output to be produced with the same volume of inputs, or the same output with lesser inputs.'

What is being emphasized here is output holding standards constant but varying the techniques of production. This is just one perspective capturing the essence of technical change. Whilst the concept of production possibility frontier which is the maximum obtainable amount of one commodity for any given amount of another commodity, given the availability of factors of production and the society's technology and management skills is used to capture the extent to which any change in technology, or factors of production or management skills, can shift outwards or inwards this curve (technical change), the idea can be captured within the context of firms from developing countries, and especially small businesses trying to survive. This is because their targets are different.

The question is: what are the targets of small businesses from developing countries if they must be competitive internationally? The answer is simple and of course it is neither increasing output nor maximizing profit alone but to first meet some minimal local and international product standards. If this is 
the case for these businesses, then, in using the production possibility frontiers $(\mathrm{PPF})$, in assessing their competitiveness, product standards should be accounted for. This implies that, this study employs standards-corrected production possibility frontier approach which defines as the maximum amount of output possible with a given technology, factors of production and managerial skills at given product standards.

\subsubsection{The Standards-corrected Production Possibility Approach}

Firms make decisions with the aim of maximizing product quantity and standards. Then, apparel output/standards depend on some exogenous factor inputs, managerial skills and some technology characteristics. Technical change is therefore not only induced by the relative factor prices and factor endowments but by standards improvement as well. For textile or apparel industry, we will assume that technical change is not localized, in that a change of technique at one stage of production spills over into all other stages and this is reflected in the output/standards of the product. In order to ensure that there is no technological lock-in, we have to assume that variable returns to scale but focus on non-increasing returns to every technique so that at one stage of the production process, there will be the need to switch to better technologies, techniques and skills. Assume that we have the ith level of output/standard $y$ to depend on some input $x$ : and technology. In the case of a single firm switching from one technique to the other (see Figure 5.1), we have:

\subsection{1 $\Delta y=f(\Delta A)$}

An increase in output $(\Delta y)$ in equation 5.1 .1 captured by the distance between point $\mathrm{E}_{2}$ and point $\mathrm{E}_{4}$ could be viewed as a shift or $\Delta A$ shown in Figure 5.1. This shift in PPF or $\Delta A$ could result from technical change, shifting from old to new products or standards improvements(quality or non quality improvement). In Figure 4.1, a firm producing at $E_{1}$ is operating inefficiently because it is not on the production frontier. The firm operating at Eo on the other hand is both technically efficient and scale efficient because it is on the production frontier $\mathrm{PPF}_{0}$ at the same time located at the 
intersection where the ray from the origin which depicts constant returns meets $\mathrm{PPF}_{0}$. The portion of $\mathrm{PPF}_{0}$ curve to the left of $\mathrm{E}_{0}$ indicates increasing returns to scale and that to the right reflects decreasing returns to scale. Any firm operating at $\mathrm{E}_{1}$ would be seeking to move towards the frontier at $\mathrm{E}_{0}$ and $\mathrm{E}_{2}$ would also be seeking to be more scale efficient by moving towards E.

Figure 5.1: Shift of Production Possibility Frontier

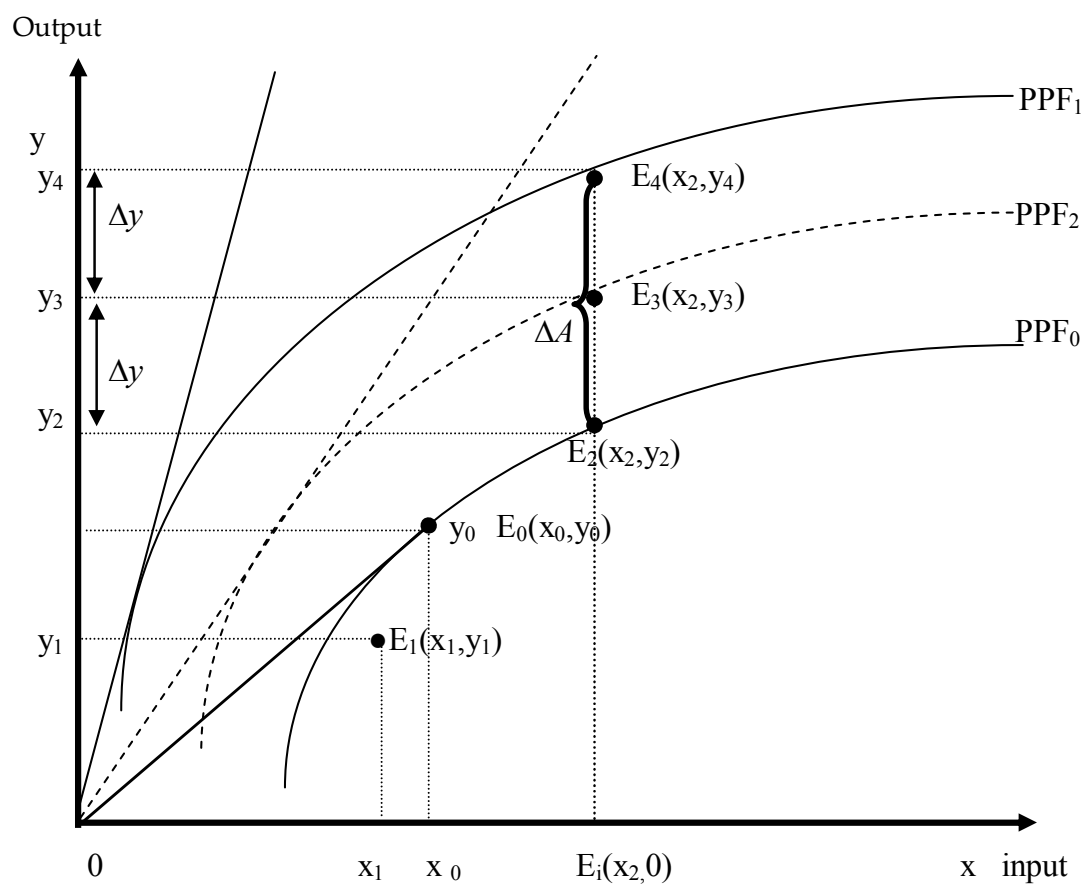

\subsection{The Methodology}

\subsubsection{Accounting for Standards in Productivity Measurement}

Productivity measures that 1) account for quantity expansion and 2) incorporate quality performance have appeared in the works of Fixler and Zieschang (1992), and Färe, Grosskopf and Roos (1995). They recognized that quality improvement is equally as important a component of productivity growth as quantity expansion but it is difficult to measure accurately. In fact, productivity measures can be misleading if product 
standards measures are not incorporated. Fixler and Zieschang noted that it is proper to expand the concept of output beyond output quantities and that it is justifiable to measure productivity growth overtime even when products quantities are held constant with a given set of inputs. Atkinson (2005) even proposed that in the national account data, it is possible to measure quality change based on these technique ${ }^{26}$ :

> Using a volume measure based on the level of activity, with a quality adjustment which is 'marked up or down' by a percentage reflecting indicators or success and contribution of the service to that success.

In productivity assessment, standards, especially international ones are requirements which if met make a product or service suitable for worldwide use and very important in performance analysis and competitiveness building. Thus the surest way to make businesses competitive is to meet these requirements be they safety, sanitary, quality, or cultural among others. Standards can be put into two components namely quality and nonquality categories with both defining the nature, type and general acceptability of the product or service and form integral part of performance and competitiveness measure of any economic unit.

\subsubsection{Non-separability of a product from its standards}

Interestingly, the question we raise is how should standards be introduced in productivity assessment?

1) Should they appear as separate vectors? Or

2) Should they be part of the inputs and outputs?

The answer to this question, we believe lies specifically with what the study is focused on. Clearly in accounting for quality in the productivity measurement, Fixler and Zieschang (1992), and Färe, Grosskopf and Roos (1995), define (x, a, y) where $x$ refers to a vector of inputs, a denotes a vector

\footnotetext{
${ }^{26}$ For details, refer to a Paper by UK Department of Health on ' Healthcare Output and Productivity: Accounting for Quality Change published Dec 2005,
} 
of output attributes appearing separately and $y$ is the output set. In the product market, dissociating products from their attributes becomes more tricky, which prompt this study to device a simple approach to account for the standards of the product by using standards indicator SIP (standards intensities of the product) which captures the observed apparel output standards (quality + non-quality) of each firm measured in percentage of nature of fabric, design and patronization percentage among others. The SIP is used to mark-up or down the products as it captures their 'standards intensities'. In line with $(x, a, y)$, this study specifies $(x, y / a)$ because of its output oriented nature and instead of ' $a$ ' uses 'SIP' with different meaning to give $(x, y / S I P)$. As illustrated in figure $\mathrm{A}$, a firm's competitiveness defined by its level and rate of productivity performance, tends to reflect clearly when standards are accounted for. It is therefore obvious that for a given $y$ and tend to mark-up and down $y$ resulting in the shifting upwards and downwards shift of PPF. For example a firm that meets $80 \%$ of a set of standards is marked up by the $20 \%$ left not met.

\subsubsection{Measuring Standards Intensities of the Product (SIP)}

This part proceeds from the notion that before a business is set up, producers know whatever products or services they want to supply in whatever quantities and levels of standards to match or exceed. With this information in mind, inputs and technological choices are made. The producers are also supposed to be able to know whether what they succeed in producing is actually up to the output standards aimed at. Dealing with quantities is relatively easier as treated in the traditional framework. This is because in the apparel industry for example, quantities produced are measurable in terms of figures. But the true nature of a product actually depends on its quantities and some other characteristics such as standards, among others. This means that, the ability to meet these other characteristics too must be accounted for in order to have more accurate picture of the state of business in terms of its relative competitiveness on the local and international front.

With standards of products known to producers and apart from meeting the minimum requirements to stay in business, they have to make a choice of how much to add to the required minimum. These standards which give 
details of various aspects of the products sometimes number in the thousands are expressed in measurable units referred to in this study and denoted by $s$. The $s$ actually measures the difference between the minimum standards that must be met for the product to be acceptable locally and the actual standards attained by the producer. In the apparel sector, $s$ is defined and measured along the lines of idea of Atkinson (2005), Dawson et al. (2005) and Kelly (2004) thus:

Standards (quality and non-quality) of apparel is defined as the value attached by producers and users alike to the characteristics of each of its components from fiber to fabric to the very last finishing detail and change in this standards refers to the rate of change of these characteristics (captured in \%).

\subsubsection{Models}

Different models have been used in the past to capture technical change, efficiency change and productivity change in general. They are the nonparametric and parametric/econometric models. The non-parametric approach can be used to decompose productivity into its components namely technical efficiency (i.e. how rapid is the catching-up process?) and technical change (the degree of upgrading or innovation). The parametric method which was used by, Griliches (1961) Jorgenson (1966), Hulten (1992 and 2000) and Nishimuzu and Page (1982) among others make a priori assumption about the distribution of the data. The non-parametric method as proposed in this study is based on Malmquist (1953) productivity index. This is supported by the theoretical efficiency argument advanced by Farrell (1957). The issue that the study is trying to address is finding out whether small businesses in the apparel sector are experiencing technological change and building competitiveness. If this is happening, applying say 2007 technologies to 2002 inputs should result in higher output compared to applying 2002 technology to 2002 inputs. It is a non-parametric technique and does not make any prior assumption about the distribution from which the data is drawn. The Malmquist index can be estimated using Shephard's $(1953,1970)$ distance functions. 


\subsubsection{The Non-parametric Method based on Malmquist Index}

Assuming that technologies are employed in apparel manufacturing over different periods in time, the Malmquist index can be computed with multioutputs and multi-inputs using either input distance function which rescales all inputs towards the frontier technology or output distance function which rescales all outputs towards the frontier technology (Chavas and Cox, 1999). This study prefers the latter because of the aim of trying to find out the extent to which output can be rescaled towards the frontier with a given set of inputs. The assumption here is that both inputs and outputs are disposable and the frontier is attainable with efficient use of available factors.

As the study seeks to establish change between 2002 and 2007 represented by $\mathrm{t}-5$ and $\mathrm{t}$ respectively for say firm $\mathrm{s}$, for k level of apparel output, $y \in R_{+}^{k}$ and 1 amount of inputs, $x \in R_{+}^{l}$, and input-output set $(\mathrm{x}, \mathrm{y}), \mathrm{t}$ period production set for firm s can be defined as:

\subsection{1 $P^{t, s}=\left\{\left(x^{t, s}, y^{t, s}\right) \in R_{+}^{k+l} \mid x^{t, s}\right.$ can produce $\left.y^{t, s}\right\}$}

Using an output oriented set define for all $y \in P^{t, s}$, we have:

$$
\text { 5.2.2 } Q\left(x^{t, s}\right)=\left\{y^{t, s} \in R_{+}^{k} \mid\left(x^{t, s}, y^{t, s} \in P^{t, s}\right\}\right.
$$

The output oriented Malmquist indexes and distance functions defined for the two periods follow $M_{o}^{t-5, s}, M_{o}^{t, s}$ and $D_{o}^{t-5, s}, D_{o}^{t, s}$ in that order. The subscript ' $O$ ' defines the output oriented function. $D_{o}^{t, s}\left(x^{t, s}, y^{t, s}\right)=\min \left\{\phi:\left(y^{t, s} / \phi\right) \in Q\left(x^{t, s}\right)\right\}$. This implies that with some given inputs, isoquant $Q\left(x^{t, s}\right)$ is attainable and the rescaling is done towards it. Specifications of the index follow:

$$
\text { 5.2.3 } M_{o}^{t, s}\left(x^{t-5, s}, y^{t-5, s}, x^{t, s}, y^{t, s}\right)=\frac{D_{o}^{t-5, s}\left(x^{t, s}, y^{t, s}\right)}{D_{o}^{t-5, s}\left(x^{t-5, s}, y^{t-5, s}\right)}
$$

Where the index is expressed with technology occurring in initial period as the reference point. The numerator is expressed as an adjacent period output distance function because of the application of the second period observations to the first period technology. The denominator is within 
period output distance function because it represents the feasible output with a given set of inputs based on technology occurring at that time.

5.2.4 $M_{o}^{t, s}\left(x^{t-5, s}, y^{t-5, s}, x^{t, s}, y^{t, s}\right)=\frac{D_{o}^{t, s}\left(x^{t, s}, y^{t, s}\right)}{D_{o}^{t, s}\left(x^{t-5, s}, y^{t-5, s}\right)}$

Similarly, technology occurring in the second period can be used as the reference point as in equation 5.2.4. However, in order to avoid arbitrary choice of technology as the reference point, the geometric mean of equations 5.2.3 and 5.2.4 as appears in equation 5.2.5 is preferred for the sake of consistency (Caves, Christiansen and Diewert 1982; Färe, Grosskopf, Norris and Zhang 1994; and Griffel-Tatjé and Lovell 1997).

--- Non standards corrected TFP change between $t$ and $t-5$ follows:

5.2.5 $M_{o}^{-5, s, t, s}\left(x^{t-5, s}, y^{t-5, s}, x^{t, s}, y^{t, s}\right)=\left[\frac{D_{o}^{t-5, s}\left(x^{t, s}, y^{t, s}\right) D_{o}^{, s}\left(x^{t, s}, y^{t, s}\right)}{D_{o}^{-5, s}\left(x^{t-5, s}, y^{t-5, s}\right) D_{o}^{t, s}\left(x^{t-5, s}, y^{t-5, s}\right)}\right]^{\frac{1}{2}}$

Standards difference at a point in time and standards difference overtime for a given output is measured as a ratio of a standards-corrected output distance function to output constant distance function. The argument here lies in the nonseparability of the product and its standards which appear as relative weight in output measure defined as $(\hat{y})$. These follow:

5.2 .6

$$
\hat{D}_{o}^{t, s}\left(x^{t, s}, \hat{y}^{t, s}\right) \quad D_{o}^{t, s}\left(x^{t, s}, y^{t, s}\right)
$$

$\Rightarrow s \tan$ dard difference at a point in time $(t)$

5.2 .7

$$
\text { Simple Index }=\frac{\hat{D}_{o}^{t, s}\left(x^{t, s}, \hat{y}^{t, s}\right)}{D_{o}^{t, s}\left(x^{t, s}, y^{t, s}\right)}
$$$$
\hat{D}_{o}^{t-5, s}\left(x^{t-5, s}, \hat{y}^{t-5, s}\right) \quad D_{o}^{t-5, s}\left(x^{t-5, s}, y^{t-5, s}\right)
$$

$s$ tan dard difference at a po int in time $(t-5)$

Simple Index $=\frac{\hat{D}_{o}^{t-5, s}\left(x^{t-5, s}, \hat{y}^{t-5, s}\right)}{D_{o}^{t-5, s}\left(x^{t-5, s}, y^{t-5, s}\right)}$

5.2.8 Standards corrected TFP change ( $\triangle$ STAND) between $t$ and $t-5$ follows:

$$
\Delta S T A N D^{-5, t, s}\left(x^{t-5, s}, \hat{y}^{t-5, s}, x^{t, s}, \hat{y}^{t, s}\right)=\left[\frac{\hat{D}_{o}^{t-5, s}\left(x^{t, s}, \hat{y}^{t, s}\right)}{\hat{D}_{o}^{t-5, s}\left(x^{t-5, s}, \hat{y}^{t-5, s}\right)} \frac{\hat{D}_{o}^{t, s}\left(x^{t, s}, \hat{y}^{t, s}\right)}{\hat{D}_{o}^{t, s}\left(x^{t-5, s}, \hat{y}^{t-5, s}\right)}\right]^{\frac{1}{2}}
$$




\subsubsection{Summary of Expected Estimations}

$\left[M_{o}^{t-5, s, t, s}\left(x^{t-5, s}, y^{t-5, s}, x^{t, s}, y^{t, s}\right)\right] \underset{<}{<}\left\{\begin{array}{l}\text { productivi ty growth (catchning -up) } \\ \text { No growth (stagnating ) } \\ \text { productivi ty decline (falling behind) }\end{array}\right.$

$\Delta$ Overall productivity growth

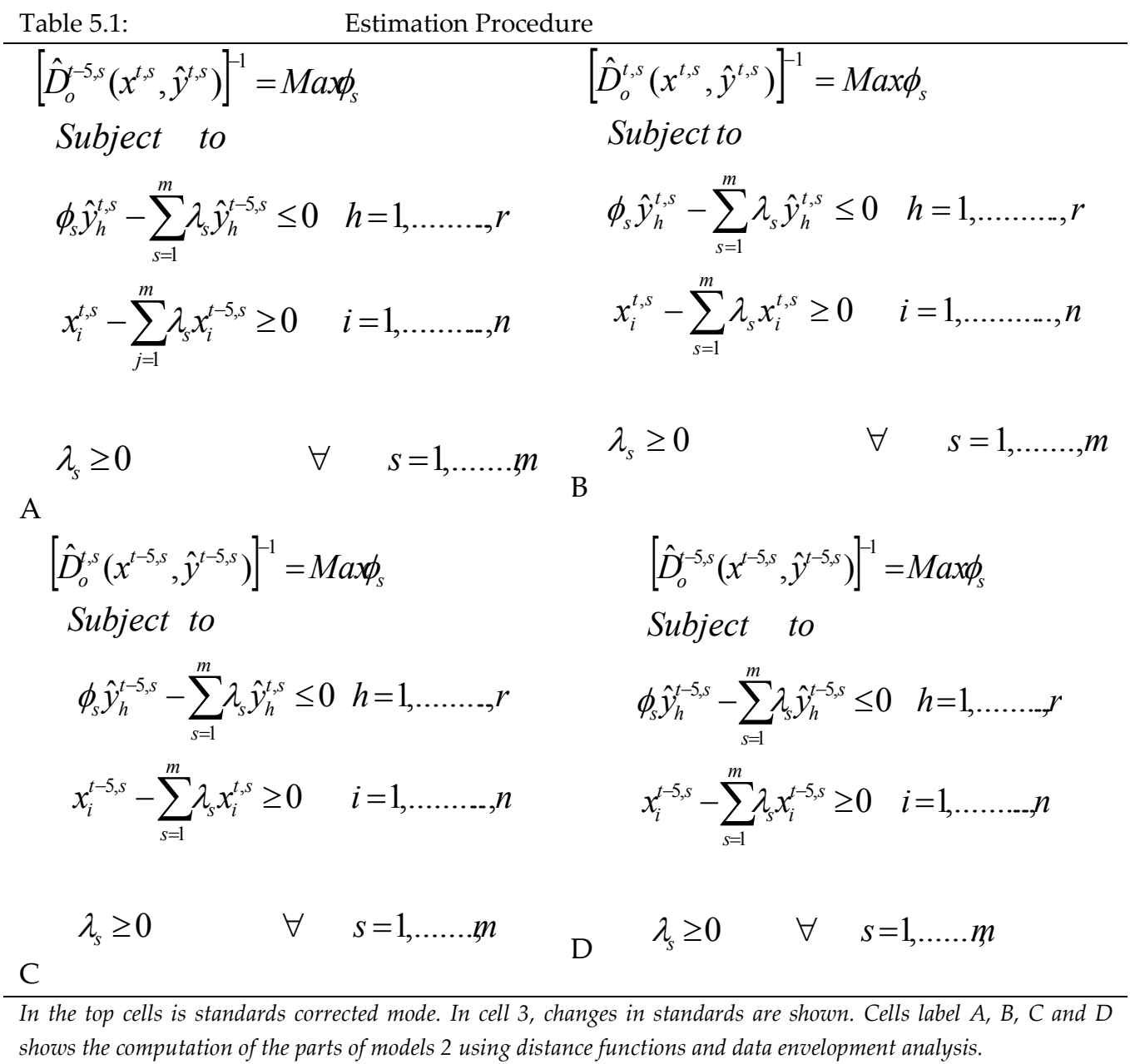

\subsubsection{Calculation of the TFP scores}

With the aid of multi-stage data envelopment analysis (DEA) and an outputoriented mathematical linear programming technique, calculation of the TFP 
scores is possible (Table 5.1, cells A, B, C and D). Charnes, Cooper and Rhodes' (CCR) publications in 1978 and 1981 established the foundation for DEA which involves the use of mathematical linear programming system to construct a non-parametric production frontier in order to calculate efficiencies in production. Following CCR, the output oriented mathematical linear programming specification for $\mathrm{s}^{\text {th }}$ firm with $\mathrm{i}^{\text {th }}$ amount of inputs $(x)$ and $\mathrm{h}^{\text {th }}$ amount of output $(\hat{y})$ between two time periods $(t-5, t)$ with $\lambda \mathrm{s}$ as the weight are as follows in the table:

The efficiency level of output denoted by $\phi_{s}$ measures the extent to which output of each apparel manufacturing firm can be scaled up by employing factors of production in an efficient manner. This expansion is that of radial nature because it is done with a given set of inputs. Thus, if $\phi_{s}$ value is calculated to be equal to 1.0, efficient position is attained, greater than 1.0 implies inefficiency. The value of 1.50 means that with efficient employment of factors of production, output can be expanded by $50 \%$ and so the current state of efficiency of this firm is $0.50(50 \%)$. The weights $\left(\lambda_{s} s\right)$ relate to the firm or firms operating on the frontier against which other firms are being measured and compared. In this expression, this is based on estimating the inverse of the distance functions, constant returns to scale is specified. The software used in this study is Frontier Efficiency Analysis in R (FEAR) created by Wilson (2007).

\subsubsection{Outliers and Choice of bandwidth}

It is a well known fact that DEA tends to envelop the entire data associated with the decision making units, in this study, the firms under investigation. Inability to account for firms that are doing extremely well due to some other factors might render all other firms looking rather too inefficient in comparism. The same is true for the firms performing very poorly, in which case, all other firms will appear to be extremely efficient. In dealing with outliers that might be present in our data, the study employed Wilson (1993) log-ratio plot and Grubbs (1969) test for outlier detection. The impact of one or two outliers did not make any difference in our results. This was realized even

when we dropped the outliers. Our choice of the bandwidth or smoothing 
parameter $h$ and the type of kernel estimation follows (Silverman 1986) datadriven automatic selection procedure which is less controversial because it is based on widely used algorithm(see density plots in Figure 5.2).

\subsubsection{Data and Description of Variables}

\begin{tabular}{ll}
\hline Variable & description \\
\hline $\begin{array}{l}\text { Output } \\
\text { Inputs }\end{array}$ & Observed annual apparel output of each firm $(\mathrm{y} 1, \ldots, \mathrm{y} 140)$ measured in cedis \\
$\mathbf{1}$ & Amount of labour $(11, \ldots, 1140)$ measured in person hours/year \\
$\mathbf{k}$ & $\begin{array}{l}\text { Amount of capit al }(\mathrm{k} 1, \ldots, \mathrm{k} 140) \text { measured as the value of fixed assets plus cash } \\
\text { spent on daily operations in cedis }\end{array}$ \\
$\mathbf{m}$ & $\begin{array}{l}\text { Amount of material used }(\mathrm{m} 1, \ldots, \mathrm{m} 140) \text { measured in value of yards or } \\
\text { meters/year in cedis }\end{array}$ \\
$\hat{\text { Other }}$ & $\begin{array}{l}\text { Observed apparel output standards (quality }+ \text { non-quality) of each firm } \\
(\mathrm{v} 1, \ldots, \mathrm{v} 140) \text { measured in \% of nature of fabric, design and patronization }\end{array}$ \\
\hline
\end{tabular}

Descriptive Statistics (N=140)

\begin{tabular}{cccccccccc}
\hline 2002 & Mean & Max & Min & Median & 2007 & Mean & Max & Min & Median \\
\hline yt-5 & 2156.88 & 25200 & 70.5 & 1075 & yt & 3678.01 & 25000 & 100 & 2200 \\
vt-5 & 0.34 & 0.8 & 0.1 & 0.25 & vt & 0.44 & 0.9 & 0.1 & 0.39 \\
k-5 & 1321.1 & 6000 & 60 & 900 & $\mathbf{k}$ & 2706.22 & 16000 & 70 & 1600 \\
l-5 & 1213.6 & 14080 & 320 & 960 & $\mathbf{I}$ & 1581.2 & 5440 & 320 & 1360 \\
m-5 & 862.15 & 7400 & 30 & 420 & $\mathbf{m}$ & 1636.43 & 9500 & 80 & 900 \\
\hline
\end{tabular}

NB: Values of output (y), capital(k) and material (m) are measured in '0000 old Ghana Cedi whilst labour (l) is measured in person hour/year and output standards (v) measured in \%

The observed apparel output (y) for 2002 and 2007 was captured in a single survey as the value of total products at factory-gate prices. The intention is to get the true value of the product without any transportation cost and other market charges. The total value was obtained from the sum of the values of children's wear, men's wear and women's wear produced by a firm. However some firms specialized in only one or two of the three items. For both years the values were measured based on 2002 prices in old Ghana cedis to ensure that both years are comparable. Aggregating the various values for a single firm produces one apparel output indicator for 2002 and one for 2007 respectively.

The study uses three inputs namely labor (l), capital (k) and amount of fabric and material $(\mathrm{m})$ used in the production of apparel. Annual labour input for 
2002 and 2007 was measured in hours and derived from the average number of workers who go to work per day, average of actual number of days worked in a week and average of actual number of hours spent working in a day. This is then computed for the entire year to get a single labour indicator for each for both years. Capital on the other hand is measured by summing the values in cedis of fixed assets and variable assets. In this study, the fixed assets comprise the values of equipments, machinery and workspace or office among others. Variable capital consists of value in cedis of inventory, semi-finished or finished products and working capital commonly referred to as money for day to day running of the business. The third input which is the fabric or material for apparel manufacturing is measured in value of yards or meters used per year in cedis for the two years based of course on 2002 prices.

Observed product standards (s) comprising both quality and non-quality standards of each firm which for some firms vary between 2002 and 2007 is also obtained. The indicator has some element of subjectivity in that even though derived from objective fabric characteristics such as durability, smoothness, weaving style, comfort, colour, heat conduction, speed of shrinkage, extent of wrinkling and bagging measures among others, the use of fabric hand based on external appearance cannot always be objective. Apparel producers provided their candid assessment of their own products based on the quality, style and types of fabric inputs based on the degree of patronization of the finished apparel products. Interviewers also through the external appearance and fabric hand are also able to confirm the extent of the local and even international standards of the products. The indicator obtained captures in percentages the degree of international standard being met in 2002 and 2007. Year 2002 coincided with an era dubbed the 'Golden Age of Business' and start of AGOA and PSI for textile and garments, making the data reliable as respondents checked the data.

\subsection{The Presentation and Analysis of Results}

\subsubsection{Incidence of Productivity Growth among small apparel businesses}

This section seeks to present and analyze the results of the two models namely the non standard- corrected (Model 5.2.5) and standard-corrected (Model 5.2.8) 
which were estimated to establish the performance of the firms with respect to productivity growth. The main idea is to find out whether these firms are losing their competitiveness as a result of the occurrence of low or no productivity growth among them, and whether firms are even reducing output just to survive in which case output growth over the period would be negative.

\begin{tabular}{|c|c|c|c|}
\hline \multirow[b]{2}{*}{ Unit } & \multicolumn{2}{|r|}{ Model 5.2.5: } & \multirow{2}{*}{$\begin{array}{l}\text { Model 5.2.8: } \\
+\quad \text { Standards Corrected }\end{array}$} \\
\hline & $\mathrm{n}+$ & Non standards Corrected & \\
\hline Entire Sample & 140 & $96(69 \%)$ & $52(37 \%)$ \\
\hline Micro-Firms & 85 & $58(68 \%)$ & $32(38 \%)$ \\
\hline Small \& Medium Firms & 55 & $38(69 \%)$ & $20(24 \%)$ \\
\hline Greater Accra Region & 58 & $39(67 \%)$ & $24(41 \%)$ \\
\hline Eastern Region & 37 & $27(73 \%)$ & $11(30 \%)$ \\
\hline Volta Region & 45 & $30(67 \%)$ & $17(38 \%)$ \\
\hline
\end{tabular}

$\Delta$ defines change in non standards corrected and standards corrected rate of productivity growth

Table 5.3.1 shows the results of firms which experience productivity growth between 2002 and 2007. In the first column are units of firms categorized according to their size and regional representations. The alphabet ' $\mathrm{n}$ ' represents the number of firms in each category. As discussed in the previous sections, the performance of the firms is gauged using model 5.2 .5 which does not account for output standards and Model 5.2.8 which accounts for output standards. For the entire sample, our results established that 69 per cent of 140 firms recorded some growth of 1 per cent and above (Model 5.2.5). The number of firms experiencing growth in standards corrected (model 5.2.8) was far less constituting only 52 per cent and just 37 per cent of the 140 firms in the entire sample. 
The differences in performance among these firms with respect to non standards corrected and standards corrected output reflects various strategies being adopted by each firm in order to survive. The apparel industry is basically demand-driven and therefore standards improvements are necessary to be competitive. The number of firms experiencing negative productivity growth is many, constituting 31 per cent for non standards corrected and 63 per cent standards corrected. This is an indication that the sub sector is actually in difficulty with respect to growth.

Growth performance by firm size, in this case micro firms compared with small and medium sized firms revealed an interesting situation where 69 per cent of the latter registered positive growth compared to 68 per cent of the former in non standards corrected model (Model 5.2.5). However, the variation between the two size categories in Model 5.2.8 indicated more micro firms improved their product standards relative to their small and medium counterparts. This implies that there are some efforts by many micro firms to survive the rather liberalized market environment through higher standards products. Many of the small and medium sized firms on the other hand appear to be more focused on output expansion by increasing fabric use rather than the quality and non- quality standards that could increase the cost of production.

At the regional level, the best performing region of the three appears to be the Eastern which is known for its good entrepreneurial skills and management styles. The 73 per cent of the firms in the Eastern Region (Model 5.2.5) that have recorded some growth over the 2002 to 2007 period can not make up for the 27 per cent of them that are actually coming to terms with negative growth and therefore are on their way to exiting the business altogether. Measures that can guarantee their continuous stay in the business include laying-off people and cutting back on the amount of output produced. It is therefore of no surprise that people in the apparel related activities continued to lose their jobs with each passing season.

In Table 5.3.2, clearer information is presented by capturing the counts of firms in categories of total factor productivity (TFP) growth among the entire sample, micro-sized firms, small and medium sized firms, Greater Accra, Eastern and Volta Regions. The results of the non standards corrected model 
and standard corrected model 5.2.8 are shown by the figures without the brackets and those within the brackets respectively. From the entire sample of 140 firms, 11 of them comprising of 7.9 per cent experienced TFP growth by 40 per cent and above in non standards corrected model (model 5.2.5). Of the number of firms with phenomenal growth of 40 per cent and over in non standards corrected model, most are from micro firms compared to small and medium sized ones whereas at the regional level they appear to be evenly spread. This is an indication that best performers can be found among different size and regional groups.

The number of firms recording what can be said to be excellent growth of 20 to 39 per cent are understandably more than those with phenomenal growth forming 17 and 2 per cent respectively in models 5.2.5 and 5.2.8. Again they are fairly common among different size and regional groups. Consistent with Table 5.3.1, the upper half section of Table 5.3.2 establishes that for the entire sample 69 per cent of firms are doing well with growth of 1 per cent and above in model 5.2.5 and 37 per cent of them are experiencing same in model 5.2.8. That positive picture painted by the upper half of Table 5.3.2 is quickly countered by the gloomy one exposed at the bottom half of Table 5.3.2 which conveys the information that all has not been well with some firms over the 2002 and 2007 period in which various initiatives including the PSI on garments was lunched by the government.

For the entire sample, the results indicate that at least 31 per cent of the firms (model 5.2.5) and 55 per cent (model 5.2.8) did not only fail to improve upon their product performance but actually faced some slump in output growth. Even if 10 per cent of the firms in a sub-sector are cutting back on production, the consequences on employment, household income and welfare become very grave. To talk of 31 and 55 per cent of firms in our sample confronted with negative growth with respect to non standards corrected and standards corrected output respectively can best be seen as a sub-sector in crisis which needs immediate attention.

In Figure 5.2, the situation is confirmed as many firms found themselves located to the left half of the distribution characterized by negative growth. In Tables 5.1 and 5.2 in Appendix 5, only 17 firms from Volta region, out of a total of 45 recorded positive growth in standards corrected TFP growth model 
compared to 30 for non standards corrected TFP growth model. The rest either maintained their standards or adjusted downwards. Of the 37 firms sampled from the Eastern region, only 11 of them namely firm 46, 47, 49, 51, 62, 64, 66, 67, 70, 78 and 79 appear to have experienced some positive standards corrected TFP growth in compared to 27 of them in non standards corrected TFP growth.

Table 5.3.2: Counts of Firms in categories of TFP Growth between

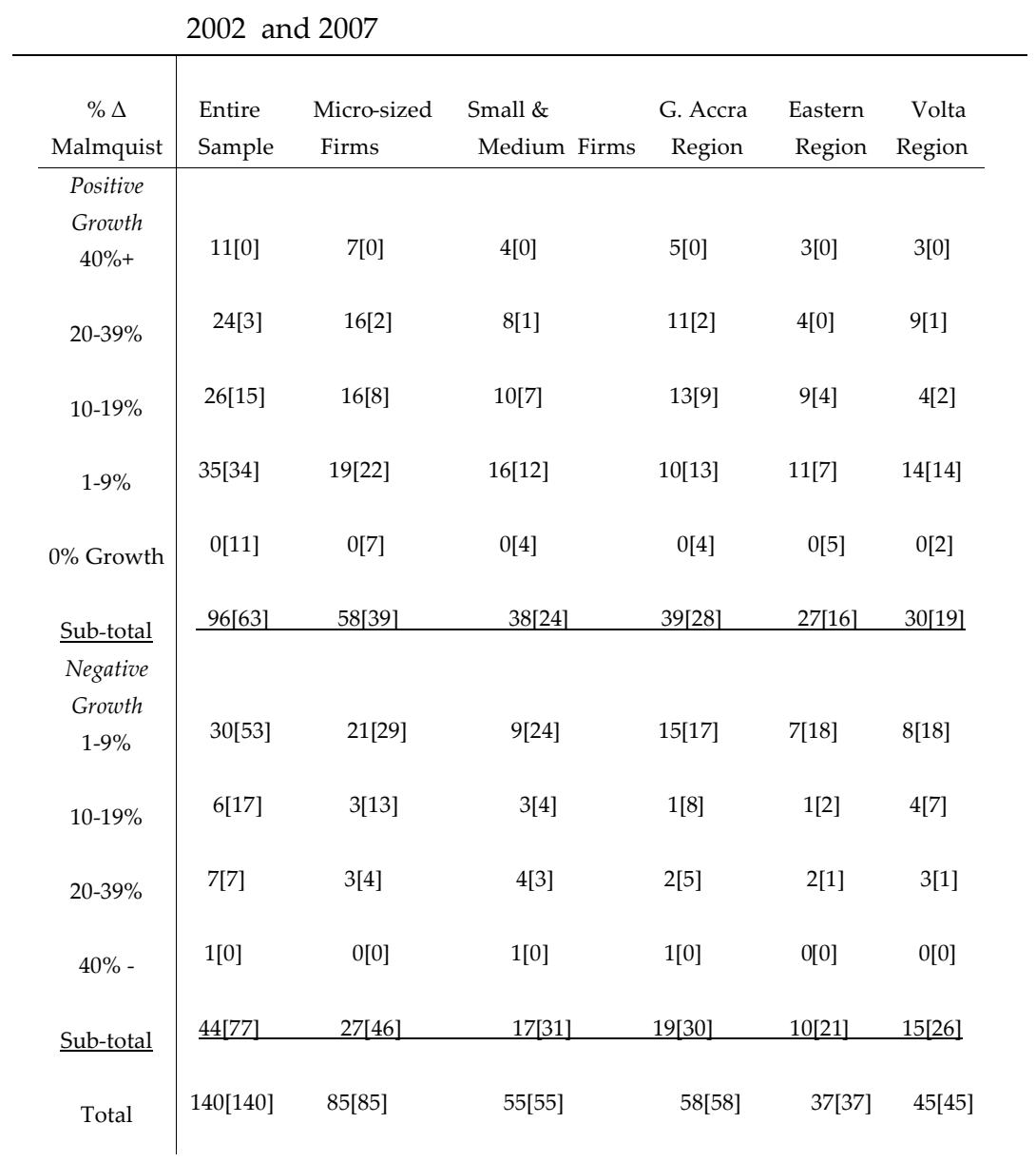

Figures in the brackets capture counts of firms with standards corrected TFP growth and those outside the bracket capture counts of firms with non standards corrected TFP growth. 
Apart from firms 53,56,60,70 and 80 which registered zero no changes in non standards corrected TFP growth, the rest had to contend with negative non standards corrected TFP growth (Appendix 5). About 56.8 per cent of all the firms in the Eastern region did improve their standards corrected TFP growth compared to 27 per cent that did not improve non standards corrected TFP growth (Appendix 5). Whist it may be true that most of the firms are

Figure 5.2: Growth Distribution by Region, Firms Size and Entire Sample for Models 1 \& 2b
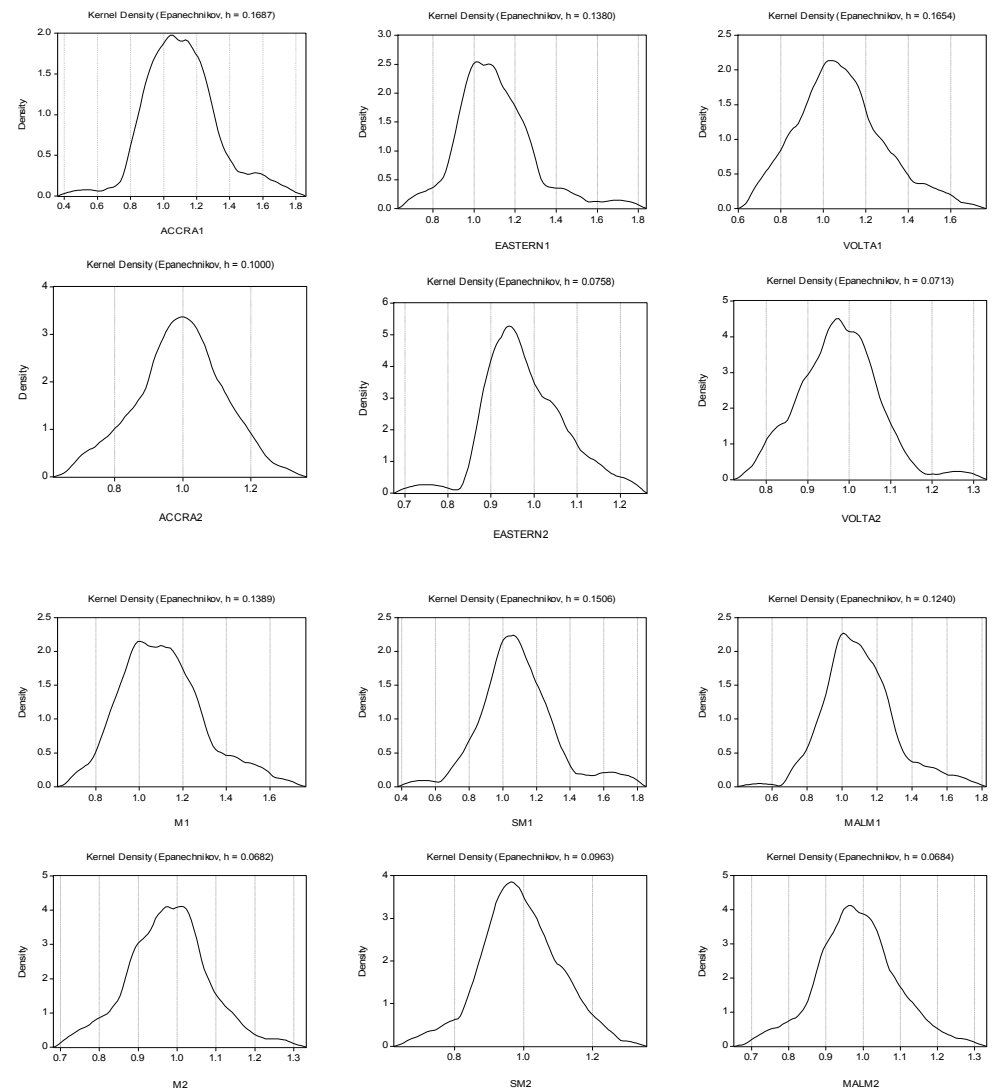

Note: Distributions are based on non-standards corrected model (1) and standards corrected model (2) respectively

producing at low standards and trying to balance their survival strategies with the choice of the level of product standards, others might not have any need to improve given their circumstances. 


\subsection{Research Hypothesis: Firms are losing competitiveness due to slow TFP Growth}

The question we seek to answer here is whether SMEs in the apparel manufacturing business are building competitiveness through significant TFP growth. We therefore progressed with non standards corrected TFP scores and standards corrected TFP scores. Since the estimated TFP scores derived from the data envelopment analysis (DEA) procedure alone is not enough to establish the level of statistical significance, we based our statistical inference on the construction of confidence intervals at $95 \%$ level of significance using the homogeneous bootstrap procedure with 2000 replications for three inputs and one output(Simar and Wilson, 1998). Results for non standard corrected and standards corrected TFP scores are presented in Figure 5.3.

Figure 5.3: TFP growth by Firm Size and Region

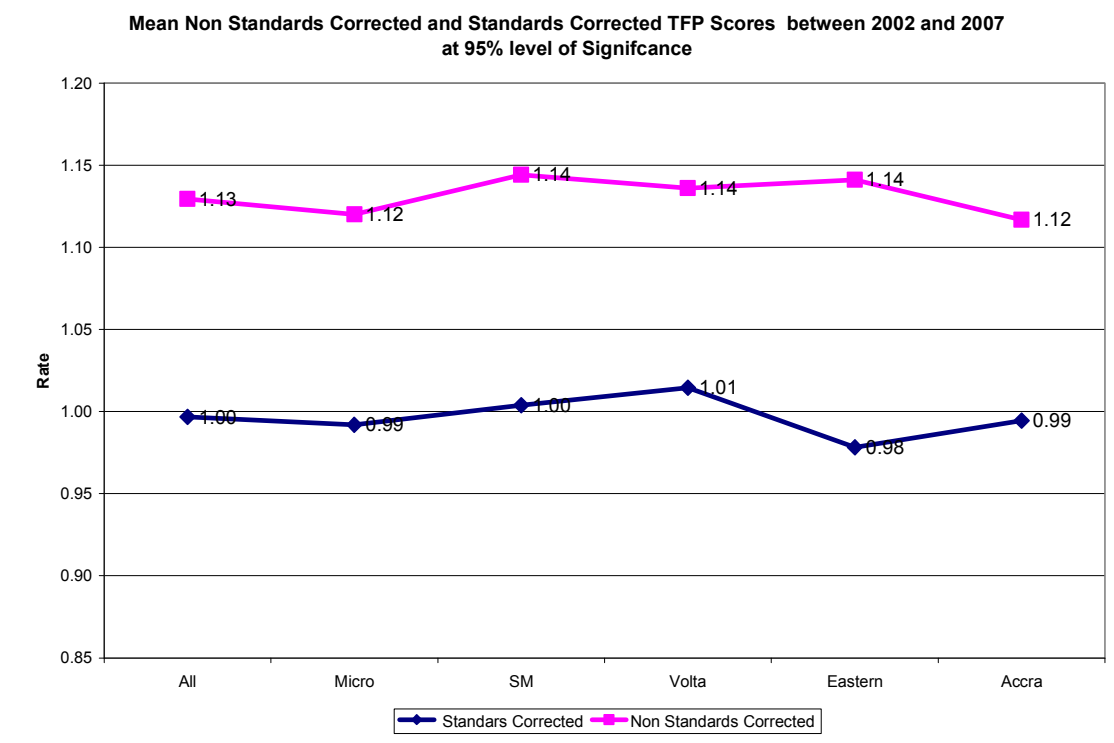

Subtracting unity from the scores provide the answer to our question as to the direction of TFP growth. Scores equal to unity indicate no change in TFP growth.

The results for non standards corrected TFP scores indicate 13 per cent growth compared to standard corrected TFP scores that indicate no change at $95 \%$ 
level of significance (See All in Figure 5.3). Small and medium sized firms(SM) appear to have performed better than micro firms (see Micro). In all size and location groups, non standards corrected TFP scores are higher than the standards corrected TFP scores revealing that these firms are losing competitiveness through low standards corrected TFP growth.

\subsection{Summary and conclusion}

In this chapter, the performance of SMEs in the apparel industry is assessed using both non-standards corrected and standards corrected TFP growth measures. Both non-standards corrected and standards corrected TFP measures are necessary to compare how well the firms have performed with either of them and which one needs emphasizing. The results revealed that more firms experienced TFP growth with non-standards corrected measure compared to that of the standards corrected measure. At the regional level, there were differences in the distribution of non-standards corrected TFP growth and standards corrected TFP growth. Eastern region was established as having performed best in increasing the non-standards corrected TFP growth but worst with standards corrected TFP growth. Greater Accra region was the best performer in non-standards corrected TFP growth.

Regardless of size and location, these businesses have been characterized by low non standards corrected TFP growth and low standards corrected TFP growth which implies that more has to be done so as not to lose competitiveness due to low overall TFP. The apparel sub-sector as a whole has therefore been losing its competitive edge over the 2002 and 2007 period in both domestic and international markets resulting from low TFP growth.

The findings lent credence to the long standing notion that these firms are performing poorly. In the standards corrected TFP growth measures, the revelation that SMEs are performing poorly is worrying as the market is so liberalized that the competition is felt from both domestic and international producers. 


\section{Appendix 5}

Table 5.1: Mean TFP Changes(Non Standards Corrected) between 2002-2007 period

\begin{tabular}{cccccccccc} 
Firm & Index & Firm & Index & Firm & Index & Firm & Index & Firm & Index \\
\hline \hline 1 & 1.0704 & 29 & 1.6006 & 57 & 1.6989 & 85 & 1.3464 & 113 & 1.0940 \\
2 & 1.2101 & 30 & 1.0709 & 58 & 1.1155 & 86 & 1.1264 & 114 & 0.9271 \\
3 & 0.7652 & 31 & 1.4834 & 59 & 0.8978 & 87 & 1.0124 & 115 & 0.7990 \\
4 & 0.9652 & 32 & 0.9156 & 60 & 0.9503 & 88 & 0.9305 & 116 & 1.0643 \\
5 & 1.0407 & 33 & 1.3488 & 61 & 1.2127 & 89 & 1.1516 & 117 & 1.0241 \\
6 & 1.0826 & 34 & 1.0493 & 62 & 1.2613 & 90 & 1.0873 & 118 & 1.1819 \\
7 & 1.0911 & 35 & 1.1492 & 63 & 1.1764 & 91 & 1.2599 & 119 & 1.1193 \\
8 & 1.2834 & 36 & 1.2234 & 64 & 0.9963 & 92 & 1.1714 & 120 & 0.9063 \\
9 & 1.2480 & 37 & 0.7982 & 65 & 1.2305 & 93 & 0.8725 & 121 & 1.1853 \\
10 & 1.0639 & 38 & 0.9422 & 66 & 0.9863 & 94 & 1.2242 & 122 & 0.9119 \\
11 & 1.0486 & 39 & 1.0413 & 67 & 0.7692 & 95 & 0.9103 & 123 & 0.9077 \\
12 & 1.2584 & 40 & 0.9662 & 68 & 1.1906 & 96 & 1.4614 & 124 & 1.2830 \\
13 & 0.8750 & 41 & 0.9036 & 69 & 1.1953 & 97 & 1.1886 & 125 & 1.6254 \\
14 & 0.7718 & 42 & 1.1485 & 70 & 1.0278 & 98 & 1.1700 & 126 & 0.7845 \\
15 & 1.2469 & 43 & 1.1960 & 71 & 1.0805 & 99 & 0.9870 & 127 & 1.2023 \\
16 & 0.9811 & 44 & 1.3836 & 72 & 1.0838 & 100 & 0.9314 & 128 & 1.5448 \\
17 & 0.9500 & 45 & 1.4772 & 73 & 1.1804 & 101 & 1.1610 & 129 & 0.5303 \\
18 & 0.9719 & 46 & 1.1861 & 74 & 1.0137 & 102 & 1.2702 & 130 & 0.9967 \\
19 & 0.8174 & 47 & 0.9351 & 75 & 1.0372 & 103 & 0.9545 & 131 & 0.9879 \\
20 & 1.2604 & 48 & 1.4140 & 76 & 1.4906 & 104 & 1.6890 & 132 & 1.2844 \\
21 & 1.0443 & 49 & 1.0021 & 77 & 0.9773 & 105 & 1.2057 & 133 & 0.9241 \\
22 & 1.0500 & 50 & 0.9957 & 78 & 1.0446 & 106 & 1.1457 & 134 & 1.1024 \\
23 & 0.8048 & 51 & 1.0032 & 79 & 1.1582 & 107 & 1.0199 & 135 & 0.9491 \\
24 & 1.0345 & 52 & 0.7836 & 80 & 1.1854 & 108 & 1.4809 & 136 & 1.0252 \\
25 & 1.1257 & 53 & 1.0777 & 81 & 1.3415 & 109 & 0.9477 & 137 & 1.2305 \\
26 & 1.0954 & 54 & 0.9841 & 82 & 1.0113 & 110 & 0.9139 & 138 & 1.1650 \\
27 & 1.0721 & 55 & 1.0406 & 83 & 1.0247 & 111 & 1.0347 & 139 & 1.0704 \\
28 & 0.8040 & 56 & 1.1913 & 84 & 1.3352 & 112 & 1.2734 & 140 & 1.1655 \\
\hline
\end{tabular}

Table 5.2: Mean TFP Changes(Standards Corrected) between 2002-2007 period

\begin{tabular}{cccccccccc} 
Firm & Standards & Firm & Standards & Firm & Standards & Firm & Standards & Firm & Standards \\
\hline \hline 1 & 1.0000 & 29 & 1.0278 & 57 & 0.9050 & 85 & 1.0016 & 113 & 0.8948 \\
2 & 0.8932 & 30 & 0.9937 & 58 & 0.9107 & 86 & 1.0736 & 114 & 0.9598 \\
3 & 0.9204 & 31 & 1.0724 & 59 & 0.9243 & 87 & 1.1346 & 115 & 0.9355 \\
4 & 0.9688 & 32 & 1.0613 & 60 & 1.0000 & 88 & 0.9477 & 116 & 1.2634 \\
5 & 0.9189 & 33 & 0.9790 & 61 & 0.9209 & 89 & 0.8829 & 117 & 0.9865 \\
6 & 0.9713 & 34 & 0.9261 & 62 & 1.1022 & 90 & 0.9985 & 118 & 0.8868 \\
7 & 0.8433 & 35 & 1.0298 & 63 & 0.9449 & 91 & 0.9790 & 119 & 1.1020 \\
8 & 0.9093 & 36 & 1.0013 & 64 & 1.0490 & 92 & 1.0507 & 120 & 1.0256 \\
9 & 0.9352 & 37 & 0.8080 & 65 & 0.9289 & 93 & 0.7615 & 121 & 0.7849 \\
10 & 0.9865 & 38 & 0.9207 & 66 & 1.0558 & 94 & 1.1632 & 122 & 0.9858 \\
11 & 1.0082 & 39 & 0.9495 & 67 & 1.0932 & 95 & 0.8407 & 123 & 1.1822 \\
12 & 1.0560 & 40 & 1.0131 & 68 & 0.9127 & 96 & 1.1146 & 124 & 0.9932 \\
13 & 1.1434 & 41 & 1.0373 & 69 & 0.9293 & 97 & 1.0498 & 125 & 1.0000 \\
14 & 0.9996 & 42 & 1.1068 & 70 & 1.0235 & 98 & 1.0000 & 126 & 1.0371 \\
15 & 1.0000 & 43 & 0.8382 & 71 & 0.9194 & 99 & 0.9826 & 127 & 1.1622 \\
16 & 1.0217 & 44 & 1.0572 & 72 & 0.9264 & 100 & 1.1496 & 128 & 0.7213 \\
17 & 0.8315 & 45 & 1.0102 & 73 & 1.0000 & 101 & 1.0251 & 129 & 0.7458 \\
18 & 0.9357 & 46 & 1.0318 & 74 & 0.9450 & 102 & 0.7547 & 130 & 0.9907 \\
19 & 0.9255 & 47 & 1.1158 & 75 & 0.9062 & 103 & 0.8430 & 131 & 0.9838 \\
20 & 0.8596 & 48 & 0.9804 & 76 & 0.9696 & 104 & 1.0732 & 132 & 1.0000 \\
21 & 1.2593 & 49 & 1.1814 & 77 & 0.8996 & 105 & 0.9128 & 133 & 0.9145 \\
22 & 0.7937 & 50 & 0.8878 & 78 & 1.1859 & 106 & 0.9155 & 134 & 0.8746 \\
23 & 1.0815 & 51 & 1.0749 & 79 & 1.0430 & 107 & 0.9227 & 135 & 1.1448 \\
24 & 1.0994 & 52 & 0.9108 & 80 & 1.0000 & 108 & 1.1305 & 136 & 0.9884 \\
25 & 0.9719 & 53 & 1.0000 & 81 & 0.9442 & 109 & 0.8706 & 137 & 1.0570 \\
26 & 0.8624 & 54 & 0.7511 & 82 & 0.9498 & 110 & 0.8419 & 138 & 1.2367 \\
27 & 0.9239 & 55 & 0.9386 & 83 & 0.9589 & 111 & 1.0000 & 139 & 1.0946 \\
28 & 0.9323 & 56 & 1.0000 & 84 & 1.0424 & 112 & 1.0278 & 140 & 1.0906 \\
\hline \hline
\end{tabular}




\section{Chapter 6}

\section{Appraisal of sources of Productivity Growth in the Apparel Sector}

\subsection{Introduction}

This Chapter tries to establish the sources of TFP growth among small business in the apparel sub-sector in Ghana. The key component to be investigated carefully is technical change. Contrary to the view that traditional sectors such as apparel manufacturing are not affected by new technologies, others believe that new technologies are making a difference in such sectors. Small businesses in the apparel manufacturing industry for instance need considerable reduction in production cost, speed up the production process and improve upon efficiency levels of operations to match consumers taste, variety and demand in general. The role of technical efficiency change and the contribution of scale change are also crucial to the success of these firms. There is a view that is widely held by the New Trade Theory advanced by Krugman (1984, and 1987) and Grossman and Helpman (1991) that Africa's manufacturing sector is characterized by technical inefficiencies. High Efficiency in manufacturing firms is considered as key to the competitiveness and survival of the industry. In order to ascertain what the situation is with small businesses in the apparel sector, a number of questions have being raised.

1. Have technical changes occurred among SMEs in the Apparel sector? And if so, how widespread is the phenomenon?

2. Are there production inefficiencies among these businesses? And if so, how pervasive are they?

3. If there are technical changes, are they being off-set by levels of inefficiencies if any? And

4. What contribution has emanated from scale change? If any, how extensive has scale change been over the period? 
Attempt is made to provide answers to these questions. Madu (1993) identified that productivity growth, quality/standards improvement and competitiveness of a firm are all related to technology but there must be efficient management of these technologies in order to be able to exploit their full potential. Full advantage can be taken of technical change when high levels of efficiencies are achieved in the manufacturing production. We proceed to test the propositions that:

1 Apparel firms are characterized by technical inefficiencies versus Apparel firms are not characterized by technical inefficiencies

2 Apparel firms are characterized by technical change versus Apparel firms are not characterized by technical change

3 Apparel firms are being scale efficient versus

Apparel firms are not being scale efficient

\subsection{Technical change as a source of TFP growth: Some theoretical backdrop}

Technical change has been an integral part of productivity growth literature and has been an important point of focus in economic growth literature for several decades. In seeking answers to why the rates of profit for example, were falling, David Ricardo (1773-1823) alluded to diminishing returns due to the scarcity of natural resources which then causes a decline in labor productivity. The solution to diminishing returns and falling labour productivity, he noted lies in technical change that can cut back on scarce natural resources and temporarily raise labor productivity and the rate of profit. Marx (1861) also explained that capitalist economies by systematically generating technical change can overcome diminishing returns to scarce factors of production.

Schumpeter's (1939) theory of economic growth and technology divides the technological change process into three stages. The first stage is the invention process, which comprises the generation of new ideas followed by 
the second stage known as the innovation process which pushes for the development of new ideas into marketable products and processes and the third, is the stage of diffusion where new products and processes spread unto the market. The impact of new technology is realized at the diffusion stage. Thus capturing the impact is very much a measurement of how an economy adjusts with the introduction and use of new technologies.

Solow in the 1950s developed a model which features a neoclassical production function that explains the level of output using labor and capital inputs. To explain the growth of per capita output (a crude measure of the standard of living), Solow introduced the idea of technological change. An assumption of decreasing returns, however, ensures that per capita output does not grow without technological progress. Intuitively, this assumption means that successive increases in the amount of, say, capital used in production (holding the number of workers constant) will yield progressively smaller increases in output. If returns to additional investments do not fall, it will always be profitable to invest, capital will continue to accumulate, and per capita output can continue to rise. Solow's growth model showed that long term growth arose only in the presence of labour augmenting technical change.

In Solow's model, technical change which was the source of growth was also exogenous. As such it was hardly a satisfactory answer to the question of what causes long-term growth. Lucas (1988) took up the challenge of endogenising labour augmenting technical change by linking it to human capital accumulation decisions. The latter emphasized the inter-temporal nature of the growth process that relies on investing first and getting a return later. It also underlines the importance of incentives, albeit implicitly, in making these investment decisions. In the Lucas model, growth rate depends positively on productivity of learning process, negatively on discount rate, positively on inter-temporal elasticity of substitution, and on knowledge spillovers implying sub-optimal growth leading to policy intervention.

The recent literature on endogenous growth was initiated by Romer (1986), who examined the idea that spillovers could be associated with the accumulation of knowledge. (A spillover is an action taken by one person or 
firm that affects another person or firm). Romer showed that spillovers could be strong enough to outweigh the drag caused by decreasing returns to capital and sustain growth in per capita output. Later, Romer refined his model to explain why companies invest in research and development (R\&D) when they know that any ideas that result will eventually benefit their competitors. He found that as long as society does not reach some type of technological limit, continuous innovation can allow per capita output to grow forever. One important advantage of Romer's model is that it does not supplant the neoclassical model. Instead, it fills an important gap in the neoclassical theory by providing a rigorous description of the source of technological progress. Romer points out that if innovation in his model was to stop, then his model would collapse to the neoclassical model.

In the Aghion and Howitt (1992) model, an innovation outperforms existing technologies by assumption, rather than supplementing them as in Romer, and drives existing technologies into extinction. That also eradicates the profit flows associated with those technologies and therefore the means to finance R\&D activity out of these profits. Higher future expected R\&D activities would shorten the lifetime of existing technologies, and would therefore make inventing these technologies less attractive. Hence, Aghion and Howitt explicitly acknowledged the importance of technological expectations in the R\&D process. In addition, they focused on the probabilistic and discrete character of the arrival of R\&D results, although, in practice, that didn't affect the results very significantly, as they centered on expected arrival rates, rather than the actual stochastics associated with a probabilistic R\&D process.

The conclusions that Romer and Aghion and Howitt arrived at indicated that economies with bigger populations (more human capital resources) should grow faster. This scale-effect is not really supported by empirical evidence, and Jones (1995) first pointed this out and provided an alternative model, in which long term growth was ultimately determined by the growth rate of the population, very much as in Solow's (1950s) original model. With endogenous theories, growth depends on behaviour or inter-temporal tradeoffs, profit incentives leading to market imperfections implying that if there are no imperfections then there is no growth, and so because of market 
imperfections, higher welfare would be through policy interventions. Economic behaviour therefore provides policy entry points.

Kuznets (1966) employed the application of science-based technology to production to explain the economic epoch of the last 250 years. 'An economic epoch is a relatively long period (over a century) with distinctive characteristics that give it unity and differentiate it from other epochs (1966, p. 2)'. Some characteristics that are generally observed in the growth process of some developed countries include high rates of growth of per capita product, of population, and of factor productivity, and a high rate of structural transformation. Major aspects of structural change include the shift away from agriculture, increase in the scale of productive units, shifts in organization and in the status of labor, and shifts in the structure of consumption. Modern economic growth is therefore a process full of discontinuities, structural transformations and institutional change. This according to Verspagen (2005) gave rise to an evolutionary interpretation of economic growth -a notion that economic growth is a process that goes well beyond a mere increase in living standard. Clark, Freeman and Soete (1981) looked into the question of technological innovation and the phases of the long waves. They focused mainly on the important distinction between the invention of a new technology and its actual "innovation" (significant use). They presented substantial evidence that it is only during innovation that a technology has impact on the economy and hence on the long wave.

\subsubsection{Some empirical insights on productivity growth}

Empirical growth accounting began with the famous studies of Abramovitz (1956, 1962) and Solow (1957). Their procedure in calculating technical progress was to deduct the growth rates of capital and labor (multiplied by their respective factor prices) and ascribing the "residual" to technical progress. The striking feature of the early investigations of growth accounting was the size of the Solow residual. Solow (1957), for instance, calculates that only $12.5 \%$ of growth in output per capita in the $1909-1949$ period in the United States was due to factor accumulation leaving $87.5 \%$ to be explained by technical progress! This is a bit dispiriting as it implies that the overwhelming majority of the growth that is empirically observed is "outside" the explanatory power of the Solow-Swan growth model! 
In a series of studies, Denison (1962), Griliches (1963) and Jorgensen and Griliches (1967) argued that there were errors in measurement in the early growth accounting work. For instance, if we remind ourselves that technical progress usually arrives "embodied" in new capital goods, then a lot more of growth can be ascribed to the "qualitative growth" of capital inputs. Thus, the importance of the Solow residual -- the growth in "total factor productivity" -- was argued to be substantially less than that estimated by earlier researchers. One of the most recognizable empirical results of Solow model is that countries with similar technologies and preferences will converge at the same steady state output levels. Studies carried out show that this appears to hold for a few countries (see Baumal and Wolf (1988), Barro and Sala-i-Martin (1989) and Romer (1990)).

Elsewhere, Chemingui and Isaksson (2003) investigated the Moroccan growth experience between 1960 and 2000 and identified that total factor productivity (TFP) growth accounted for 30 per cent of the overall growth over the period. Their growth accounting analysis revealed some technical regress over the period but improvement in technical efficiency somehow offset the negative impact of technical regress. The contribution of TFP growth however, was shown to have declined in the later periods closed to the year 2000. Yanrui $\mathrm{Wu}$ (2004) applies an extended Solow approach to examine the role of productivity in China's economic growth. The extended Solow approach allows the decomposition of output growth into factor contributions, technological progress and efficiency change. It is found that total factor productivity (TFP) has on average contributed to 13.5 percent of China's economic growth in the past two decades. This contribution is mainly due to technological progress which tends to accelerate over time.

\subsection{Analytical Framework}

The main sources of productivity growth among the SMEs in the apparel manufacturing sector is assessed within the framework in Figure 6.1 where the long-run survival strategy of every producer is to make their businesses competitive through productivity growth depends on the choices they make. The assumption here is that there are two types of growth which can be achieved in three ways. The first is by just increasing the quantity produced of a product without adding to or reducing its standards leaving its intrinsic 
value to be the same. The other approach is to maintain the quantity produced of the product by improving its on its standards in which case its intrinsic value rises. The third approach is to increase both the quantity of the product and improve upon its standards.

Figure 6.1: The Producer's Decision:

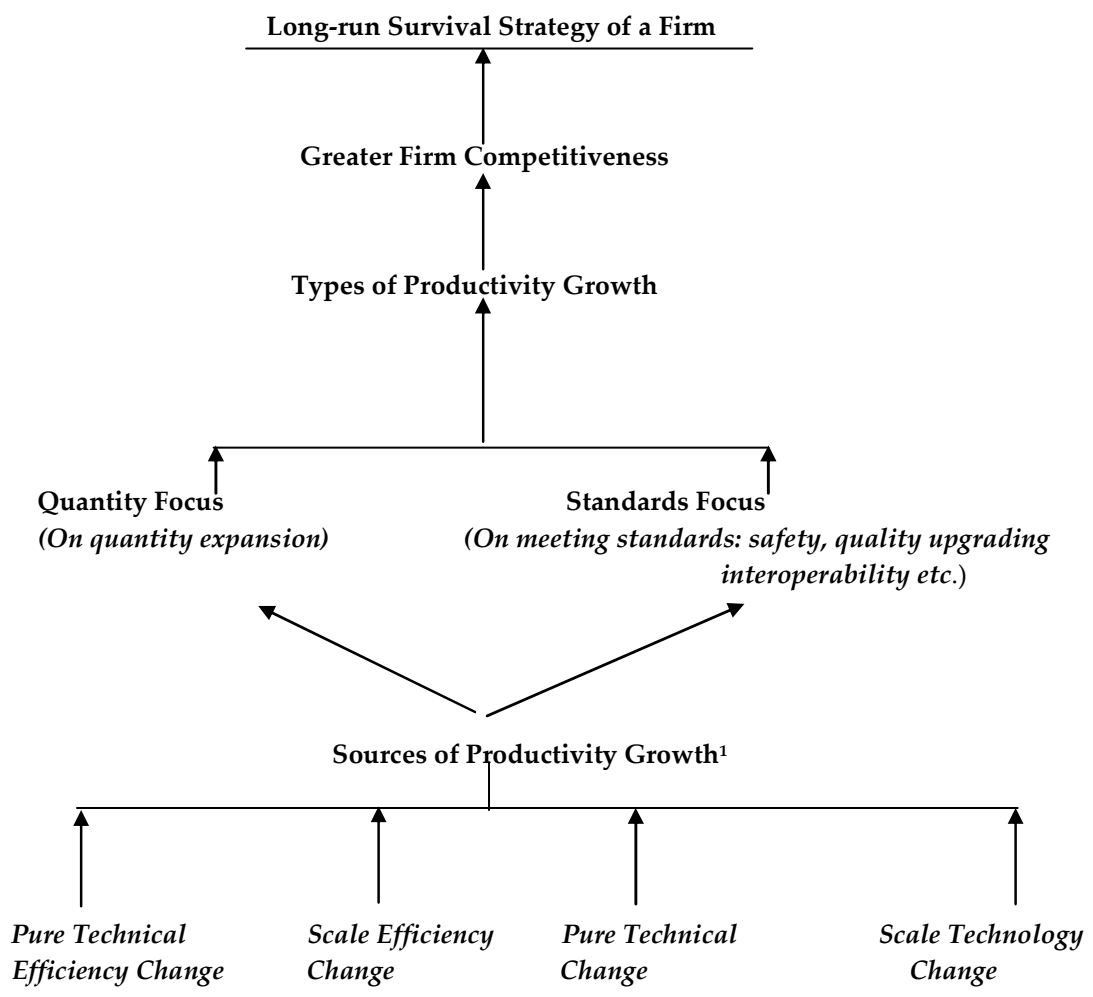

Sources of productivity growth follow Wheelock and Wilson (1999)

decomposition

The main sources of productivity growth can therefore be decomposed into various components using Malmquist productivity index. Relative performance with respect to pure technical efficiency change, scale efficiency change, pure Technical change and Scale technology change as in Figure 6.1. Pure Technical efficiency change measures a firm's success in producing maximum outputs from a given set of inputs. Scale efficiency change appraises the change in output in relation to percentage change in inputs. Pure Technical 
change considers the shift in production frontier resulting from the application of new technologies or techniques using the same amount of inputs. Scale technology change also known as the 'residual' shows whether a firm is operating towards constant returns to scale or not.

\subsection{Estimation Procedure}

Taking a set of inputs $x_{i}$ such that $\mathrm{i}=1,2, \ldots, \mathrm{p}$ and a set of outputs $y_{j}$ such that $\mathrm{j}=1,2, \ldots, \mathrm{q}$ then the vector of inputs and outputs $(\mathrm{x}, \mathrm{y})$ implies $x \in \mathfrak{R}_{+}^{p}$ and $y \in \mathfrak{R}_{+}^{q}$. The production possibility set for firm $\mathrm{s}$ in period $\mathrm{t}$ therefore follows:

$\Psi^{t, s}=\left\{\left(x^{t, s}, y^{t, s}\right) \in R_{+}^{p+q} \mid x^{t, s}\right.$ can produce $\left.y^{t, s}\right\}$

Using an output oriented set defines for all $y \in \Psi^{t, s}$ with Shephard(1970) distance function gives:

$\Delta^{t, s}\left(x^{t, s}, y^{t, s}\right)=1 /\left\{\max \phi:\left(x^{t, s}, \phi y^{t, s}\right) \in \Psi^{t, s}\right\} \mid$

Following Wheelock and Wilson (1999), the upper boundary $\Psi^{t, s}$ defines the technology of firm $s$ at time $t$. For all $x \in \mathfrak{R}_{+}^{p}$ and $y \in \mathfrak{R}_{+}^{q}, \Psi^{t, s}$ is convex, bounded and both inputs and outputs are disposable implying that at aiven technology, firms could adjust their inputs or outputs quantities. The location of the $S$ firm in the input-output space in period $t$ is measured by the distance function $\Delta^{t, s}\left(x^{t, s}, y^{t, s}\right)$. Equation 2 can be estimated by assuming constant returns to scale(CRS)

$\left[\bar{\Delta}_{C R S}^{t, s}\left(x^{t, s}, y^{t, s}\right)\right]^{-1}=\max \left\{\lambda_{s} \mid X^{t} \Gamma^{s} \leq x^{t}, Y^{t} \Gamma^{s} \leq \lambda y^{t, s}, \Gamma \in \mathfrak{R}_{+}^{N}\right\}$ or $\quad$ by assuming variable returns to scale(VRS)

$$
\begin{gathered}
{\left[\bar{\Delta}_{V R S}^{t, s}\left(x^{t, s}, y^{t, s}\right)\right]^{-1}=\max \left\{\lambda_{i} \mid X^{t} \Gamma^{s} \leq x^{t}, Y^{t} \Gamma^{s} \leq \lambda y^{t, s}, N 1^{\prime} \Gamma=1,\right. \text { including }} \\
\left.\Gamma^{s} \in \mathfrak{R}_{+}^{N}\right\}
\end{gathered}
$$

the term $N 1 \Gamma^{s}=1$ and $X=\left(x_{1}, x_{2}, \ldots \ldots x_{N}\right)$

and $Y=\left(y_{1,} y_{2}, \ldots \ldots y_{N}\right)$ describe a vector of observed inputs and outputs respectively with $\mathrm{t}=1 \ldots . \mathrm{T}, \mathrm{s}=1 \ldots . \mathrm{N}$ and $\Gamma^{s}$ indicating the time periods, the 
number of firms and intensity variables( or non-negative weights)

accordingly.

The total factor productivity (TFP) change over 2002 (denoted by $\mathrm{t}-5$ ) and 2007 (denoted by $t$ ) period employing Malmquist index using the geometric mean of two time periods as the reference point provides the following decomposition based on Wheelock and Wilson (1999).

\section{STEP ONE}

$$
\begin{aligned}
M_{o}^{t, t-5, s}= & {\left[\frac{\Delta_{C R S}^{t-5, s}\left(x^{t, s}, y^{t, s}\right)}{\Delta_{C R S}^{t-5, s}\left(x^{t-5, s}, y^{t-5, s}\right)} \times \frac{\Delta_{C R S}^{t, s}\left(x^{t, s}, y^{t, s}\right)}{\Delta_{C R S}^{t, s}\left(x^{t-5, s}, y^{t-5, s}\right)}\right]^{\frac{1}{2}} \ldots \ldots . . I } \\
= & {\left[\frac{\Delta_{C R S}^{t, s}\left(x^{t, s}, y^{t, s}\right)}{\Delta_{C R S}^{t-5, s}\left(x^{t-5, s}, y^{t-5, s}\right)}\right] \times\left[\frac{\Delta_{C R S}^{t-5, s}\left(x^{t, s}, y^{t, s}\right)}{\Delta_{C R S}^{t, s}\left(x^{t, s}, y^{t, s}\right)} \times \frac{\Delta_{C R S}^{t-5, s}\left(x^{t-5, s}, y^{t-5, s}\right)}{\Delta_{C R S}^{t, s}\left(x^{t-5, s}, y^{t-5, s}\right)}\right]^{\frac{1}{2}} } \\
& \uparrow \text { Efficiency Change } \uparrow \text { Technical Change } \ldots . . . I I
\end{aligned}
$$

The STEP ONE comprise of the decomposition of the geometric mean of the two time periods $\mathrm{t}$ and $\mathrm{t}-5$ in equation $I$ into efficiency change and technical change in II.

\section{$\underline{\text { STEP TWO }}$}

But according to Fare et al.(1994), equation II which is expressed as:

$$
\begin{aligned}
\text { TFP Change }= & \text { Efficiency Change } \\
& \times \text { Technical Change }
\end{aligned}
$$

can further be decomposed into three components

$$
\begin{array}{r}
\text { TFP Change = Pure Efficiency Change } \\
\times \text { Scale Change } \\
\times \text { Technical Change }
\end{array}
$$

as presented in equation III. 


$$
\begin{aligned}
M_{o}^{t, t-5, s} & =\left\{\frac{\Delta_{V R S}^{t, s}\left(x^{t, s}, y^{t, s}\right)}{\Delta_{V R S}^{t-5, s}\left(x^{t-5, s}, y^{t-5, s}\right)}\right\} \ldots . . \text { Pure Efficiency Change } \\
& \times\left\{\frac{\Delta_{C R S}^{t, s}\left(x^{t, s}, y^{t, s}\right) / \Delta_{V R S}^{t, s}\left(x^{t, s}, y^{t, s}\right)}{\Delta_{C R S}^{t-5, s}\left(x^{t-5, s}, y^{t-5, s}\right) / \Delta_{V R S}^{t-5, s}\left(x^{t-5, s}, y^{t-5, s}\right)}\right\} \ldots . \text { Scale Change } \\
& \times\left\{\frac{\Delta_{C R S}^{t-5, s}\left(x^{t, s}, y^{t, s}\right)}{\Delta_{C R S}^{t, s}\left(x^{t, s}, y^{t, s}\right)} \times \frac{\Delta_{C R S}^{t-5, s}\left(x^{t-5 . s}, y^{t-5, s}\right)}{\Delta_{C R S}^{t, s}\left(x^{t-5, s}, y^{t-5, s}\right)}\right\}^{\frac{1}{2}} \text {...Technical Change }
\end{aligned}
$$

\section{STEP THREE}

Finally we arrive at the components in $I V$ defined by Wheelock and Wilson (1999) as :

$$
\begin{aligned}
& \text { TFP Change }=\text { Pure Efficiency Change } \\
& \quad \times \text { Scale Change } \\
& \quad \times \text { Pure Technical Change } \\
& \quad \times \text { Scale Technology Change }
\end{aligned}
$$

and expressed as:

$$
\begin{aligned}
& M_{o}^{t, t-5, s}=\left\{\frac{\Delta_{V R S}^{t, s}\left(x^{t, s}, y^{t, s}\right)}{\Delta_{V R S}^{t-5, s}\left(x^{t-5, s}, y^{t-5, s}\right)}\right\} \ldots . . \text { Pure Efficiency Change } \\
& \quad \times\left\{\frac{\Delta_{C R S}^{t, s}\left(x^{t, s}, y^{t, s}\right) / \Delta_{V R S}^{t, s}\left(x^{t, s}, y^{t, s}\right)}{\Delta_{C R S}^{t-5, s}\left(x^{t-5, s}, y^{t-5, s}\right) / \Delta_{V R S}^{t-5, s}\left(x^{t-5, s}, y^{t-5, s}\right)}\right\} \ldots . \text { Scale Change } \\
& \times\left\{\frac{\Delta_{V R S}^{t-5, s}\left(x^{t, s}, y^{t, s}\right)}{\Delta_{V R S}^{t, s}\left(x^{t, s}, y^{t, s}\right)} \times \frac{\Delta_{V R S}^{t-5, s}\left(x^{t-5, s}, y^{t-5, s}\right)}{\Delta_{V R S}^{t, s}\left(x^{t-5, s}, y^{t-5, s}\right)}\right\}^{\frac{1}{2}} \ldots . \text { Pure Technical Change } \\
& \times\left\{\frac{\Delta_{C R S}^{t-5, s}\left(x^{t, s}, y^{t, s}\right) / \Delta_{V R S}^{t-5, s}\left(x^{t, s}, y^{t, s}\right)}{\Delta_{C R S}^{t, s}\left(x^{t, s}, y^{t, s}\right) / \Delta_{V R S}^{t, s}\left(x^{t, s}, y^{t, s}\right)} \times \frac{\Delta_{C R S}^{t-5, s}\left(x^{t-5, s}, y^{t-5, s}\right) / \Delta_{V R S}^{t-5, s}\left(x^{t-5, s}, y^{t-5, s}\right)}{\Delta_{C R S}^{t, s}\left(x^{t-5, s}, y^{t-5, s}\right) / \Delta_{V R S}^{t, s}\left(x^{t-5, s}, y^{t-5, s}\right)}\right\}^{\frac{1}{2}} \\
& \uparrow
\end{aligned}
$$

Scale Techno $\log y$ Change $\quad$........................IV 
These for components of as sources of productivity growth namely pure efficiency change, scale change, pure technical change and scale technology change are estimated analyzed for both non-standards corrected and standards corrected productivity changes in the subsequent sections.

Interpretation

Part 1 of equation $I V$ measures pure efficiency change and this value could be less, equal or more than 1 in which case there is a reduction, no change or an increase in pure efficiency respectively.

Scale efficiency change in part 2 of equation $I V$ needs to be greater than 1 for an improvement and less than one 1 for deterioration in efficiency.

Pat 3 of equation $I V$ which captures pure technical change has to be greater than 1 for any positive technological changes to have occurred. A score that is less than 1 is an indication of deterioration in technical change and if it is equal to 1 then there is zero improvement.

Change in scale of technology in part 4 of equation $I V$ sometimes refers to as the residual defines the shape of the technology and must be greater than 1 to have the shape of technology flattening and less than 1 to indicate an increasing curvature.

\subsubsection{Test for statistical significance: Bootstrapping procedure}

Having decomposed growth into various components, the next question we want to answer is the significance of each of these components in terms of their contribution to growth. Our focus would especially be on the contribution that technical change has made. To do this, we have to establish whether the components are significantly different from one or not. This section therefore, seeks to carry out the statistical testing of productivity components in order to establish their relative significance and whether they make any difference in the growth. Simar and Wilson (1998) proposed the bootstrapping method which is a simulation technique that allows confidence intervals to be constructed and statistical inference to be carried 
out with DEA. Prior to this technique, DEA was often criticized as being rather deterministic and that even statistical inference could not be performed on the estimated efficiency scores. Statistical bootstrapping of efficiency scores in order to perform the necessary test therefore automatically overcomes this weakness that had remained with DEA for decades. This study tries to gain insight into the performance of the productivity components in the apparel sector in Ghana by using Simar and Wilson (1998) technique.

Before getting into the detail about the kernel smoothing estimator, we carry out a brief overview of the kind of problems that are likely to be encountered when other bootstrapping techniques such as naïve bootrstrapping is applied in this study. Naïve bootstrapping, simply refers to re-sampling with replacement from the original data or the distribution of that data. Goncalves and Vogelsand (2006) define naïve bootstrapping as a situation where the formula used in the bootstrap world to compute the test is the same as the formula used on the original data. However, as noted in many studies including Simar and Wilson (1999), naïve bootstrapping can render some estimates such as confidence intervals and variances, which are necessary for valid conclusions, inconsistent in some cases, a virtue which should not be compromised in any empirical statistical analysis especially one in relation to statistical inference. Of particular concern with regards to naïve bootstrapping is whether it does make any sense when applied to efficiency scores. Proponents of how to bootstrap efficiency scores in order to construct confidence intervals advised that researchers employ smooth bootstrap method particularly when bootstrapping efficiency scores. Knowing how inconsistent estimators can be, especially with regards to this work, has informed the choice of smooth bootstrapping procedure in order to circumvent this problem.

In this study, we employ the smooth bootstrapping technique to carry out the statistical analysis of the efficiency scores. Unlike standard bootstrapping in which re-sampling is done with replacement from the empirical data and might include some data points and exclude some in the process, smooth bootstrapping tries to account for these and other properties by not drawing directly from the data but through an estimated non-parametric density function (Silverman and Young, 1987). The non-parametric kernel density 
function provides an environment within which to carry out smooth bootstrapping by constructing confidence intervals and perform our statistical analysis. Non-parametric bootstrapping approach is grounded on the idea that the population distribution is not known and that estimating empirical distribution will give us the knowledge about the population distribution itself. However, as with studies employing sampling techniques, the sample is assumed to represent the population under investigation and running independent re-sampling several number of times will give the known empirical distribution and approximate the unknown population distribution being dealt with. In other words "a reflection of the reflection of the truth" will be established without compromising the validity and authenticity of the results.

The choice of the bandwidth or smoothing parameter and the type of kernel are two very important determinants of the density that is estimated (Silverman 1986, Sheather and Jones 1991).We follow the approach of Silverman (1986) and specify the bandwidth for bivariate data as $h=0.96 N^{-1 / 6}$ where $\mathrm{N}$ is equal to the 140 apparel manufacturing firms in our sample. Even though there are so many types of kernels that can be employed in non-parametric density estimations, more importance has been attached the choice of the bandwidth which has the characteristics of smoothing out all the relevant features in the data. Care must be excised in the bandwidth selection process as over-smoothing may result from large bandwidth selection and under-smoothing may result from small bandwidth selection.

\subsection{Data Sources}

This analysis uses three inputs namely labor (l), capital (k) and amount of fabric and material $(\mathrm{m})$ used in the production of apparel. Annual labour input for 2002 and 2007 was measured in hours and derived from the average number workers who go to work per day, average of actual number of days worked in a week and average of actual number of hours spent working in a day. This is then computed for the entire year to get a single labour indicator for each of both years. Capital on the other hand is measured by summing the values in cedis of fixed assets and variable assets. In this study, the fixed assets comprise of replacement values of equipments, 
machinery and workspace or office among others. Variable capital consists of value in cedis of inventory, semi-finished or finished products and working capital commonly referred to as money for day to day running of the business. The third input which is the fabric or material for apparel manufacturing is measured in value of yards or meters used per year in cedis for the two years based in 2002 prices.

Data was collected in Ghana from January-April 2008 by a stratified sample survey and the stratification was done according to size and location (micro, small \& medium sized firms, Greater Accra, Eastern and Ashanti region in Ghana). The 140 apparel manufacturing firms were a vital source of information. Semi-structured questionnaire were used. Data on observed apparel output quantity of each firm measured as the number of garments sewn per year (in cedis). Observed apparel inputs quantities of each firm namely: amount of labour or labour productivity measured in number of garments per person-hour (L), amount of capital or capital productivity measured as the amount of output per machine-hour (K), observed amount of material used (M) measured in yards/month, and observed apparel output standards indices of each firm (s) measured in grades/dozen of material used and captured as a combination of object apparel characteristics and subjective fabric hand in percentage.

\subsection{Presentation and analysis of results}

\subsubsection{Sources of Productivity Growth}

Our main point of interest here is to establish the sources of TFP growth and their level of significance. Of 140 firms, some of them are estimated to have experienced efficiency gains but judging these by looking at the positive scores alone is not enough as some might actually not be significant. Confidence intervals were therefore constructed using the homogeneous bootstrap procedure (Simar and Wilson, 1998) with 2000 replications for 3 inputs $(\mathrm{p}=3)$ and 1 output $(\mathrm{q}=1)$. The idea here is to establish which firms actually have scores that are significantly different from unity. Any firm with the confidence interval containing unity is considered not significantly different from unity. Firms are considered to make some gains if their lower 
confidence bounds are greater than unity and making significant lose if their upper bounds are less than unity.

\section{Pure Technical Efficiency}

The degree of inefficiencies among the firms is staggering. From a sample of 140 firms, 54(38.6\%) and 55(39.3\%) of them were established to be battling with various levels of pure technical inefficiencies in non standards corrected and standards corrected estimates respectively. Only 47(33.6\%) of the firm were established to be catching up (Table 6.1). Whilst it was true that some firms did improve, most did not and so these gains were limited. Consequently the general contribution of pure technical efficiency to TFP growth of firms in the sample can only be said to be poor.

The 47(33.6\%) firms that were catching-up comprised of 25 micro firms (29.4\%) and 22 small and medium sized firms (40.0\%). This shows that more small and medium sized firms experienced pure technical efficiency gains compared to micro-firms. The regional distribution of firms indicates that 16 from the Volta region (35.6\%), 10 firms from the Eastern region (27\%), and 21 firms from the Greater Accra Region (36.2\%) experienced pure efficiency gains. Greater Accra has therefore experienced the highest pure technical efficiency gains, followed by Volta Region and Eastern Region in that order. The bottom-line is that, only $33.6 \%$ of the 140 firms are established to have experienced significant efficiency gains.

Again, in Table 6.1, out of 140 firms, 54 (38.6\%) are actually falling behind. In Greater Accra Region, 23 firms (39.7\%) are established to be falling behind, Eastern and Volta Regions have 14(37.8\%) and 17(37.8\%) firms respectively falling behind in both non standards corrected and standards corrected estimates. We therefore conclude in favour of our proposition that that these firms have been characterized by pure technical inefficiencies.

Pure Technical Change

The way pure technical change is captured within these apparel manufacturing firms is based on the principle that any new technique or 
technology employed at one stage of the production process affects all stages. As an example, firms that adopt newer and more efficiency marker making technologies facilitate the cutting stages of a production process and sewing becomes easier. With this approach, the estimated results of technological change indicate that all the firms in the sample have adopted one new form of technology or another at various stages of their production process between 2002 and 2007. This makes a lot of sense since simple but more efficient designing machines, cutting equipments and sewing machines are readily available on the market at relatively affordable prices. In fact, the results revealed that only $1(0.7 \%)$ firm is downgrading compared to $108(77.1 \%)$ which are upgrading in both non standards corrected and standards corrected estimates respectively (Table 6.2).

Understandably, old apparel manufacturing machines are fast being replaced by modern and more efficient ones. The interesting finding is that there has been some shift from the application of old technologies to new ones but more important though is the extent of that shift. Even firms that opted for new marker making machines alone were considered to be making some progress and so reflected in the results.

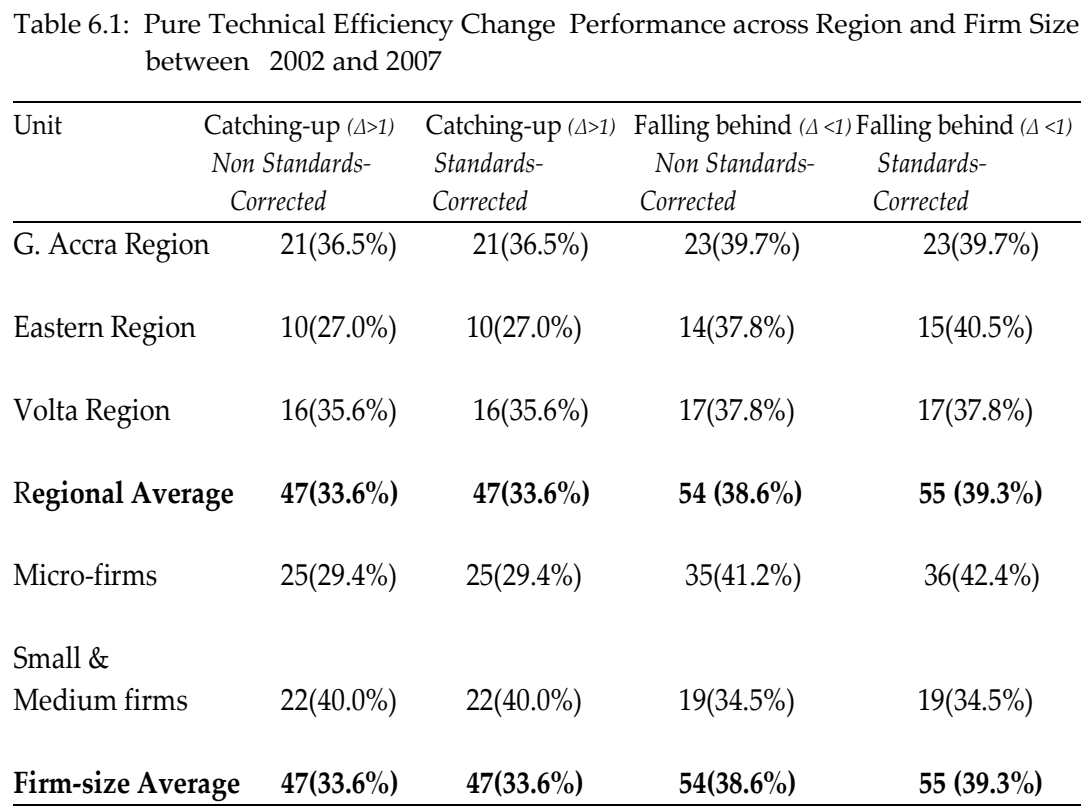




\begin{tabular}{|c|c|c|c|c|}
\hline $\begin{array}{l}\text { Upg } \\
\text { Non } \\
\text { Cor }\end{array}$ & $\begin{array}{l}\text { ading }(\Delta>1) \quad \mathrm{L} \\
\text { Standards- } \\
\text { rected }\end{array}$ & $\begin{array}{l}\text { Upgrading }(\Delta>1) \\
\text { Standards- } \\
\text { Corrected }\end{array}$ & $\begin{array}{c}\text { Downgrading }(\Delta<1) \\
\text { Non Standards- } \\
\text { Corrected }\end{array}$ & $\begin{array}{l}\text { Downgrading }(\Delta<1) \\
\text { Standards- } \\
\text { Corrected }\end{array}$ \\
\hline G. Accra Region & $42(72.4 \%)$ & $42(72.4 \%)$ & $1(1.7 \%)$ & $1(1.7 \%)$ \\
\hline Eastern Region & $27(73.0 \%)$ & $27(73.0 \%)$ & $0(0 \%)$ & $0(0 \%)$ \\
\hline Volta Region & $39(86.0 \%)$ & $39(86.0 \%)$ & $0(0 \%)$ & $0(0 \%)$ \\
\hline Regional Average & $108(77.1 \%)$ & $108(77.1 \%)$ & $1(0.7 \%)$ & $1(0.7 \%)$ \\
\hline Micro-firms & $60(70.6 \%)$ & $60(70.6 \%)$ & $1(1.1 \%)$ & $1(1.1 \%)$ \\
\hline \multicolumn{5}{|l|}{ Small \& } \\
\hline Medium firms & $48(87.3 \%)$ & $48(87.3 \%)$ & $0(0 \%)$ & $0(0 \%)$ \\
\hline Firm-size Average & $108(77.1 \%)$ & $108(77.1 \%)$ & $1(0.7 \%)$ & $1(0.7 \%)$ \\
\hline
\end{tabular}

\section{Scale Efficiency}

The role of scale efficiency is relevant here because we are exploring firms of various sizes ${ }^{27}$ starting from micro sized to small and medium sized firms. Dealing with a sub-sector which is user-driven requires apparel products to meet the taste and style of the buyers. The choice of scale of operation is also very crucial to satisfy the target market. The aim is to establish whether, scale efficiency is widespread across these firms in our sample.

For non standards corrected estimates (Table 6.3), 14 firms constituting $10.0 \%$ of the firms in our sample were scale efficient compared with $15(10.7 \%)$ in the standards corrected estimates that were also scale efficient. Only 4 firms making up $2.9 \%$ were established to be scale inefficient in the third and fourth column of Table 6.3. The 14 scale efficient firms comprised of $9(10.6 \%)$ of micro firms and $5(5.9 \%)$ small and medium sized firms in the

\footnotetext{
${ }^{27}$ Size measured by the number of employees. Micro sized firms (1-4 persons, small sized firm(5-20 persons), medium sized firms (21-99 persons)
} 
non standards corrected estimates which is just one firm less than those in the standards corrected estimates. Of the 4 scale inefficient firms, 2(2.4\%) are from micro sized firms and $2(3.6 \%)$ are from small and medium sized firms in both the non standards corrected and standards corrected estimates respectively. This shows that in terms of relative percentages, more small and medium sized firms were scale efficient compared to micro-firms. Regional distribution of firms signify that $4(8.9 \%)$ from the Volta region, $6(16.2 \%)$ of firms from the Eastern region, and $4(6.8 \%)$ of firms from the Greater Accra Region were scale efficient in both non standards corrected and standards corrected estimates correspondingly.

\section{Scale Technology Change}

Scale Technology define as the shape of the technology, Simar and Wilson (1999) is interpreted differently and gives insights into whether changes in the scale of technology are helping firms shifting towards constant returns to scale or making them shifting away from it. This means that firms with estimated scores of scale technology $<1$ are believed to be moving towards constant returns to scale, a sign of technological progress and firms with scores of scale technology $>1$ are believed not to be moving towards constant returns to scale.

Our results in Table 6.4 show that 10.7 per cent of firms appear to be moving towards constant returns to scale compared to 2.9 percent of them that are not moving towards constant returns to scale. For those firms that are moving towards constant returns to scale, they constitute $9(10.6 \%)$ of micro firms and $6(10.9 \%)$ of small and medium sized firms. Those that are not moving towards constant returns to scale comprised of $2(2.4 \%)$ of micro firms and 2(3.6\%) of small and medium sized firms respectively for both non standards corrected and standards corrected estimates.

At the regional level, we have 5(11.1\%) of firms from Volta, $6(16.2 \%)$ from Eastern and 4(6.9\%) from Greater Accra that are moving towards constant returns to scale compared to $0(0 \%), 1(2.7 \%)$ and $3(5.1 \%)$ respectively for those moving away from constant returns to scale. Table 6.8 in appendix 6 shows that firms' number 32, 37, 41 and 44 from the Volta Region all 
statistically significant and firms' 63, 67, 68, 80, 81, and 82 from the Eastern Region and firm 86, 87, 91, 95, 98, and 102 from Greater Accra Region are all statistically significant(non standards corrected scores).

Table 6.3: Scale Efficiency Change Performance across Region and Firm Size between 2002 and 2007

\begin{tabular}{|c|c|c|c|c|}
\hline \multicolumn{3}{|c|}{ Scale Efficient $(\Delta>1)$ Scale Efficient $(\Delta>1)$} & \multicolumn{2}{|c|}{ Scale inefficient $(\Delta<1)$ Scale Inefficient $(\Delta<1)$} \\
\hline & $\begin{array}{l}\text { Standards- } \\
\text { rected }\end{array}$ & $\begin{array}{l}\text { Standards- } \\
\text { Corrected }\end{array}$ & $\begin{array}{l}\text { Non Standards- } \\
\text { Corrected }\end{array}$ & $\begin{array}{l}\text { Standards- } \\
\text { Corrected }\end{array}$ \\
\hline G. Accra Region & $4(6.8 \%)$ & $4(6.8 \%)$ & $3(5.1 \%)$ & $3(5.1 \%)$ \\
\hline Eastern Region & $6(16.2 \%)$ & $6(16.2 \%)$ & $1(2.7 \%)$ & $1(2.7 \%)$ \\
\hline Volta Region & $4(8.9 \%)$ & $5(11.1 \%)$ & $0(0 \%)$ & $0(0 \%)$ \\
\hline Regional Average & $14(10.0 \%)$ & $15(10.7 \%)$ & $4(2.9 \%)$ & $4(2.9 \%)$ \\
\hline Micro-firms & $9(10.6 \%)$ & $9(10.6 \%)$ & $2(2.4 \%)$ & $2(2.4 \%)$ \\
\hline \multicolumn{5}{|l|}{ Small \& } \\
\hline Medium firms & $5(5.9 \%)$ & $6(7.1 \%)$ & $2(3.6 \%)$ & $2(3.6 \%$ \\
\hline Firm-size Average & $14(10.0 \%)$ & $15(10.7 \%)$ & $4(2.9 \%)$ & $4(2.9 \%)$ \\
\hline
\end{tabular}

Table 6.4: Scale Technology Change Performance across Region and Firm Size between 2002 and 2007

\begin{tabular}{|c|c|c|c|c|}
\hline Unit & $\begin{array}{l}\text { Downgrading }(\Delta>1) \\
\text { Non Standards- } \\
\text { Corrected }\end{array}$ & $\begin{array}{l}\text { Downgrading }(\Delta>1) \\
\text { Standards- } \\
\text { Corrected }\end{array}$ & $\begin{array}{l}\text { Upgrading }(\Delta<1) \\
\text { Non Standards- } \\
\text { Corrected }\end{array}$ & $\begin{array}{l}\text { Upgrading }(\Delta<1) \\
\text { Standards- } \\
\text { Corrected } \\
\end{array}$ \\
\hline G. Accra Region & $3(5.1 \%)$ & $3(5.1 \%)$ & $4(6.9 \%)$ & $4(6.9 \%)$ \\
\hline Eastern Region & $1(2.7 \%)$ & $1(2.7 \%)$ & $6(16.2 \%)$ & $6(16.2 \%)$ \\
\hline Volta Region & $0(0 \%)$ & $0(0 \%)$ & $5(11.1 \%)$ & $5(11.1 \%)$ \\
\hline Regional Average & $4(2.9 \%)$ & $4(2.9 \%)$ & $15(10.7 \%)$ & $15(10.7 \%)$ \\
\hline Micro-firms & $2(2.4 \%)$ & $2(2.4 \%)$ & $9(10.6 \%)$ & $9(10.6 \%)$ \\
\hline $\begin{array}{l}\text { Small \& } \\
\text { Medium firms }\end{array}$ & $2(3.6 \%)$ & $2(3.6 \%)$ & $6(10.9 \%)$ & $6(10.9 \%)$ \\
\hline Firm-size Average & e $4(2.9 \%)$ & $4(2.9 \%)$ & $15(10.7 \%)$ & $15(10.7 \%)$ \\
\hline
\end{tabular}




\section{Pure Technical Efficiency across firm size and region groups}

Figure 6.4a: Mean Pure Technical Efficiency Change with 95\% Confidence Bounds(Non Standards Corrected \& Standards Corrected)

Non Standards Corrected Pure Efficiency Change with $95 \%$ confidence bounds

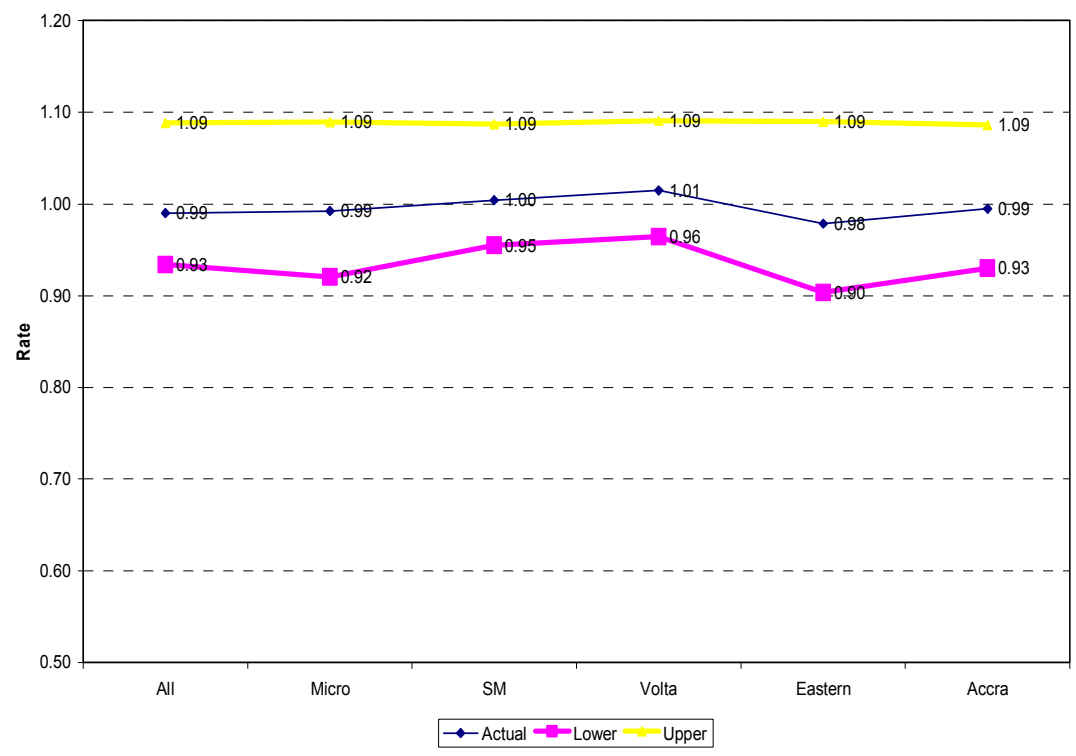

Standards Corrected Pure Technical Efficiency with 95\% Confidence Bounds

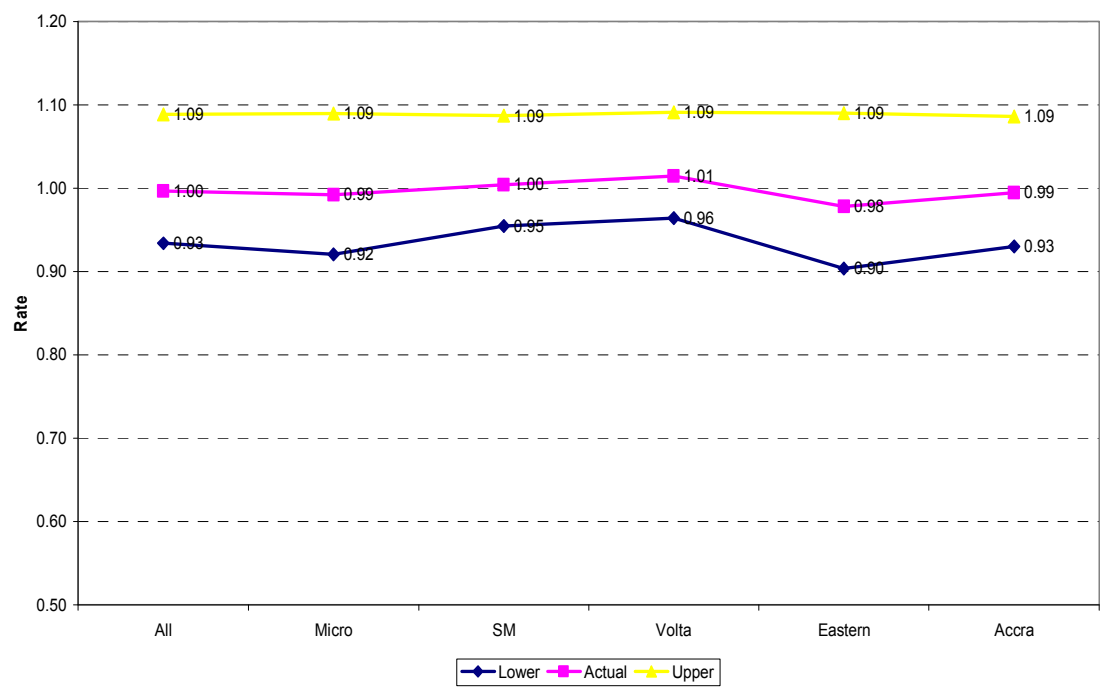

Groups with the confidence interval containing unity are considered not significantly different from unity. Groups are considered to make some gains if their lower confidence bounds are greater than unity and making significant lose if their upper bounds are less than unity. 
Pure Technical Change across firm size and region groups

Figure 6.4b: Mean Pure Technical Change with 95\% Confidence Bounds(Non Standards Corrected \& Standards Corrected)

Non Standards-Corrected Technical Change with 95\% Confidence Bounds

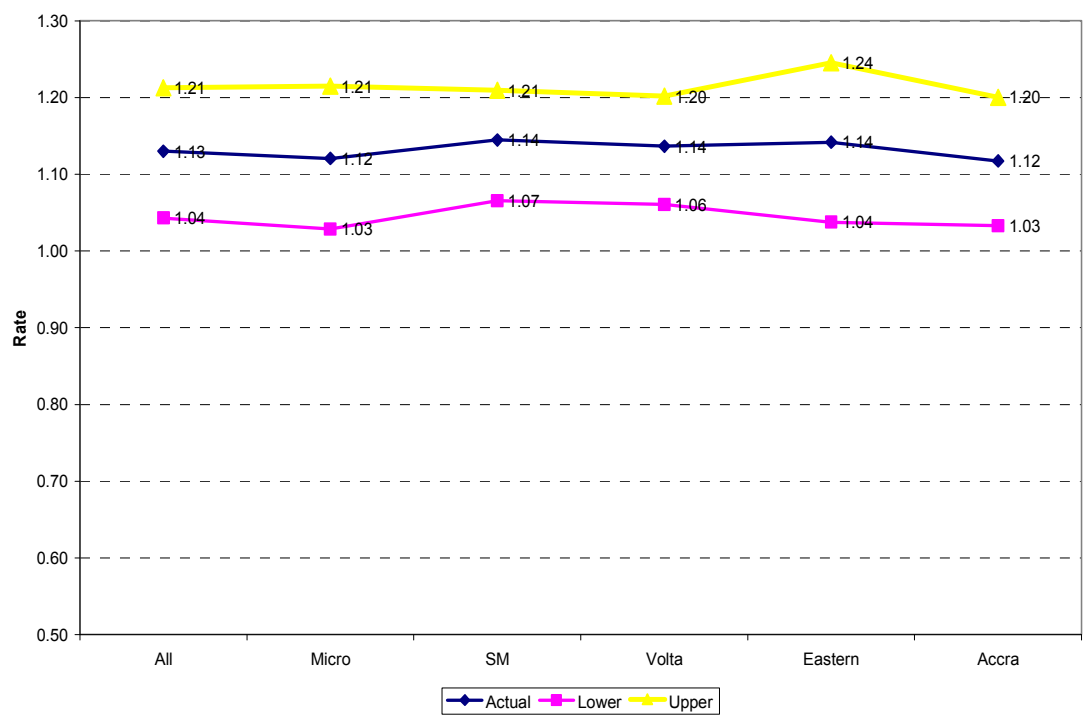

Standards-Corrected Technical Change with 95\% Confidence Bounds

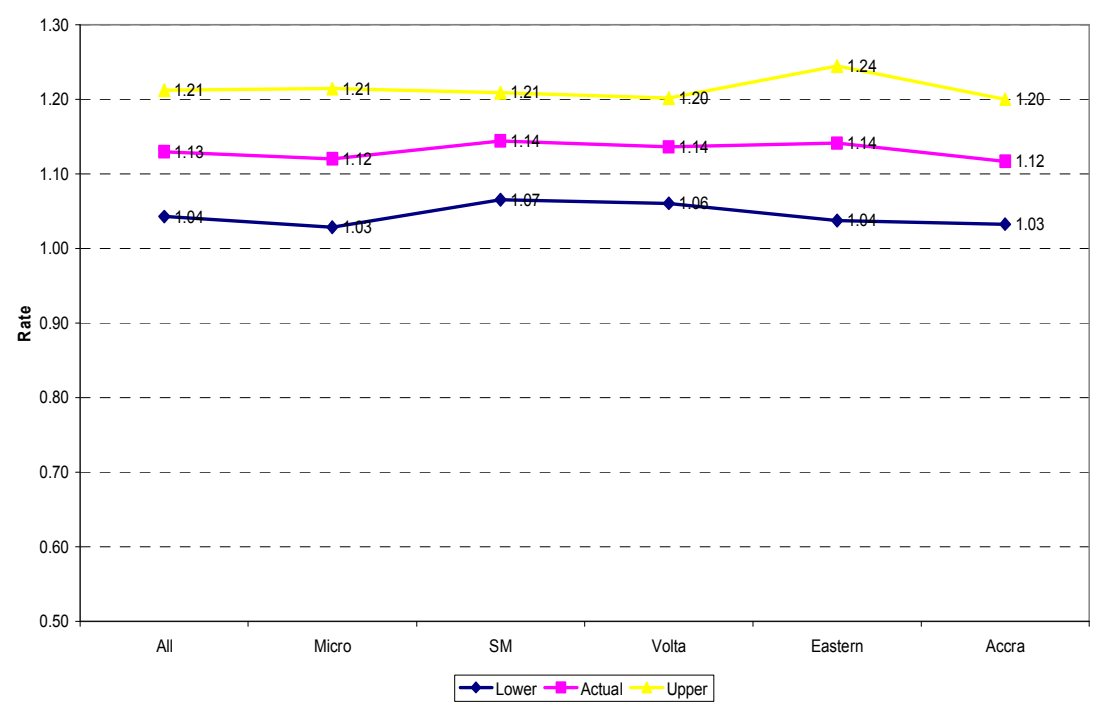

Groups with the confidence interval containing unity are considered not significantly different from unity. Groups are considered to make some gains if their lower confidence bounds are greater than unity and making significant lose if their upper bounds are less than unity. 


\section{Scale efficiency across firm size and region groups}

Figure 6.4c: Mean Scale Efficiency Change with 95\% Confidence Bounds (Non Standards Corrected \& Standards Corrected)

Non Standards Corrected Scale Efficiency Change with 95\% Confidence Bounds

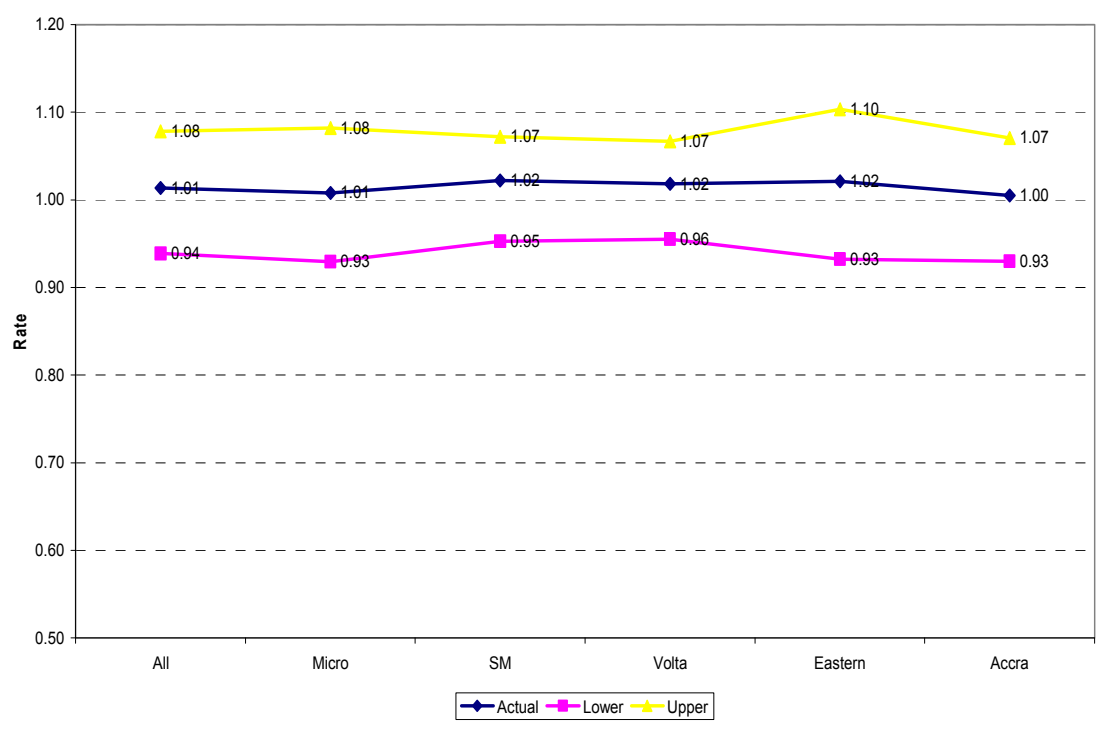

Standards Corrected Scale Efficiency Change with 95\% Confidence Bounds

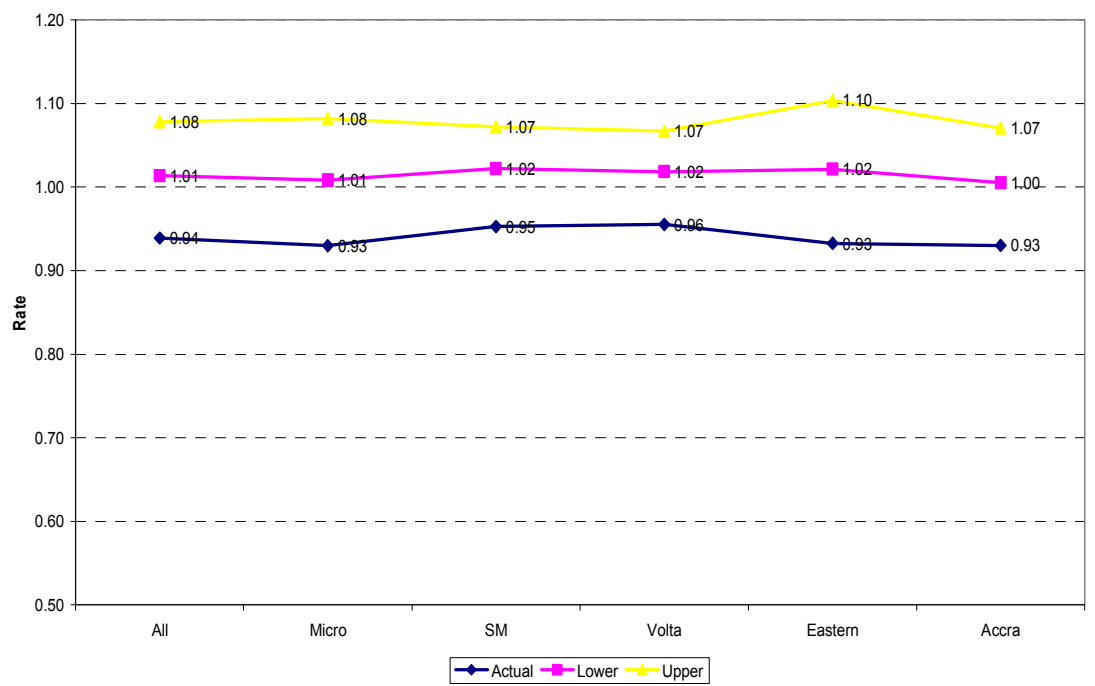

Groups with the confidence interval containing unity are considered not significantly different from unity. Groups are considered to make some gains if their lower confidence bounds are greater than unity and making significant lose if their upper bounds are less than unity. 


\section{Scale technology across size and region groups}

Figure 6.4d: Mean Scale Technology Change with 95\% Confidence Bounds (Non Standards Corrected \& Standards Corrected)

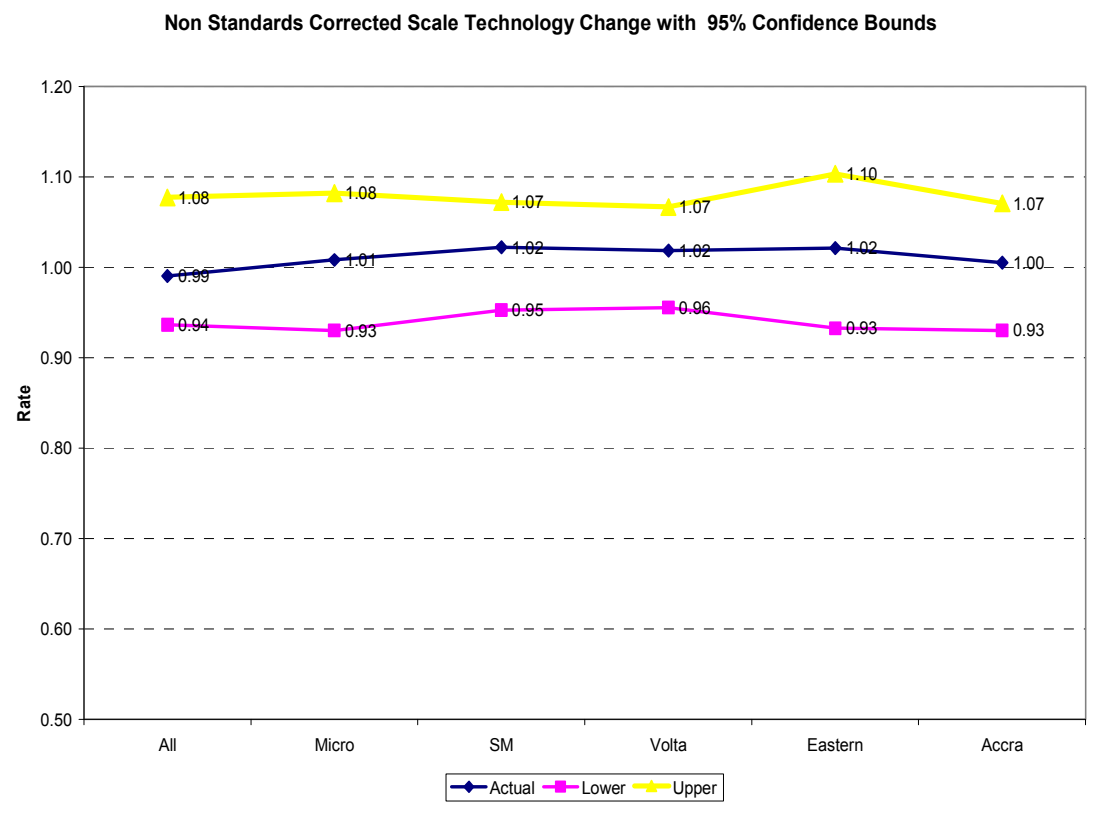

Standards Corrected Scale technology Change with 95\% Confidence Bounds

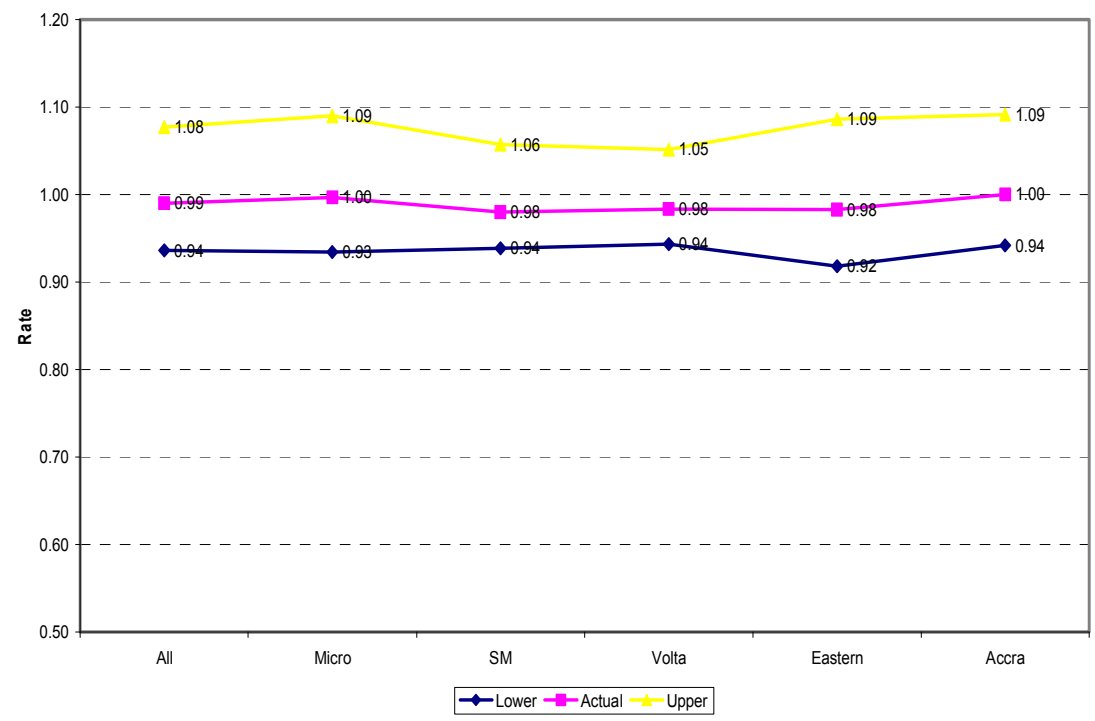

Groups with scale technology $<1$ are believed to be moving towards constant returns to scale, a sign of technological progress and groups with estimates of scale technology $>1$ are believed not to be moving towards constant returns to scale 


\subsection{Summary and Conclusion}

In this Chapter we established that 77.1 per cent of the 140 firms experienced significant pure technical change. Small and medium sized firms appear to have performed better than micro sized firms. On the average, micro firms appear to have upgraded by 12 per cent over the period whilst small and medium sized firms upgraded by 14 percentage points.

Pure technical inefficiencies on the other hand have been established to be widespread. Scale efficiency has basically remained relatively unchanged and a larger number of firms have been scale efficient over the period. Scale technology change referred to as the residual which defines the shape of the technology must be greater than 1 to have the shape of technology flattening and less than 1 to indicate an increasing curvature. Firms on the average had scale technology scores below unity which implies that they are moving towards constant returns to scale which is good news.

In conclusion therefore, we established that there is increasing application of new apparel manufacturing technologies as indicated by widespread pure technical change. Their full positive effects is however being undone by the

pure technical inefficiencies which are widespread among firms in the subsector. 


\section{Appendix 6}

Table 6.5: Confidence intervals obtained based on homogeneous bootstrap procedure(non standards corrected scores)

\begin{tabular}{|c|c|c|c|c|c|c|c|c|c|c|c|}
\hline Firm & $\begin{array}{c}\Delta \text { PPure } \\
\text { Efficiency }\end{array}$ & $\begin{array}{l}\text { Lower } \\
\text { Bound }\end{array}$ & $\begin{array}{l}\text { Upper } \\
\text { Bound }\end{array}$ & Firm & $\begin{array}{l}\text { PPure } \\
\text { Efficiency }\end{array}$ & $\begin{array}{l}\text { Lower } \\
\text { Bound }\end{array}$ & $\begin{array}{l}\text { Upper } \\
\text { Bound }\end{array}$ & Firm & $\begin{array}{c}\Delta \text { Pure } \\
\text { Efficiency }\end{array}$ & $\begin{array}{l}\text { Lower } \\
\text { Bound }\end{array}$ & $\begin{array}{l}\text { Upper } \\
\text { Bound }\end{array}$ \\
\hline 1 & 1.0000 & 0.7629 & 1.3985 & 48 & 0.9704 & 0.9432 & 1.0447 & 95 & $1.2185^{* *}$ & 1.1095 & 1.3617 \\
\hline 2 & $0.8730^{* *}$ & 0.8235 & 0.9401 & 49 & $0.8376^{* *}$ & 0.8155 & 0.8690 & 96 & $0.8886^{* *}$ & 0.8793 & 0.9287 \\
\hline 3 & 0.9826 & 0.9331 & 1.0137 & 50 & 1.0578 & 0.9737 & 1.1736 & 97 & $1.4312^{* *}$ & 1.3838 & 1.5628 \\
\hline 4 & $1.0872^{* *}$ & 1.0709 & 1.1438 & 51 & $0.7762^{* *}$ & 0.7454 & 0.7905 & 98 & 1.0000 & 0.7478 & 1.3892 \\
\hline 5 & 1.0000 & 0.9777 & 1.0339 & 52 & $0.7540^{* *}$ & 0.6596 & 0.8325 & 99 & $0.7908^{* *}$ & 0.7736 & 0.8195 \\
\hline 6 & $1.1836^{* *}$ & 1.1589 & 1.2551 & 53 & 1.0000 & 0.7489 & 1.3824 & 100 & $0.7261^{* *}$ & 0.7134 & 0.7560 \\
\hline 7 & 0.9848 & 0.9246 & 1.0292 & 54 & $1.1649^{* *}$ & 1.1001 & 1.2035 & 101 & 0.9207 & 0.8322 & 1.0005 \\
\hline 8 & $1.0730^{* *}$ & 1.0405 & 1.1659 & 55 & $0.8185^{* *}$ & 0.7972 & 0.8687 & 102 & $0.8197^{* *}$ & 0.8183 & 0.8556 \\
\hline 9 & 0.9572 & 0.8839 & 1.0671 & 56 & 1.0000 & 0.7579 & 1.3805 & 103 & $0.8917^{* *}$ & 0.8723 & 0.9302 \\
\hline 10 & $0.8153^{* *}$ & 0.7908 & 0.8566 & 57 & 1.1565 & 0.9864 & 1.3941 & 104 & $1.1417^{* *}$ & 1.1320 & 1.1825 \\
\hline 11 & $1.0422^{* *}$ & 1.0170 & 1.0778 & 58 & $1.3628^{* *}$ & 1.3500 & 1.4643 & 105 & $1.1060^{* *}$ & 1.0524 & 1.1802 \\
\hline 12 & $0.8797^{* *}$ & 0.7955 & 0.9670 & 59 & $1.1330^{* *}$ & 1.1157 & 1.1889 & 106 & $1.1146^{* *}$ & 1.0411 & 1.2050 \\
\hline 13 & $0.8184^{* *}$ & 0.8013 & 0.8557 & 60 & 1.0000 & 0.7506 & 1.3818 & 107 & $0.9168^{* *}$ & 0.8174 & 0.9694 \\
\hline 14 & $1.1605^{* *}$ & 1.1026 & 1.2589 & 61 & 0.9565 & 0.8703 & 1.0150 & 108 & $0.9267^{* *}$ & 0.9045 & 0.9495 \\
\hline 15 & 1.0000 & 0.7548 & 1.3877 & 62 & $1.4571^{* *}$ & 1.3975 & 1.5369 & 109 & $0.9376^{* *}$ & 0.8665 & 0.9808 \\
\hline 16 & $1.6031^{* *}$ & 1.5589 & 1.6515 & 63 & $0.5978^{* *}$ & 0.5903 & 0.6424 & 110 & $1.2948^{* *}$ & 1.2694 & 1.3334 \\
\hline 17 & $1.2225^{* *}$ & 1.1319 & 1.3618 & 64 & $1.1874^{* *}$ & 1.1505 & 1.2102 & 111 & 1.0000 & 0.7486 & 1.3928 \\
\hline 18 & $1.1124^{* *}$ & 1.0007 & 1.2198 & 65 & $0.9574^{* *}$ & 0.9109 & 0.9962 & 112 & $1.0468^{* *}$ & 1.0159 & 1.1227 \\
\hline 19 & 0.9845 & 0.9554 & 1.0409 & 66 & $0.9332^{* *}$ & 0.9168 & 0.9627 & 113 & 1.0000 & 0.7551 & 1.2945 \\
\hline 20 & $1.2475^{* *}$ & 1.2154 & 1.3191 & 67 & 0.9878 & 0.9759 & 1.0261 & 114 & $0.7693^{* *}$ & 0.7576 & 0.8085 \\
\hline 21 & 1.0198 & 0.9939 & 1.0929 & 68 & $0.7193^{* *}$ & 0.7004 & 0.7465 & 115 & $0.8678^{* *}$ & 0.8502 & 0.9109 \\
\hline 22 & $1.2059^{* *}$ & 1.1602 & 1.2322 & 69 & $0.8547^{* *}$ & 0.8352 & 0.8842 & 116 & $1.1757^{* *}$ & 1.0979 & 1.2288 \\
\hline 23 & $1.0985^{* *}$ & 1.0767 & 1.1637 & 70 & $0.8497^{* *}$ & 0.7933 & 0.9041 & 117 & $1.1368^{* *}$ & 1.1101 & 1.1860 \\
\hline 24 & $0.8912^{* *}$ & 0.8536 & 0.9217 & 71 & 1.0000 & 0.7761 & 1.2427 & 118 & 0.9305 & 0.8242 & 1.0634 \\
\hline 25 & $0.7634^{* *}$ & 0.7510 & 0.8084 & 72 & $0.8305^{* *}$ & 0.8050 & 0.8670 & 119 & $1.1169^{* *}$ & 1.1031 & 1.1719 \\
\hline 26 & $0.7793^{* *}$ & 0.7581 & 0.7976 & 73 & 1.0000 & 0.7410 & 1.3777 & 120 & $1.1073^{* *}$ & 1.0725 & 1.1729 \\
\hline 27 & $0.8866^{* *}$ & 0.8734 & 0.9186 & 74 & 0.9989 & 0.9314 & 1.0411 & 121 & $1.3754^{* *}$ & 1.2348 & 1.5357 \\
\hline 28 & $0.8936^{* *}$ & 0.8541 & 0.9164 & 75 & $0.8534^{* *}$ & 0.8152 & 0.8651 & 122 & $0.8115^{* *}$ & 0.7838 & 0.8305 \\
\hline 29 & 0.9495 & 0.9282 & 1.0120 & 76 & $1.0937^{* *}$ & 1.0561 & 1.1873 & 123 & 1.0500 & 0.9850 & 1.1303 \\
\hline 30 & $1.2606^{* *}$ & 1.1917 & 1.3224 & 77 & $1.1153^{* *}$ & 1.1024 & 1.1699 & 124 & $1.1413^{* *}$ & 1.1145 & 1.1795 \\
\hline 31 & $0.9380^{* *}$ & 0.8525 & 0.9753 & 78 & $1.3609^{* *}$ & 1.2712 & 1.5769 & 125 & 1.0000 & 0.7462 & 1.4137 \\
\hline 32 & $1.4624^{* *}$ & 1.4402 & 1.5781 & 79 & 1.0014 & 0.9555 & 1.0545 & 126 & 0.9943 & 0.8298 & 1.1345 \\
\hline 33 & $0.8543^{* *}$ & 0.8178 & 0.9081 & 80 & 1.0000 & 0.7553 & 1.4066 & 127 & $0.8377^{* *}$ & 0.8185 & 0.8637 \\
\hline 34 & $0.8403^{* *}$ & 0.7451 & 0.9939 & 81 & $1.0880^{* *}$ & 1.0437 & 1.1738 & 128 & $0.9383^{* *}$ & 0.9128 & 0.9986 \\
\hline 35 & 1.0252 & 0.9547 & 1.1783 & 82 & $1.0618^{* *}$ & 1.0502 & 1.1483 & 129 & $1.2577^{* *}$ & 1.2419 & 1.3228 \\
\hline 36 & $1.2043^{* *}$ & 1.1543 & 1.2419 & 83 & $1.0980^{* *}$ & 1.0073 & 1.2195 & 130 & $0.6421^{* *}$ & 0.6031 & 0.6682 \\
\hline 37 & $0.8985^{* *}$ & 0.8919 & 0.9337 & 84 & 0.9715 & 0.9426 & 1.0459 & 131 & $0.8786^{* *}$ & 0.8570 & 0.9064 \\
\hline 38 & 0.9574 & 0.8005 & 1.1059 & 85 & $1.1413^{* *}$ & 1.1035 & 1.2194 & 132 & 1.0000 & 0.7545 & 1.3943 \\
\hline 39 & 0.8420 & 0.8087 & 0.8613 & 86 & $1.1464^{* *}$ & 1.1305 & 1.1940 & 133 & $0.8654^{* *}$ & 0.8365 & 0.8831 \\
\hline 40 & 0.9743 & 0.9628 & 1.0038 & 87 & $0.7708^{* *}$ & 0.7596 & 0.8277 & 134 & $1.0468^{* *}$ & 1.0220 & 1.0923 \\
\hline 41 & $0.8987^{* *}$ & 0.8922 & 0.9339 & 88 & $0.8895^{* *}$ & 0.7586 & 0.9867 & 135 & 1.0153 & 0.9955 & 1.0380 \\
\hline 42 & $1.0465^{* *}$ & 1.0366 & 1.0905 & 89 & $0.8805^{* *}$ & 0.8206 & 0.9548 & 136 & 1.0065 & 0.9564 & 1.0573 \\
\hline 43 & $0.9367^{* *}$ & 0.9116 & 0.9615 & 90 & 0.9839 & 0.9634 & 1.0193 & 137 & $1.0776^{* *}$ & 1.0447 & 1.1247 \\
\hline 44 & $1.1077^{* *}$ & 1.0916 & 1.1529 & 91 & $0.7951^{* *}$ & 0.7843 & 0.8196 & 138 & $0.7496^{* *}$ & 0.7114 & 0.7982 \\
\hline 45 & $0.8963^{* *}$ & 0.8799 & 0.9339 & 92 & $1.2429^{* *}$ & 1.2140 & 1.2870 & 139 & $0.7305^{* *}$ & 0.6962 & 0.7467 \\
\hline 46 & $0.5799^{* *}$ & 0.5664 & 0.6058 & 93 & 1.0000 & 0.7719 & 1.3417 & 140 & $0.9005^{* *}$ & 0.8492 & 0.9782 \\
\hline 47 & $0.6806^{* *}$ & 0.6626 & 0.7010 & 94 & $1.1637^{* *}$ & 1.1385 & 1.2035 & & & & \\
\hline
\end{tabular}

Firm 1-45 from Volta Region, 46-82 from Eastern and 83-140 from Greater Accra 
Table 6.6: Confidence intervals obtained based on homogeneous bootstrap procedure(non standards corrected scores)

\begin{tabular}{|c|c|c|c|c|c|c|c|c|c|c|c|}
\hline \multicolumn{12}{|c|}{ Estimation of Pure Technical Change of firms between 2002 and 2007 (2000 bootstrap replications) } \\
\hline Firm & $\begin{array}{l}\Delta \text { PPure } \\
\text { Technology }\end{array}$ & $\begin{array}{l}\text { Lower } \\
\text { Bound }\end{array}$ & $\begin{array}{l}\text { Upper } \\
\text { Bound }\end{array}$ & Firm & $\begin{array}{l}\Delta \text { PPure } \\
\text { Technology }\end{array}$ & $\begin{array}{l}\text { Lower } \\
\text { Bound }\end{array}$ & $\begin{array}{l}\text { Upper } \\
\text { Bound }\end{array}$ & Firm & $\begin{array}{l}\Delta \text { Pure } \\
\text { Technology }\end{array}$ & $\begin{array}{l}\text { Lower } \\
\text { Bound }\end{array}$ & $\begin{array}{l}\text { Upper } \\
\text { Bound }\end{array}$ \\
\hline 1 & 1.0797 & 0.7721 & 1.4153 & 48 & $1.1736^{* *}$ & 1.0901 & 1.2074 & 95 & 0.9783 & 0.8754 & 1.0744 \\
\hline 2 & $1.1422^{* *}$ & 1.0605 & 1.2108 & 49 & $1.1646^{* *}$ & 1.1225 & 1.1961 & 96 & $1.1746^{* *}$ & 1.1238 & 1.1870 \\
\hline 3 & $1.0897^{* *}$ & 1.0562 & 1.1475 & 50 & $1.2092 * *$ & 1.0899 & 1.3136 & 97 & $1.0986^{* *}$ & 1.0061 & 1.1363 \\
\hline 4 & $1.1354^{* *}$ & 1.0792 & 1.1527 & 51 & $1.1307^{* *}$ & 1.1102 & 1.1774 & 98 & $0.7383^{* *}$ & 0.5315 & 0.9874 \\
\hline 5 & $1.1528^{* *}$ & 1.1151 & 1.1791 & 52 & $1.1195^{* *}$ & 1.0140 & 1.2796 & 99 & $1.1686^{* *}$ & 1.1277 & 1.1945 \\
\hline 6 & $1.1507^{* *}$ & 1.0852 & 1.1753 & 53 & 1.1214 & 0.8112 & 1.4974 & 100 & $1.1547^{* *}$ & 1.1090 & 1.1754 \\
\hline 7 & $1.1164^{* *}$ & 1.0683 & 1.1891 & 54 & 1.0327 & 0.9996 & 1.0936 & 101 & 1.0802 & 0.9940 & 1.1951 \\
\hline 8 & $1.1480^{* *}$ & 1.0564 & 1.1837 & 55 & $1.1444^{* *}$ & 1.0783 & 1.1750 & 102 & $1.1897^{* *}$ & 1.1398 & 1.1917 \\
\hline 9 & $1.1306^{* *}$ & 1.0141 & 1.2243 & 56 & 1.0683 & 0.7738 & 1.4096 & 103 & $1.1434^{* *}$ & 1.0961 & 1.1690 \\
\hline 10 & $1.1377^{* *}$ & 1.0828 & 1.1730 & 57 & 1.0812 & 0.8970 & 1.2676 & 104 & $1.1577^{* *}$ & 1.1178 & 1.1676 \\
\hline 11 & $1.1568^{* *}$ & 1.1185 & 1.1855 & 58 & $1.2065^{* *}$ & 1.1228 & 1.2178 & 105 & $1.0779^{* *}$ & 1.0101 & 1.1328 \\
\hline 12 & 1.0403 & 0.9464 & 1.1504 & 59 & $1.1720^{* *}$ & 1.1169 & 1.1903 & 106 & 1.0367 & 0.9589 & 1.1098 \\
\hline 13 & $1.1501^{* *}$ & 1.0999 & 1.1745 & 60 & 1.0569 & 0.7649 & 1.4081 & 107 & 1.0548 & 0.9976 & 1.1831 \\
\hline 14 & $1.0981^{* *}$ & 1.0122 & 1.1558 & 61 & $1.0640^{* *}$ & 1.0027 & 1.1694 & 108 & $1.1487^{* *}$ & 1.1211 & 1.1768 \\
\hline 15 & $1.4075^{* *}$ & 1.0143 & 1.8648 & 62 & $1.1528^{* *}$ & 1.0930 & 1.2020 & 109 & $1.0619^{* *}$ & 1.0151 & 1.1491 \\
\hline 16 & $1.0990^{* *}$ & 1.0668 & 1.1301 & 63 & $1.1964^{* *}$ & 1.1134 & 1.2117 & 110 & $1.1594^{* *}$ & 1.1257 & 1.1825 \\
\hline 17 & 1.0353 & 0.9294 & 1.1181 & 64 & $1.1417^{* *}$ & 1.1201 & 1.1782 & 111 & 1.2370 & 0.8881 & 1.6523 \\
\hline 18 & $1.1001^{* *}$ & 1.0033 & 1.2230 & 65 & $1.1343^{* *}$ & 1.0901 & 1.1922 & 112 & $1.1627^{* *}$ & 1.0841 & 1.1980 \\
\hline 19 & $1.1145^{* *}$ & 1.0541 & 1.1484 & 66 & $1.1648^{* *}$ & 1.1292 & 1.1858 & 113 & 1.0913 & 0.8430 & 1.4453 \\
\hline 20 & $1.1648^{* *}$ & 1.1017 & 1.1957 & 67 & $1.1781^{* *}$ & 1.1342 & 1.1925 & 114 & $1.1750^{* *}$ & 1.1181 & 1.1932 \\
\hline 21 & $1.1352^{* *}$ & 1.0593 & 1.1647 & 68 & $1.1433^{* *}$ & 1.1016 & 1.1741 & 115 & $1.1496^{* *}$ & 1.0952 & 1.1734 \\
\hline 22 & $1.1291^{* *}$ & 1.1050 & 1.1735 & 69 & $1.1614^{* *}$ & 1.1227 & 1.1886 & 116 & $1.1171^{* *}$ & 1.0688 & 1.1961 \\
\hline 23 & $1.1803^{* *}$ & 1.1141 & 1.2041 & 70 & 1.0452 & 0.9824 & 1.1196 & 117 & $1.1226^{* *}$ & 1.0760 & 1.1495 \\
\hline 24 & $1.0817^{* *}$ & 1.0458 & 1.1293 & 71 & 1.0412 & 0.8379 & 1.3415 & 118 & $1.1702^{* *}$ & 1.0240 & 1.3212 \\
\hline 25 & $1.1515^{* *}$ & 1.0875 & 1.1705 & 72 & $1.1568^{* *}$ & 1.1081 & 1.1935 & 119 & $1.1235^{* *}$ & 1.0707 & 1.1375 \\
\hline 26 & $1.1442^{* *}$ & 1.1179 & 1.1762 & 73 & 1.0393 & 0.7543 & 1.4026 & 120 & $1.1253^{* *}$ & 1.0623 & 1.1617 \\
\hline 27 & $1.1475^{* *}$ & 1.1076 & 1.1649 & 74 & 1.0357 & 0.9938 & 1.1108 & 121 & 1.0559 & 0.9457 & 1.1761 \\
\hline 28 & $1.1238^{* *}$ & 1.0959 & 1.1758 & 75 & $1.1247^{* *}$ & 1.1095 & 1.1774 & 122 & $1.1454^{* *}$ & 1.1193 & 1.1858 \\
\hline 29 & $1.1775^{* *}$ & 1.1048 & 1.2045 & 76 & $1.1883^{* *}$ & 1.0946 & 1.2306 & 123 & 1.0318 & 0.9585 & 1.0999 \\
\hline 30 & $1.1260^{* *}$ & 1.0733 & 1.1910 & 77 & $1.1472^{* *}$ & 1.0936 & 1.1605 & 124 & $1.1558^{* *}$ & 1.1185 & 1.1836 \\
\hline 31 & 1.0070 & 0.9686 & 1.1081 & 78 & $1.2285^{* *}$ & 1.0602 & 1.3152 & 125 & 1.2406 & 0.8775 & 1.6626 \\
\hline 32 & $1.1806^{* *}$ & 1.0939 & 1.1987 & 79 & $1.1180^{* *}$ & 1.0616 & 1.1716 & 126 & 0.9547 & 0.8368 & 1.1440 \\
\hline 33 & $1.1185^{* *}$ & 1.0522 & 1.1684 & 80 & $1.5508^{* *}$ & 1.1025 & 2.0533 & 127 & $1.1592^{* *}$ & 1.1243 & 1.1864 \\
\hline 34 & 1.0750 & 0.9089 & 1.2123 & 81 & 1.0687 & 0.9906 & 1.1141 & 128 & $1.1577^{* *}$ & 1.0878 & 1.1900 \\
\hline 35 & 1.1069 & 0.9631 & 1.1887 & 82 & $1.1984^{* *}$ & 1.1081 & 1.2116 & 129 & $1.1497^{* *}$ & 1.0931 & 1.1644 \\
\hline 36 & $1.1291^{* *}$ & 1.0949 & 1.1780 & 83 & 1.0033 & 0.9034 & 1.0936 & 130 & $1.1054^{* *}$ & 1.0623 & 1.1770 \\
\hline 37 & $1.1784^{* *}$ & 1.1340 & 1.1871 & 84 & $1.1112^{* *}$ & 1.0322 & 1.1452 & 131 & $1.1496^{* *}$ & 1.1144 & 1.1787 \\
\hline 38 & $1.1819^{* *}$ & 1.0232 & 1.4135 & 85 & $1.0979^{* *}$ & 1.0276 & 1.1355 & 132 & 1.0734 & 0.7698 & 1.4227 \\
\hline 39 & $1.1341^{* *}$ & 1.1088 & 1.1809 & 86 & $1.1788^{* *}$ & 1.1317 & 1.1954 & 133 & $1.1338^{* *}$ & 1.1110 & 1.1729 \\
\hline 40 & $1.1722^{* *}$ & 1.1377 & 1.1862 & 87 & $1.1847^{* *}$ & 1.1033 & 1.2022 & 134 & $1.1686^{* *}$ & 1.1199 & 1.1969 \\
\hline 41 & $1.1789^{* *}$ & 1.1344 & 1.1875 & 88 & $1.1222^{* *}$ & 1.0117 & 1.3160 & 135 & $1.1584^{* *}$ & 1.1332 & 1.1815 \\
\hline 42 & $1.1369^{* *}$ & 1.0911 & 1.1478 & 89 & 1.0627 & 0.9800 & 1.1403 & 136 & 1.0353 & 0.9855 & 1.0895 \\
\hline 43 & $1.1354^{* *}$ & 1.1061 & 1.1666 & 90 & $1.1082^{* *}$ & 1.0697 & 1.1318 & 137 & $1.1300^{* *}$ & 1.0827 & 1.1656 \\
\hline 44 & $1.1784^{* *}$ & 1.1322 & 1.1958 & 91 & $1.1724^{* *}$ & 1.1374 & 1.1886 & 138 & $1.0653^{* *}$ & 1.0005 & 1.1226 \\
\hline 45 & $1.1708^{* *}$ & 1.1237 & 1.1926 & 92 & $1.1658^{* *}$ & 1.1259 & 1.1936 & 139 & $1.1201^{* *}$ & 1.0959 & 1.1753 \\
\hline 46 & $1.1445^{* *}$ & 1.0957 & 1.1719 & 93 & 1.2357 & 0.9210 & 1.6007 & 140 & $1.0916^{* *}$ & 1.0049 & 1.1575 \\
\hline 47 & $1.1213^{* *}$ & 1.0886 & 1.1518 & 94 & $1.1577^{* *}$ & 1.1194 & 1.1833 & & & & \\
\hline
\end{tabular}

Firm 1-45 from Volta Region, 46-82 from Eastern and 83-140 from Greater Accra 
Table 6.7: Confidence intervals obtained based on homogeneous bootstrap procedure(non standards corrected scores)

\begin{tabular}{|c|c|c|c|c|c|c|c|c|c|c|c|}
\hline \multicolumn{12}{|c|}{ Estimation of change in Scale Efficiency of firms between 2002 and 2007 (2000 bootstrap replications) } \\
\hline Firm & $\begin{array}{l}\Delta \text { Scale } \\
\text { Efficiency }\end{array}$ & $\begin{array}{l}\text { Lower } \\
\text { Bound }\end{array}$ & $\begin{array}{l}\text { Upper } \\
\text { Bound }\end{array}$ & Firm & $\begin{array}{l}\Delta \text { Scale } \\
\text { Efficiency }\end{array}$ & $\begin{array}{l}\text { Lower } \\
\text { Bound }\end{array}$ & $\begin{array}{l}\text { Upper } \\
\text { Bound }\end{array}$ & Firm & $\begin{array}{l}\Delta \text { Scale } \\
\text { Efficiency }\end{array}$ & $\begin{array}{l}\text { Lower } \\
\text { Bound }\end{array}$ & $\begin{array}{l}\text { Upper } \\
\text { Bound }\end{array}$ \\
\hline 1 & 0.9982 & 0.6997 & 1.2450 & 48 & 1.0192 & 0.9890 & 1.0164 & 95 & $0.8806^{* *}$ & 0.7846 & 0.9701 \\
\hline 2 & 0.9945 & 0.9579 & 1.0338 & 49 & 1.0265 & 0.9799 & 1.0583 & 96 & 1.0463 & 0.9965 & 1.0505 \\
\hline 3 & 0.9816 & 0.9703 & 1.0225 & 50 & 1.0636 & 0.9602 & 1.1522 & 97 & 0.9983 & 0.9156 & 1.0064 \\
\hline 4 & 1.0007 & 0.9669 & 1.0150 & 51 & 1.0080 & 0.9763 & 1.0557 & 98 & $0.6551^{* *}$ & 0.4776 & 0.8764 \\
\hline 5 & 1.0326 & 0.9966 & 1.0691 & 52 & 0.9993 & 0.9448 & 1.0670 & 99 & 1.0384 & 0.9887 & 1.0664 \\
\hline 6 & 1.0359 & 0.9834 & 1.0335 & 53 & 0.9988 & 0.7140 & 1.3343 & 100 & 1.0243 & 0.9868 & 1.0275 \\
\hline 7 & 0.9970 & 0.9762 & 1.0144 & 54 & 0.9654 & 0.9360 & 1.0016 & 101 & 0.9694 & 0.8994 & 1.0565 \\
\hline 8 & 1.0109 & 0.9734 & 1.0119 & 55 & 1.0139 & 0.9753 & 1.0140 & 102 & $1.0582^{* *}$ & 1.0068 & 1.0616 \\
\hline 9 & 0.9962 & 0.9052 & 1.0761 & 56 & 0.9510 & 0.6873 & 1.2588 & 103 & 1.0254 & 0.9846 & 1.0278 \\
\hline 10 & 1.0305 & 1.0000 & 1.0503 & 57 & 0.9985 & 0.8203 & 1.1123 & 104 & 1.0320 & 0.9940 & 1.0314 \\
\hline 11 & 1.0254 & 0.9820 & 1.0592 & 58 & 1.0629 & 0.9881 & 1.0596 & 105 & 0.9872 & 0.9285 & 1.0074 \\
\hline 12 & 0.9337 & 0.8606 & 1.0374 & 59 & 1.0623 & 0.9915 & 1.0651 & 106 & 0.9952 & 0.9046 & 1.0392 \\
\hline 13 & 1.0113 & 0.9770 & 1.0149 & 60 & 0.9851 & 0.7013 & 1.3039 & 107 & 0.9966 & 0.9806 & 1.0272 \\
\hline 14 & 0.9777 & 0.9064 & 1.0155 & 61 & 0.9793 & 0.9427 & 1.0392 & 108 & 1.0270 & 0.9821 & 1.0587 \\
\hline 15 & 1.2398 & 0.8817 & 1.6412 & 62 & 0.9771 & 0.9564 & 1.0218 & 109 & 0.9952 & 0.9655 & 1.0264 \\
\hline 16 & 1.0236 & 0.9969 & 1.0322 & 63 & $1.0489^{* *}$ & 1.0079 & 1.0539 & 110 & 1.0163 & 0.9919 & 1.0600 \\
\hline 17 & 0.9778 & 0.8698 & 1.0431 & 64 & 1.0217 & 0.9854 & 1.0613 & 111 & 1.1156 & 0.7909 & 1.4765 \\
\hline 18 & 0.9846 & 0.8961 & 1.0698 & 65 & 0.9750 & 0.9446 & 1.0400 & 112 & 1.0194 & 0.9859 & 1.0150 \\
\hline 19 & 1.0142 & 0.9689 & 1.0252 & 66 & 1.0223 & 0.9999 & 1.0646 & 113 & 1.0199 & 0.7842 & 1.3278 \\
\hline 20 & 1.0404 & 0.9820 & 1.0440 & 67 & $1.0437^{* *}$ & 1.0055 & 1.0618 & 114 & 1.0801 & 0.9911 & 1.0826 \\
\hline 21 & 1.0232 & 0.9634 & 1.0197 & 68 & $1.0399^{* *}$ & 1.0043 & 1.0636 & 115 & 1.0391 & 0.9801 & 1.0373 \\
\hline 22 & 0.9848 & 0.9634 & 1.0596 & 69 & 1.0278 & 0.9900 & 1.0650 & 116 & 0.9932 & 0.9731 & 1.0228 \\
\hline 23 & 1.0474 & 0.9844 & 1.0558 & 70 & 0.9668 & 0.8969 & 1.0302 & 117 & 1.0001 & 0.9618 & 1.0094 \\
\hline 24 & 1.0083 & 0.9903 & 1.0205 & 71 & 0.9418 & 0.7529 & 1.1859 & 118 & 1.0365 & 0.8997 & 1.1668 \\
\hline 25 & 1.0458 & 0.9922 & 1.0472 & 72 & 1.0060 & 0.9786 & 1.0412 & 119 & 1.0194 & 0.9765 & 1.0162 \\
\hline 26 & 1.0144 & 0.9890 & 1.0611 & 73 & 0.9892 & 0.7005 & 1.3069 & 120 & 0.9873 & 0.9696 & 1.0083 \\
\hline 27 & 1.0381 & 0.9984 & 1.0543 & 74 & 0.9979 & 0.9567 & 1.0138 & 121 & 0.9651 & 0.8559 & 1.0788 \\
\hline 28 & 0.9938 & 0.9654 & 1.0658 & 75 & 1.0027 & 0.9751 & 1.0562 & 122 & 1.0168 & 0.9810 & 1.0561 \\
\hline 29 & 1.0412 & 0.9775 & 1.0524 & 76 & 1.0460 & 0.9693 & 1.0765 & 123 & 0.9861 & 0.9028 & 1.0282 \\
\hline 30 & 1.0054 & 0.9850 & 1.0129 & 77 & 1.0121 & 0.9763 & 1.0189 & 124 & 1.0243 & 0.9836 & 1.0597 \\
\hline 31 & 0.9649 & 0.9226 & 1.0033 & 78 & 1.0402 & 0.9385 & 1.1012 & 125 & 1.0919 & 0.7792 & 1.4882 \\
\hline 32 & $1.0568^{* *}$ & 1.0045 & 1.0692 & 79 & 1.0314 & 0.9648 & 1.0330 & 126 & 0.8666 & 0.7608 & 1.0351 \\
\hline 33 & 1.0146 & 0.9628 & 1.0142 & 80 & $1.3930^{* *}$ & 1.0027 & 1.8549 & 127 & 1.0280 & 0.9902 & 1.0642 \\
\hline 34 & 0.9698 & 0.8280 & 1.0945 & 81 & $0.9529^{* *}$ & 0.8908 & 0.9995 & 128 & 1.0627 & 0.9988 & 1.0757 \\
\hline 35 & 0.9807 & 0.8618 & 1.0558 & 82 & $1.0388^{* *}$ & 1.0030 & 1.0434 & 129 & 1.0159 & 0.9788 & 1.0144 \\
\hline 36 & 1.0088 & 0.9771 & 1.0694 & 83 & $0.9035^{* *}$ & 0.8112 & 0.9874 & 130 & 0.9876 & 0.9590 & 1.0244 \\
\hline 37 & $1.0469^{* *}$ & 1.0018 & 1.0496 & 84 & 1.0097 & 0.9429 & 1.0119 & 131 & 1.0340 & 0.9991 & 1.0725 \\
\hline 38 & 1.0559 & 0.9039 & 1.2570 & 85 & 0.9807 & 0.9275 & 1.0075 & 132 & 0.9693 & 0.7028 & 1.2841 \\
\hline 39 & 1.0001 & 0.9685 & 1.0534 & 86 & $1.0392^{* *}$ & 1.0059 & 1.0606 & 133 & 1.0061 & 0.9796 & 1.0635 \\
\hline 40 & 1.0434 & 1.0000 & 1.0653 & 87 & $1.0624^{* *}$ & 1.0029 & 1.0695 & 134 & 1.0349 & 0.9828 & 1.0680 \\
\hline 41 & $1.0474^{* *}$ & 1.0021 & 1.0502 & 88 & 0.9931 & 0.9125 & 1.1437 & 135 & 1.0350 & 0.9955 & 1.0645 \\
\hline 42 & 1.0176 & 0.9923 & 1.0290 & 89 & 0.9427 & 0.8747 & 1.0116 & 136 & 0.9776 & 0.9226 & 1.0086 \\
\hline 43 & 1.0287 & 0.9987 & 1.0645 & 90 & 1.0192 & 0.9944 & 1.0256 & 137 & 1.0355 & 0.9785 & 1.0313 \\
\hline 44 & $1.0452^{* *}$ & 1.0083 & 1.0751 & 91 & $1.0481^{* *}$ & 1.0020 & 1.0667 & 138 & 0.9737 & 0.9161 & 1.0049 \\
\hline 45 & 1.0341 & 0.9943 & 1.0467 & 92 & 1.0358 & 0.9868 & 1.0653 & 139 & 1.0029 & 0.9778 & 1.0681 \\
\hline 46 & 1.0448 & 0.9906 & 1.0406 & 93 & 1.0764 & 0.8319 & 1.4054 & 140 & 0.9847 & 0.9111 & 1.0256 \\
\hline 47 & $1.0338^{* *}$ & 1.0009 & 1.0523 & 94 & 1.0227 & 0.9928 & 1.0690 & & & & \\
\hline
\end{tabular}

Firm 1-45 from Volta Region, 46-82 from Eastern and 83-140 from Greater Accra 
Table 6.8: Confidence intervals obtained based on homogeneous bootstrap procedure(non standards corrected scores)

\begin{tabular}{|c|c|c|c|c|c|c|c|c|c|c|c|}
\hline Firm & $\begin{array}{l}\Delta \text { Scale } \\
\text { Technology }\end{array}$ & $\begin{array}{l}\text { Lower } \\
\text { Bound }\end{array}$ & $\begin{array}{l}\text { Upper } \\
\text { Bound }\end{array}$ & Firm & $\begin{array}{l}\Delta \text { SScale } \\
\text { Technology }\end{array}$ & $\begin{array}{l}\text { Lower } \\
\text { Bound }\end{array}$ & $\begin{array}{l}\text { Upper } \\
\text { Bound }\end{array}$ & Firm & $\begin{array}{l}\Delta \text { Scale } \\
\text { Technology }\end{array}$ & $\begin{array}{l}\text { Lower } \\
\text { Bound }\end{array}$ & $\begin{array}{l}\text { Upper } \\
\text { Bound }\end{array}$ \\
\hline 1 & 1.0018 & 0.8032 & 1.4292 & 48 & 0.9812 & 0.9839 & " 1.0111 & 95 & $\bar{~}$ & 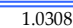 & 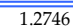 \\
\hline 2 & 1.0055 & 0.9673 & 1.0439 & 49 & 0.9742 & 0.9449 & 1.0205 & 96 & 0.9557 & 0.9519 & 1.0035 \\
\hline 3 & 1.0187 & 0.9780 & 1.0306 & 50 & 0.9402 & 0.8679 & 1.0414 & 97 & 1.0016 & 0.9937 & 1.0922 \\
\hline 4 & 0.9993 & 0.9852 & 1.0342 & 51 & 0.9920 & 0.9472 & 1.0242 & 98 & $1.5264^{* *}$ & 1.1411 & 2.0939 \\
\hline 5 & 0.9685 & 0.9354 & 1.0035 & 52 & 1.0007 & 0.9372 & 1.0584 & 99 & 0.9630 & 0.9377 & 1.0114 \\
\hline 6 & 0.9653 & 0.9676 & 1.0168 & 53 & 1.0012 & 0.7495 & 1.4006 & 100 & 0.9763 & 0.9732 & 1.0134 \\
\hline 7 & 1.0030 & 0.9858 & 1.0244 & 54 & 1.0358 & 0.9984 & 1.0684 & 101 & 1.0316 & 0.9465 & 1.1119 \\
\hline 8 & 0.9892 & 0.9882 & 1.0273 & 55 & 0.9862 & 0.9862 & 1.0253 & 102 & $0.9450^{* *}$ & 0.9420 & 0.9933 \\
\hline 9 & 1.0038 & 0.9293 & 1.1047 & 56 & 1.0515 & 0.7944 & 1.4549 & 103 & 0.9753 & 0.9730 & 1.0156 \\
\hline 10 & 0.9704 & 0.9521 & 1.0000 & 57 & 1.0015 & 0.8990 & 1.2191 & 104 & 0.9690 & 0.9695 & 1.0061 \\
\hline 11 & 0.9753 & 0.9441 & 1.0183 & 58 & 0.9408 & 0.9437 & 1.0120 & 105 & 1.0130 & 0.9926 & 1.0771 \\
\hline 12 & 1.0710 & 0.9639 & 1.1620 & 59 & 0.9414 & 0.9389 & 1.0085 & 106 & 1.0048 & 0.9623 & 1.1054 \\
\hline 13 & 0.9888 & 0.9853 & 1.0235 & 60 & 1.0151 & 0.7669 & 1.4259 & 107 & 1.0035 & 0.9735 & 1.0198 \\
\hline 14 & 1.0229 & 0.9847 & 1.1033 & 61 & 1.0212 & 0.9623 & 1.0608 & 108 & 0.9737 & 0.9446 & 1.0183 \\
\hline 15 & 0.8066 & 0.6093 & 1.1342 & 62 & 1.0235 & 0.9786 & 1.0456 & 109 & 1.0048 & 0.9743 & 1.0358 \\
\hline 16 & 0.9769 & 0.9688 & 1.0031 & 63 & $0.9534^{* *}$ & 0.9488 & 0.9921 & 110 & 0.9840 & 0.9434 & 1.0082 \\
\hline 17 & 1.0227 & 0.9587 & 1.1497 & 64 & 0.9787 & 0.9422 & 1.0149 & 111 & 0.8964 & 0.6773 & 1.2643 \\
\hline 18 & 1.0156 & 0.9347 & 1.1159 & 65 & 1.0256 & 0.9615 & 1.0587 & 112 & 0.9810 & 0.9852 & 1.0143 \\
\hline 19 & 0.9860 & 0.9754 & 1.0321 & 66 & 0.9782 & 0.9393 & 1.0001 & 113 & 0.9805 & 0.7531 & 1.2751 \\
\hline 20 & 0.9612 & 0.9579 & 1.0183 & 67 & $0.9582^{* *}$ & 0.9418 & 0.9946 & 114 & 0.9259 & 0.9237 & 1.0090 \\
\hline 21 & 0.9773 & 0.9807 & 1.0380 & 68 & $0.9617^{* *}$ & 0.9402 & 0.9957 & 115 & 0.9623 & 0.9640 & 1.0203 \\
\hline 22 & 1.0155 & 0.9438 & 1.0380 & 69 & 0.9729 & 0.9390 & 1.0101 & 116 & 1.0068 & 0.9778 & 1.0276 \\
\hline 23 & 0.9548 & 0.9471 & 1.0158 & 70 & 1.0343 & 0.9707 & 1.1149 & 117 & 0.9999 & 0.9907 & 1.0397 \\
\hline 24 & 0.9917 & 0.9799 & 1.0098 & 71 & 1.0618 & 0.8432 & 1.3281 & 118 & 0.9648 & 0.8570 & 1.1114 \\
\hline 25 & 0.9562 & 0.9550 & 1.0078 & 72 & 0.9941 & 0.9604 & 1.0219 & 119 & 0.9810 & 0.9840 & 1.0241 \\
\hline 26 & 0.9858 & 0.9424 & 1.0112 & 73 & 1.0109 & 0.7652 & 1.4276 & 120 & 1.0129 & 0.9917 & 1.0314 \\
\hline 27 & 0.9633 & 0.9485 & 1.0016 & 74 & 1.0021 & 0.9864 & 1.0453 & 121 & 1.0362 & 0.9269 & 1.1683 \\
\hline 28 & 1.0063 & 0.9383 & 1.0358 & 75 & 0.9973 & 0.9468 & 1.0255 & 122 & 0.9835 & 0.9469 & 1.0194 \\
\hline 29 & 0.9605 & 0.9503 & 1.0230 & 76 & 0.9560 & 0.9290 & 1.0317 & 123 & 1.0141 & 0.9726 & 1.1076 \\
\hline 30 & 0.9946 & 0.9873 & 1.0153 & 77 & 0.9880 & 0.9814 & 1.0242 & 124 & 0.9763 & 0.9437 & 1.0166 \\
\hline 31 & 1.0364 & 0.9967 & 1.0839 & 78 & 0.9613 & 0.9081 & 1.0656 & 125 & 0.9158 & 0.6720 & 1.2834 \\
\hline 32 & $0.9462^{* *}$ & 0.9352 & 0.9955 & 79 & 0.9695 & 0.9681 & 1.0365 & 126 & 1.1540 & 0.9661 & 1.3144 \\
\hline 33 & 0.9856 & 0.9860 & 1.0387 & 80 & $0.7179^{* *}$ & 0.5391 & 0.9973 & 127 & 0.9727 & 0.9397 & 1.0099 \\
\hline 34 & 1.0312 & 0.9137 & 1.2077 & 81 & $1.0495^{* *}$ & 1.0005 & 1.1226 & 128 & 0.9410 & 0.9296 & 1.0012 \\
\hline 35 & 1.0197 & 0.9471 & 1.1604 & 82 & $0.9626^{* *}$ & 0.9584 & 0.9970 & 129 & 0.9844 & 0.9858 & 1.0217 \\
\hline 36 & 0.9913 & 0.9351 & 1.0235 & 83 & $1.1068^{* *}$ & 1.0128 & 1.2328 & 130 & 1.0127 & 0.9762 & 1.0428 \\
\hline 37 & $0.9552^{* *}$ & 0.9527 & 0.9982 & 84 & 0.9904 & 0.9882 & 1.0605 & 131 & 0.9671 & 0.9324 & 1.0009 \\
\hline 38 & 0.9471 & 0.7956 & 1.1063 & 85 & 1.0197 & 0.9925 & 1.0782 & 132 & 1.0317 & 0.7788 & 1.4229 \\
\hline 39 & 0.9999 & 0.9493 & 1.0325 & 86 & $0.9623^{* *}$ & 0.9429 & 0.9941 & 133 & 0.9939 & 0.9403 & 1.0208 \\
\hline 40 & 0.9585 & 0.9387 & 1.0000 & 87 & $0.9413^{* *}$ & 0.9350 & 0.9971 & 134 & 0.9663 & 0.9363 & 1.0175 \\
\hline 41 & $0.9548^{* *}$ & 0.9522 & 0.9979 & 88 & 1.0070 & 0.8744 & 1.0959 & 135 & 0.9662 & 0.9394 & 1.0045 \\
\hline 42 & 0.9827 & 0.9718 & 1.0078 & 89 & 1.0608 & 0.9885 & 1.1432 & 136 & 1.0229 & 0.9915 & 1.0839 \\
\hline 43 & 0.9720 & 0.9394 & 1.0013 & 90 & 0.9811 & 0.9751 & 1.0057 & 137 & 0.9657 & 0.9696 & 1.0220 \\
\hline 44 & $0.9568^{* *}$ & 0.9301 & 0.9917 & 91 & $0.9541^{* *}$ & 0.9375 & 0.9980 & 138 & 1.0270 & 0.9952 & 1.0916 \\
\hline 45 & 0.9670 & 0.9554 & 1.0057 & 92 & 0.9654 & 0.9387 & 1.0133 & 139 & 0.9972 & 0.9362 & 1.0227 \\
\hline 46 & 0.9572 & 0.9610 & 1.0095 & 93 & 0.9290 & 0.7115 & 1.2020 & 140 & 1.0156 & 0.9750 & 1.0976 \\
\hline 47 & $0.9673^{* *}$ & 0.9503 & 0.9991 & 94 & 0.9779 & 0.9354 & 1.0072 & & & & \\
\hline
\end{tabular}

Firm 1-45 from Volta Region, 46-82 from Eastern and 83-140 from Greater Accra 


\section{Chapter 7}

\section{Poverty Measures and Analysis in the Apparel Sector using Fuzzy Sets and Techniques}

\subsection{Introduction}

Households whose livelihoods largely depend on small businesses endeavor to protect them and make sure they work. More often than not, people are poor not because they are not working but because their businesses are not doing well. In the previous chapters, we investigated how competitive these apparel manufacturing businesses have been between 2002 and 2007 based on TFP growth. The sources of that competitiveness through TFP growth have also been investigated. The purpose of this chapter is to address two main issues namely: 1) the incidence of poverty among the apparel manufacturers in Ghana, 2) establish the sources of this deprivation, and 3) investigate the dynamics of the deprivation between 2002 and 2007.

\subsection{Conceptualization of Poverty and Well-being}

The concept of poverty and well-being can be defined broadly or narrowly depending on the nature of the study objectives and the types of questions being addressed. The conceptualization is necessary in order to facilitate the identification and the choice of the right technique of measurement and indicators. Sen (1976) was critical of the poverty measures namely 'headcount ratio' and 'poverty-gap' which were widely used at the time describing the former as violating both the basic monotonicity ${ }^{28}$ and transfer ${ }^{29}$ axioms. Whilst the head-count approach is based on real income and classified as poor all those below some pre-determined income level, the

\footnotetext{
${ }^{28}$ Monotonicity here implies that a reduction in income of persons below the poverty line leads to increase in poverty measure assuming other factors remain unchanged. 29 Violating transfer axiom means that reassignment of income from one person below the poverty line to another person above the poverty line must increase the poverty measure, all factors remaining the same.
} 
poverty-gap approach accounts for the aggregate difference between the income of all the poor and that of the poverty line. However, both measures are insensitive to income redistribution among the people. Sen (1976) therefore, constructed an index ${ }^{30}$ comprising of the two measures and including the Gini coefficient to account for the income redistribution effects lacking in the previous methods. Even Sen's (1976) index hinges on income and therefore a uni-dimensional technique of capturing poverty. It should however, be noted that Sen's approach was reducing what was essentially multi-dimensional to single dimensional by aggregating various goods for a single person using the market prices thus getting real income for that individual which is comparable to that of others. Questions over differences in individual indirect utility functions which might render this aggregation based on prices misleading have been raised.

Foster, Greer and Thorbecke (1984) employ a parametric measure of poverty that satisfies Sen's axioms of monotonicity and transferability with the formulae specification as $P_{b}=1 / n \sum_{h=1}^{q}\left[\left(z-y_{h}\right) / z\right]^{b}$ where z represents some predetermined poverty line greater than zero, $y_{\mathrm{h}}$ is the hth household income, $\mathrm{n}$ captures total number of households and $\mathrm{q}$ represents households with income levels higher than $\mathrm{z}$. $\mathrm{P}$ is the poverty measure, $\mathrm{b}$ is the nonnegative parameter and $\mathrm{Pb}$ indicates some class of poverty measure in general where $b$ can assume values such as 0,1 or 2 . The equation defines some weighted sum of the income shortfalls of poor households. Setting b to 0 provides headcount poverty index measuring the incidence of poverty thus the proportion of those below the predetermined poverty line. $\mathrm{P}_{1}$ is interpreted as the poverty gap index measuring the depth of poverty which makes it easier for policy makers and implementers to know exactly the amount of income needed to reduce poverty. $\mathrm{P}_{2}$ measures that squared poverty gap accounting for the degree of inequality among the poor people. Even though Foster et al. (1984) provide insights into knowing the percentage of the people who are poor in a particular society, the approach still suffers from the fact that it is based on either income or expenditure

\footnotetext{
${ }^{30}$ Sen (1976) poverty index where $\mathrm{P}$ symbolizes poverty index, $\mathrm{H}$ denotes headcount, I denotes income poverty-gap and $\mathrm{G}$ denotes Gini coefficient.
} 
and only few researchers on poverty may doubt that poverty is much broader than those two indicators and the choice of poverty line might not even be accurate if based on these two indicators alone.

Some authors therefore have proposed measures which are multidimensional and can help capture poverty more accurately than the single indicator approaches. Atkinson and Bourguignon (1982) writing on the comparison of multi-dimensioned distributions of economic status noted that the single measure approach in gauging even inequality needs to incorporate many more factors made up of monetary and non-monetary variables such as health status and housing in addition to income. However, before one sets out to even measure poverty, it is advisable to identify the units to be focused on whether individuals, families or household among others. The issue of who to really classify as poor has been amply discussed by authors from various backgrounds.

In the written works of Halper (1973), phrases such as 'deserving poor', 'undeserving poor' and 'undeserving rich' were employed to highlight the differences that exist among the poor themselves referring basically to some who are hardworking enough but their circumstances are such that they are still poor through no fault of theirs and such people deserved to be assisted out of poverty. The undeserving poor though constitute the bulk of the poor who are widely perceived as being poor out of their own laziness or luck of good judgment among others and so do not need any assistance as they themselves do not put in any efforts to escape their current circumstances. Those who also escape poverty too quickly might end up being undeserving rich. Poverty according to Halper (1973) was considered a temporary process responding to the cycles of boons and bursts and likely to right itself finally with individual efforts and drive. Perhaps, more importantly though is the fact that people are becoming more aware of the fact that poverty results from exploitative economic injustices and so stands the chance of being totally eradicated with right approaches and policies.

\subsection{Theoretical Framework and Multidimensional Measure of Poverty}

Unlike the classical set theory and logic which deals with precise measures, for example, one either belongs to a set of poor people or rich people or not. 
Fuzzy set theory and logic (Zadeh, 1965) is based on the idea that it is better to be vaguely right than to be precisely wrong and admits membership values in their imprecise form. For example, with respect to poverty/deprivation, the measurements will accommodate the degree of deprivation from completely deprived through partially deprived to completely non-deprived. Thus, this is quite different from the likelihood of belonging to a specific set of poor people which must be obeyed without which no flexibility is possible. Betti, Chelli, Lemi and Verma (2006) wrote that most approaches employed in the analysis of poverty have two weaknesses in that not only are they based on single proxy of poverty such as income or consumption expenditure but also categorize the people into poor and non-poor based on some arbitrary poverty line. Betti et al. (2006), realized in part that the classification into poor and non-poor leaves out such vital information that other approaches like fuzzy sets would not had left out because they are less rigid and capture welfare as a matter of degree from the very poor to relatively non-poor.

\subsubsection{Classical versus Fuzzy Sets}

Before proceeding to our poverty analysis, let us put these two concepts of classical and fuzzy sets and the logic behind them in perspective. Whilst classical set defines in rigid way members of a particular group and therefore strictly admits only those who fall into a category and excludes all those who do not fall into it, fuzzy set theory assumes that in reality, things might not look as sharply divided as the classical set theory appears to portray and so instead of strict admission into membership, it treats membership as a matter of degree starting from those who are totally part of the group and gradually moves on to those who are totally not part of the group. Looking at the logic behind them, it is clear that the classical set deals with bi-valued or two-way logic e.g. hot or cold with regards to the state of water temperature, yes or no as an answer, tall or short as height of people, large or small, fast or slow among others whilst fuzzy logic encapsulates hot or cold as in the state of water temperature and associates them with extreme conditions, water temperature can be something other than hot or 
cold. In effect, fuzzy logic is an extension of the classical logic and tends to complement it rather than substitute it. According to Betti, Cheli and Verma (2006), fuzzy sets operations are generalization of classical set operations and in situations where there are only dichotomous variables, creation of membership functions that spun the entire range of $[0,1]$ can be reduced to a series of $\{0,1\}$ dichotomies.

Figure 7.1a

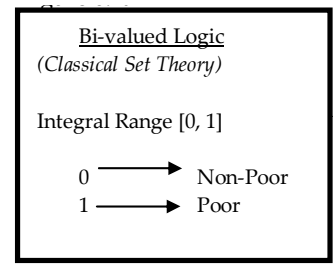

Figure 7.1a

\begin{tabular}{|c|}
\hline $\begin{array}{c}\text { Multi-valued Logic } \\
\text { (Fuzzy Set Theory })\end{array}$ \\
Numeric Range [0, 1] \\
0 Completely Non-Poor \\
$1 \longrightarrow$ Completely Poor \\
$0<x_{i}<1$ Values other than the \\
Extremes
\end{tabular}

Formerly, Figures 7.1a and 7.1b defined the two types of logic and show that where as bi-valued logic (classical approach) captures the extremes of membership function by way of 'Haves' and 'Have nots', multi-valued logic (fuzzy approach) captures both the integral range namely 0 and 1 and all those values (non-integers of course) that occur between them.

\subsection{The Methodology}

This study is informed by two methodological approaches. Within the theoretical framework of fuzzy sets and logic, two methodologies have been employed to capture the degree or intensity of individual/household poverty in a multi-dimensional sense. The first approach deals with the notion that poverty measure should not be along the line of arbitrary choice of poverty line but should rather be based on generally accepted thresholds set with regards to the extent to which a household is deprived with respect to multiple attributes.

The second approach is that by Cheli and Lemmi (1995) who proposed a methodological approach known as the Totally Fuzzy and Relative (TFR) that allows poverty to be measured with multiple dimensions whilst avoiding setting thresholds. Instead, the degree to which one is deprived is based simply on a multiple of attributes determined objectively with mathematical formulations. 
The study follows Dagum (2002) and Dagum and Costa (2004) approach which is grounded on Cerioli and Zani (1990) with the modifications required to help address these sets of issues specifically:

- Poverty/deprivation index for each household (both static and dynamic measures)

- Poverty index for $\mathrm{j}$-th attribute

- Composite poverty index for all the 140 households (both static and dynamic measures)

- Sources of poverty/deprivation

We start by:

First, let $X=\left(X_{1}, \ldots, X_{j}, \ldots . . X_{m}\right)$ denote $\mathrm{j}(\mathrm{j}=1,2, \ldots, \mathrm{m})$ number of attributes in $\mathrm{m}$-dimension $(\mathrm{m}=2,3, \ldots)$ vector of attributes. Costa (2002) defined m-dimension vector of attributes to be made of economic, social and cultural among others. Second, let $H=\left(h_{1}, h_{2}, \ldots \ldots . ., h_{n}\right)$ denotes a vector of $\mathrm{n}$ households and third, let $D$ denotes a subset of deprived households such that $h_{i} \in D(\mathrm{i}=1,2, \ldots, \mathrm{n})$ indicates deprivation of some $\mathrm{j}$ attributes in m-dimension of attributes.

Let us define members of deprived set of households as $\mu_{D}\left(X_{j}\left(h_{i}\right)\right)=x_{i j}$, where $0 \leq x_{i j} \leq 1$. This implies that:

$$
\begin{cases}-\quad x_{i j}=0 \quad & \begin{array}{l}
\text { iff the } i-\text { th houshold } \\
\text { possess the } j-\text { th attribute }
\end{array} \\
-x_{i j}=1 & \begin{array}{l}
\text { iff the } i-\text { th household does not } \\
\text { possesses the } j-\text { th attribute }
\end{array} \\
-0 \prec x_{i j} \prec 1 & \begin{array}{l}
\text { iff the } i-\text { th household partially } \\
\text { possesses the } j-\text { th attribute } \\
\text { with intensity belonging to } \\
\text { the open interval }[0,1]
\end{array}\end{cases}
$$


As there are $m$ attributes that may collectively define the level of deprivation of each household in which case we have m-dimension of attributes, our poverty index of the i-th household becomes:

7.1. $\quad \mu_{D}\left(h_{i}\right)=\frac{\sum_{j=1}^{m} x_{i j} w_{j}}{\sum_{j=1}^{m} w_{j}}$ where $w_{j}$ captures the weight assigned to the $\mathrm{j}$-th attribute defined as the intensity of deprivation of $X_{j}$. The are various weighting systems that have been proposed by various authors including Cerioli and Zani 1990, Cheli and Lemmi (1995), and Filippone et al (2001) who attempted to compare different weighting system with the aim of establishing differences in outcomes with respect to these system. However, not veering into other weighting systems, we consider Cerioli and Zani's (1990) which have been readily employed by several writers including Dagum and Costa (2002). They modelled their weights $w_{j}$ as the inverse function of average degree of deprivation formally defined as:

7.2. $w_{j}=\log \left[\frac{n}{\sum_{i=1}^{n} x_{i j} n_{i}}\right] \geq 0$

For equation 7.2 to be positive or equal to zero implies $\sum_{i=1}^{n} x_{i j} n_{i}>0$ condition must hold. The weighting is so defined such that any attribute $X_{j}$ with degree of membership $x_{i j}=0$ and $x_{i j}=1$ for all $\mathrm{i}, \mathrm{i}=1 \ldots . . \mathrm{n}$, show extreme situations with the former indicating no deprivation in the said attribute and therefore makes inconsequential the intention to capture levels of deprivation with respect to the attribute and can be excluded. The latter indicates the opposite where the $\mathrm{j}$-th attribute is not possessed by any of the i-th household hence situation of complete deprivation shown by $w_{j}=\log [n / n]=\log [1]=0$. Equation 7.2 satisfies an important property by attaches more importance to attributes that are common with few households deprived of them meaning that all factors held constant, the 
intensity of deprivation is much more pronounced where people find it difficult to conform to the norm. For example, if having access to at least basic education is a norm in a society, the signs of derivation become obvious where some people are without this basic education. Miceli (1998) gave more insight into the appropriateness of the weighting system in equation 7.2 when he cited Theil (1967) common information function defined over $(0, \infty)$ which decreases with the probability of the occurrence of an event meaning that the more unlikely the occurrence of an event, the more shocked people become with the cite of the event.

Having specified the poverty estimate for the i-th household in the sample population along the lines of Dagum and Costa (2004) using the weights of Cerioli and Zani (1990), the study proceeds to the specification of poverty index for the population follows:

7.3. $\quad \mu_{D}=\frac{\sum_{i=1}^{n} \mu_{D}\left(h_{i}\right) g\left(h_{i}\right)}{\sum_{i=1}^{n} g\left(h_{i}\right)}=\frac{1}{n} \sum_{i=1}^{n} \mu_{D}\left(h_{i}\right) g\left(h_{i}\right)$

where equation 7.3 is simply a weighted average of equation 7.1 (the weighted average of the $\mathrm{i}$-th household). The function $g\left(h_{i}\right)$ symbolizes the number of households. For each of $\mathrm{m}$ attributes under consideration, the theory of fuzzy sub-set provides an opportunity to capture one-dimension of $j$-th attribute possessed by the i-th household where we recall the degree of membership $x_{i j}$ and define poverty index for the $\mathrm{j}$-th attribute as:

7.4 .

$$
\mu_{D}\left(X_{j}\right)=\frac{\sum_{i=1}^{n} x_{i j} g\left(h_{i}\right)}{\sum_{i=1}^{n} g\left(h_{i}\right)}=\frac{\sum_{i=1}^{n} x_{i j} n_{i}}{\sum_{i=1}^{n} n_{i}}
$$

where equation 7.4 measures the degree of deprivation of population $n$ in $\mathrm{j}$-th attribute with the difference in using $n_{i}$ instead of $w_{j}$ as weights underlies the fact that the former has to do with the weight or importance attached to the ith sample observation whilst the latter with the degree of deprivation of $X_{j}$. 


\subsection{The Choice of Membership Functions}

In our methodology, the following steps were followed. Poverty indicators based on Ghana Living Standard Surveys were first selected as in Appendix 3. We classify these poverty indicators according to the membership function that defined them (see examples in Table 7.1). The binary functions define YES/NO, HAVE/HAVE NOT and DEPRIVED/NOT DEPRIVED questions among others. Almost all the household assets in dimension three (D3) of our questionnaire in Appendix 3 fall into this category of binary or dichotomous attributes. These attributes comprised of possessing of telephone $/ \mathrm{mobile}$ phone, refrigerator, air conditioner, computer, electrical iron/other iron, water boiler, bed, video recorder/TV, car, wrist watch/clock and others.

Table 7.1: Examples of Membership Functions

Binary Function
$f(x)=\left\{\begin{array}{ccc}1 & \begin{array}{l}\text { deprived of } \\ \text { attribute } x\end{array} \\ 0 & \text { not deprived } \\ & \text { of attribute } x\end{array}\right.$

Questions here apply to possession of an item e.g. car. The answer is either yes or no.

Categorical Function(Positive slope)

$$
f(x)=\left\{\begin{array}{lll}
1 & \text { if } & x \prec x_{\min } \\
\frac{x_{\max }-x}{x_{\max }-x_{\min }} & \text { if } & x_{\min } \leq x \prec x_{\max } \\
0 & \text { if } & x \geq x_{\max }
\end{array}\right.
$$

Questions here apply to categories of say education. The higher the level of education, Applying binary function to dichotomous Variable( Car)

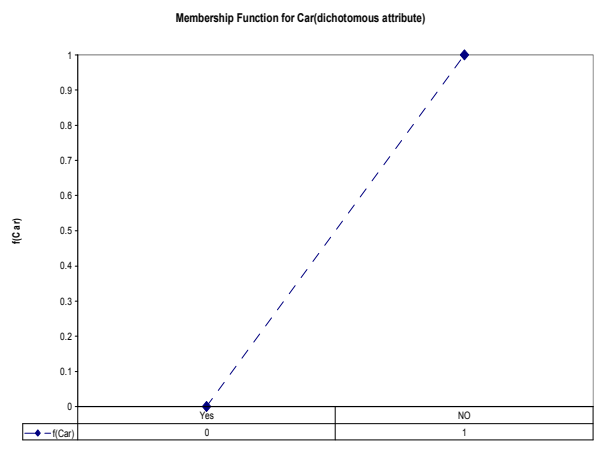

Applying categorical function to categorical Variable( e.g. levels of education) the better and hence a positive slope

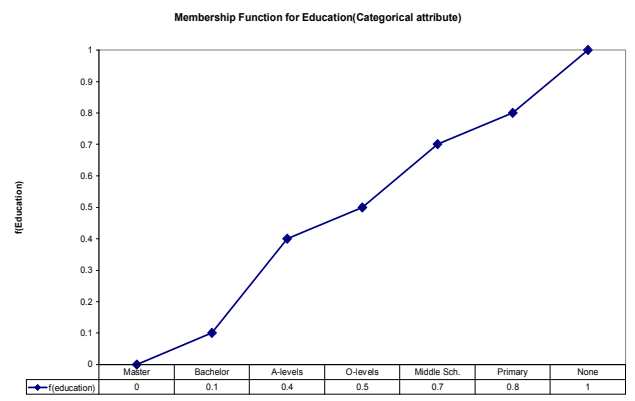


Categorical Function(Negative slope)

$$
f(x)= \begin{cases}1 & \text { if } x<x_{\min } \\ \frac{x-x_{\min }}{x_{\max }-x_{\min }} & \text { if } x_{\min } \leq x<x_{\max } \\ 0 & \text { if } x \geq x_{\max }\end{cases}
$$

Questions here apply to levels of say crime. The higher the level of crime, the worse and hence a negative slope
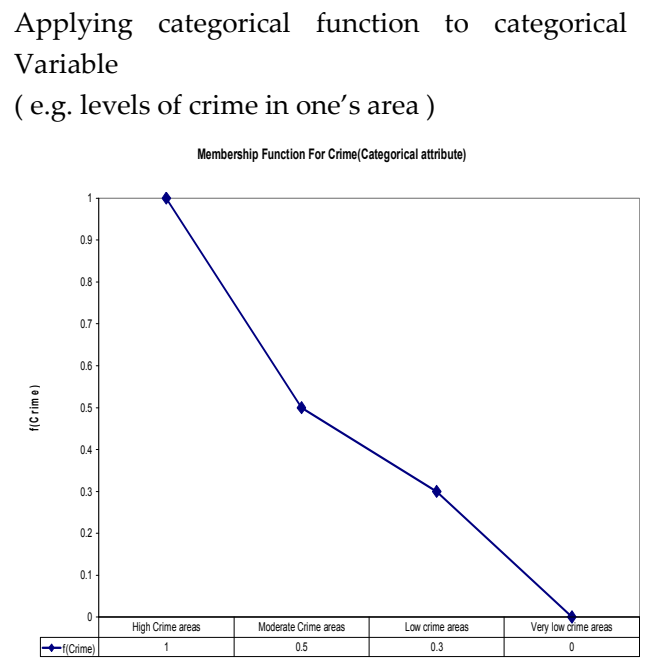

Categorical functions define attributes such as levels of education which comprise of tertiary, secondary, primary and basic/adult education. For these attributes, the higher the level of education, the less deprived one is with respect to those attributes and hence the positive slopes for the membership function. Other attributes such as levels of crime in the neighborhoods range from low on the average, relatively high to very high. Cost of living varies from low on the average, relatively high to very high. These are defined by categorical functions with negative slopes as in Table 7.1. Thus, the multidimensional computation of poverty indices is illustrated in Table 7.2 which presents:

- poverty index of the $\mathrm{i}$-th household $\left(\mu_{D}\left(h_{i}\right)\right)$

- weight assigned to the $\mathbf{j}$-th attribute $\left(w_{j}\right)$

- poverty index for the population $\left(\mu_{D}\right)$

- poverty index for the $\mathrm{j}$-th attribute $\left(\mu_{D}\left(X_{j}\right)\right)$

The D1, D2, D3, D4 and D5 capture five dimensions of attributes over six households in the first column (Table 7.2). From equations 7.1, 7.2, 7.3 and 7.4 we compute the example in Table 7.2. The membership values of each dimension (Di) of attributes were first defined by the respective membership 
functions in Table 7.1 and the results for each of these dimension then used for multidimensional computation in Table 7.2.

Table 7.2: Example of multidimensional measure of poverty at a point in time

\begin{tabular}{|c|c|c|c|c|c|c|}
\hline $\begin{array}{l}\text { Dimensions } \\
\text { (Di) } \\
\text { Households } \\
\end{array}$ & $\begin{array}{l}\text { Car } \\
\text { (D1) } \\
\end{array}$ & $\begin{array}{r}\text { Income } \\
\text { (D2) } \\
\end{array}$ & $\begin{array}{c}\text { Education } \\
\text { (D3) } \\
\end{array}$ & $\begin{array}{l}\text { Food } \\
\text { (D4) } \\
\end{array}$ & $\begin{array}{l}\text { Crime } \\
\text { (D5) } \\
\end{array}$ & $\begin{array}{l}\mu_{D}\left(h_{i}\right) \\
\text { (Poverty } \\
\text { index for i-th } \\
\text { household) }\end{array}$ \\
\hline 1 & 1 & 1 & 1 & 1 & 1 & 0.978 \\
\hline 2 & 1 & 0.7 & 0 & 0.6 & 1 & 0.535 \\
\hline 3 & 1 & 0.3 & 0.1 & 0 & 0.5 & 0.167 \\
\hline 4 & 1 & 0.7 & 0.4 & 0 & 0.5 & 0.325 \\
\hline 5 & 1 & 0 & 1 & 0 & 0.5 & 0.302 \\
\hline 6 & 1 & 0 & 0 & 0 & 0 & 0 \\
\hline$\sum_{i=1}^{n} x_{i j}$ & 6 & 2.7 & 2.5 & 1.6 & 3.5 & \\
\hline$w_{j}$ & 0 & 0.347 & 0.38 & 0.574 & 0.234 & $\begin{array}{c}\mu_{D}= \\
0.394\end{array}$ \\
\hline$\mu_{D}\left(X_{j}\right)$ & 1 & 0.45 & 0.417 & 0.267 & 0.583 & (poverty \\
\hline$\mu_{D}\left(X_{j}\right) * w_{j}$ & 0 & 0.156 & 0.158 & 0.153 & 0.137 & $\begin{array}{l}\text { index for the } \\
\text { population) }\end{array}$ \\
\hline
\end{tabular}

\subsubsection{Capturing Poverty/Deprivation Changes Overtime:}

\section{Longitudinal Measure}

In the previous sections, we specified the static measures of deprivation and now we have to establish changes in this deprivation overtime. This section is based on the works of Betti and Verma (1998), Betti and Cheli (2000), Verma and Betti (2002), Dubois and Parade (1980) and Zadeh (1965). In consonance with the period specified for productivity assessment in Chapters 5 and 6, poverty is measured over $t$ (current time period) and $t-5$ (previous time period defining 5 years back). This implies that our degree of membership takes the forms: $\mu_{D}\left[X_{j}\left(h_{i}\right)\right]^{t}$ and $\mu_{D}\left[X_{j}\left(h_{i}\right)\right]^{t-5}$, our poverty index of the i-th household becomes: $\mu_{D}\left(h_{i}\right)^{t}$ and $\mu_{D}\left(h_{i}\right)^{t-5}$, our poverty index for the 
population becomes: $\mu_{D}{ }^{t}$ and $\mu_{D}{ }^{t-5}$, our poverty index for the $\mathrm{j}$-th attribute becomes: $\mu_{D}\left(X_{j}\right)^{t}$ and $\mu_{D}\left(X_{j}\right)^{t-5}$.

Occurrence of poverty/deprivation in both time periods as proposed by Betti and Verma (2002) is captured as fuzzy intersection of situations in both sets as:

$$
\begin{aligned}
& a_{1} \cdot \quad\left[\mu_{D}\left(h_{i}\right)^{t-5} \cap \mu_{D}\left(h_{i}\right)^{t}\right]=\min \left[\mu_{D}\left(h_{i}\right)^{t-5}, \mu_{D}\left(h_{i}\right)^{t}\right] \\
& \text { 7.6. } \quad b_{1} \cdot \quad\left[\mu_{D}^{t-5} \cap \mu_{D}^{t}\right]=\min \left[\mu_{D}^{t-5}, \mu_{D}^{t}\right] \\
& c_{1} \cdot \quad\left[\mu_{D}\left(X_{j}\right)^{t-5} \cap \mu_{D}\left(X_{j}\right)^{t}\right]=\min \left[\mu_{D}\left(X_{j}\right)^{t-5}, \mu_{D}\left(X_{j}\right)^{t}\right]
\end{aligned}
$$

Occurrence of poverty/deprivation in either time period is captured as fuzzy union of both sets:

$$
\begin{array}{ll}
a_{2} . & {\left[\mu_{D}\left(h_{i}\right)^{t-5} \cup \mu_{D}\left(h_{i}\right)^{t}\right]=\max \left[\mu_{D}\left(h_{i}\right)^{t-5}, \mu_{D}\left(h_{i}\right)^{t}\right]} \\
b_{2} . & {\left[\mu_{D}^{t-5} \cup \mu_{D}^{t}\right]=\max \left[\mu_{D}^{t-5}, \mu_{D}^{t}\right]} \\
c_{2} . & {\left[\mu_{D}\left(X_{j}\right)^{t-5} \cup \mu_{D}\left(X_{j}\right)^{t}\right]=\max \left[\mu_{D}\left(X_{j}\right)^{t-5}, \mu_{D}\left(X_{j}\right)^{t}\right]}
\end{array}
$$

Equations 7.6 and 7.7 allow us to measure on all fronts whether poverty has gradually reduced or increased among the apparel manufacturers since early 2000s. More formally, Betti et al. (2006) framework enables studies like this one to establish whether $\mathrm{i}$-th individual or household is exiting, entering or never in poverty using fuzzy operators. Never deprived households within the two periods are represented by the fuzzy intersection where the $\bar{\mu}$ connotes 'never in poverty' as: 


$$
a_{3} . \quad\left\lfloor\bar{\mu}_{D}\left(h_{i}\right)^{t-5} \cap \bar{\mu}_{D}\left(h_{i}\right)^{t}\right\rfloor=1-\max \left\lfloor\mu_{D}\left(h_{i}\right)^{t-5}, \mu_{D}\left(h_{i}\right)^{t}\right\rfloor
$$

7.8 .

$$
b_{3} . \quad\left[\bar{\mu}_{D}^{t-5} \cap, \bar{\mu}_{D}^{t}\right]=1-\max \left[\mu_{D}^{t-5}, \mu_{D}^{t}\right]
$$

Exiting from poverty is captured by fuzzy intersection:

$$
a_{4} .\left\lfloor\mu_{D}\left(h_{i}\right)^{t-5} \cap \bar{\mu}_{D}\left(h_{i}\right)^{t}\right\rfloor=\max \left\lfloor 0, \quad \mu_{D}\left(h_{i}\right)^{t-5}-\mu_{D}\left(h_{i}\right)^{t}\right\rfloor
$$

7.9 .

$$
b_{4} . \quad\left[\mu_{D}^{t-5} \cap \bar{\mu}_{D}^{t}\right]=\max \left[0, \mu_{D}^{t-5}-\mu_{D}^{t}\right]
$$

Entering into poverty is defined by the fuzzy intersection:

$$
a_{5} .\left\lfloor\mu_{D}\left(h_{i}\right)^{t-5} \cap \bar{\mu}_{D}\left(h_{i}\right)^{t}\right\rfloor=\max \left\lfloor 0, \quad \mu_{D}\left(h_{i}\right)^{t}-\mu_{D}\left(h_{i}\right)^{t-5}\right\rfloor
$$

$$
b_{5} . \quad\left[\mu_{D}^{t-5} \cap \bar{\mu}_{D}^{t}\right]=\max \left[0, \mu_{D}^{t}-\mu_{D}^{t-5}\right]
$$

\subsection{Data Sources and Variables}

The data (described in chapter 3) were collected from a sample of 140 households connected directly to apparel manufacturing. Household heads, most of whom are the owners of these micro, small and medium sized apparel businesses were interviewed and information on household attributes was obtained for 2002 and 2007. These households were expected to have depended on apparel manufacturing for a couple of years which could be at least five years. Comparison of some selected household indicators in 2007 against 2002 enabled multidimensional assessment to be made overtime.

The first dimension referred to as D1 in Table 7.3 captures attributes on shelter. Data on the nature of the flooring materials, roofing, walling, and the number of rooms were obtained. The second dimension (D2) detailed the source of water supply to the household. Whilst dimension three (D3) subdivided into three categories namely durable assets, food, and other assets are listed. D4 and D5 provided daily expenditure on food and monthly expenditure on clothing respectively. D6 dwelled on sanitation attributes. 
Other dimensions such as D7 raised multiple choice questions on source of household energy supply classified into lighting and cooking. D8 on health categorized into orthodox medication and self medication. D9 on capabilities grouped into education at home, education at school and education at workplace.

Table 7.3: Variable Combinations

\begin{tabular}{|c|c|}
\hline 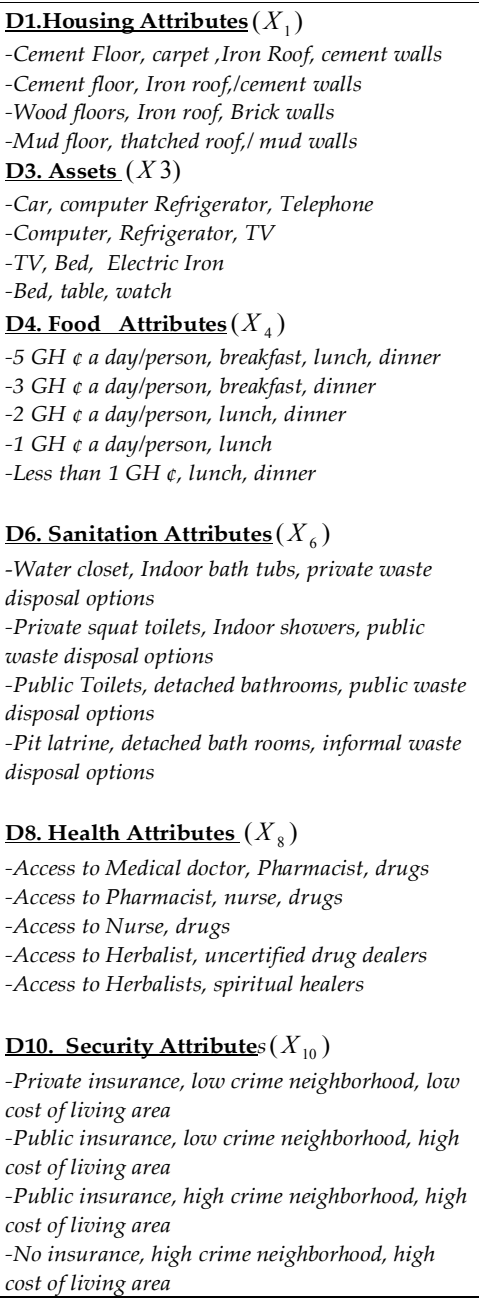 & 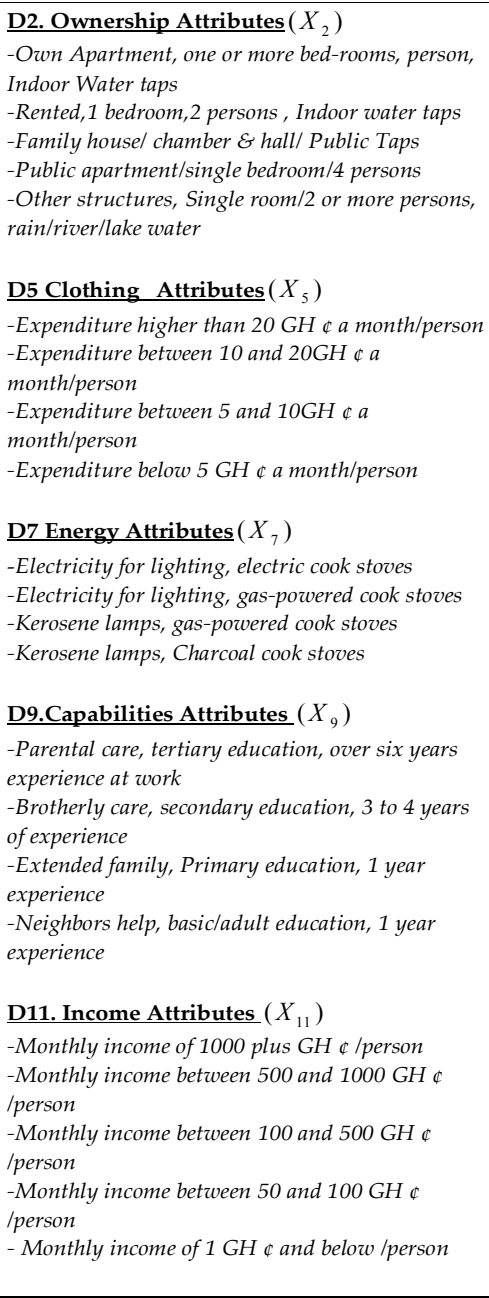 \\
\hline
\end{tabular}

D10 captures security and safety of location attributes partitioned into financial and social measures as well as violence and cost of living. The final 
dimension D11 posted issues on category of income that best describes the respondent's situation. Care is taken in the designing of the questionnaire to ensure that only relevant questions are raised and any other issue that might be of less interest is given second treatment (see chapter 3 ).

\subsubsection{Aggregation of attributes and their dimensions}

Relying on the membership functions specified in Table 7.1, applying and matching them to each attribute according to their nature and using the aggregation and weighting functions in section 7.5, we compute the static measures of deprivation for all the 140 households together (composite index) and for each household individually. The dynamic measures are calculated from the application of the functions specified in section 7.5.3. Aggregation of (a) different dimensions of deprivation with respect to the $j$-th attributes ,(b) single dimension of deprivation with respect to $\mathrm{j}$-th attributes and (c) assignment of weights to these attributes $\left(w_{j}\right)$ was carried out with the aim of capturing the degree of the importance of these attributes to the deprived households.

\subsection{Presentation and analysis of results: Static measures}

\subsubsection{Poverty index for the population}

The results are presented in Table 7.4. In 2002, poverty index for the population stood at 0.418 comprising 41.8 per cent of the households judged to be deprived compared to 0.342 in 2007 constituting 34.2 per cent in that year. The trend seems a little favorable with a reduction of deprivation by 7.6 percentage points over the years. However, the rate of occurrence of deprivation among households in 2007 is even very high and it would be good to know the share of contribution by each dimension of attributes to the deprivation index. Columns (a) and (c) of Table 7.3 present values for weights attached to the household attributes in the sample computed from equation 7.2 . 
These apparel manufacturing households appear to attach the highest importance to housing attributes with the weight of 0.524 in 2002 and 0.644 in 2007, health attributes with the values of 0.469 and 0.505 compared to Food 0.081 and 0.300 , income 0.148 and 0.358 and clothing with values of 0.254 and 0.476 in that order in both years respectively. This is understandable in that people residing in their own homes do not need to spend a large proportion of their incomes on rent.

\begin{tabular}{lcccccc} 
Table 7.4: Poverty index for the j-th attribute and Population \\
\hline $\begin{array}{l}\text { Index } \backslash \\
\text { Attribute }\end{array}$ & $\begin{array}{c}w_{j}^{2002} \\
\text { (a) }\end{array}$ & $\begin{array}{c}\mu_{D}\left(X_{j}^{2002}\right) \\
\text { (b) }\end{array}$ & $\begin{array}{c}w_{j}^{2007} \\
\text { (c) }\end{array}$ & $\begin{array}{c}\mu_{D}\left(X_{j}^{2007}\right) \\
\text { (d) }\end{array}$ & $\begin{array}{c}\Delta w \\
\text { (c-a) }\end{array}$ & $\begin{array}{c}\Delta \mu_{D}\left(X_{j}\right) \\
\text { (d-b) }\end{array}$ \\
\hline \hline D1.Housing $\left[\mu_{D}\left(X_{1}\right)\right]$ & 0.524 & 0.299 & 0.644 & 0.227 & 0.119 & -0.072 \\
D2.Ownership $\left[\mu_{D}\left(X_{2}\right)\right]$ & 0.396 & 0.401 & 0.457 & 0.349 & 0.061 & -0.053 \\
D3.Assets $\left[\mu_{D}\left(X_{3}\right)\right]$ & 0.388 & 0.409 & 0.490 & 0.324 & 0.102 & -0.086 \\
D4.Food $\left[\mu_{D}\left(X_{4}\right)\right]$ & 0.081 & 0.830 & 0.300 & 0.501 & 0.219 & -0.329 \\
D5.Clothing $\left[\mu_{D}\left(X_{5}\right)\right]$ & 0.254 & 0.557 & 0.476 & 0.334 & 0.222 & -0.223 \\
D6.Sanitation $\left[\mu_{D}\left(X_{6}\right)\right]$ & 0.283 & 0.520 & 0.439 & 0.360 & 0.156 & -0.160 \\
D7.Energy $\left[\mu_{D}\left(X_{7}\right)\right]$ & 0.403 & 0.396 & 0.550 & 0.282 & 0.147 & -0.114 \\
D8.Health[ $\left.\mu_{D}\left(X_{8}\right)\right]$ & 0.469 & 0.340 & 0.505 & 0.313 & 0.036 & -0.027 \\
D9.Capabilities $\left[\mu_{D}\left(X_{9}\right)\right]$ & 0.355 & 0.442 & 0.460 & 0.346 & 0.106 & -0.095 \\
D10.Security $\left[\mu_{D}\left(X_{10}\right)\right]$ & 0.459 & 0.348 & 0.341 & 0.456 & -0.118 & 0.109 \\
D11.Income $\left[\mu_{D}\left(X_{11}\right)\right]$ & 0.148 & 0.712 & 0.358 & 0.438 & 0.211 & -0.274 \\
Total $\left[\mu_{D}\right]$ & $\mathbf{3 . 7 5 9}$ & $\mu_{D}=\mathbf{0 . 4 1 8}$ & $\mathbf{5 . 0 2 0}$ & $\mu_{D}=\mathbf{0 . 3 4 2}$ & $\mathbf{1 . 2 6 0}$ & $\mathbf{- 0 . 0 7 6}$ \\
\hline \hline
\end{tabular}

High importance is also attached to security and energy attributes with the index of $0.459,0.341$ and $0.403,0.550$ in 2002 and 2007 respectively. The importance attached to these attributes have not been stable because apart from security attributes, all other 10 dimensions of attributes appear to have greater weights attached to them in 2007 compared to 2002 that increased the cumulative weight from 3.759 to 5.020 over the years.

\subsubsection{Sources of Poverty}

Even though much importance has been attached to housing attributes, the greatest influence on poverty has been from expenditure on food recording the 
highest poverty ratio of 0.830 and 0.501 in 2002 and 2007 respectively in Table 7.4. This constitutes 15.8 and 12.7 per cent of contribution to deprivation among all categories as shown in Figure 7.1. Despite the fact that some families have subsistence farms to supplement their food needs, the bulk of their earnings is still spent on food. The share of expenditure on food however dropped by more than 3 percentage points between 2002 and 2007 for the households. As the share of expenditure on food is directly linked to the level of income, the prevailing situation of high expenditure on food is therefore an indication of underdevelopment.

The second highest cause and contributor to poverty is the inadequate income that these households have to contend with. The poverty ratio of 0.712 in 2002 and 0.438 in 2007 constituting 13.5 and 11.1 per cent in that order made this source very important. Many families of sizes between two and four persons made net monthly income of between 50 and 100 Ghana cedies in both 2002 and 2007. Fewer families earned monthly income between 100 and 500 Ghana cedies over the period. Rarely did a family of any size exceed 500 Ghana cedies per month. Apparel manufacturing profession even though good is not among the highest paid jobs in the country and thus the low levels of income. In multi-dimensional measure of poverty, inadequacy of income gets compensated for by other attributes not captured in monetary terms. Getting some food stuff from one's backyard garden for example might not be captured in monetary terms but this actually alleviates the severity of lack of income.

Security and safety of location attributes are captured broadly as they include source of families' support in difficult times. Such support may comprised of own resources, government support, family support, friends support and others. Security and safety of location emerged as a very large source of deprivation in 2007 contributing 11.6 per cent compared to 2002 rate of 6.6 per cent. Many household heads during the interviews acknowledged that the cost of living has really been increasing and this might be accounting for that relatively high influence on poverty. The contribution of expenditure on clothing to the deprivation of these households was higher in 2002 reaching the poverty ratio of 0.557 constituting 10.6 per cent, but reduced in 2007 to 0.334 comprising 8.5 percent. 
One more important factor that contributed significantly to poverty is lack of sanitation facilities. Sanitation attributes include toilet facilities indicating whether families have access to private flush toilets or water closets, private squat toilets, public toilets, boreholes or pit latrines. Access to bathing facilities such as indoor bathtubs, indoor showers, total or semi-detached outdoor bathing rooms and others were captured as well. Waste disposal systems very important especially for urban folks involving access to private waste disposal options, public waste disposal options or informal disposal options and others are incorporated. Many households are deprived of some of these facilities. Thus, the poverty index for this attribute was 0.520 in 2002 and 0.360 in 2007 evolving as the fourth major contributor to overall poverty. In fact, it formed 9.9 percent of the index in 2002 and 9.2 percent in 2007.

\section{Figure 7.1}

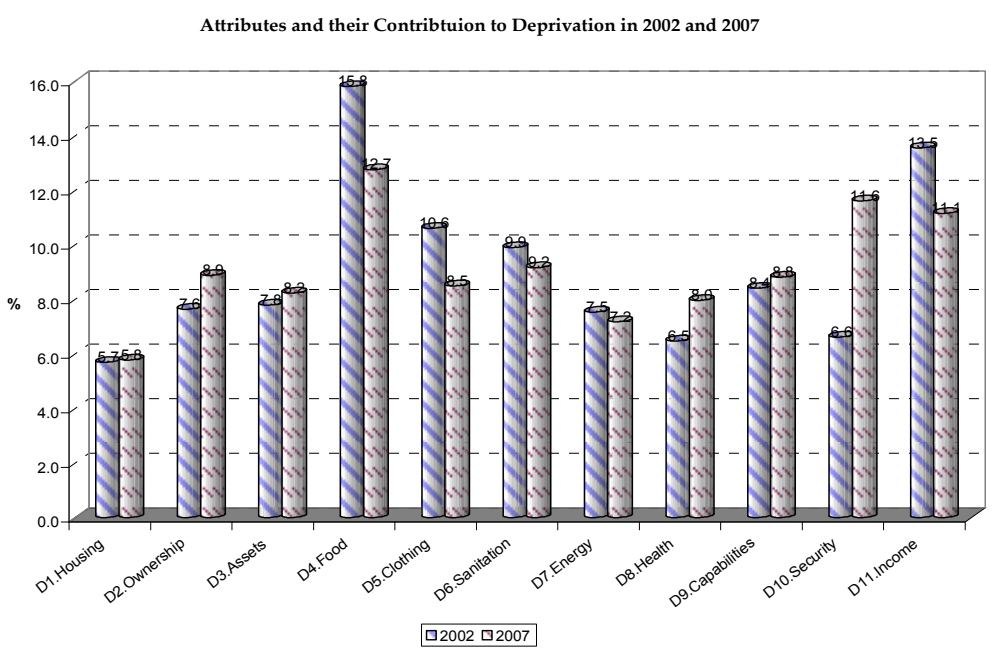

We tried to also look into how central a problem for apparel manufacturing families' ability to own homes by investigating whether the houses in which they live are self-owned, rented, family homes, public apartments and others. Poverty ratio for home ownership was 0.401 in 2002 and 0.349 in 2007 which actually translated to 7.6 per cent and 8.9 per cent respectively. The higher share of percentage contribution to poverty in 2007 seems to indicate that, it is getting more difficult for these people to own homes. Majority of them duel in 
rented homes, a rather costly option as more expenditure on rental payments weighs heavily on their already meager incomes.

On the other hand, considering access to housing in general, apparel manufacturing families do not seem to have much of a problem. The least contributing variable to deprivation in 2002 and 2007 has been access to housing with poverty index of 0.229 and 0.227 correspondingly. These ratios amount to 5.7 percent in 2002 and 5.8 in 2007 in terms of their contribution to population poverty index. It is obvious that barely anything has change with respect to access to housing over the period. Another important source of deprivation is from capability related attributes. We classified them into three categories namely education at home, education at school and education at workplace. The estimated poverty ratio for capability attributes as in Table 7.4 is 0.442 in 2002 and 0.346 in 2007. This ratio translates into 8.4 percent contribution to the population poverty ratio in 2002 and a little bit higher in 2007 reaching 8.2 percent (see Figure 7.1).

Health of apparel manufacturers is vital to the sustenance of their businesses and access to quality health care is a major decision for these households to make. The level of deprivation with respect to access to healthcare was estimated to be 0.340 in 2002 and 0.313 in 2007. This translates into 6.5 percent of total deprivation in 2002 and went up to 8 per cent in 2007. Access to healthcare measures include ones ability to have the services of a private doctor, access to hospitals, access to the services of pharmacist and nurses including midwifery services among others.

Another important source of deprivation is lack of durable and non-durable assets. Durable assets comprise of day-to-day basic stuffs from beds, electric irons, clocks and wristwatches, mobile phones and telephones to more expensive items like television sets, computers, refrigerators, air conditioners and automobiles. Non-durable items include food items for breakfast, lunch and dinner. Poverty index for assets stood at 0.409 in 2002 and 0.324 in 2007. This converts to 7.8 percent contribution to deprivation in 2002 and 8.2 per cent in 2007. It was clear during interviews that whereas many households possess items such as coloured-television sets, only a negligible number possess cars. Since our weighting system is such that less importance is attached to items generally not possessed by many households in the 
population as they might not be seen as needs, inability to possess automobiles and items to facilitate mobility of members of households underlines a developing countries situation where cars are considered luxurious items. Worst of all, the little rise in their contribution to poverty by even 0.4 of a percentage point is no good news.

One last source of deprivation is energy supply to households for lighting, heating and cooking. The deprivation index for energy attributes even though large is among the least contributors to the overall deprivation in both years. It was 0.396 in 2002 but reduces to 0.282 in 2007. The relative contribution to overall deprivation was 7.5 per cent in 2002 and 7.2 per cent in 2007. A reduction of 0.3 of a percentage point highlights the efforts being made by government over the years for most households in Ghana to have access to electricity and in line with the general trend in the country that more and more households across regions and business groups are being connected to the national grid over the years.

In Table 7.5 in appendix 7, poverty index for each of 140 households is presented for 2002 and 2007. The general understanding for the entire 140 households is that, deprivation index, appears to be relatively lower in 2007 compared to 2002. Again in Table 7.5 in appendix 7, we see a disturbing trend where some households are experiencing rising deprivation. The number even though low is noteworthy. There are 13 out of 140 households sampled that are falling deeper and deeper into poverty. The number translates to 9.3 percent of the households in the sample.

\subsubsection{Dynamic Assessment of Poverty}

In this section, we tried to assess the situation of poverty in both time periods by estimating the extent to which poverty is persisting and the level of deprivation likely to be affecting these households at any-time period. Table 7.6 in appendix 7 shows that persistent deprivation index for all 140 households which capture poverty in both 2002 and 2007 stood at 0.34 and any-time poverty index which measures poverty in either 2002 or 2007 stood

at 0.42 . These deprivation indices are quite high for households linked to 
apparel related jobs. Table 7.6 in appendix 7 also presents the index of each of the 140 households.

A look at Figure 7.2 and Table 7.7 in appendix 7 depicts what the dynamics are with respect to the rate of persistence poverty, any-time poverty, those households never in poverty, those households exiting and those entering poverty. Out of the 140 households, poverty continues to persist among 34 percent of them and at any-time, about 42 per cent of the households are likely to be deprived. About 58 per cent of household were never in poverty over the period and 8 per cent of those likely to be in poverty are exiting.

Figure 7. 2:

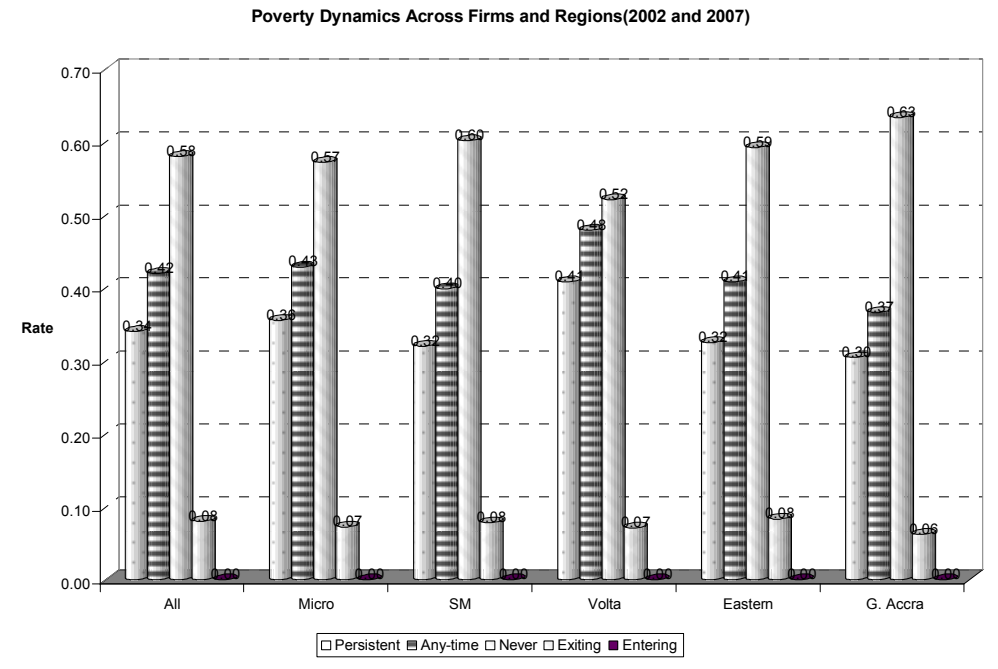

Starting with the rate of persistent of poverty, 36 per cent of households linked to micro firms are likely to have their poverty persisting compare to 32 per cent of households linked to small and medium sized enterprises. With anytime poverty, 43 per cent of households linked to micro firms are likely to be affected compared to 40 per cent for those linked to small and medium sized enterprises. Correspondingly, the proportion of households never in poverty stood at 57 per cent for households linked to micro firms compared to 60 per cent for those linked to small and medium sized firms. More households 
linked to small and medium sized firms appear to be exiting poverty at a faster rate of 8 per cent compared to households linked to micro firms that are exiting at 7 per cent over the period.

Also, we look closely at Figure 7.2 for the distribution of poverty among apparel manufacturing related households across the three regions. Among the three regions, poverty is more persistent in the Volta region measuring up to 41 per cent compared to 32 per cent for Eastern region and 30 per cent for Greater Accra region. The proportion of households never in poverty was 63 per cent for Greater Accra region, 59 percent for the Eastern region and 52 percent for the Volta region. Considering the rates at which households are lifting themselves out of poverty, the best performing region is Eastern with the rate of 8 percent followed by Volta region with 7 per cent and Greater Accra with 6 per cent. Across the three regions, there are not many households that appear to be entering poverty which is an encouraging sign that people are becoming less and less deprived in most of the attributes presented in Figure 7.1.

\subsection{Summary and Conclusion}

In this chapter, we set out to estimate and analyze the incidence of poverty among households linked to apparel manufacturing jobs. We also focused on the sources of this deprivation. Dynamic assessment was also made across households. Deprivation among these households is quite high with poverty index for 140 households estimated to be 41.8 percent in 2002 but dropped to 34.2 percent in 2007. Food deprivation and income inadequacy have been established to be among the highest sources of poverty for these households in the apparel related jobs.

Other important sources of deprivation are inadequate personal capabilities including lack of formal education due to the fact that the apparel sub-sector is known to attract huge numbers of school drop-outs mostly female. Security attributes also ranked high among the crucial sources of poverty. These security attributes include insurance against any unforeseen health and business conditions as well high cost of living. Most of these households are also unable to own their own homes due to low incomes and high expenditure 
on food. However, they are able to rent houses and have made progress with respect to access to energy.

Between 2002 and 2007, we estimated that, on the average, poverty persisted among 34 per cent of the households in the sample and any-time poverty affects 42 per cent of the households. Households linked to small and medium sized firms were relatively less deprived than those connected to micro firms. And among the three regions, the highest rate of deprivation occurred among households linked to firms in the Volta region. Those households connected to firms located in the Greater Accra region have been established to be relatively least deprived compared to those in the Eastern region. 


\section{Appendix 7}

Table 7.5: poverty index of the i-th household and population

\begin{tabular}{|c|c|c|c|c|c|c|c|c|}
\hline $\begin{array}{c}\text { Household } \\
h_{i}\end{array}$ & $\begin{array}{c}2002 \\
\mu_{D}\left(h_{i}\right)\end{array}$ & $\begin{array}{c}2007 \\
\mu_{D}\left(h_{i}\right)\end{array}$ & $\begin{array}{c}\text { Household } \\
h_{i}\end{array}$ & $\begin{array}{c}2002 \\
\mu_{D}\left(h_{i}\right)\end{array}$ & $\begin{array}{c}2007 \\
\mu_{D}\left(h_{i}\right)\end{array}$ & $\begin{array}{c}\text { Household } \\
h_{i}\end{array}$ & $\begin{array}{c}2002 \\
\mu_{D}\left(h_{i}\right)\end{array}$ & $\begin{array}{c}2007 \\
\mu_{D}\left(h_{i}\right)\end{array}$ \\
\hline 1 & 0.45 & 0.31 & 48 & 0.62 & 0.48 & 95 & 0.35 & 0.39\#\# \\
\hline 2 & 0.53 & 0.44 & 49 & 0.34 & 0.32 & 96 & 0.42 & 0.33 \\
\hline 3 & 0.56 & 0.39 & 50 & 0.36 & 0.26 & 97 & 0.37 & 0.31 \\
\hline 4 & 0.37 & $0.47 \# \#$ & 51 & 0.21 & $0.22 \# \#$ & 98 & 0.30 & 0.25 \\
\hline 5 & 0.30 & 0.25 & 52 & 0.37 & 0.32 & 99 & 0.34 & 0.27 \\
\hline 6 & 0.42 & 0.35 & 53 & 0.29 & 0.23 & 100 & 0.41 & 0.31 \\
\hline 7 & 0.48 & 0.40 & 54 & 0.34 & 0.32 & 101 & 0.34 & $0.35 \# \#$ \\
\hline 8 & 0.39 & $0.43 \# \#$ & 55 & 0.41 & 0.30 & 102 & 0.29 & 0.24 \\
\hline 9 & 0.64 & 0.54 & 56 & 0.44 & 0.37 & 103 & 0.70 & 0.63 \\
\hline 10 & 0.67 & 0.44 & 57 & 0.36 & 0.33 & 104 & 0.39 & 0.32 \\
\hline 11 & 0.65 & 0.41 & 58 & 0.35 & 0.29 & 105 & 0.36 & 0.29 \\
\hline 12 & 0.56 & 0.42 & 59 & 0.40 & 0.40 & 106 & 0.45 & 0.30 \\
\hline 13 & 0.56 & 0.41 & 60 & 0.40 & 0.32 & 107 & 0.34 & 0.31 \\
\hline 14 & 0.45 & 0.35 & 61 & 0.34 & 0.26 & 108 & 0.33 & 0.31 \\
\hline 15 & 0.62 & 0.38 & 62 & 0.45 & 0.36 & 109 & 0.40 & 0.35 \\
\hline 16 & 0.51 & 0.38 & 63 & 0.48 & 0.33 & 110 & 0.14 & $0.18 \# \#$ \\
\hline 17 & 0.48 & 0.36 & 64 & 0.52 & 0.37 & 111 & 0.46 & 0.34 \\
\hline 18 & 0.53 & 0.38 & 65 & 0.44 & 0.34 & 112 & 0.37 & 0.31 \\
\hline 19 & 0.47 & 0.29 & 66 & 0.46 & 0.29 & 113 & 0.36 & 0.30 \\
\hline 20 & 0.39 & 0.29 & 67 & 0.45 & 0.38 & 114 & 0.27 & 0.25 \\
\hline 21 & 0.44 & 0.30 & 68 & 0.35 & 0.27 & 115 & 0.28 & 0.23 \\
\hline 22 & 0.77 & 0.51 & 69 & 0.41 & 0.32 & 116 & 0.32 & 0.29 \\
\hline 23 & 0.62 & 0.43 & 70 & 0.47 & 0.35 & 117 & 0.32 & 0.21 \\
\hline 24 & 0.61 & 0.33 & 71 & 0.49 & 0.30 & 118 & 0.33 & 0.31 \\
\hline 25 & 0.43 & 0.33 & 72 & 0.54 & 0.42 & 119 & 0.20 & $0.25 \# \#$ \\
\hline 26 & 0.39 & 0.32 & 73 & 0.41 & 0.27 & 120 & 0.32 & 0.32 \\
\hline 27 & 0.60 & 0.49 & 74 & 0.30 & 0.26 & 121 & 0.24 & 0.26 \\
\hline 28 & 0.52 & $0.64 \# \#$ & 75 & 0.39 & 0.31 & 122 & 0.40 & 0.35 \\
\hline 29 & 0.65 & 0.56 & 76 & 0.35 & 0.29 & 123 & 0.38 & 0.32 \\
\hline 30 & 0.60 & 0.44 & 77 & 0.34 & 0.32 & 124 & 0.35 & 0.28 \\
\hline 31 & 0.40 & $0.42 \# \#$ & 78 & 0.40 & 0.27 & 125 & 0.27 & 0.24 \\
\hline 32 & 0.51 & 0.44 & 79 & 0.41 & $0.46 \# \#$ & 126 & 0.41 & $0.43 \# \#$ \\
\hline 33 & 0.51 & 0.43 & 80 & 0.37 & $0.39 \# \#$ & 127 & 0.26 & 0.21 \\
\hline 34 & 0.44 & 0.38 & 81 & 0.42 & 0.36 & 128 & 0.32 & 0.13 \\
\hline 35 & 0.48 & 0.39 & 82 & 0.40 & 0.39 & 129 & 0.34 & 0.25 \\
\hline 36 & 0.48 & 0.44 & 83 & 0.34 & 0.21 & 130 & 0.33 & 0.28 \\
\hline 37 & 0.48 & 0.39 & 84 & 0.35 & $0.36 \# \#$ & 131 & 0.30 & 0.19 \\
\hline 38 & 0.52 & 0.46 & 85 & 0.49 & 0.40 & 132 & 0.25 & 0.24 \\
\hline 39 & 0.53 & 0.45 & 86 & 0.34 & 0.34 & 133 & 0.37 & 0.30 \\
\hline 40 & 0.51 & 0.44 & 87 & 0.39 & 0.29 & 134 & 0.40 & 0.38 \\
\hline 41 & 0.46 & 0.43 & 88 & 0.43 & 0.37 & 135 & 0.41 & 0.25 \\
\hline 42 & 0.50 & 0.44 & 89 & 0.31 & 0.25 & 136 & 0.39 & 0.29 \\
\hline 43 & 0.44 & 0.38 & 90 & 0.32 & $0.40 \# \#$ & 137 & 0.41 & 0.35 \\
\hline 44 & 0.58 & 0.47 & 91 & 0.39 & 0.33 & 138 & 0.40 & 0.32 \\
\hline 45 & 0.43 & 0.40 & 92 & 0.35 & 0.35 & 139 & 0.35 & 0.28 \\
\hline 46 & 0.45 & 0.34 & 93 & 0.37 & 0.32 & 140 & 0.39 & 0.32 \\
\hline 47 & 0.46 & 0.31 & 94 & 0.42 & 0.24 & $\operatorname{Total}\left(\mu_{D}\right)$ & 0.42 & 0.34 \\
\hline
\end{tabular}

\#\# indicates households with increased deprivation 
Table 7.6: Persistent of Poverty and Any-time Poverty across Households and Population

\begin{tabular}{|c|c|c|c|c|c|c|c|c|}
\hline $\begin{array}{c}\text { Household } \\
h_{i}\end{array}$ & $\begin{array}{c}\text { Persistent } \\
\mu_{D}\left(h_{i}\right) \\
\end{array}$ & $\begin{array}{l}\text { Any-time } \\
\mu_{D}\left(h_{i}\right)\end{array}$ & $\begin{array}{c}\text { Household } \\
h_{i}\end{array}$ & $\begin{array}{c}\text { Persistent } \\
\mu_{D}\left(h_{i}\right)\end{array}$ & $\begin{array}{l}\text { Any-time } \\
\mu_{D}\left(h_{i}\right)\end{array}$ & $\begin{array}{c}\text { Household } \\
h_{i}\end{array}$ & $\begin{array}{c}\text { Persistent } \\
\mu_{D}\left(h_{i}\right)\end{array}$ & $\begin{array}{l}\text { Any-time } \\
\mu_{D}\left(h_{i}\right)\end{array}$ \\
\hline 1 & 0.31 & 0.45 & 48 & 0.48 & 0.62 & 95 & 0.35 & 0.39 \\
\hline 2 & 0.44 & 0.53 & 49 & 0.32 & 0.34 & 96 & 0.33 & 0.42 \\
\hline 3 & 0.39 & 0.56 & 50 & 0.26 & 0.36 & 97 & 0.31 & 0.37 \\
\hline 4 & 0.37 & 0.37 & 51 & 0.21 & 0.22 & 98 & 0.25 & 0.30 \\
\hline 5 & 0.25 & 0.30 & 52 & 0.32 & 0.37 & 99 & 0.27 & 0.34 \\
\hline 6 & 0.35 & 0.42 & 53 & 0.23 & 0.29 & 100 & 0.31 & 0.41 \\
\hline 7 & 0.40 & 0.48 & 54 & 0.32 & 0.34 & 101 & 0.34 & 0.35 \\
\hline 8 & 0.39 & 0.39 & 55 & 0.30 & 0.41 & 102 & 0.24 & 0.29 \\
\hline 9 & 0.54 & 0.64 & 56 & 0.37 & 0.44 & 103 & 0.63 & 0.70 \\
\hline 10 & 0.44 & 0.67 & 57 & 0.33 & 0.36 & 104 & 0.32 & 0.39 \\
\hline 11 & 0.41 & 0.65 & 58 & 0.29 & 0.35 & 105 & 0.29 & 0.36 \\
\hline 12 & 0.42 & 0.56 & 59 & 0.40 & 0.40 & 106 & 0.30 & 0.45 \\
\hline 13 & 0.41 & 0.56 & 60 & 0.32 & 0.40 & 107 & 0.31 & 0.34 \\
\hline 14 & 0.35 & 0.45 & 61 & 0.26 & 0.34 & 108 & 0.31 & 0.33 \\
\hline 15 & 0.38 & 0.62 & 62 & 0.36 & 0.45 & 109 & 0.35 & 0.40 \\
\hline 16 & 0.38 & 0.51 & 63 & 0.33 & 0.48 & 110 & 0.14 & 0.18 \\
\hline 17 & 0.36 & 0.48 & 64 & 0.37 & 0.52 & 111 & 0.34 & 0.46 \\
\hline 18 & 0.38 & 0.53 & 65 & 0.34 & 0.44 & 112 & 0.31 & 0.37 \\
\hline 19 & 0.29 & 0.47 & 66 & 0.29 & 0.46 & 113 & 0.30 & 0.36 \\
\hline 20 & 0.29 & 0.39 & 67 & 0.38 & 0.45 & 114 & 0.25 & 0.27 \\
\hline 21 & 0.30 & 0.44 & 68 & 0.27 & 0.35 & 115 & 0.23 & 0.28 \\
\hline 22 & 0.51 & 0.77 & 69 & 0.32 & 0.41 & 116 & 0.29 & 0.32 \\
\hline 23 & 0.43 & 0.62 & 70 & 0.35 & 0.47 & 117 & 0.21 & 0.32 \\
\hline 24 & 0.33 & 0.61 & 71 & 0.30 & 0.49 & 118 & 0.31 & 0.33 \\
\hline 25 & 0.33 & 0.43 & 72 & 0.42 & 0.54 & 119 & 0.20 & 0.25 \\
\hline 26 & 0.32 & 0.39 & 73 & 0.27 & 0.41 & 120 & 0.32 & 0.32 \\
\hline 27 & 0.49 & 0.60 & 74 & 0.26 & 0.30 & 121 & 0.24 & 0.26 \\
\hline 28 & 0.52 & 0.52 & 75 & 0.31 & 0.39 & 122 & 0.35 & 0.40 \\
\hline 29 & 0.56 & 0.65 & 76 & 0.29 & 0.35 & 123 & 0.32 & 0.38 \\
\hline 30 & 0.44 & 0.60 & 77 & 0.32 & 0.34 & 124 & 0.28 & 0.35 \\
\hline 31 & 0.40 & 0.40 & 78 & 0.27 & 0.40 & 125 & 0.24 & 0.27 \\
\hline 32 & 0.44 & 0.51 & 79 & 0.41 & 0.46 & 126 & 0.41 & 0.43 \\
\hline 33 & 0.43 & 0.51 & 80 & 0.37 & 0.39 & 127 & 0.21 & 0.26 \\
\hline 34 & 0.38 & 0.44 & 81 & 0.36 & 0.42 & 128 & 0.13 & 0.32 \\
\hline 35 & 0.39 & 0.48 & 82 & 0.39 & 0.40 & 129 & 0.25 & 0.34 \\
\hline 36 & 0.44 & 0.48 & 83 & 0.21 & 0.34 & 130 & 0.28 & 0.33 \\
\hline 37 & 0.39 & 0.48 & 84 & 0.35 & 0.36 & 131 & 0.19 & 0.30 \\
\hline 38 & 0.46 & 0.52 & 85 & 0.40 & 0.49 & 132 & 0.24 & 0.25 \\
\hline 39 & 0.45 & 0.53 & 86 & 0.34 & 0.34 & 133 & 0.30 & 0.37 \\
\hline 40 & 0.44 & 0.51 & 87 & 0.29 & 0.39 & 134 & 0.38 & 0.40 \\
\hline 41 & 0.43 & 0.46 & 88 & 0.37 & 0.43 & 135 & 0.25 & 0.41 \\
\hline 42 & 0.44 & 0.50 & 89 & 0.25 & 0.31 & 136 & 0.29 & 0.39 \\
\hline 43 & 0.38 & 0.44 & 90 & 0.32 & 0.40 & 137 & 0.35 & 0.41 \\
\hline 44 & 0.47 & 0.58 & 91 & 0.33 & 0.39 & 138 & 0.32 & 0.40 \\
\hline 45 & 0.40 & 0.43 & 92 & 0.35 & 0.35 & 139 & 0.28 & 0.35 \\
\hline 46 & 0.34 & 0.45 & 93 & 0.32 & 0.37 & 140 & 0.32 & 0.39 \\
\hline \multirow[t]{2}{*}{47} & 0.31 & 0.46 & 94 & 0.24 & 0.42 & Total & & \\
\hline & & & & & & $\left.\mu_{D}\right)$ & 0.34 & 0.42 \\
\hline
\end{tabular}


Table 7.7: Household and the extent to which they were Never in Poverty, Exiting' Poverty and Entering Poverty (2002 and 2007)

\begin{tabular}{|c|c|c|c|c|c|c|c|c|c|c|c|}
\hline Household & Never & Exiting & Entering & Household & Never & Exiting & Entering & Household & Never & Exiting & Entering \\
\hline 1 & 0.55 & 0.15 & 0.00 & 48 & 0.38 & 0.15 & 0.00 & 95 & 0.61 & 0.00 & 0.04 \\
\hline 2 & 0.47 & 0.09 & 0.00 & 49 & 0.66 & 0.01 & 0.00 & 96 & 0.58 & 0.09 & 0.00 \\
\hline 3 & 0.44 & 0.17 & 0.00 & 50 & 0.64 & 0.10 & 0.00 & 97 & 0.63 & 0.06 & 0.00 \\
\hline 4 & 0.53 & 0.00 & 0.10 & 51 & 0.78 & 0.00 & 0.01 & 98 & 0.70 & 0.06 & 0.00 \\
\hline 5 & 0.70 & 0.05 & 0.00 & 52 & 0.63 & 0.05 & 0.00 & 99 & 0.66 & 0.07 & 0.00 \\
\hline 6 & 0.58 & 0.07 & 0.00 & 53 & 0.71 & 0.05 & 0.00 & 100 & 0.59 & 0.10 & 0.00 \\
\hline 7 & 0.52 & 0.08 & 0.00 & 54 & 0.66 & 0.03 & 0.00 & 101 & 0.65 & 0.00 & 0.01 \\
\hline 8 & 0.57 & 0.00 & 0.05 & 55 & 0.59 & 0.11 & 0.00 & 102 & 0.71 & 0.04 & 0.00 \\
\hline 9 & 0.36 & 0.10 & 0.00 & 56 & 0.56 & 0.08 & 0.00 & 103 & 0.30 & 0.08 & 0.00 \\
\hline 10 & 0.33 & 0.23 & 0.00 & 57 & 0.64 & 0.03 & 0.00 & 104 & 0.61 & 0.07 & 0.00 \\
\hline 11 & 0.35 & 0.24 & 0.00 & 58 & 0.65 & 0.06 & 0.00 & 105 & 0.64 & 0.07 & 0.00 \\
\hline 12 & 0.44 & 0.14 & 0.00 & 59 & 0.60 & 0.00 & 0.00 & 106 & 0.55 & 0.15 & 0.00 \\
\hline 13 & 0.44 & 0.15 & 0.00 & 60 & 0.60 & 0.08 & 0.00 & 107 & 0.66 & 0.04 & 0.00 \\
\hline 14 & 0.55 & 0.10 & 0.00 & 61 & 0.66 & 0.09 & 0.00 & 108 & 0.67 & 0.01 & 0.00 \\
\hline 15 & 0.38 & 0.24 & 0.00 & 62 & 0.55 & 0.09 & 0.00 & 109 & 0.60 & 0.06 & 0.00 \\
\hline 16 & 0.49 & 0.13 & 0.00 & 63 & 0.52 & 0.16 & 0.00 & 110 & 0.82 & 0.00 & 0.04 \\
\hline 17 & 0.52 & 0.13 & 0.00 & 64 & 0.48 & 0.14 & 0.00 & 111 & 0.54 & 0.11 & 0.00 \\
\hline 18 & 0.47 & 0.15 & 0.00 & 65 & 0.56 & 0.10 & 0.00 & 112 & 0.63 & 0.06 & 0.00 \\
\hline 19 & 0.53 & 0.18 & 0.00 & 66 & 0.54 & 0.17 & 0.00 & 113 & 0.64 & 0.06 & 0.00 \\
\hline 20 & 0.61 & 0.11 & 0.00 & 67 & 0.55 & 0.07 & 0.00 & 114 & 0.73 & 0.02 & 0.00 \\
\hline 21 & 0.56 & 0.14 & 0.00 & 68 & 0.65 & 0.08 & 0.00 & 115 & 0.72 & 0.05 & 0.00 \\
\hline 22 & 0.23 & 0.26 & 0.00 & 69 & 0.59 & 0.09 & 0.00 & 116 & 0.68 & 0.03 & 0.00 \\
\hline 23 & 0.38 & 0.19 & 0.00 & 70 & 0.53 & 0.12 & 0.00 & 117 & 0.68 & 0.10 & 0.00 \\
\hline 24 & 0.39 & 0.27 & 0.00 & 71 & 0.51 & 0.19 & 0.00 & 118 & 0.67 & 0.02 & 0.00 \\
\hline 25 & 0.57 & 0.10 & 0.00 & 72 & 0.46 & 0.12 & 0.00 & 119 & 0.75 & 0.00 & 0.05 \\
\hline 26 & 0.61 & 0.06 & 0.00 & 73 & 0.59 & 0.13 & 0.00 & 120 & 0.68 & 0.00 & 0.00 \\
\hline 27 & 0.40 & 0.10 & 0.00 & 74 & 0.70 & 0.05 & 0.00 & 121 & 0.74 & 0.00 & 0.02 \\
\hline 28 & 0.36 & 0.00 & 0.12 & 75 & 0.61 & 0.08 & 0.00 & 122 & 0.60 & 0.05 & 0.00 \\
\hline 29 & 0.35 & 0.09 & 0.00 & 76 & 0.65 & 0.06 & 0.00 & 123 & 0.62 & 0.05 & 0.00 \\
\hline 30 & 0.40 & 0.16 & 0.00 & 77 & 0.66 & 0.02 & 0.00 & 124 & 0.65 & 0.07 & 0.00 \\
\hline 31 & 0.58 & 0.00 & 0.02 & 78 & 0.60 & 0.13 & 0.00 & 125 & 0.73 & 0.03 & 0.00 \\
\hline 32 & 0.49 & 0.07 & 0.00 & 79 & 0.54 & 0.00 & 0.05 & 126 & 0.57 & 0.00 & 0.03 \\
\hline 33 & 0.49 & 0.07 & 0.00 & 80 & 0.61 & 0.00 & 0.02 & 127 & 0.74 & 0.05 & 0.00 \\
\hline 34 & 0.56 & 0.05 & 0.00 & 81 & 0.58 & 0.06 & 0.00 & 128 & 0.68 & 0.19 & 0.00 \\
\hline 35 & 0.52 & 0.10 & 0.00 & 82 & 0.60 & 0.01 & 0.00 & 129 & 0.66 & 0.09 & 0.00 \\
\hline 36 & 0.52 & 0.04 & 0.00 & 83 & 0.66 & 0.13 & 0.00 & 130 & 0.67 & 0.06 & 0.00 \\
\hline 37 & 0.52 & 0.09 & 0.00 & 84 & 0.64 & 0.00 & 0.02 & 131 & 0.70 & 0.11 & 0.00 \\
\hline 38 & 0.48 & 0.06 & 0.00 & 85 & 0.51 & 0.09 & 0.00 & 132 & 0.75 & 0.02 & 0.00 \\
\hline 39 & 0.47 & 0.09 & 0.00 & 86 & 0.66 & 0.00 & 0.00 & 133 & 0.63 & 0.07 & 0.00 \\
\hline 40 & 0.49 & 0.07 & 0.00 & 87 & 0.61 & 0.10 & 0.00 & 134 & 0.60 & 0.02 & 0.00 \\
\hline 41 & 0.54 & 0.03 & 0.00 & 88 & 0.57 & 0.06 & 0.00 & 135 & 0.59 & 0.15 & 0.00 \\
\hline 42 & 0.50 & 0.07 & 0.00 & 89 & 0.69 & 0.06 & 0.00 & 136 & 0.61 & 0.10 & 0.00 \\
\hline 43 & 0.56 & 0.07 & 0.00 & 90 & 0.60 & 0.00 & 0.08 & 137 & 0.59 & 0.06 & 0.00 \\
\hline 44 & 0.42 & 0.12 & 0.00 & 91 & 0.61 & 0.05 & 0.00 & 138 & 0.60 & 0.08 & 0.00 \\
\hline 45 & 0.57 & 0.02 & 0.00 & 92 & 0.65 & 0.00 & 0.00 & 139 & 0.65 & 0.08 & 0.00 \\
\hline 46 & 0.55 & 0.10 & 0.00 & 93 & 0.63 & 0.05 & 0.00 & 140 & 0.61 & 0.07 & 0.00 \\
\hline 47 & 0.54 & 0.15 & 0.00 & 94 & 0.58 & 0.17 & 0.00 & All & 0.58 & 0.08 & 0.00 \\
\hline
\end{tabular}

144 


\section{Chapter 8}

\section{Linking Firm Competitiveness/Productivity Growth to Poverty in the Apparel Sector}

\subsection{Introduction}

In this chapter, we attempt to establish the relationship between SMEs competitiveness building through output growth, TFP growth and poverty reduction among micro, small and medium scaled apparel manufacturers in Ghana. This is carried out at two levels viz. (1) ascertain the direction of association between deprivation indicators and competitiveness measures and 2) ascertain the degree of the relationship between these poverty indicators and firm competitiveness indicators. Thus, establish the: i) output growth as well as ii) efficiency and technical change effects on the rates of deprivation/poverty.

In 2003, operationalizing pro-poor growth (OPPG) programme was initiated by Agence française de développement (AFD), Bundesministerium für wirtschaftliche Zusammenarbeit und Entwicklung (BMZ), Kreditanstalt für Wiederaufbau (KfW-entwicklungsbank), Deutsche Gesellschaft für Technische Zusammenarbeit (GTZ), Department for International Development (DFID) and the World Bank to have a better understanding of how to make growth impact on poverty. The idea is that the issue of poverty reduction must be based on country specific conditions which mean that there is no general policy that can work for all countries because of the variations in the level of their economic development, geographical location and culture and ideologies among others.

To do this therefore, there is the need to better understand, within each regional, country and even sectoral context, the channels for the poor to participate in growth, their level of efficiency and the pace of technical change which form the integral part of productivity growth. Efforts to help 
advance and deliberate on the need for further investigation into the sources and drivers of poverty in the world at large and developing countries in particular rest on researchers from all fields.

Using parametric approach, this chapter establishes the effects of output growth, technical change, efficiency improvement, scale change and scale technology on poverty. The choice of the methodology is guided by the nature of data generated from Chapters 5, 6 and 7.

\subsection{Theoretical framework}

Theoretically, it is believed that any changes that lead to gains in productivity should lead to reduction in poverty as suggested by Pineau (2004) and the Centre for the Study of Living Standards (2002 and 2003).

Figure 8.1: $\quad$ Simplifying Framework and Units of Analysis

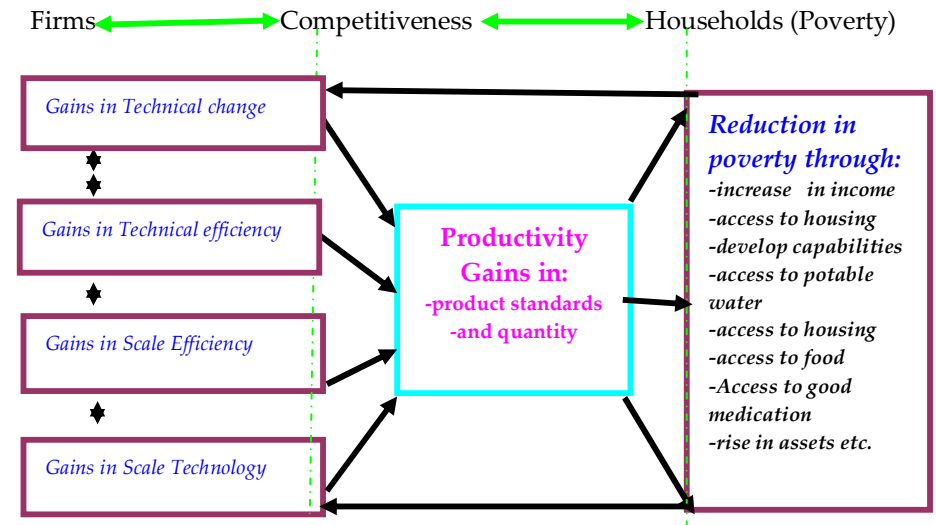

Following the framework in Figure 8.1, any gains in technical change given other components of productivity translates into overall gains in productivity and finally poverty reduction through increase in income, access to housing, develop capabilities, access to potable water, access to food, access to good medication and rise in durable and non-durable assets 
among others. Gains in technical efficiency given other factors leads to productivity gains and a positive effect on the welfare of the apparel related households. Gains in scale efficiency and scale technology should also lead to gains in productivity through product standards improvement or quantity expansion or both and these should affect overall poverty index.

From the previous chapters, technical efficiency measures a firm's success in producing maximum outputs from a given set of inputs. Scale change appraises the changes in output in relation to percentage change in inputs. Technical change considers the shift in production frontier resulting from the application of new technologies or techniques using the same amount of inputs. These were computed for both standards corrected and nonstandards corrected measures.

\subsection{Data Set}

The data set comprised of the response variable namely the rate of deprivation (Poverty) for 140 households and the observed apparel output (y) for 2002 and 2007. Other variables include TFP growth(TFP) defined as output growth not accounted for by the growth in inputs, pure technical change(ptech) regarded as technological progress, pure technical efficiency(peff) described as obtaining optimum amount of output from a given set of inputs, scale efficiency(scale) expressed as attaining optimal size of a firm and scale technology(sctech) defined as operating towards constant returns to scale (non standards corrected and standards corrected estimates) for 140 firms were derived in Chapter 6.

As we can see in Figure 8.2, the variables including our dependent variable (poverty) are not normally distributed. All the variables except our observed outputs ( $\mathrm{y} 1$ and $\mathrm{y} 2)$ were derived from previous chapters. Thus we have the first stage where we derived some of our variables including poverty and second stage where we try to predict poverty using outputs growth, TFP growth and its components as explanatory variables. The variables appear skewed and not normally distributed. 


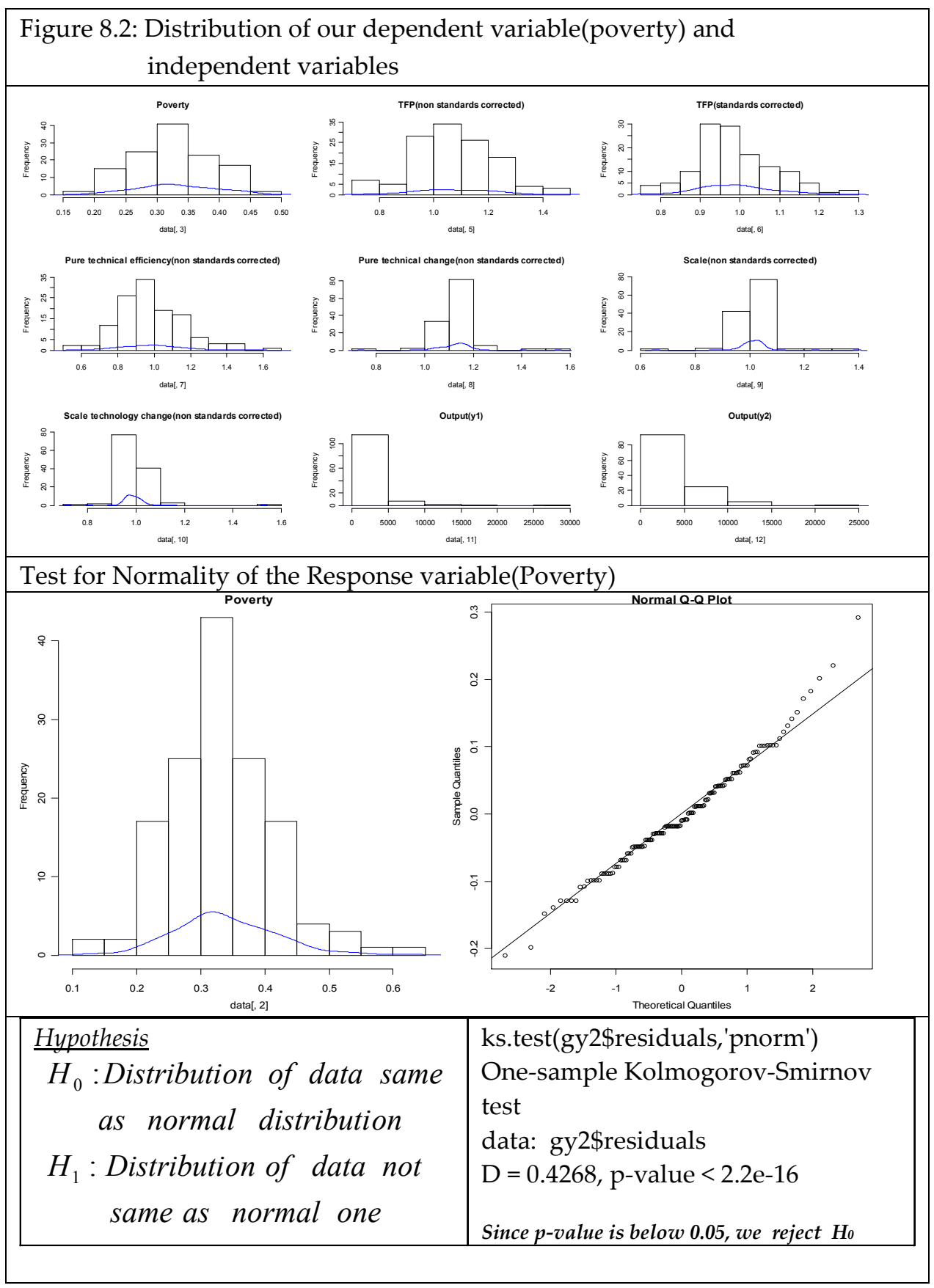




\subsubsection{The main Hypothesis:}

There should be some relationships between Output growth, TFP growth and poverty reduction among apparel manufacturers where growth in output as well as TFP growth should lead to reduction in poverty (Corporation for Enterprise Development in US, CFED, 2002).

\section{Specifically:}

Output growth should lead to a reduction in poverty. TFP growth as well as its components should impact on poverty. The components of TFP growth comprised of pure efficiency change, pure technical change, scale change and scale technology change.

\subsection{The Methodology}

As we are predicting the rates of deprivation among apparel manufacturers and given that productivity growth namely pure technical efficiency change, pure technical change, scale change and scale technology change are also rates, we modeled our rates of deprivation specifically persistent poverty on explanatory variables as defined over the interval $(0,1)$. Functions define over the interval $(0,1)$ could be non linear and exhibit flexible characteristics which must be captured for accurate predictions.

\subsubsection{The Beta Regression Approach and Parameter Estimation}

We have already seen that our variables are derived from estimations in Chapter 7 (poverty), estimations in Chapter 5 (TFP growth) and estimations in Chapter 6 (pure technical efficiency, pure technical change, scale change and scale technology change). These derived variables exhibit some shapes that cannot be ignored. As seen in Figure 8.2, they are skewed and not normally distributed. Predicting poverty derived from fuzzy models requires distributions that model the exact nature of the data and accounts for possible violations of the assumptions of the Normal theory and the 
Central Limit Theorem. The normal theory requires that we have independent and identically distributed random variables but when the variables are derived, they may not be independent. The Central Limit Theorem holds when for large enough samples, the mean of independent and identically distributed random variables are approximately normally distributed.

Based on the nature of our variables, we know that Ordinary Least Squares (OLS) may not be suitable because it assumes that the dependent variable should be unbounded and normally distributed which our response variable (poverty) and other variables violate. The Beta regression is viewed as a generalization of the logistic regression and particularly suitable for modeling dependent variables that violate the assumption of normality. This is the case when the response variable is bounded between 0 and $1(0 \%$ to $100 \%$ ). The level of deprivation among households range from fully non deprived (skewed towards 0 ) to fully deprived (skewed towards 1).

\section{The Beta Regression Model}

Following Ferrari and Cribari-Neto (2004), we let the response variable $\mathbf{Y}=\left(y_{1}, \ldots, y_{n}\right)$ be defined over an open interval such that $y_{i} \in[0,1]$ follows a beta distribution in equation $8.1 \mathrm{a}$ :

$$
8.1 a \pi(y ; \mu, \phi)=\frac{\Gamma(\phi)}{\Gamma(\mu \phi) \Gamma((1-\mu) \phi)} y^{\mu \phi-1}(1-y)^{(1-\mu) \phi-1}, \quad 0<y<1,
$$

where $E(y)=\mu$ is the mean of the response variable and $\phi$ is the dispersion parameter modeled by the gamma function $\Gamma($.). The mean $\mu$ and dispersion parameter $\phi$ are both positive and provide the shape that $y$ assumes. Taking the log-likelihood of equation 8.1a for the $\mathrm{t}$-th observation, we have:

$$
\begin{aligned}
8.1 b \ln \left(y_{t} ; \mu_{t}, \phi\right) & =\log \Gamma(\phi)-\log \Gamma\left(\mu_{t} \phi\right)-\log \Gamma\left(\left(1-\mu_{t}\right) \phi\right) \\
& +\left(\mu_{t} \phi-1\right) \log y_{t}+\left\{\left(1-\mu_{t}\right) \phi-1\right\} \log \left(1-y_{t}\right)
\end{aligned}
$$


Maximizing the sum of the log-likelihoods over $y_{t}$ yields the maximum likelihood estimators. The beta regression model which accommodates heteroscedasticity (variance of the dependent variable varies across the data) and twice differentiable follows a generalised linear model (GLM) which uses the link function $g($.$) to map \mu \in[0,1]$ into observation as:

8.1c $g\left(\mu_{t}\right)=\sum_{i=1}^{k} x_{t i} \alpha_{i}=\eta_{t}=\ln [\mu /(1-\mu)]$, $t=1, \ldots \ldots ., n$ and $i=1, \ldots \ldots ., k, k<n$

where our choice of the link function $g\left(\mu_{t}\right)$ is the logit function expressed as $\mu_{t}=\frac{e^{x_{t}^{T} \alpha}}{1+e^{x_{t}^{T} \alpha}}$ for $x_{t}^{T}=\left(x_{t 1}, \ldots ., x_{t k}\right)$. A row vector of unknown regression parameters are $\alpha=\left(\alpha_{1}, \ldots . ., \alpha_{k}\right)$ and the observations on $\mathrm{k}$ covariates are $x_{1}, \ldots \ldots, x_{k} \quad$ where $\mathrm{k}<\mathrm{n}$. The estimates of $\alpha^{\prime} s$ as well as the standard errors and p-values are obtained through the maximum likelihood procedure using R software package.

From equation $8.1 \mathrm{c}$, we can predict poverty using the predictors [i.e. output growth $(\hat{Y})]$ by estimating: $\ln \left[(\mu /(1-\mu)]=\alpha_{0}+\alpha_{1} \hat{Y}\right.$. For TFP growth, we estimate: $\ln \left[(\mu /(1-\mu)]=\alpha_{0}+\alpha_{1} T F \hat{P}\right.$ (Also see Smithson and Verkuilen (2006).

The statistical significance of the regression parameters $\alpha_{i}$ are tested by dividing parameter estimates $\left(\hat{\alpha}_{i}\right) i=1, . ., k$ by their respective standard errors $\operatorname{se}\left(\hat{\alpha}_{i}\right)$ to get $\left[\hat{\alpha}_{i} / \operatorname{se}\left(\hat{\alpha}_{i}\right)\right]$.

\subsection{Presentation and analysis of results}

We now proceed to analyse the effects of our covariates on poverty and the strength of the association. We modeled the main effects of output growth, TFP growth and their respective components on poverty. 
From Table 8.1, we can see that, there is evidence of statistically significant relationship between the response variable (poverty) and output growth albeit small. The results show negative relationship between output growth and poverty in all estimates (OLS and Beta Regression models). An increase in output growth by one unit given other factors induces a nominal change in poverty by -0.002 units (see Non Standards Corrected Beta Regression model). In the standards corrected estimates, output growth is not statistically significant (see OLS and Beta Regression models in Table 8.1). This is understandable as accounting for product standards may have reduced the growth effects on poverty.

Table 8.1: Results:

Modeling the effects of output growth on Poverty (response variable is persistent poverty)

\begin{tabular}{|c|c|c|c|c|}
\hline & \multicolumn{2}{|c|}{ OLS } & \multicolumn{2}{|c|}{ Beta Regression } \\
\hline & $\begin{array}{l}\text { Non-Standards } \\
\text { Corrected Model }\end{array}$ & $\begin{array}{c}\text { Standards } \\
\text { Corrected Model }\end{array}$ & $\begin{array}{l}\text { Non-Standards } \\
\text { Corrected Model }\end{array}$ & $\begin{array}{c}\text { Standards } \\
\text { Corrected Model }\end{array}$ \\
\hline$\alpha_{0}$ & $\begin{array}{r}0.324^{* * *} \\
(0.011) \\
\end{array}$ & $\begin{array}{r}0.322^{* * *} \\
(0.011) \\
\end{array}$ & $\begin{array}{c}-0.740^{* * *} \\
(0.048) \\
\end{array}$ & $\begin{array}{c}-0.750^{* * *} \\
(0.048) \\
\end{array}$ \\
\hline$\alpha_{\text {Output Growth }}$ & $\begin{array}{l}-0.0004^{*} \\
(0.0002)\end{array}$ & $\begin{array}{l}-0.0001 \\
(0.0001)\end{array}$ & $\begin{array}{l}-0.002^{* *} \\
(0.0008)\end{array}$ & $\begin{array}{l}-0.0002 \\
(0.0004)\end{array}$ \\
\hline$\alpha_{\text {Gender-Male }}$ & $\begin{array}{c}-0.0241^{* *} \\
(0.011)\end{array}$ & $\begin{array}{l}-0.022^{* *} \\
(0.011)\end{array}$ & $\begin{array}{c}-0.109^{* * *} \\
(0.047)\end{array}$ & $\begin{array}{l}-0.104^{* *} \\
(0.048)\end{array}$ \\
\hline$\alpha_{\text {Region-Eastern }}$ & $\begin{array}{l}0.037^{* * *} \\
(0.037)\end{array}$ & $\begin{array}{l}0.032^{* *} \\
(0.013)\end{array}$ & $\begin{array}{l}0.175^{* * *} \\
(0.061)\end{array}$ & $\begin{array}{l}0.153^{* *} \\
(0.061)\end{array}$ \\
\hline$\alpha_{\text {Region-Volta }}$ & $\begin{array}{l}0.105^{* * *} \\
(0.013)\end{array}$ & $\begin{array}{r}0.105^{* * *} \\
(0.013)\end{array}$ & $\begin{array}{c}0.468^{* * *} \\
(0.055)\end{array}$ & $\begin{array}{r}0.468^{* * *} \\
(0.056)\end{array}$ \\
\hline$\alpha_{\text {size-small.medium. }}$ & $\begin{array}{c}-0.031^{* * *} \\
(0.011)\end{array}$ & $\begin{array}{c}-0.033^{* * *} \\
(0.011)\end{array}$ & $\begin{array}{c}-0.144^{* * *} \\
(0.049)\end{array}$ & $\begin{array}{c}-0.151^{* * *} \\
(0.050)\end{array}$ \\
\hline$R^{2}$ & 0.40 & 0.39 & Pseudo R^2: 0.37 & Pseudo $\mathrm{R}^{\wedge} 2: 0.36$ \\
\hline$\phi$ & & & 56.022 & 54.923 \\
\hline \multicolumn{2}{|c|}{$\begin{array}{l}\text { Standard Errors in brackets } \\
* * *=\text { significant at } 1 \% \\
* *=\text { significant at } 5 \% \\
*=\text { significant at } 10 \%\end{array}$} & & $\begin{array}{l}\text { Residual Deviance: } \\
123.9503 \text { on } 119 \\
\text { degrees of freedom }\end{array}$ & $\begin{array}{l}\text { Residual Deviance: } \\
123.9474 \text { on } 119 \\
\text { degrees of freedom }\end{array}$ \\
\hline
\end{tabular}

The estimates of the $R^{2}$ in the OLS models are 0.40 and 0.39 compared with the pseudo $R^{2}$ of 0.37 and 0.36 in Beta Regression respectively. The gender, 
Figure 8.3: Effects of output growth on poverty by location, gender and firm size(Beta Regression)
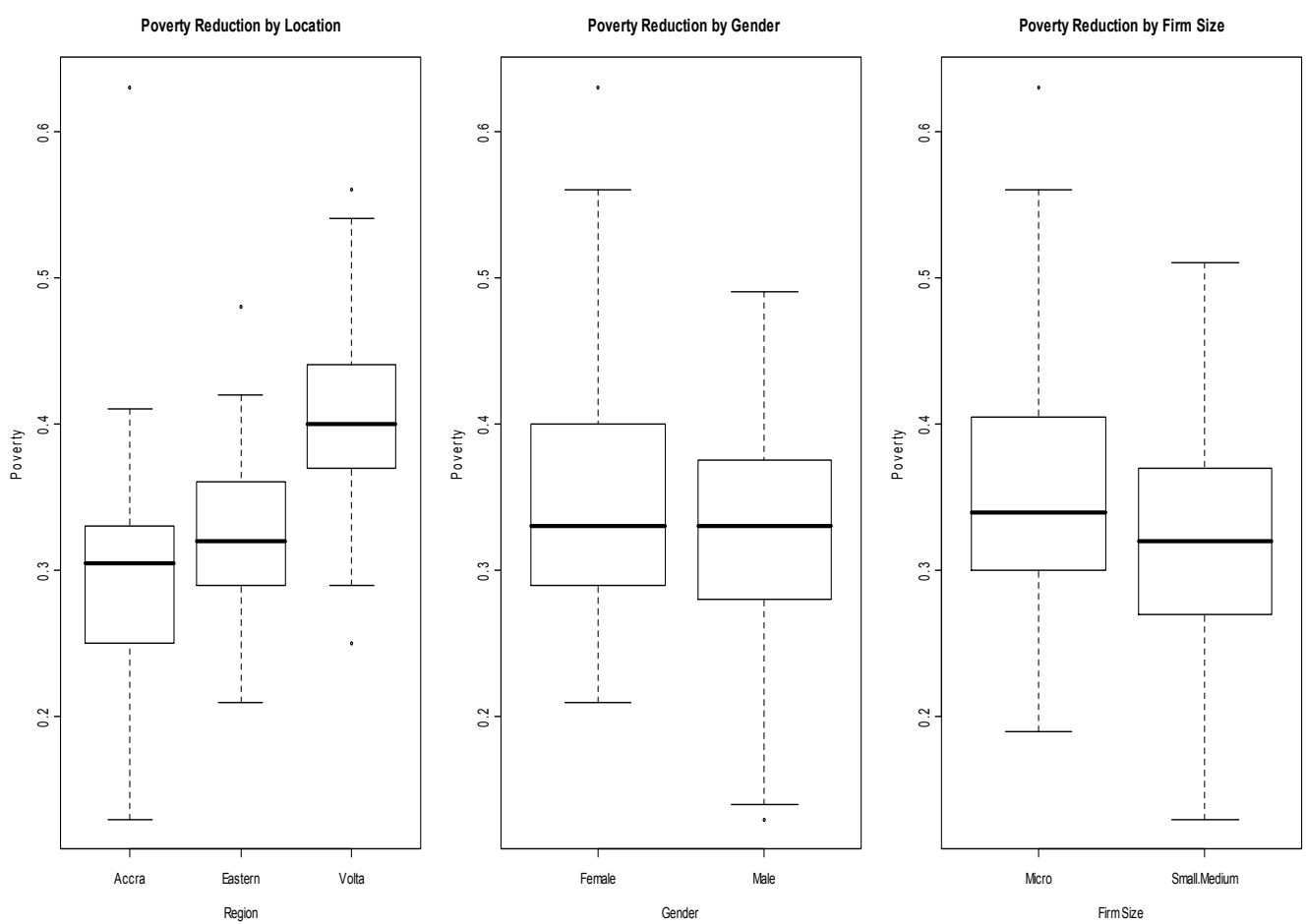

\begin{tabular}{|c|c|}
\hline & Model \\
\hline$\alpha_{0}$ & $\begin{array}{r}-0.740^{* * *} \\
(0.048) \\
\end{array}$ \\
\hline$\alpha_{\text {Output Growth }}$ & $\begin{array}{c}-0.002^{* *} \\
(0.0008) \\
\end{array}$ \\
\hline$\alpha_{\text {Gender-Male }}$ & $\begin{array}{r}-0.109^{* * *} \\
(0.047)\end{array}$ \\
\hline$\alpha_{\text {Region-Eastern }}$ & $\begin{array}{c}0.175^{* * *} \\
(0.061)\end{array}$ \\
\hline$\alpha_{\text {Region-Volta }}$ & $\begin{array}{r}0.468^{* * *} \\
(0.055) \\
\end{array}$ \\
\hline$\alpha_{\text {Size-small.med.. }}$ & $\begin{array}{c}-0.144^{* * *} \\
(0.049) \\
\end{array}$ \\
\hline$\phi$ & 56.022 \\
\hline \multicolumn{2}{|c|}{$\begin{array}{l}\text { Standard Errors in brackets } \\
* * *=\text { significant at } 1 \% \\
{ }^{* *}=\text { significant at } 5 \%\end{array}$} \\
\hline
\end{tabular}

Since our results indicate that output growth has been the significant source of poverty reduction among apparel manufacturers over the 2002 and 2005 period, Figure 8.3 depicts the results by location, gender and firm size (results in leftpanel).

By location, the boxplots (upper-panel) show that Greater Accra region experienced the lowest rate of poverty with the median of about 0.3 (30\%---see thick line in the boxes) compared to the Eastern region (32\%) and Volta region (39\%) with the highest rate of deprivation.

Among gender groups, rate of deprivation appear to be higher among women than men (both have same median of about 0.33 ).

By firm size, households linked to small and medium sized firms experienced lower rates of poverty (median $=0.32$ ) compared to households linked to micro firms (median $=0.33$ ).

The results in the estimated model (left column) show significant differences among location, gender and firm size groups. 
location and size relationships with poverty which are all statistically significant are summarized in Figure 8.3. The dispersion parameters $\phi^{\prime}$ 's in the Beta Regression are 56.022 and 54.923 respectively and the residual deviance of 123.95 on 119 degrees of freedom and 123.95 on 119 degrees of freedom(for Non-standards corrected and Standards corrected models) indicate that the models are quite adequate. Diagnostic analysis of residuals, checking for independence of errors and that errors are not correlated with output, back up the adequacy of the model specification and eschew concerns about the problem of endogeneity.

In Table 8.2, we modeled the main effects of TFP growth and it components on poverty. Thus continuing from our results in Table 8.1, where we modeled the effects of output growth on poverty among apparel manufacturers, TFP growth isolates that part of output not accounted for by inputs. It is obvious that TFP growth did not have any significant effect on poverty reduction among apparel manufacturers over the 2002 and 2007 period (Models 2i and 2ii).

By modeling the main effects of the components of TFP growth namely pure efficiency (peff), pure technical change (ptech), scale change (scale) and scale technology change (sctech) on poverty, we established that all the four components did not reveal any statistically significant relationships(Models $2 a$ and $2 b$ ). The signs are right as exposed by the results but pure efficiency (peff), pure technical change (ptech), scale change and scale technology change (sctech) have not been enough to affect poverty significantly over the period. Our estimated residual deviance in Models 2i, 2ii, 2a and $2 \mathrm{~b}$ all indicate acceptable results and adequacy of the models estimated.

Finally, the hypothesis that TFP growth has had any significant effect on poverty over the period was not borne out by the results. This holds true for all the components of TFP growth as well. The results make sense as the output growth by some firms in the apparel sub-sector over the 2002 and 2007 period was completely offset by the negative growth rates in other firms. Inefficiency has dragged down modest gains in technological change rendering TFP growth effects weak. 


\begin{tabular}{|c|c|c|c|}
\hline Model 1a & Coefficient & Std. Errors & $\operatorname{Pr}(>|z|)$ \\
\hline$\alpha_{0}$ & -0.664 & 0.1729 & 0.0001 \\
\hline$\alpha_{\text {TFP(non stand. corrected) }}$ & -0.005 & 0.1548 & 0.9738 \\
\hline$\phi$ & 33.5844 & & \\
\hline \multicolumn{4}{|c|}{ Residual Deviance: 137.0389 on 138 degrees of freedom } \\
\hline Model $1 \mathrm{~b}$ & Coefficient & Std. Errors & $\operatorname{Pr}(>|z|)$ \\
\hline$\alpha_{0}$ & -0.722 & 0.2886 & 0.0123 \\
\hline$\alpha_{\mathrm{TFP}(\text { stand. corrected) }}$ & 0.053 & 0.2919 & 0.8554 \\
\hline$\phi$ & 33.59249 & & \\
\hline \multicolumn{4}{|c|}{ Residual Deviance: 137.0361 on 138 degrees of freedom } \\
\hline \multicolumn{4}{|c|}{ Model 2a: Non Standards Corrected } \\
\hline & Coefficient & Std. Errors & $\operatorname{Pr}(>|z|)$ \\
\hline$\alpha_{0}$ & 1.348 & 3.482 & 0.699 \\
\hline$\alpha_{p e f f}$ & -0.011 & 0.1713 & 0.947 \\
\hline$\alpha_{p t e c h}$ & 1.907 & 1.185 & 0.107 \\
\hline$\alpha_{\text {scale }}$ & -3.044 & 2.328 & 0.191 \\
\hline$\alpha_{\text {sctech }}$ & -1.087 & 1.695 & 0.521 \\
\hline$\phi$ & 34.38767 & & \\
\hline \multicolumn{4}{|c|}{$\begin{array}{l}\text { Residual Deviance: } 137.1150 \text { on } 135 \text { degrees of } \\
\text { freedom }\end{array}$} \\
\hline \multicolumn{4}{|c|}{ Model 2b: Standards Corrected } \\
\hline & Coefficient & Std. Errors & $\operatorname{Pr}(>|z|)$ \\
\hline$\alpha_{0}$ & 1.36 & 3.482 & 0.696 \\
\hline$\alpha_{p e f f}$ & -0.011 & 0.1713 & 0.947 \\
\hline$\alpha_{p t e c h}$ & 1.907 & 1.185 & 0.108 \\
\hline$\alpha_{\text {scale }}$ & -3.05 & 2.328 & 0.19 \\
\hline$\alpha_{\text {sctech }}$ & -1.093 & 1.696 & 0.519 \\
\hline$\phi$ & 34.38826 & & \\
\hline
\end{tabular}




\subsection{Summary and Conclusion}

In this chapter, we attempt to answer the research question on whether we can establish any connection between poverty reduction and output growth on one hand and poverty reduction and TFP growth on the other hand, over the 2002 and 2007 period. Our results indicate that output growth had some effect on poverty reduction and that pure technical efficiency change, pure technical change, scale change and scale technology change did not significantly reduce poverty. Pure technical change as a component of TFP growth was expected to have some significant effect on poverty but the expectation was not borne out by the results indicating that not enough progress has been made.

Correcting for product standards (the standards corrected models) appeared to have diminished the effect of output growth on poverty reduction (as the main effects of output growth on poverty reduction were not statistically significant). In the non standards corrected estimates, the effect of output growth on poverty was obvious with statistically significant relationship clearly established. The main effects of the components of TFP growth supported the hypothesis that TFP growth did not have any significant effect on poverty reduction over the period (in both non standards corrected and standards corrected models). This is troubling because lack of TFP growth can only lead to lost of firm competitiveness and deeper deprivation among apparel manufacturers with output growth coming only from other sources instead of firms engaging in more technically efficient operations coupled with technological progress. 


\section{Chapter $9^{31}$}

\section{CASE STUDIES}

\section{(Textile-Apparel industry in Ghana)}

\subsection{Introduction}

This Chapter focuses on the information from interviews the author conducted in some major textile and apparel manufacturing companies in Ghana. The intention is to assess the performance of the top textile companies and top apparel manufacturing companies in the country. Even though the focus was on these six companies, it is not limited to them alone as we carried out some studies on other large companies in Ghana as well. The assessment of the textile industry centers around both indigenous manufacturers of textile specifically 'Kente' for niche markets in Ghana, Europe, US and other parts of the world on one hand and those companies producing standard textile products for domestic and foreign markets on the other. The top three apparel manufacturing companies are also analyzed with respect to products for niche markets and those standard products for common markets in Ghana and abroad.

\subsection{Methodology}

The interviews sought to find answers to how new technologies in general and ICT in particular as well as other strategies are contributing to the survival, growth and general performance of the companies. To do this, companies were taken on case by case basis and discussions conducted with managers or their representatives on the measures the companies have adopted since their inception in responding to the changing international trade rules and domestic

\footnotetext{
${ }^{31}$ Most parts of this chapter are published in a book entitled 'Innovation Policies and International Trade Rules-The Textiles and Clothing Industry in Developing Countries' Edited by Kaushalesh Lal and Pierre A Mohnen. Palgrave Macmillan, 2009
} 
policies. Some semi-structured questionnaire and interviews were employed. The questions and interviews centered on the history of the firm or company, product profile, growth in employment, cost of production and types of technology being used. Other questions were on role of ICT and government policy in company performance. The extent of linkages to downstream main markets and networks among others also form part of the questioning. Other secondary information was also obtained during the interviews to support the discussions and follow-ups were carried out later for more information. Discussions were also held and information obtained from some stakeholders such as Ghana Export Promotion Council and some members of Association of Ghana Industries (AGI).

\subsection{Profile of Sampled Companies}

The randomly selected textile and apparel companies are the Printex Limited Company formerly known as the Millet Textile Corporation, Akosombo Textile Limited (ATL), Ghana Textile Printing (GTP) and a Pagbo Kente Weaving Village to represent indigenous Kente weavers producing for domestic and foreign markets. The apparel companies comprise of The Global Garments and Textile Limited, Sleek Garments Exports and Premier Quality Limited.

\subsubsection{Printex Limited Company (formerly Millet Textiles Corporation)}

Printex limited company is 100 per cent owned by Ghana and it is a private limited company. It started as Millet Textiles Corporation in the late 1950s and has since being transformed to Spintex Limited in 1980. It is totally into textile production engaging in vertically integrated activities such as spinning, weaving and finishing departments until 2000 when the spinning department was completely closed down and weaving department was partially closed down, a deliberate strategy to remain in business and in operation as a result of intense competition from giant producing countries such as China which has unlimited access to the Ghanaian markets due to unrestrictive trade liberalization climate prevailing in Ghana. The company produces a range of textiles products namely furnishing materials, suiting, shirting, school

uniforms, traditional dress materials and factory work clothing materials among others. 
These decisions saw the number of employees of the company dropped from record levels of 1100 including management staff in 1985 to undesirably low of 300 in 2005, consist of 367 percentage dropped from the 1985 attainment. There was however, showed some signs of improvement with some marginal increase by 100 people in 2007 and perhaps signs of recovering from the downward trend that has characterized the company since 1985 with this 33 per cent improvement.

\subsubsection{Akosombo Textile Limited}

Established in 1967 as a Ghanaian venture, Akosombo Textile Limited (ATL) is located within the Eastern Region of Ghana in Akosombo. The plant which operates for 24 hours a day has a Dyeing and Finishing Capacity of 30 million yards a month. ATL main line of business activities are in weaving, spinning and finishing. Operating from a site with land area of 47 acres, provides more opportunity to modernize and expand and it was in responding to competitive business environment being presented by products from China and other parts of the world that about 950 billion old Ghana cedis (over 94 million US dollars) worth of wax print machinery was installed in 2005. This was a partnership arrangement between A. Brunnschweiler and Company (ABC) based in UK and ATL to boost production and export and to improve upon the quality of their products.

From spinning and weaving through quality inspection, cotton stores, water treatment tanks, wax printing and rotary screens printing, to dyeing and finishing plant, chemical store and apartments, ATL has maintained its reputation as a giant textile company in Ghana and it is by far the largest employer within the textile industry with workforce of 1,400 in 2007 which has dropped compared to 2003 figure of 1450 about 3 percentage points reduction. Unlike other companies which have either effected massive layoffs or closed down completely in the face of dumping from other countries, ATL is still performing relatively better amid intense competition. Apart from Real Wax and African Fancy Prints, which have been patronized by consumers over the years, ATL is also known for its high quality designs and materials targeting at this stage the local market which comprise up to 80 per cent of the demand. The demand for ATL products is however not limited to Ghana as they sell well beyond the boundaries of Ghana. 
However, ATL, like many other textile companies has its own grievances emanating from the unfair competition and market environment prevailing in Ghana where some textile products find their way into the market through illegal routs, evading all the taxes and thereby setting lower prices for their items. Considering the relatively poor average Ghanaian consumer who is more likely to be influenced more by price than quality, the choice is obvious. To address this concern, the government is charged to curb the smuggling of such items into Ghana as goods intended for other neighboring countries such as Togo somehow find their way into the Ghanaian market.

\subsubsection{Ghana Textile Printing (GTP)}

Ghana Textiles Printing is a subsidiary manufacturing company of Vlisco which was established in Holland in 1846. As a joint venture, known as GTP, between Vlisco, the Government of Ghana and some firms from United Kingdom, started production of Real Wax in 1966 and has maintained a good image among other apparel manufacturers in Ghana in particular and in West Africa in general. Located in the city of Tema, some $25 \mathrm{~km}$ from Accra the capital of Ghana, GTP maintained about 500 workforce by 2007 having threatened to close down in 2005 and laying-off of about 700 workers due to difficult market conditions. The difficulties of GTP was also compounded by the problems with the sister company Juapong Textile Limited (JTL) which supply yarns to GTP. JTL has laid-off it workforce of 1000 people since 2005 and announced its closure but has since struggled to re-start to no avail.

\subsubsection{The Pagbo Kente Village}

Pagbo Kente Village is made up of a group of weavers pooling resources together to form a cooperative business with the aim of imparting and training the youth in the art of weaving. It is located at Ho in the Volta Region of Ghana. The objective is to establish Kente weaving as a tradition that should attract the youth since its trade has been and it is still lucrative in both the domestic and international market. Unlike the standard textile and apparel manufactured across the globe, Kente is unique in the sense that it is only produced in Ghana and mostly by the Ewe and Ashanti tribes. 
Registered in 1995 as a sole proprietor business, the village has earned an enviable reputation among the Kente weavers in the region whose products are patronized by buyers from USA and Europe. This is as a result of good customer relations developed by honoring quality specifications and contract agreements as well as onetime delivery. The village is managed and directed by Mr. Gbortsyo under whose initiative it was set up. The textile village also serves as a training center for foreigners who seek to learn new skills in Kente weaving or developed and upgrade their skills. The village has networks with the Kente Weavers Association of Ho.

The company which started with one person operating two looms currently employs thirteen people and operating fifteen international looms and producing quality Kente cloth for both men and women and batakari made of yarn and sewing tread. The technology is relatively simple and comprise of international looms. The raw material inputs which are obtained from Kpetoe, Agbosome, Ho and Accra townships normally constitute about 33 per cent of the production cost. The raw material inputs are obtained in line with customer specifications to satisfy the demand for the products not only on special occasions and royal use but for weddings as well. The operating capacity is currently 50 per cent and expected to approach 65 per cent by 2009 and increase further in the following year. With initial capital of about 50 US dollars in 1992 (not registered then), the company has grown and developed to about 20,000 US dollars in value by 2008. So far the demand for the products has far exceeded the capacity of production and has only been able to satisfy 30 per cent of the domestic market whilst demand from USA and Europe are still not being met. This means that more expansion needs to take place and even though international looms have been installed progressing from the traditional ones, more sophisticated faster industrial looms would need to be developed so as to enhance both loom and labour productivity. The local price for a piece of male Kente cloth varies from 250 to 400 US dollars.

\subsubsection{Sleek Garments Export}

Sleek Garments Export is located in the Garment Village, a Free Export Processing Zone in Accra. Registered in 2002, it is a private limited company. It is also a sister company of Sleek Fashion Ltd. Sleek Garments is 
one of the companies that was set up in response to Export Promotion Action Plan being implemented by the Ministry of Trade under the Presidential Special Initiative (PSI) on Textile and Garments since 2001. The company is purely export oriented and exports to the European and US markets in addition to some African countries. Products range from trousers to uniforms, shirts, skirts, shorts, ladies pants and blouses among others. Some of the buyers include Superior Uniform Group, WALMART and RORTEX. Seeking to be competitive in both domestic and international markets, the company emphasizes the production of quality products that are price competitive and cutting cost through that use of latest technologies.

Sleek Garments therefore has an array of technologies namely Double Needle Chain Stitch, Single Needle Lock Stitch, Double Needle Lock Stitch, Kansa machine b2000sc and Pocket creasing machines. Others include Electric snap fixing machines, Eastman cutting machines, End Cutter, Zig Zag machine, Thread safety Stitch Machines, Blind Stitch Machine and Feed of the arm chain stitch machine with 3 needle. As at 2007, the company was operating 8 production lines of 40 machines each and employing 470 people. The company has established a reputation for producing good quality products and often cited as one of the few success stories in garment exports. Sleek Garments has also established networks with companies in US such as the Ross Stores that provide direct market by placing huge orders. An example is the 75,000 pieces order of shirts that was shipped to Rose Stores in 2007. Supported by benefits in locating at the export processing zone, Sleek Garments targets the huge unexploited US and African markets.

\subsubsection{Global Garments and Textile Limited}

The Global Garments and Textile Ltd Company was established in 2004 and it is one of the companies located within the Free Export Processing Zone in Accra. It is a private company being 100 per cent owned by Ghanaians and employing 570 people as at 2007 almost twice their 2005 workforce of only 300. Enjoying some support from the government through exemption from tariffs on exports and imports in addition to the provision of the factory premises for rental and some 10 years tax holidays, only 8 per cent of tax applied and so Global Garments is experiencing an amazing growth. There 
are however, other tariffs such as ECOWAS levy of 0.5 per cent and Export Development Levy of 0.5 per cent among others that they are being met.

The mainline of business is garment manufacturing with specialization in uniforms for police and military, hospital and home fabrics, casual wear including shirts, trousers and skirts are also produced. Modern textile and apparel manufacturing technologies from China and Japan consisting of Juki and Gemsy machines operating at 96 per cent and 92 per cent of their respective capacities and producing 25,000 pieces of shirts in a single shift per month are being employed. The company has installed as many as 1,115 sewing machines together with 19 head embroidery technologies by 2007. However, apart from labour cost which constitutes the bulk of operational cost, high energy cost hitting 2000 dollars (over 2000 GH cedis) per month forms another large component of the company's production cost. The main markets are the US and EU whilst the company has networks with Japan International Cooperation Agency (JICA) and West African Trade Hub.

\subsubsection{Premier Quality Ltd.}

Premier Quality Company has a factory area of 17,200 square feet and located in an 178-acre export processing zone situated at Tema, some $25 \mathrm{~km}$ South East of Accra. It started operation in 2003 to take advantage of AGOA and other incentives from the government of Ghana in promoting garments exports and generating employment for the youth. It is 100 per cent privately owned and as at 2007 has employed 360 people compare to the 2005 figure of 200 people, an indication of growth of the company with production reaching the capacity of 33,000 woven pieces per month and 26000 pieces of knit products. Efforts to deliver on time, honour contracts and ensure quality products has put them in better position to compete internationally. Compared to textile companies, large garments companies

in Ghana are relatively newly started and most of them began as a result of good business environment in the country and market opportunities abroad.

In order to be among the best, latest industrial apparel manufacturing machines are being employed by Premier Quality. As at 2007, production is carried out with 210 industrial sewing machines and other specialized equipments. Among them are 120 Single Needle Lockstitch machines and 
Thread Overlocks of different types. The company also has 11 Bartack, 10 Lockstitch, 7 flat Lock and 6 Kasai among others. There are different types of modern apparel manufacturing equipments to help in the production of ladies and gents pants, shorts and ladies blouses. Products also include ladies dresses and skirts, men's shirts, bib pants and worker suits. The rest are jogging jackets and fleeced jackets. Premier Quality Company is much into Cut-Make-Trim (CMT) production which is basically cutting, sewing and finishing stages in garment production but it is also a labour intensive technique of manufacturing in line with giving jobs to as many people as possible. Its main export market is the US.

\subsection{Assessment of Sampled top Textile and Apparel Companies}

\subsubsection{Technology Transfer and Skills Acquisition}

Responding to questions on technological position of the companies, the author gathered that latest technologies including ICT are being employed in both textile and apparel manufacturing. The companies have constantly invested in new technologies and training of staff. ATL for example is competing favorably with other manufacturers with their Real Wax and African Fancy Prints. With their current six plants including Dying and finishing plant, new investments from sister company $\mathrm{ABC}$ up to the tune of 94 million dollars, movement of the production of standard wax to Ghana to satisfy the local demand has lead to the transfer of the latest machinery and equipment to Ghana. To maintain the quality standards associated with $\mathrm{ABC}$, workforce has been highly trained to man these equipments. Movement of production from developed countries to Ghana in the labour intensive textile production could help in the transfer of technological skills to the local people. New designs of wax prints helps in introducing innovative products to the markets and currently $A B C$ develops about 200 of these designs annually. With 1,144 weaving looms and 30,240 spindles, ATL is striking a balance among techniques that would safeguard its competitiveness.

A company such as GTP is employing the best technologies in responding to the taste of their customers. These technologies might not necessarily be cost saving because they are a blend of fast automated processes together with 
more traditional manual operation in the creation of their block prints patronized by West African Markets. With already 800 designs in stock, new ones are continually being created. The GTP Company is a joint venture between the Government of Ghana, a Dutch Company Vlisco and Lever Brothers and some other firms in United Kingdom such that latest technologies when there is the need are transferred by their parent companies. The complain is that because the Chinese use automated processing in producing the entire print, it is of low quality and cost saving than the GTP technique of using manual techniques to produce the block print.

\subsubsection{Product Profile}

There are two broad categories of textile and apparel products manufactured in Ghana by the sampled firms - the Afro- centric and standard products. The Afro-centric products are basically from different varieties of Kente products. They include men and women cloths, men and women African inspired shirts, stoles, tablecloths, handbags, place mats, Kente neck and bow ties, smocks. These products are mainly for niche markets sold locally and abroad. The other category includes the standards products that are meant for the mass market. They include uniforms, shirting, yarn, grey cloth and print fabric, men and women top, professional clothing, including lab coats, Scrubs, \& surgical gowns. The standard products are produced by the big textile and apparel companies such as ATL, GTP, Printex and GTMC, Global Textile and Garments, Sleek Garments and Premier Quality Ltd.

\subsubsection{Declining Production Capacity}

The output performance of the textile industry supported by the 'big four' namely GTMC, ATL, GTP and Printex as noted previously has been declining since 1970 and the Table 9.1 gives an idea of the state of some of these companies in 2005 compared to 1970. Interviews with the management of these companies provided some understanding as to the poor showing in the capacity to produce. The 'big four' produce what can be classified as 'standard products' where the competition for market share in is very high both at home and abroad. Even a company like the GTMC which does not 
export finds it difficult to compete at home. The problem with these imports competing industry arises from the domestic policies governing textile and apparel manufacturing. In Ghana, there is currently a 12.5 per cent value added tax (VAT) and 2.5 per cent national health insurance levy (NHIL) making it a total of 15 per cent tax on finished products. Compared to Nigerian companies those enjoy 0 per cent VAT, duty incentive grant of 10 per cent, and export expansion grant of 30 per cent. With all these incentives Nigerian textile industry also has huge protection with a ban on all finished textile products. ATL is one of the few companies that has managed to rise up to the challenge of competing within the highly liberalized market even though it is also been affected

Table 9.1: Change in production capacity of four major textile firms(in million yards)

\begin{tabular}{llll}
\hline Company & $\begin{array}{l}1970 \\
\text { Output } \\
\text { (Mil. Yards) }\end{array}$ & $\begin{array}{l}2005 \\
\text { Output } \\
\text { (Mil. Yards) }\end{array}$ & \%change \\
\hline \hline GTMC & 15 & 2.24 & $-85.10 \%$ \\
ATL & 13 & 18 & $38.50 \%$ \\
GTP & 30.7 & 9 & $-72.30 \%$ \\
Printex & 6 & 9.84 & 64 \\
\hline
\end{tabular}

Source: computed from data cited in Peter Quartey (2006)

\subsubsection{Price Competitiveness in the Domestic Market}

The Chinese and other Asian products are crowding out the made in Ghana products partly due to huge differences in prices. Figure 9.1 depicts market prices situation for some selected textile products. The price of Ghana textile products is over 4 times higher than the Chinese wax print and buyers naturally go for the cheaper products because of economic reasons. This is because the Chinese use fully automated production processes compared to Ghanaian firms. Apart from the Dutch wax, Ghana textile print is relatively less competitive than even the Togo Wax. Pirated logos and designs of the 
companies are believed to be contributing to the flooding of the markets by fake products that are sold at prices several times lower than the original counterparts. The managers of textile companies are rethinking their strategies as to whether to continue producing quality products and being able to compete or to go down the low road producing low quality and selling at lower prices to unsuspecting buyers. Unlike the complaints from the textile companies, the apparel companies appear to be facing different set of challenges such as being able to attract contracts in the foreign markets and being able to deliver on time and according to the specification.

The evidence points to the fact that the woes of textile companies emanate from the domestic market that their products are designed for. The local consumers currently have several options to go for used clothing and textile products or to go for relatively cheap products that have been smuggled into the local markets or even to go for pirated ones unknowingly because of low income and shifting in taste for western products. Efforts are being made to reintroduce the local consumers to made- in-Ghana products by promoting a nation-wide cheap and affordable National Friday Wear.

Figure 9.1: Price differences of textile print in percentage with respect to China

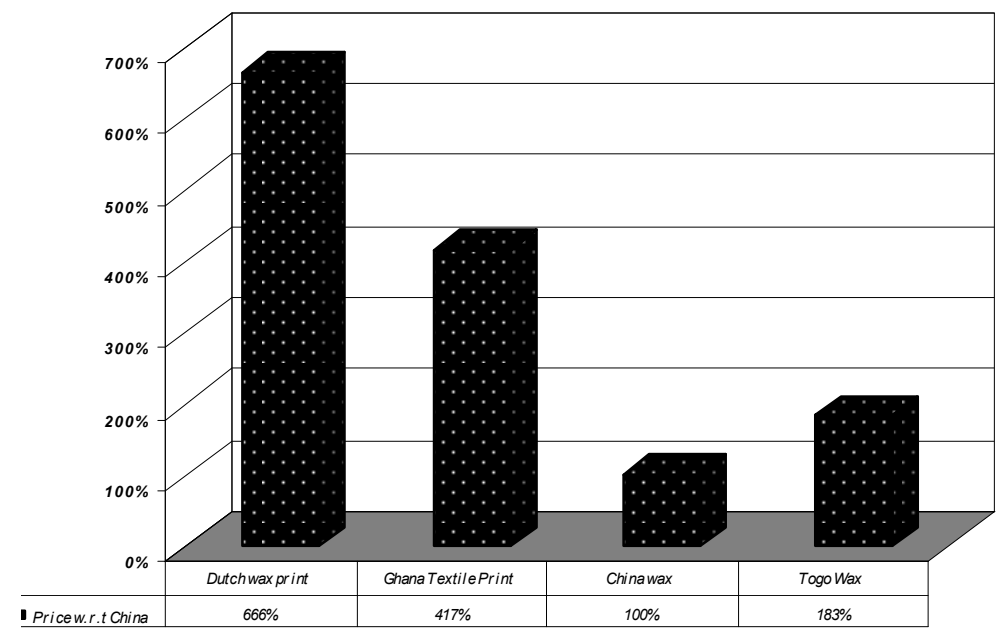

Sources: Interviews in 2008 


\subsubsection{Increasing delays in delivery times}

Based on our primary study and other secondary sources Biggs et al (1994) delivery schedules continue to post headache for Ghanaian exporters. In the first quarter of 2008, exporters from Tema Port to United States were taking longer time to US than it was five six years back (Table 9.2). Compared to other countries especially from Asia, Ghana is disadvantage when it comes to shipment of textile and apparel products to US due to few shipping lines that tend to charge way beyond what Asian countries like India pay.

Table 9. 2: Changes in Delivery Times of Exports to Unite States

\begin{tabular}{lccc}
\hline Origin & Destination & $\begin{array}{c}\text { Total Time } \\
\text { (in days) }\end{array}$ & Year \\
\hline \hline $\begin{array}{l}\text { Tema Port } \\
\text { Ghana }\end{array}$ & $\begin{array}{l}\text { East Coast of } \\
\text { United States }\end{array}$ & $21-25$ days & 2002 \\
Tema Port & East Coast of & $38-46$ days & 2008 \\
Ghana & United States & & \\
\hline
\end{tabular}

Sources: Interviews in 2008

With high ocean freight and delays at the ports due mainly to bureaucratic administrative procedures at the local ports, AGOA is likely not to be of optimal benefits to the exporters in particular and the nation as a whole. Even though the US market is there for exporters to exploit, it does not come easy. For example an exporter can not just wake up and start exporting to US without having first built the networks and the reputation to entice bulk purchase. 


\section{Chapter 10}

\section{Discussion and Conclusions}

In this chapter, we sought to discuss the research questions that we specified in Chapter 1 and investigated in the latter chapters. The main issue is to establish the effects of output and TFP growth rates on poverty among small and medium scaled apparel manufacturers with focus on the role of technical change. We know that TFP growth is part of output growth not explained by the growth of production inputs. Growth in output could totally come from increasing the use of production inputs especially when TFP growth is absent. In the previous chapters, we had sought to study the issues one at a time and the final results and conclusions are brought together as follows:

1) Have SMEs within the apparel industry in Ghana built Competitiveness overtime through Technical Change, Technical Efficiency, Scale Efficiency, TFP Growth in general and output growth in particular?

Output growth across firms has been particularly anemic with some nominal growth of 15.13 per cent over the period which is largely due to a few firms with positive growth. The rate of TFP growth (non standards corrected and standards corrected) among SMEs in apparel manufacturing businesses was assessed in Chapter 5. TFP on the average indicate 13 per cent growth when non standards corrected measure was employed but no growth at all in the standards corrected measure. This partly explains why the two measures are important in making a better assessment because what is revealed by one measure might not necessarily show up in the other. Apparently these firms are losing out in product standards development. In all size and location groups firms are losing competitiveness through weak TFP growth.

In Chapter 6, the role of pure technical change in TFP growth was established to be widespread as 77.1 per cent of the 140 firms have been estimated to have experienced significant technological progress through 
increasing applications of new techniques and apparel manufacturing machines. Pure technical inefficiencies have been established to be prevalent as well and the proportion of firms falling behind was estimated to be 38.5 per cent compared to only 33.6 per cent of those catching up (non standards corrected measure). At the regional level only 35.6 per cent of firms from the Volta region were catching up with best practiced firms compared to 27 from Eastern region and 36.5 percent from the Greater Accra region. Scale efficiency has remained relatively unchanged among these 140 firms.

In conclusion therefore, the question as to how the SMEs within the apparel industry in Ghana have built competitiveness over time through technical change, technical efficiency, scale efficiency and TFP growth has been investigated. The prevailing TFP growth rates among these SMEs are not enough to keep them in business. The only positive news was provided by the widespread technical change among firms in the sub-sector but these gains are being offset by the respective technical inefficiencies.

In terms of technical change, some progress has already been made and the efforts must be encouraged through increasing application of technologies such as Double Needle Chain Stitch, Single Needle Lock Stitch, Double Needle Lock Stitch and Kansa machine b2000sc among others. Investment in building apparel manufacturing capabilities through continuous application of new technologies such as computer-aided designing, computer-aided manufacturing and automated multi-dimensional sewing technologies are necessary. This will help the apparel industry, an industry considered by many to be for the low skilled workers and the poor to survive in this liberalized economy.

With respect to dealing with technical inefficiencies, training and development of skills necessary in the application of state of the art industrial sewing machines should be facilitated. Many more Clothing Technology Training Centers (CTTC) such as the one in Accra should be established across all regions and districts to help build capacity to train manufacturers in the use of latest industrial sewing machines. This should include undertaking of R\&D on how to enhance the existing techniques and make them work at various stages of the production process. CTTCs 
facilities designated for Kumasi and Takoradi in an effort to develop the critical mass of human resource to feed small and medium sized textile and garment enterprises located within the Export Processing Zone and industrial hub of Ghana and beyond should be extended to micro firms. All the CTTCs should be equipped with cutting edge technologies including computer aided design technology an example of a broader information and communication technology (ICT) for accelerated development policy to boost the skills of these manufacturers. The scale inefficiencies have not been a problem over the period and the current sizes of these SMEs are no problem to their global competitiveness especially as the apparel industry is moving gradually away from mass scale production to tailor made products. Product standards can be improved with greater technical efficiency in the application of new technologies.

(2) What is the nature and depth of poverty/deprivation among the apparel manufacturers in Ghana?

In Chapter 7, dynamic assessment of the nature and depth of poverty/deprivation among the apparel manufacturers in Ghana revealed the incidence of deprivation across households linked to apparel manufacturing in three regions namely Volta, Eastern and Greater Accra. Deprivation in all attributes aggregated into eleven dimensions among these households is quite high with the mean composite index estimated to be 41.8 per cent in 2002 but dropped to 34.2 percent in 2007. Food deprivation and income inadequacy have been estimated to be among the highest sources of poverty for these households in apparel related jobs. Other sources of deprivation include inadequate personal capabilities as well as formal education due to the fact that apparel sub-sector is known to attract huge numbers of school drop-outs mostly female. Security attributes also ranked high among the crucial variables.

Between 2002 and 2007, we estimated that, on the average, poverty persisted among 34 percent of the households in the sample and any-time poverty affected 42 percent of the households. Households linked to small and medium sized firms have been relatively less deprived than those connected to micro firms. And among the three regions, the highest rate of deprivation 
occurred among households linked to firms in the Volta region. Those households connected to firms located in the Greater Accra region have been established to be relatively least deprived than those in the Eastern region.

In conclusion therefore, policy measures to help protect these households connected to micro, small and medium scaled apparel manufacturing jobs are needed. The crucial areas include building capabilities, acquiring insurance to insure their health at least if not their businesses and the need to help them in acquiring at least their workspace. Public facilities should therefore be developed and rent out to these manufacturers at reasonable prices so as to reduce the pressure of having to compete for workspace from private owners at exorbitant prices.

To what extent is this poverty/deprivation connected with and is explained by the performance/competitiveness of their businesses?

In Chapter 8, we tried to address the research question on the extent of relationships between poverty and TFP growth among apparel manufacturers over the period. Our results indicate that output growth had some significant effects on poverty reduction albeit not a large one as one unit rise in output has the odds of reducing poverty by less than one unit. However, TFP growth and its components namely pure technical efficiency, pure technical change, scale change and scale technology change did not significantly reduce poverty over the 2002 and 2007 period.

In conclusion, even though our findings agree with Lall (2001, p. 2) that poverty can be reduced by building competitiveness in manufacturing industry in general, the effects in the apparel sub-sector in particular as evidence by some impact of output growth on poverty has been limited. TFP growth and its components did not have any effect on the level of deprivation over the 2002 and 2007 period. Emphasis on technical efficiency and increasing application of new technologies are needed to make decisive the impact of TFP growth on deprivation among apparel manufacturers. However, care should be taken so as not to make technical change counter productive as the sub-sector can gradually move away from labour-intesive operations especially when the processes are automated to capital- intensive operations. There is therefore the need to strike a balance between the extent 
of automation and manual processes in order to keep people in business, take them out of poverty and keep them out of it.

(4) How can the businesses of textile and apparel manufacturers in general be improved upon in Ghana? (General Findings and Policy Recommendations)

The findings in Chapters 4 and 9 showed that the pre-liberalization ${ }^{32}$ gains in the sector could be pinned down to a few factors and the protection that these firms enjoyed before the 1980s. The textile firms such as GTP were able to establish themselves as the main companies producing to satisfy the taste of the local customers. Focusing on the local market meant that the international trade agreements such as MFA and first Lome Convention to open oversea markets were little exploited. Thus, the capacity utilization in the textile industry got to its peak in 1977 recording 60 per cent. By 1970, the import substitution agenda initiated in the late 1950s and the bigger government involvement in the production of essential items enabled the big four textile companies, GTMC, ATL, GTP and Printex to produce one of their biggest outputs yet. Among the four of them, they produce a total of 64.7 million yards of textile of which GTP accounted for 30.7 million yards, followed by GTMC's 15 million yards, ATL 13 million and the lowest coming from Printex that recorded 6 million yards by 1970. It could be said that there was a departure form the free trade philosophy advocated by the GATT in 1947 as many countries sought to protect their domestic markets against textile and apparel products from international markets flooding their markets. For Ghana, the big textile companies expanded and employed up to 25,000 people in the 1970s compared to only 7000 by 1995 .

The liberalization period actually ushered in serious competition from international producers that the textile and apparel industry was not used to. It was thought that about two decades of protection would have given them ample time to build up capacities and become competitive but unfortunately that was not the case. It must be said that the protection even led to the shortage of basic textile and clothing products in the domestic

32 The pre-liberalization period (1957-1983), the liberalization period (1984-2000) and the period dubbed the 'Golden Age of Business' (2001-2009). 
market as local demand could hardly be met by the local producers and this went beyond the textile and apparel industry to nation-wide shortages of basic products such as soap and meat items. From capacity utilization rate of 60 per cent in 1977 in the textile industry, that dropped to a low of 17.3 per cent by 1984. The situation was mixed with the garment industry as it experienced mixed fortunes in the liberalization era with the capacity utilization for large and medium sized companies rising slightly from 20.2 per cent in 1984 to 25 per cent in 1987 but then decreased to 22 in 1981 and up again to 53 per cent by 1993. Both Textile and garment companies appeared to have responded to the external competition by increasing their combined capacity utilization from only 18 per cent in 1984 to 45.7 per cent by 1993 . In line with the recovery in capacity utilization, the growth in textile and garment manufacturing production showed an improvement as well. From 22.9 percentage growth rates in 1986, two years after liberalization, there was a marked improvement to 28.7 per cent in1988, dropped a little in the following year to 24 per cent and increased again to 39.1 per cent in 1991. The subsequent years displayed no consistent pattern of growth even the rates were very unpredictable hitting 60.2 per cent in 1993, the highest registered over the 13 year period.

In the period so-called the 'Golden Age of Business' in which Ghana has developed better relationship with US, EU and the rest of the world, both the textile and clothing trade with the world, displayed some disturbing trends that even the current PSI on textile and garments has failed to address. The nation is still a net importer of the textile and clothing products that comparative advantage with respect to labour cost comparable to Asian countries and abundance of mid-level textile and garment skills should make the nation export more than it actually imports. Over the 1998 to 2006 period, not in a single year, in both textile and clothing trade with the world did the nation export more than it imported as the difference for textile rose from 33 million dollars in 1992 to over 100 million in 2006. The same applied to the performance in clothing as well rising from 10.9 million to 25 million dollars.

The PSI on textile and garments as well as AGOA have essentially been supportive of the garments companies located within the Free Zone area but has not impacted on the textile industries which have survived several 
decades of policy shocks. Diffusion of old innovations such as electricity to help in the production process has actually not attained that critical mass and frequent power outages have been identified as impacting negatively on the sector. The sampled companies have kept on losing their competitive position with each passing day. The declining productive capacity coupled with relatively higher prices compared to products from competitors has contributed to this situation. Delay in delivery times being experienced by the Ghanaian exporters compared to their Asian competitors is proving to be a serious challenge especially for garment industry. However, the industry can be expressed as having great potential and those can fully be realized when effort is made to address not only domestic problems but to also get bilateral and multilateral negotiations right. The textile industry in particular is suffering from unique problems such as pirating of designs that only a well laid down policy to curb this from within can be effective.

Findings of the study suggests that although international trade rules such as AGOA and Lome Convention have contributed to some extent in the improvement in the performance of garment sector, governance has been a major problem for the expected growth of both textiles and garments sectors. For the garments sector government has to help exporters by providing better and efficient shipments facilities. One of the possible ways could be to provide single window services to exporters for shipment and delivery in international markets. For the textile sector, which is predominantly domestic oriented, government can help local producers by enforcing existing piracy laws, and if needed it might enact suitable new legislation to curb the menace of smuggling and other illegal trading activities. Firms in textiles sector need to encourage the adoption of automated production technologies. We conclude that good governance coupled with international trade rules could change the present levels of performance of textiles and clothing industry in Ghana.

\subsection{Some other contribution of the study}

Product standards have become very important in the competitiveness building of firms. Defined variously as technical specifications of production

processes, products and services standards have increasingly been used as a disguised tool and barrier to international trade. The goal of many firms 
especially SMEs in developing countries is therefore not only to maximize profits but to meet these ever changing standards so that they can survive in this era of increasing globalization. This thesis accounted for standards in productivity assessment as the technological choice and adoption by firms is in part driven by the aim to meet these technical requirements. Two arguments can be advanced namely:

First, producers and suppliers of any product or service generally have some ultimate goals. The traditional theory of production explains that the ultimate goal of firms and businesses is to maximize profits or revenues. It is not surprising therefore, that firms declare their profits and revenues periodically to establish the extent to which they are attaining the goals that have been stated in the production theories for ages. But when critical assessment is made of the producers and the way they behave, it becomes clear that even though most, if not all, producers will claim that their ultimate goal is to maximize profits or revenues, except of course for the socalled non-profit oriented firms, which also want to survive anyway, the ultimate goal of all firms and businesses is to survive. There is no firm on earth, which is immune to death and so all available means are employed to ensure that the businesses survive. Profit or revenue maximization or not, all firms want to remain in business. The question we then ask is: why do almost all of those in business claim that their ultimate goal is to maximize profits or revenues which are in consonance with the classical and the neoclassical theories of production? The answer is simple, profit or revenue motives are merely proxies of survival and that the actual goal is not the amount of profits or revenues declared by these businesses per se but the extent of survival itself. The reality is that the extent of survival is not easy to measure but profits and revenues can easily be measurable.

Secondly, the conditions under which firms from developed countries build competitiveness are different from those of the developing countries and so are their targets. It is evident that models of induced technical change, evolutionary theory and path dependence theory emphasize the conditions and the targets of firms from developed countries. For example, whilst firms of developed nations might be thinking of how to save labour and cut total cost of production, labour can be employed at relatively competitive rates in developing countries. In developing countries, cost cuts are important but 
the main goal to remain competitive is to meet some minimum local and international product/service standards without which product sales and export is not possible. The task, challenging as it was, in this study we defined measures to account for standards in productivity and competitiveness assessment and captured poverty as a multidimensional phenomenon as oppose to a single measure of income approach.

\subsection{Limitations of the study and prospects for further research}

This study is essentially a micro-based evidence research on the role of technical change in competitiveness building through productivity growth. The ultimate aim was to establish the link between firm competitiveness and the livelihoods of those directly involved in these businesses. Thus, we covered a sample of 140 micro, small and medium sized apparel manufacturing firms located within three regions in Ghana. There are ten regions in Ghana and many insights could be gained by extending the investigation to cover the rest of the seven regions in order to have a much broader picture of the state of businesses and poverty across the country. More so, the study focused only on micro, small and medium sized apparel manufacturing firms leaving out large companies because of the intention to investigate pro-poor businesses which are understood to be worst hit by the increasing globalization and free market environment currently prevailing in Ghana.

To understand the state of some large textile and apparel manufacturing businesses in Ghana meant that we carried out case studies of some few companies. However, even though the performance of these businesses was established, the study did not focus on the link between productivity growth of these large firms and the livelihoods of those associated with them. The link between performance of large firms and poverty may constitute an entirely separate study outside the scope of this study. In future studies, a study of large firms and cross-country comparisons will provide many insights. 


\section{REFERENCES}

- Abramovitz, M. (1956): "Resource and Output Trends in the United States Since 1870", American Economic Review, May 46 (2), 5-23.

- Acemoglu, D. (2001): Directed Technical Change. NBER Working Paper No. 8287.

- Aghion, P. and Howitt, P. (1992: "A Model of Growth through Creative Destruction". Econometrica 60: 323 - 351.

- AGI, (2007): "Textile and Garments, Food Processing and Wood Processing. The country case of Ghana". A draft report (unpublished)

- Ahiakpor, J.C. W. (1989): “Do Firms Choose Inappropriate Technology in LDCs? Economic Development and Cultural Change, Vol. 37, No. 3. (Apr., 1989), pp. 557-571.

- Ahmad, S. (1966): "On the Theory of Induced Innovation". Economic Lournal, 76: 344-57

- Amor-Wilks, D. A. (2007): "Peasants, Settlers and Weavers in Africa. Structural and Institutional Change in a 'Peasant' and 'Settler' Economy of Africa: Ghana and Zimbabwe, 1890-2000". Department of Economic History, London School of Economics and Political Science.

- Ampofu-Tuffuor, E., DeLorme, C. D. and David R Kamerschen (1991): "The Nature, Significance, and Cost of Rent Seeking in Ghana". Kyklos, 1991, vol. 44, issue 4, pages 537-59.

- Antonelli, C. (2003): "The Economics of Innovation, New Technologies and Structural Change". Studies in Global Competition Series, Routledge, London.

- Appiah-kubi, K.; E. Amannning-Ampomah and C. Ahortor (2007): "Multidimensional Poverty Analysis in Ghana using Fuzzy Set Theory", PEP PMMA working Paper 
- Aryeetey, E. and A. McKay (2004): “Ghana: Operationalizing ProPoor Growth: Ghana Case Study. Papers from the International Conference on "Shared Growth in Africa" La Palm Royal Beach Hotel, Accra, Ghana, July 21-22 by ISSER/Cornell/World Bank/DFID/USAID.

- Asante, Y. (2002): “A Case Study of the Manufacturing Sector in Ghana". Paper Presented at an AERC Workshop in Kampala, Uganda. November 13 - 162002.

- Atkinson, A. B. and F. Bourguignon (1982): "The Comparison of Multi- dimensioned Distribution of Economic Status", Review of Economic Studies 49, 183-201.

- Atkinson, Anthony B. and J. E. Stiglitz (1969): A New View of Technological Change". Economic Journal. 79, Sept. 1969, 573-578.

- Barro, R., and X. Sala-i-Martin (1995). "Technological Diffusion, Convergence, and Growth," Lournal of Economic Growth 2, 1-26.

- Baumol, W.J. and E.N. Wolff (1988): "Productivity growth, convergence, and welfare": Reply. American Economic Review 78

- Betti G., Cheli B. (2000): “A model for the dynamics between two fuzzy states": theoretic advances, in J. Blasius, J. Hox, E. de Leeuw, P. Schmidt (eds.), Proceeding of the Fifth International Conference on Logic and Methodology, October 3-6 2000, Cologne, Germany.

- Betti G., Cheli B., Lemmi A., Verma V., (2006): “On the construction of fuzzy measures for the analysis of poverty and social exclusion", Statistica \& Applicazioni, 4(1), pp. 77-97.

- Betti G., Verma V. (1998): "Measuring the degree of poverty in a dynamic and comparative context: a multi-dimensional approach using fuzzy set theory", Working Paper no. 22, Dipartimento di Metodi Quantitativi, Università di Siena.

- Biggs, T., Miller, M.; Otto C. and Tyler, G. (1996): “Africa Can Compete! Export Opportunities and Challenges for Garments and Home Products in the European Market,' World Bank Discussion 
Papers, Africa Technical Department Series, No. 300, IBRD, Washington.

- Binswanger, Hans P. (1974): “The Measurement of Technical Change Biases with Many Factors of Production", American Economic Review 64, 964-976

- Blomstrom, M. and A. Kokko Ari, (1997): "How foreign investment affects host countries", Policy Research Working Paper Series 1745, The World Bank

- Borger, Bruno D. and K. Kerstens (2000): "The Malmquist Productivity Index and Plant Capacity Utilization". Scandinavian Lournal of Economics, Vol. 102, No 2. (June 2000)

- Brehm, J. and S. Gates(1993). "Donut Shops and Speed Traps: Evaluating Models of Supervision on Police Behavior," American Lournal of Political Science, May, Pp. 555-581.

- Busy Internet (2003): "ICT-Enabled Development Case Studies Series: Busy Internet (Accra)". An initiative of IICD and bridges.org.http://www.bridges.org/case_studies/127

- Caves, D., L. Christensen and W. E. Diewert (1982): “The Economic Theory of Index Numbers and the Measurement of Input, Output, and Productivity". Econometrica 50, 1393-1414.

- Cerioli A., Zani S. (1990): “A Fuzzy Approach to the Measurement of Poverty, In Dagum C., Zenga M. (1990), Income and Wealth Distribution, Inequality and Poverty". Springer-Verlag Berlin Heidelberg, pp.272-284

- Chamberlain, E. (1947): "The Theory of Monopolistic Competition", 5th Edition, Cambridge: Harvard University Press.

- Charnes A., W. W. Cooper, E. Rhodes. (1981): “Evaluating Program and Managerial Efficiency: An Application of Data Envelopment Analysis to Program Fellow Through". Manage Science, Vol. 27, No. 6. (Jun., 1981), pp. 668-697. 
- Chavas J. and T. L. Cox. (1999): “A Generalized Distance Function and the Analysis of Production Efficiency". Southern Economic Lournal, Vol. 66, N. 2. (Oct., 1999), pp. 294-318.

- Cheli B., Lemmi A. (1995): “ A Totally Fuzzy and Relative Approach to the Multidimensional Analysis of Poverty", Economic Notes by Monte dei Paschi di Siena, Vol. 24, 1-1995, pp. 115-134

- Chemingui, A.M. and A. Isaksson (2003): "Explaining productivity change in Morocco". Research and Statistics Branch Staff Working Paper 09/2007. (UNIDO).

- Clark, J., C. Freeman and L. Soete, (1981): "Long Waves, Inventions, and Inno- vations," Futures, August, 4, 308-22.

- Cobb, Charles W. and P. H. Douglas (1928): "A Theory of Production". The Review of Economics and Statistics, Vol. 18, No. 1.(Mar.., 1928), pp. 139-165

- Cohen, D. L.; M. A. Tribe (1972): "Suppliers' Credits in Ghana and Uganda - An Aspect of the Imperialist System". The Journal of Modern African Studies, Vol. 10, No. 4. (Dec., 1972), pp. 525-541.

- Corporation for Enterprise Development in US, CFED(2002)

- Costa, M. (2002): “A Multidimensional Approach to the Measurement of Poverty", IRISS Working Paper 2002-05, CEPS/INSTEAD, Differdange, G.-D. Luxembourg.

- CSLS (2002 and 2003): “Centre for the Study of Living Standards Research Reports", 111 Sparks Street, Ste. 500, Ottawa, ON K1P 5B5

- Dagum, C. (2002): “Analysis and measurement of poverty and social exclusion using fuzzy set theory. Application and policy implications". University of Bologna.

- Dagum, C. and M. Costa (2004): “Analysis and Measurement of Poverty. Univariate and Multivariate Approaches and their Policy Implications. A case of Study: Italy", In Dagum C. and Ferrari G. (eds.); Household Behaviour, Equivalence Scales, Welfare and Poverty, Springer Verlag, Germany, 221-271. 
- Datt, G. and M. Ravallion. (1998): “Farm Productivity and Rural Poverty in India".Journal of Development Studies, April, vol. 34 (4), pp.62-85.

- Dawson, D., Gravelle, H., O'Mahony, M., Street, A., Weale, M., Castelli, A., Jacobs, R.,Kind, P., Loveridge, P., Martin, S., Stevens, P. and Stokes, L. (2005): "Developingnew approaches to measuring NHS outputs and productivity: final report". York Centre for Health Economics. Research Paper 6.

- Denison, E.F. (1964): "The Unimportance of the Embodied Question". American Economic Review 54, 90-93.

- Desai, M., S. Fukuda-Parr, C. Johansson and F. Sagasti (2002): "Measuring the Technology Achievement of Nations and the Capacity to Participate in the Network Age". Iournal of Human Development, Vol. 3, No. 1,2002

- Domar, Evsey D.(1963): "Total Productivity and the Quality of Capital". Journal of Political Economy 71:6 (December 1963), 586-88.

- Dosi, G. (1988): "Sources, Procedures, and Microeconomic effects of Innovation". Journal of Economic Literature. 1988, 26:1120-71

- Dosi, G., D. Teece and J. Chytry, (1998): “Technology, Organization, and Competitiveness - Perspectives on Industrial and Corporate Change". Print ISBN-10: Oxford

- Dubois, D. and Prade, H.(1980): "FuzzySets and Systems: Theory and Applications". New York: Academic Press.

- Durand, D. (1937): "Some Ihoughts on Marginal Productivity, with Special Reference to Professor Douglas' Analysis." Lournal of Political Economy 45, no. 6 (December ): 740-58.

- Dzisah, J. (2006): “Science Technology \& Society. Information and Communication Technologies and Development in Ghana". Science Technology Society 2006,11;379 
- Edmondson, N. (1973): "Capacity Utilization in Major Materials Industries." Federal Reserve Bulletin, August: 564-566.

- Enos, J. L. (1995): "In pursuit of science and technology in SubSaharan Africa: The impact of structural adjustment programmes". UNU/INTECH Studies in New Technology and Development. Routlet 11 New Fetter Lane, London EC4P 4EE.

- Evenson, R. E., \& Westphal, L. E. (1994): “Technological change and technology strategy". UNU/INTECH Working Paper No. 12.

- $\quad$ Färe, R., S. Grosskopf and E. Kokkelenberg (1989): “Measuring Plant Capacity, Utilization and Technical Change: A Nonparametric Approach". International Economic Review 30, 655-666.

- $\quad$ Färe, R., S. Grosskopf, S-K. Li (1992): “Linear Programming Models for Firm and Industry Performance". Scandinavian Journal of Economics, 94(4), 599-608.

- Fare, R., S. Grosskopf and P. Roos (1995), "Productivity and quality changes in Swedish pharmacies", International Journal of Production Economics, 1995, vol. 39, issue 1-2, pages 137-144

- Ferrari, SLP and F. Cribari-Neto (2004): "Beta Regression for Modelling Rates and Proportions." Lournal of Applied Statistics, 31(7), $799\{815$.

- Farrel M._J. (1957): "The Measurement of Productive Efficiency. Lournal of the Royal Statistical Society. Series A (General), Vol. 120, No. 3. (1957), pp. 253-290.

- Farrell, M. J. and Fieldhouse, M. (1962): “Estimating efficient production functions under increasing returns to scale". Journal of the Royal Statistical Society 125, Series A, part 2, 252-267

- Fellner, W. (1961): “Two Propositions in the Theory of Induced Inventions". Economic Journal, June., 1957), pp. 305-308 
- Ferrari, S. L. P. and Cribari-Neto, F. (2004): "Beta Regression for Modeling Rates and Proportions". Journal of Applied Statistics, 10, 118.

- Filippone, A, Cheli, B. and A. D'Agostino (2001): “Addressing the Interpretation and the Aggregation Problems in Totally Fuzzy and Relative Poverty Measures". Working Papers 2001-22 of the Institute for Social and Economic Research. Colchester: University of Essex

- Fixler, D., and K. Zieschang (1992): "Incorporating Ancillary Measures of Processes and Quality Change into a Superlative Productivity Index". Lournal of Productivity Analysis 2: 245-267.

- Fluet, C. and P. Lefebvre. (1987): “The Sharing of Total Factor Productivity Gains in Canadian Manufacturing: A Price Accounting Approach". 1965-1980, Applied Economics, February, vol. 19 (2), pp. 245-257.

- Foster, J.; J. Greer and E. Thorbecke (1984): “A class of decomposable poverty measures". Econometrica, 52, 761-766.

- Fosu, A. K. (2001): “Emerging Africa: The Case of Ghana in the African Economic Outlook." A joint African Development Bank OECD Development Centre project.

- Freeman, C. and C. Perez (1990): "Structural crises of adjustment: business cycles and investment behaviour" in Giovanni Dosi et al. Londres, Pinter Publisher Limited

- Ghana Customs, Excise and Preventive Service (CEPS, April 2008)

- Ghana's Export Bulletin (1997): Ghana Investment Promotion Centre

- Ghana's Ministry for Private Sector Development and PSI (2005)

- Gon ${ }_{3}$ calves, S. and T. J.Vogelsang (2006): “Block Bootstrap HAC Robust Tests: The Sophistication of the Naive Bootstrap," Working paper, Universit'e de Montr' eal and Cornell University. 
- Guibaud, O. (2003): “Productivity Growth and Poverty Reduction in Developing Countries". CSLS Research Report 2003-06

- Griliches, Zvi,(1961): "Hedonic Price Indexes for Automobiles: An Econometric Analysis of Quality Change," in The Price Statistics of the Federal Government: Review, Ap- praisal and Recommendations, New York: National Bureau of Economic Research, pp. 137-96.

- Grossman, G. and E. Helpman (1991): "Innovation and growth in the Global Economy". Cambridge, Mass: MIT Press.

- Halper, T.(1973): "The Poor as Pawns: The New 'Deserving Poor' and the Old". Polity $6: 79.59$

- Hayes, K. J., D. J. Slottje, Michael L. Nieswiadomy and Edward N. Wolff. (1994:. "The Relationship between Productivity Changes and Poverty in the United States". Journal of Income Distribution, vol. 4 (1), pp. 107-119.

- Hicks, J.R.(1932)”“"The Theory of Wages” London Macmillan.

- Hogan, Warren P. (1958): “Technical Change Production Functions. The Review of Economics and Statistics, Vol. 40., No. 4 (Nov.., 1958), pp. 407-411

- Hulten, Charles R. (2000): “Total Factor Productivity: A Short Biography, in Hulten, Dean and Harper (Eds.)". New Directions in Productivity Analysis, University of Chicago Press for National Bureau of Economic Research.

- Ingram, D. W.; Scott R. Pearson (1981): “The Impact of Investment Concessions on the Profitability of Selected Firms in Ghana." Economic Development and Cultural Change, Vol. 29, No. 4. (Jul., 1981), pp. 831-839.

- Inikori, J. E. (1989): "Slavery and the Revolution in Cotton Textile Production in England". Social Science History, Vol. 13, No. 4. (Winter, 1989), pp. 343-379. 
- Intsiful, J. P. ; F. Okere and S. Osae (2003): “Use of ICT for Education, Research and Development in Ghana: Challenges, Opportunities and Potentials". 2003 Round Table on Developing Countries Access to Scientific Knowledge, the Abdus Salam ICTP, Trieste, Italy.

- JICA (2007): "Research Report on Good Practices and Experiences of Sampled Successful SMEs in the Manufacturing Sector in Ghana". Pentax Management Consultancy Services, Accra.

- Johansen, L. (1959): "Substitution versus fixed production coefficients in the theory of economic growth: a synthesis". Econometrica, Vol. 27, pp. 157-76

- Jones, C. I. (1995). R\&D-Based Models of Economic Growth. Lournal of Political Economy 103: 759 - 784.

- Jorgenson, Dale W.(1966): “The Embodiment Hypothesis" Journal of Political Economy 74:1 (February ), 1-17

- Kamien, Morton I. and N. L Schwartz (1968): “Optimal Induced Technical Change”. Econometrica, Vol. 36No. 1. (Jan., 1968), pp. 1-7

- Kennedy, C. (1964): "Induced Bias in Innovation and the Theory of Distribution". Economic Journal 74, 541-47

- Kennedy C. and A.P. Thirwall. (1972): "Survey in Applied Economics: Technical Progress". Economic Journal, Vol. 82, No. 325. (Mar.,1972), pp. 11-72

- Kieschnick, R. and BD. McCullough (2003): "Regression Analysis of Variates Observed on $(0 ; 1)$ : Percentages, Proportions and Fractions." Statistical Modelling, 3(3), 193\{213.

- Klein, Lawrence R. (1960): "Some Theoretical Issues in the Measurement of Capacity,". Econometrica, Vol. 28, pp. 272-286.

- Klein, Lawrence R. (1973): "Capacity Utilization: Concept, Measurement, and Recent Estimates". Brookings Papers on Economic Activity, No. 3: 743-756. 
- Kim, L. (1997): “Imitation to Innovation: The Dynamics of Korea's Technological Learning". Harvard Business School Press.

- Kim, L. and Nelson, R. R. (2000) (eds): "Technology, Learning and Innovation: Experiences of Newly Industrializing Economies". Cambridge: Cambridge University Press

- Krugman P. (1984): "Import Protection as Export Promotion: Internal Competition in the presence of oligopolies and economies of scale" In Kierkowski H. ed, Monopolistic Competition and International trade. Oxford University Press.

- Krugman, P. (1987): "The Narrow Moving Bank, the Dutch Disease and the competitive Consequences of Mrs Thatcher: Notes on trade in the presence of Dynamic Scale Economies". Lournal of Development Economics 27: 41-55.

- Krugman, P. (1994): "The myth of competitiveness". $\underline{\text { Harper's }}$ Magazine, vol. 288, issue 1729, p. 24.

- Kumar, R. and D. Chadee (2002): "International Competitiveness of Asian Firms: An Analytical Framework," ERD Working Paper Series, No. 4. Manila: Asian Development Bank.

- Kumbhakar, S. B. Park, L. Simar and E. Tsionas(2007): "Nonparametric stochastic frontiers: A local maximum likelihood approach". Lournal of Econometrics 137 (2007), pp. 1-27.

- Kuznets, Simon (1966): “Modern Economic Growth". New Haven, CT: Yale University Press.

- Lall, S. (2000): "Strengthening SMEs for International Competitiveness. For the Egyptian Center of Economic Studies Workshop on: what makes your firm internationally competitive?". Cairo, March 6-8, 2000.

- Lall, S. (2000): "The Technological Structure and Performance of Developing Country Manufacturing Exports, 1985-1998)". $\underline{Q E H}$ working Paper Series-QEHWPS44 
- Lall, S. (2001): “New Technologies, Competitiveness and Poverty Reduction. Asia and Pacific Forum on Poverty: Reforming Policies and Institutions for Poverty Reduction"., held at the Asian Development Bank, Manila, 5-9 February 2001.

- Lall, S. and Pietrobelli, C. (2003): "Manufacturing in Sub-Saharan Africa and the need of a National Technology System", in M. Muchie, B.Å. Lundvall and P. Gammeltoft (Eds.) The Making of African Innovation Systems, Aalborg University Press,

- Learned, E.P., C. R. Christensen, K.R Andrews, and W. Guth, (1965): “.Business policy". Homewood, Ill.: Irwin, 1965.

- Leith, Clark J. (1974): "Foreign Trade Regimes and Economic Development". Ghana(National Bureau of Economic Research, New York, 1974), pp.216

- Lucas, Robert E. Jr.(1967): “Tests of a Capital-Theoretic Model of Technological Change". Review of Economic Studies, 34:175-80.

- Lucas, Robert E. Jr.(1988): "On the Mechanics of Economic Development". Lournal of Monetary Economics, 22:3-42.

- Madu, C.N. (1992): "Strategic Planning in Technology Transfer to Less Developed Countries". Quorum Books, Westport, CT

- Mainsah, E. (2003): "Is Ghana an Attractive Proposition for IT Services and Business Processes Outsourcing". The Trustees of Columbia University in the City of New York.

- Mani, S. and H. Romijn (Eds) (2004): "Innovation, Learning and Technological Dynamism of Developing Countries". UNU Press, Tokyo and New York.

- Marx, Karl and Frederick Engels(1988-1994): “Marx-Engels Collected Works". Volumes 30- 34. New York: International Publishers.

- McDonald, F. and S. Dearden (1992): “European Economic Integration". $4^{\text {th }}$ ed. Bell and Bain Glasgow. 
- Miceli, D. (1998): “Measuring Poverty Using Fuzzy Sets". NATSEM Discussion Paper No. 38.

- Nadiri, M.I. (1970): "Some approaches to the theory and measurement of total factor productivity: A survey". Lournal of Economic Literature, 8, 1137-77.

- Nelson, Richard (1964): "Aggregate Production Functions and Medium-Range Growth Projections." American Economic Review, September 1964, 54(5), pp. 575-606.

- Nelson, R. A. (1989): “On the Measurement of Capacity Utilization". The Journal of Industrial Economics, Vol. XXXVII, pp. 273-86.

- $\quad$ Nelson, R. R. and S. G. Winter (1982): "An Evolutionary Theory of Technical Change". The Belknap Press of Harvard University Press Cambridge, Massachusetts, and London, England 1982

- Nelson, Richard R. and G. S. Winter (1974): “Neoclassical versus Evolutionary Theories of Economic Growth: Critique and Prospects". Economic Journal, 1974 84:886-905

- Nishimizu, M. and J. M. Page (1982): “Total Factor Productivity Growth, Technological Progress and Technical Efficiency Change: Dimensions of Productivity Change in Yugoslavia, 1965-78". Economic Journal, 92, 920-936.

- Olaf, K., J. Downing and M. Field(2006): “Value chain programmes to integrate competitiveness, economic growth and poverty reduction". Small Enterprise Development 17: 2, 2006, pp. 23-35.

- Pearson, S. R.; William D. Ingram (1980): “Economies of Scale, Domestic Divergences, and Potential Gains from Economic Integration in Ghana and the Ivory Coast". The Journal of Political Economy, Vol. 88, No. 5. (Oct., 1980), pp. 994-1008.

- Perry, George L. (1973): “Capacity in Manufacturing". Brookings Papers on Economic Activity, Vol. 3, 701 - 742. 
- Pomeranz, D. (2001): "Africa And The Uruguay Round: Did SubSaharan Africa Lose as a Result of The Trade Agreement?". Discussion Paper Presented for the Seminar on International Trade Policy: Theory and Practice of Prof. R. Blackhurst.

- Porter, Robert H. (1983): “A Study of Cartel Stability: The Joint Executive Committee, 1880-1886," Bell Journal of Economics, 14, 301314.

- Prochaska, F.J. (1978): “Theoretical and Empirical Considerations for Estimating Capacity and Capacity Utilization in Commercial Fisheries". American Journal of Agricultural Economics, 60(5): pp. 10201025.

- Quartey, P.(2006): “The Textile and Clothing Industry in Ghana, in Herbert Jauch and Rudolf Traub-Merz (eds), The Future of the Textile and Clothing Industry in Sub-Saharan Africa. Bub Bonner Universitats-Buckdruckerei, Germany, pp. 135-146

- Rankin,N., M. Soderbom and F. Teal (2002): “The Ghanaian Manufacturing Enterprise Survey 2000". REP/2002-05 at http://www.csae.ox.ac.uk/reports/main.html.

- Republic of Ghana (2003): "The Ghana ICT for Accelerated Development (ICT4AD) Policy". A Policy Statement for the realization of the Vision to Transform Ghana into an InformationRich Knowledge-based Society and Economy through the Development, Deployment and Exploitation of ICTs within the Economy and Society. http://www.ict.gov.gh/pdf/Ghana\% . 20ICT4AD\%20Policy.pdf

- Ricardo, D. (1951): "Principles of Political Economy in Works and Correspondence". I, Cambridge.

- Romer, Paul M. (1986): "Increasing Returns and Long-run Growth". Lournal of Political Economy. 1986, 94:1002-37.

- Romer, P.M. (1990): “Endogenous Technological Change". Journal of Political Economy 98, 71-102. 
- Ruttan, Vernon W. (2001): “Sources of Technical Change: Induced Innovation, Evolutionary Theory and Path Dependence". VWR Working Copy Evolution Theory Manuscript, Draft: February 12, 2001

- Salinger, L. and A. Greenwood (2001): AGOA Textile and Garments: What Future for Uganda's Exports? Report prepared for USAID/Uganda in response to OUT-PCE-I-807-98-00016

- Salter, W.E.G.(1960): "Productivity and Technical Change". Cambridge: Cambridge University Press.

- Samuelson, P. (1965): “A Theory of Induced Innovation along Kennedy-Weisacker Lines". The Review of Economics and Statistics, Vol. 47, No. 4.(Nov., 1965), pp. 343-356

- Schumpeter, J.A. (1939): "Business Cycles" 2 vols. New York: McGraw-Hill.

- Sen, A. K.(1976): "Poverty: An Ordinal Approach to Measurement". Econometrica, 44, 219-231

- Sheather, S. J. and M. C. Jones (1991): "A reliable data-based bandwidth selection method for kernel density estimation". Iournal of the Royal Statistical Society, Series B, 53, 683-690.

- Silverman, B. W. (1986): “Density Estimation for Statistics and Data Analysis". Monographs on Statistics and Applied Probability. Chapman \& Hall.

- Silverman, B.W. and G. Young (1987): “The bootstrap: To smooth or not to smooth?". Biometrika. 74, 469-479.

- Simar L. and P. W. Wilson (1998): "Sensitivity Analysis of Efficiency Scores: How to Bootstrap in Nonparametric Frontier Models". Management Science, Vol. 44, No. 1. (Jan., 1998),pp. 49-61

- Smithies, A. (1957): "Economic Fluctuations and Growth". Econometrica, Vol. 25, No. 1, pp.1-52. 
- Smithson, M. and J. Verkuilen (2006): “A Better Lemon Squeezer? Maximum-Likelihood Regression with Beta-Distributed Depedent Variables". Psychological Methods, 11(1), 54\{71.

- Solow, Robert M. (1956): "A Contribution to the Theory of Economic Growth". Quarterly Journal of Economics 70: 65-94.

- Solow, Robert M. (1957): "Is Factor Substitution a Crime, and if so, How Bad?". Reply to Professor Eisner. The Economic Journal, Vol. 39, No. 275..(Sep., 1959), pp. 597-599

- Solow, Robert M. (1957): “Technical Change and Aggregate Production Function". The Review of Economics and Statistics, Vol. 39, No. 3.(Aug., 1957), pp. 312-320

- Solow, Robert M. (1958): :Technical Change and Production Functions: Reply". The Review of Economics and Statistics, Vol. 40, No.4.(Nov.., 1958), pp. 411-413

- Solow, R.M. (1960): "Investment and technical progress", in Arrow, K., Karlin, S. and Suppes, P. (Eds), Mathematical Methods in the Social Sciences, 1959, Stanford University Press, Palo Alto, CA, pp. 89-104.

- Steel W. F. (1972): "Import Substitution and Excess Capacity in Ghana". Oxford Economic Papers, New Series, Vol. 24, No.2 (Jul.,1974) 212-240

- Steel, W. F. (1981): "Female and Small-Scale Employment under Modernization in Ghana". Economic Development and Cultural Change, Vol. 30, No. 1. (Oct., 1981), pp. 153-167.

- $\quad$ Teal, F. (1999): “Why can Mauritius Export Manufactures and Ghana Not?". The World Economy 22, pp. 981-993.

- Theil, H. (1967): "Economics and Information Theory". Amsterdam: North Holland.

- Tinbergen, J.(1942).J. Tinbergen, Zur Theorie der langfristigen Wirtschaftsentwicklung, Weltwirtschaftliches Archiv 55 (1) (1942): "On the theory of trend movements". In: L.H. Klaasen, L.M. Koyck 
and H.J. Witteveen, Editors, Jan Tinbergen, Selected Papers (1959), pp. 182-221 North-Holland, Amsterdam (English translation).

- UNDP (2001). Human Development Report 2001. Making new Technologies Work for human development. New York Oxford University Press 2001

- UNCTAD (2003): "Foreign Direct Investment and Performance Requirements: New Evidence from Selected Countries". New York and Geneva: United Nations.

- UNDP, (2003): “Human Development Report. Millennium Development Goals: A Compact among Nations to End Human Poverty". New York, Oxford University Press.

- Verma V., Betti G. (2002): "The construction of EU-SILC target variables on income: some proposal for discussion". Report to EUROSTAT under the project Development of appropriate modelling or imputation to construct the EU-SILC target income variables for each EU Member States.

- Verspagen, B. (2005): "Innovation and Economic Growth". In: Fagerberg, J. et al. (eds.): The Oxford Handbook of Innovation, pp. 487-513. (Chapter 18)

- Wangwe, S. M. (1995): “Exporting Africa. Technology, Trade and Industrialization in Sub-Saharan Africa". Routlet 11 New Fetter Lane, London EC4P 4EE.

- World Bank (2009):“World Development Indicators”.

- World Trade Organisation (2008): “Trade statistics".

- Wu, Yanrui (2004): “China's Economic Growth: A Miracle with Chinese Characteristics". London and New York: Routledge Curzon Press.

- Zadeh,L.A.(1965): “ Fuzzy sets". Information and Control 8, 338-353 


\section{Summary}

To guide future technology, industrial and poverty reduction policy planning and formulation, this study offers evidence of widespread technical inefficiencies and technical change among SMEs in apparel manufacturing business in Ghana. In this micro study and a survey of 140 firms, signs of catching-up with the best practice firms within their own locality and consequently with those on the international stage remain weak. Evidence of technical progress in the apparel industry is particularly welcoming as it indicates the extent to which the firms are upgrading with increasing application of new technologies in product manufacturing. To curb technical inefficiencies require continual training and automation of production processes.

The nature and depth of poverty/deprivation among the apparel manufacturers provide a vivid understanding of efforts that need to be made in order to reduce by one-half those faced with extreme poverty by 2015. Deprivation in all attributes aggregated into eleven dimensions among these households is quite high with the mean composite index estimated to be 41.8 per cent in 2002 but dropped to 34.2 percent in 2007. Food deprivation and income inadequacy have been estimated to be among the highest sources of poverty for these households in apparel related jobs. Other sources of deprivation include inadequate personal capabilities as well as limited formal education due to the fact that apparel sub-sector is known to attract huge numbers of school drop-outs mostly female. Security attributes also ranked high among the crucial variables. This calls for a more sustained and comprehensive policy measures to boost TFP growth through a better educated apparel manufacturing workforce.

Linking deprivation/poverty to firm performance shows that output growth has had some significant effects on poverty reduction albeit not a large one. However, TFP growth and its components namely pure technical efficiency, pure technical change, scale change and scale technology change did not significantly reduce poverty over the 2002 and 2007 period. In effect, even though our findings suggest that poverty can be reduced by building competitiveness in manufacturing industry, the effects in the apparel subsector in particular as evidence by impact of output growth on poverty has 
been limited. Also, the study revealed that openness has not had a positive effect on apparel manufacturing as the gains by firms in pre-liberalization period could be pinned down to the trade protection that these firms enjoyed before the 1980s. The textile firms such as GTP were able to establish themselves as the main companies producing to satisfy the taste of the local customers. Focusing on the local market meant that the international trade agreements such as MFA and first Lome Convention to open oversea markets were little exploited. Going forward requires good governance coupled with workable international trade rules to change the present levels of performance of textiles and clothing industry in Ghana.

Theoretically, the thesis accounted for standards in productivity assessment and employed Malmquist (1953) productivity index to measure and conceptualize technical efficiency and technical change. The Malmquist index was supported by Caves, Christensen and Diewert (1982) in their 'Economic Theory of Index Numbers...'. The study also proceeds with insights from (Farrell 1957) theoretical model developed contemporaneously with Solow (1957) neoclassical growth model which assumes exogenous technological change. Same set of input combination and a better technology would cause an outward movement of the production possibility frontier. Malmquist (1953) productivity index is a non-parametric technique (does not make any prior assumption about the distribution from which the data is drawn) allows us to: 1) estimate TFP growth and 2) decompose TFP growth into technical change and technical efficiency change. Poverty assessment was built on Fuzzy set theory and logic (Zadeh, 1965) based on admitting membership values in their imprecise form and computing poverty as a multi-attribute and multi- dimensional index.

Since the nature of our response variable (poverty) violates the Central Limit Theorem which holds when for large enough samples, the mean of independent and identically distributed random variables are approximately normally distributed, this study employed Beta regression technique to link deprivation/poverty to firm performance. Beta regression is viewed as a generalization of the logistic regression and particularly suitable for modeling dependent variables that violate the assumption of normality. 


\section{Samenvatting}

Deze studie biedt bewijsmateriaal aan van de brede technische efficientie en verandering binnen het MKB inzake kledingproductie in Ghana, om richting te geven aan toekomstige technologieën, de industriële beleidsplanning en armoedevermindering. In deze micro studie en een enquete onder 140 firma's, blijven er zwakke aanwijzigen voor het bijhouden van de beste praktijkfima's binnen hun eigen regio en daarmee ook de internationaal opererende bedrijven. Bewijs van technische vooruitgang in de kledingindustrie is bijzonder welkom, omdat het aangeeft hoezeer bedrijven nieuwe technologieën implementeren in het productieproces. Om technische ondoelmatigheid te voorkomen, is constante training en automatisering van het productie proces nodig.

De aard en ernst van de armoede/ontbering onder de kledingfabrikanten geven een levendig inzicht in de inspanningen die nodig zijn om het aantal kledingfabrikanten dat geconfornteerd wordt met deze armoede te halveren voor 2015. De grote armoede in deze huishoudens die in 11 eigenschappen wordt gemeten via een samengestelde index, is geschat op 41.8 procent in 2002 , en tot 34.2 gedaald in 2007. De ontberingen m.b.t. voedsel en inkomensontoereikendheid worden gezien als de grootste bronnen van armoede voor deze huishoudens met banen in de kledingsector. Andere bronnen van armoede zijn: ontoereikende persoonlijke ontwikkeling, evenals beperkt onderwijs, hetgeen toe te schrijven is aan het feit dat de kledingsubsector erom bekend staat enorme aantallen vroegtijdige schoolverlaters aan te trekken, over het algemeen vrouwen. Veiligheid is ook een van de meest cruciale variabelen. Dit roept op tot meer uitvoerige beleidsmaatregelen en het toezicht op de naleving ervan, om de TFP groei te stimuleren middels beter opgeleide arbeidskrachten in het kledingproductie proces.

Door de armoede/ontbering te koppelen aan de prestaties van het bedrijf, word zichtbaar dat de groei van de output een belangrijk effect heeft op de vermindering van armoede, het is echter geen groot effect. Echter, de groei van TFP en zijn componenten, namelijk technische efficiency, technische verandering, schaalverandering en technologische schaalverandering, hebben de armoede niet aanzienlijk vermindert in de periode van 2002 en 
2007. Ondanks onze bevindingen dat armoede verminderd kan worden door het versterken van de concurrentiepositie in de verwerkende industrie, zijn de effecten in de kledingindustrie als bewijsmateriaal voor het effect van groei van opbrengsten op armoede zeer beperkt. Tevens toont de studie aan dat openheid geen positief effect heeft gehad op de kledingproductie aangezien de winsten door bedrijven in de preliberalisatie periode, gekoppeld waren aan de handelsbescherming die deze firma's voor 1980 hadden. De textiel bedrijven zoals GTP waren in staat zichzelf te vestigen als de belangtrijkste spelers die produceerden om aan de vraag van de locale klanten te voldoen. De focus op de locale markt impliceerde dat de internationale handelsverdragen zoals MFA en first Lome Convention met het buitenland slechts weinig gebruikt werden. Vooruitgang eist goed bestuur gekoppeld aan werkbare internationale handelsregels om de huidige prestaties in de textiel en kledingindustrie in Ghana te veranderen.

Theoretisch geeft dit proefschrift normen aan in de beoordeling van productiviteit en went het de productiviteitsindex aan van Malmquist (uit 1953), om technische effectiviteit en technische veranderingen te meten en weer te geven. De Malmquist index is verder uitgewerkt door Caves, Christensen and Diewert (1982) in hun "Economic Theory of Index Numbers...". Het proefschrift werkt ook met inzichten van het theoretische model van Farell (1957) dat gelijktijdig ontwikkeld is met het Solow (1957) neoklassiek groeimodel dat uitgaat van exogene technologische verandering. De input van dezelfde combinatiereeks en een beter techniek, zou de grens van de mogelijkheden in de productie naar buiten verleggen.

De productiviteitsindex van Malquist (1953) is een niet-parametrische techniek (maakt geen veronderstelling betreffende de distributie waarvan de data zijn gebruikt), en staat ons toe: 1) om TPF groei te meten 2) TFP groei in technische verandering en technische effectiviteit te splitsen. Armoede beoordeling is opgebouwd uit de "Fuzzy set theorie en logica" (Zadeh, 1965), gebaseerd op het toelaten van lidmaatschapswaarden in hun onnauwkeurige vorm en verwerking van gegevens van armoede in een multi-eigenschappen en multi-dimensionale indexering.

Omdat de aard van onze reactie variabele (armoede) de Centrale Limiet Theory overtreedt, die geldt voor voorbeelden die groot genoeg zijn (de onafhankelijksheids variabele en de normale verspreiding van identieke 
variabelen), heeft deze studie gebruikt gemaakt van de Beta regressive techniek om armoede/ontbering te verbinden aan prestaties van bedrijven.

Beta regressie wordt beschouwd als generalizering van de logistieke regressie en is specifiek geschikt om afhankelijke variabelen, die niet als normaal worden beschouwd, in model brengen. 


\section{About the Author}

Donatus Kosi Ayitey is currently attached to the World Intellectual Property Organization (WIPO) working as a paid intern/fellow in Geneva Switzerland. Mr. Ayitey was a Principal Research Assistant at the Institute of Statistical, Social \& Economic Research (ISSER) at the University of Ghana and holds a B.A. and M.Phil degrees in Economics from University of Ghana specializing in Quantitative Methods/Econometrics, Monetary Economics, Public Finance and International Economics.

He gained admission into the University of Oxford in October 2008 and successfully obtained a degree in MSc. Applied Statistics in September 2009. From October 2008 to June 2009, he completed a certificate programme on Professional Training for Social Sciences (PTSS) at Said Business School, University of Oxford. As an Economist-Statistician, he has focused on Productivity and Poverty Estimations, Technical Change, Innovation Policy and Development. He is currently working on a number of topics including the role of Intellectual Property in Economic Development. 
